This PDF is a selection from a published volume from the National Bureau of Economic Research

Volume Title: Perspectives on the Economics of Aging

Volume Author/Editor: David A. Wise, editor

Volume Publisher: University of Chicago Press

Volume ISBN: 0-226-90305-2

Volume URL: http://www.nber.org/books/wise04-1

Conference Date: May 17-20, 2001

Publication Date: June 2004

Title: Healthy, Wealthy, and Wise? Tests for Direct Causal Paths between Health and Socioeconomic Status

Author: Peter Adams, Michael D. Hurd, Daniel L. McFadden, Angela Merrill, Tiago Ribeiro

URL: http://www.nber.org/chapters/c10350 


\title{
Healthy, Wealthy, and Wise? Tests for Direct Causal Paths between Health and Socioeconomic Status
}

\author{
Peter Adams, Michael D. Hurd, Daniel McFadden,
} Angela Merrill, and Tiago Ribeiro

This chapter consists of four components: (1) the paper Healthy, Wealthy and Wise? Tests for Direct Causal Paths between Health and Socioeconomic Status by Peter Adams, Michael D. Hurd, Daniel McFadden, Angela Merrill, and Tiago Ribeiro, which originally was presented at the conference and then appeared in the Journal of Econometrics, Vol. 112: (2003); (2) a new addendum that describes updates in data and analysis since its publication; (3) additional appendix tables; and (4) the authors' response to comments on the paper.

\subsection{Introduction}

\subsubsection{The Issue}

The links between health, wealth, and education have been studied in a number of populations, with the general finding that higher socioeconomic status (SES) is associated with better health and longer life. ${ }^{1}$ In a survey of

Peter Adams is affiliated with the Department of Economics at the University of California, Berkeley; Michael D. Hurd is affiliated with RAND Corporation; Daniel McFadden is affiliated with the Department of Economics at the University of California, Berkeley; Angela Merrill is affiliated with Mathematica; and Tiago Ribeiro is affiliated with the Department of Economics at the University of California, Berkeley.

We gratefully acknowledge financial support from the National Institute on Aging through a grant to the NBER Program Project on the Economics of Aging. Tiago Ribeiro acknowledges support from scholarship PRAXIS XXI/BD/16014/98 from the Portuguese Fundação para a Ciência e a Tecnologia. We thank Laura Chioda, Victor Fuchs, Rosa Matzkin, James Poterba, and Jim Powell for useful comments.

1. See Backlund, Sorlie, and Johnson (1999); Barsky et al. (1997); Bosma et al. (1997); Chandola (1998, 2000); Davey-Smith, Blane, and Bartley (1994); Drever and Whitehead (1997); Ecob and Smith (1999); Elo and Preston (1996); Ettner (1996); Feinstein (1992); 
this literature, Goldman (2001) notes that this association has been found in different eras, places, genders, and ages, and occurs over the whole range of SES levels, so that it is not linked solely to poverty. The association holds for a variety of health variables (most illnesses, mortality, self-rated health status, psychological well-being, and biomarkers such as allostatic load) and alternative measures of SES (wealth, education, occupation, income, level of social integration). ${ }^{2}$ There has been considerable discussion of the causal mechanisms behind this association, but there have been relatively few natural experiments that permit causal paths to be definitively identified. ${ }^{3}$ In this paper, we test for the absence of direct causal links in an elderly population by examining whether innovations in health and wealth in a panel are influenced by features of the historical state.

Figure 11.1 depicts possible causal paths for the health and SES innovations that occur over a short period. An individual's life history is built from these period-by-period transitions. First, low SES may lead to failures to seek medical care and delay in detection of conditions, reduced access to medical services, or less effective treatment. ${ }^{4}$ Also, increased risk of health problems may result from increased stress or frustration, or increased exposure to environmental hazards, that are associated with low

Fitzpatrick et al. (1997); Fitzpatrick and Dollamore (1999); Fox, Goldblatt, and Jones (1985); Goldblatt (1990); Haynes (1991); Hertzman (1999); Humphries and van Doorslaer (2000); Hurd (1987); Hurd and Wise (1989); Kaplan and Manuck (1999); Karasek et al. (1988); Kitawaga and Hauser (1973); Lewis et al. (1998); Leigh and Dhir (1997); Luft (1978); Marmot et al. (1991); Marmot, Bobak, and Davey-Smith (1995); Marmot et al. (1997); Martin and Preston (1994); Martin and Soldo (1997); McDonough et al. (1997); Murray, Yang, and Qiao (1992); Power, Matthews, and Manor (1996); Power and Matthews (1998); Rodgers (1991); Ross and Mirowsky (2000); Schnall, Landsbergis, and Baker (1994); Seeman et al. (2002); Shorrocks (1975); Stern (1983); Wadsworth (1991); Whitehead (1988); Wilkinson (1998); and Woodward et al. (1992).

2 . The associations can become more complex when multiple health conditions and multiple SES measures are studied. Competing risks may mask the hazard for late-onset diseases; for example, elevated mortality risk from cardiovascular diseases in low SES groups may induce an apparent reverse relationship between SES and later-onset cancer in the surviving population (Adler and Ostrove 1999). Longer-run measures of SES such as education, occupation, and wealth appear to have a stronger association with health status than current income (Fuchs 1993). Using carefully measured wealth, we find that it explains most of the association with health, and education conditioned on wealth is not systematically correlated with health.

3. Papers examining explicit causal mechanisms include Chapman and Hariharran (1994); Dohrenwend et al. (1992); Evans (1978); Felitti et al. (1998); Fox, Goldblatt, and Johnson (1985); Goldman (1994); Kelley, Hertzman, and Daniels (1997); and McEwen and Stellar (1993).

4. There may be an important distinction between direct causal mechanisms influencing mortality, conditioned on health status, and direct causal mechanisms influencing onset of health conditions. For mortality, an SES gradient could be due to differentially effective treatment of acute health conditions. For morbidity, an SES gradient could reflect differentials in prevention and detection of health conditions. These involve different parts of the health care delivery system, and differ substantially in the importance of individual awareness and discretion, and allocation of costs between Medicare and the individual. 


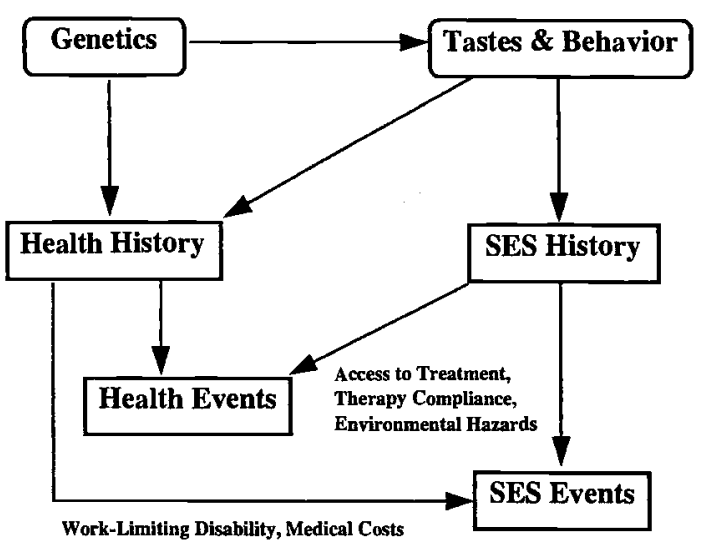

Fig. 11.1 Possible causal paths for SES and health

SES. ${ }^{5}$ These factors could provide direct causal links from SES history to health events. Second, poor health may reduce the ability to work or look after oneself, and increase medical care expenditures, leading to reduced income and less opportunity to accumulate assets. This could provide a direct causal link from health to changes in SES.

There may also be hidden common factors that lead to ecological association of health and SES. For example, unobserved genetic heterogeneity may influence both resistance to disease and ability to work. Causal links may be reinforced or confounded by behavioral response. Behavioral factors such as childhood nutrition and stress, exercise, and smoking may influence both health and economic activity level. For example, tastes for work and for "clean living," whether genetic or learned, may influence both health and earnings. Finally, rational economic decision making may induce robust consumers to accumulate in order to finance consumption over a long-expected retirement, or unhealthy individuals to spend down assets.

Preston and Taubman (1994), Smith and Kington (1997a, b), and Smith (1998, 1999) give detailed discussions of the various causal mechanisms that may be at work and the role of behavioral response from economic consumers. The epidemiological literature (Goldman 2001) uses a different terminology for the causal paths: Links from SES to health innovations are termed causal mechanisms, while links from health to SES are termed selection or reverse causation mechanisms. Apparent association due to measurement errors, such as overstatement of the SES of the healthy or under-

5. For example, industrial and traffic pollution, and poor dwelling ventilation are risk factors for lung disease, and housing prices and household income are negatively correlated with air pollution levels in census data (Chay and Greenstone 1998). 
detection of illnesses among the poor, are called artifactual mechanisms. ${ }^{6}$ This literature classifies all common factors in terms of their implicit initial action as either causal or selection mechanisms. ${ }^{7}$

\subsubsection{This Study}

We study the population of elderly Americans aged seventy and older, and in this population test for the absence of direct causal paths from SES to innovations in health, and from health status to innovations in SES. These hypotheses will in general be accepted only if no causal link is present and there are no persistent hidden factors that influence both initial state and innovations. Rejection of one of these hypotheses does not demonstrate a direct causal link, because this may be the result of common hidden factors. However, in an elderly population persistent hidden factors will often be manifest in observed covariates, so that once these covariates are controlled, the residual impact of the hidden factors on innovations will be small. For example, genetic frailty that is causal to both health problems and low wages, leading to low wealth, may be expressed through a health condition such as diabetes. Then, onset of new health conditions that are also linked to genetic frailty may be only weakly associated with low wealth, once diabetic condition has been entered as a covariate. Thus, in this population, rejection of the hypotheses may provide useful diagnostics for likely causal paths.

The objectives and conclusions of this paper are limited. We study only elderly Americans, for whom Medicare provides relatively homogeneous and comprehensive health care at limited out-of-pocket cost to the individual. This population is retired, so new health problems do not impact earnings. Statements about the presence or absence of direct causal mechanisms in this population, given previous health and SES status, say nothing about the structure of these mechanisms in a younger population, where associations of health and SES emerge as a result of some pattern of causation and operation of common factors.

Our tests for the absence of causality do not address the question of how to identify invariant models and causal links when these tests fail. If a test

6. Consider phenomena such as underestimation of the hazard of a disease due to competing risks from other illnesses or death. In an unfortunate discrepancy in terminology, economists would call this a selection effect, while epidemiologists would classify it as an artifactual mechanism rather than a selection mechanism.

7. Usually, one can argue that observed association must originate from some initial causal action so that common factors originate from some initial direction of causation. However, there is no apparent initial causal action for genetically linked conditions such as Down syndrome, which increase mortality risk and preclude work. Further, as a practical matter, it is often impossible to make observations at the high frequencies that would be required to identify causal chains when feedbacks are nearly instantaneous. Then common factors will appear at feasible levels of detection to operate simultaneously, and their true causal structure will not be identified. For these reasons, there would be considerable merit in adding common mechanisms to the epidemiologist's classification. 
for the absence of a direct causal path is rejected, it may be possible through natural or designed experiments to separate causal and ecological effects; see Angrist, Imbens, and Rubin (1996), Heckman (2000, 2001). Suppose a strictly exogenous variable is causal to SES, and clearly not itself directly causal to health or causal to common factors. Then, an association of this variable with innovations in health conditions can only be through a direct causal link from SES to health. A variable with these properties is termed a proper instrument or control variable for SES. Proper instruments are hard to find. They can be obtained through designed experiments, where random treatment assignment precludes the possibility of confounding by common factors, provided recruitment and retention of experimental subjects does not reintroduce confounding. For example, an experiment that randomly assigned co-payment rates and coverage within Medicare for prescription drugs or assisted living could provide evidence on direct causal links from SES to health conditions, provided attrition and compliance are not problems. Occasionally, natural experiments may provide random treatment assignment. Economic events that impact individuals differently and that are not related to their prior SES or health are potentially proper instruments. For example, a tax change that affects wealth differently in different states is arguably a proper instrument, as is a change in mandated Medicaid coverage that has a differential impact across states. Individual events such as receipt of inheritances may be proper instruments, although they would be confounded if they are anticipated, or if the probability of their occurrence is linked to health status; see Meer, Miller, and Rosen (2001). Weak association between SES and a proper instrument for it makes it difficult to obtain precise estimates of direct causal effects; see Staiger and Stock (1997).

Section 11.2 of this paper discusses the foundation for econometric causality tests, and sets out the models for the dynamics of health and SES that will be used for our analysis. Section 11.3 describes the panel study and data that we use. Section 11.4 describes the association of SES and prevalence of health conditions in the initial wave of the panel. Section 11.5 analyzes incidence of new health conditions, and presents tests for noncausality of SES for the incidence of health innovations. Section 11.6 tests for the absence of a causal link from health conditions to wealth accumulation and other SES indicators. Section 11.7 uses our estimated models for prevalence and incidence to simulate life histories for a current population aged seventy under counterfactual (and unrealistically simplistic) interventions that assume a major health hazard can be removed, or SES shifted for the entire population. This simulation accounts consistently for comorbidities and competing hazards over the life course. The purpose of this exercise is to demonstrate the feasibility of using our modeling approach for policy applications when the models pass the causality tests described in next section. Finally, section 11.8 gives conclusions and outlines 
topics for future research. The appendix to this paper, containing tables $11 \mathrm{~A} .1$ to $11 \mathrm{~A} .11$ with detailed estimation results and the data and computer routines we use, are posted on the internet at http://elsa.berkeley.edu/ $\mathrm{wp} / \mathrm{hww} / \mathrm{hww} 202 . \mathrm{html}$.

\subsection{Association and Causality in Panel Data}

\subsubsection{Testing Causality}

The primary purpose of this study is to test for direct causal links between SES and health. There is a large literature on the nature of causality and the interpretation of "causality tests." Our analysis fits generally within the approach of Granger (1969), Sims (1972), and Hoover (2001), but our panel data structure permits some refinements that are not available in a pure time series setting.

Let $Y_{t}$ denote a $K$-vector of demographic, health, and socioeconomic random variables for a household at date $t$ and interpret a realization of these variables as an observation in one wave of a panel survey. Let $\boldsymbol{Y}_{t}$ be the information set containing the history of this vector through date $t$. Let

$$
\begin{aligned}
& f\left(Y_{t} \mid \boldsymbol{Y}_{t-1}\right) \\
& \quad \equiv f_{1}\left(Y_{1 t} \mid \boldsymbol{Y}_{t-1}\right) \cdot f_{2}\left(Y_{2 t} \mid Y_{1 t}, \boldsymbol{Y}_{t-1}\right) \cdot \ldots \cdot f_{K}\left(Y_{K t} \mid Y_{1 t}, \ldots, Y_{K-1, t}, \boldsymbol{Y}_{t-1}\right)
\end{aligned}
$$

denote a model of the conditional distribution of $Y_{t}$ given $\boldsymbol{Y}_{t-1}$. Without loss of generality, we have written this model as a product of one-dimensional conditional distributions, given history and given components of $Y_{t}$ determined previously. Writing the model in this way does not imply that the components of $Y_{t}$ form a causal chain, as they may be simultaneously determined, or determined in some causal sequence other than the specified sequence. However, the model structure simplifies if the current components of $Y_{t}$ in the specified order do form a causal chain or are conditionally independent. If one takes Wold's view that causal action takes time, then for sufficiently brief time intervals, $f_{K}\left(Y_{K t} \mid Y_{1 t}, \ldots, Y_{K-1, t}, Y_{t-1}\right)$ will not depend on contemporaneous variables, and what Granger calls instantaneous causality is ruled out. In practice, time aggregation to observation intervals can introduce apparent simultaneous determination. Conversely, in applications where time aggregation is an issue, one can treat observed variables as indicators for some latent causal chain structure defined for very short time intervals.

8. See Dawid (2000); Freedman (1985, 2001); Granger (1969); Sims (1972); Zellner (1979); Swert (1979); Engle, Hendry, and Richard (1983); Geweke (1984); Gill and Robins (2001); Heckman (2000, 2001); Holland (1986, 1988); Pearl (2000); Robins (1999); Sobel (1997, 2000); Hendry and Mizon (1999); and Woodward (1999). 
We shall focus on first-order Markov processes, specializations of (1) in which only the most recent history conveys information,

$$
\begin{aligned}
f\left(Y_{t} \mid \boldsymbol{Y}_{t-1}\right) \equiv & f\left(Y_{t} \mid Y_{t-1}\right) \\
\equiv & f_{1}\left(Y_{1 t} \mid Y_{t-1}\right) \cdot f_{2}\left(Y_{2 t} \mid Y_{1 t}, Y_{t-1}\right) \\
& \cdot \ldots \cdot f_{K}\left(Y_{K t} \mid Y_{1 t}, \ldots, Y_{K-1, t}, Y_{t-1}\right) .
\end{aligned}
$$

Note that if (1) is a higher-order Markov process, then (2) can be obtained by expanding the variables in $Y_{t}$ to include higher-order lags. Greater generality could be achieved via a hidden Markov structure in which the observed $Y_{t}$ are deterministic functions of a latent first-order Markov process. ${ }^{9}$ We leave this extension for future research.

Model (2) is valid for a given history $\boldsymbol{Y}_{t-1}$ if it is the true conditional distribution of $Y_{t}$ given this history. Term $f$ a structural or causal model, or a (probabilistic) law, for $Y_{t}$ relative to a family of histories if it has the invariance property that it is valid for each history in the family. Operationally, this means that within specified domains, $f$ has the transferability property that it is valid in different populations where the marginal distribution of $Y_{t-1}$ changes, and the predictability or invariance under treatments property that it remains valid following policy interventions that alter the marginal distribution of $Y_{t-1}$. By including temporal or spatial variables in $Y$, it is possible to weaken invariance requirements to fit almost any application. Done indiscriminately, this creates a substantial risk of producing an "overfitted" model that will be invalid for any "out-of-sample" policy interventions. Then, proposed models should be as generic as possible. However, it may be necessary in some applications to model "regime shifts" that account for factors that are causal for some populations or time periods, and not for others.

Suppose the vector $Y_{t}=\left(H_{t}, S_{t}, X_{t}\right)$ is composed of subvectors $H_{t}, S_{t}$, and $X_{t}$, which will later be interpreted as health conditions, SES status, and strictly exogenous variables, respectively. We say that $S$ is conditionally noncausal for $H$, given $X$, if $f\left(H_{t} \mid H_{t-1}, X_{t-1}\right)$ is a valid model; that is, given $H_{t-1}$ and $X_{t-1}$, knowledge of $S_{t-1}$ is not needed to achieve the invariance properties of a causal model. Conversely, if $f\left(H_{t} \mid H_{t-1}, S_{t-1}, X_{t-1}\right) \not \equiv f\left(H_{t} \mid H_{t-1}, X_{t-1}\right)$, then knowledge of $S_{t-1}$ contributes to the predictability of $H_{t}$. Note that either one or both conditional noncausality of $S$ for $H$ and conditional noncausality of $H$ for $S$ may hold. If either holds, then $H$ and $S$ can be arrayed in a (block) causal chain, and if both hold, then $H$ and $S$ are conditionally independent. Writing model (2) as a product of univariate conditional

9. Any discrete-time stationary stochastic process can be approximated (in distribution for restrictions to a finite number of periods) by a first-order hidden Markov model so there is no loss of generality in considering only models of this form; see Kunsch, Geman, and Kehagias (1995). 
probabilities $f_{i}\left(H_{i t} \mid H_{1 t}, \ldots, H_{i-1, t}, H_{t-1}, S_{t-1}, X_{t-1}\right)$, one can test for conditional noncausality of $S$ for each component $H_{i}$. It is possible to have a causal chain in which $S$ is conditionally causal to a previous component of $H$, and this component is in turn "instantaneously" causal to $H_{j}$, yet there is no direct causal link from $S$ to $H_{i}$. Placing $S$ after $H$ in the vector $Y$, we have conditional probabilities $f\left(S_{t} \mid H_{t}, H_{t-1}, S_{t-1}, X_{t-1}\right)$. There may be instantaneous conditional independence of $H$ and $S$, with the conditional distribution of $S_{t}$ not depending on $H_{t}$ or conditional noncausality of $H$ for $S$, with the conditional distribution not depending on $H_{t-1}$, or both. The statement that $X$ is strictly exogenous in a valid model (2) is equivalent to the condition that $H$ and $S$ are conditionally noncausal for $X$ in this model. ${ }^{10}$

The conventional definition of a causal model or probabilistic law requires that $f$ be valid for the universe of possible histories (except possibly those in a set that occurs with probability zero); see Pearl (2000). It is possible to reject statistically a proposed causal model by showing that it is highly improbable that an observed sample with a given history was generated by this model. It is far more difficult using statistical analysis to conclude inductively that a proposed model is valid for the universe of possible histories. We have the far more limited objective of providing a foundation for policy analysis, where it is the invariance property under policy interventions that is crucial to predicting policy consequences. We have defined validity and noncausality as properties of a model, and of the outcomes of a process of statistical testing that could in principle be conducted on this model. Only within the domain where the model is valid, and invariance confirms that the model is accurately describing the true data generation process, can these limited positivistic model properties be related to the causal structure embedded in the true data generation process. Further, we can choose the domain over which invariance will be tested to make the definition operational and relevant for a specific analysis of policy interventions. Similarly, our definition of conditional noncausality is a positivistic construct in the spirit of the purely statistical treatment of "causality" by Granger (1969), and the test we will use is simply Granger's test for the absence of causality, augmented with invariance conditions. Thus, for example, if our analysis using this framework concludes that SES is not conditionally causal for new health events within the domain where the Medicare system finances and delivers health care, then this finding would support the conclusion that policy interventions in the Medicare system to increase access or reduce out-of-pocket medical expenses will not alter the conditional probabilities of new health events, given the health histories of enrollees in this system. It is unnecessary for this policy purpose to answer

10. Econometricians have traditionally used the term strictly exogenous to refer to properties of variables in the true data generation process, a stronger nonpositivistic version of this condition. 
the question of whether the analysis has uncovered a causal structure in any deeper sense. Econometric analysis is better matched to the modest task of testing invariance and noncausality in limited domains than to the grander enterprise of discovering universal causal laws. However, our emphasis on invariance properties of the model, and on tests for Granger causality within invariant families, is consistent with the view of philosophers of science that causality is embedded in "laws" whose validity as a description of the true data generation process is characterized by their invariance properties; see Pearl (2000), Feigl (1953), and Nozick (2001).

\subsubsection{Some Specific Formulations}

Starting from class (2), we consider operational models of the linear latent variable form

$$
Y_{i t}^{*}=Y_{1, t} \alpha_{1 i}+\ldots+Y_{i-1, t} \alpha_{i-1, i}+Y_{t-1}^{\prime} \beta_{i}+\delta_{i}-\sigma_{i} \varepsilon_{i t}
$$

with

$$
Y_{i t}=\psi_{i}\left(Y_{i t}^{*}, Y_{t-1}\right),
$$

where $Y^{*}$ is a latent variable, $\varepsilon_{i t}$ is an unobserved disturbance that is standard normal and independent across $i$ and $t$, and $\psi$ is a partial observability mapping that depends on the latent variable, and possibly on the lagged variables. For example, for a chronic health condition such as diabetes, $Y_{i t}$ will indicate whether there has ever been a diagnosis of the disease, with $Y_{i t}=\max \left\{Y_{i, t-1}, \mathbf{1}\left(Y_{i t}^{*} \geq 0\right)\right\}$. For an acute condition such as a heart attack, $Y_{i t}=\mathbf{1}\left(Y_{i t}^{*} \geq 0\right)$ indicates a new occurrence. Components of $Y$ may be binomial or ordered discrete variables such as health status, or continuous variables such as household income. In this model, the $\alpha$ 's, $\beta, \delta$, and $\sigma$ are parameters; restrictions are imposed as necessary for identification. In (3), the linearity in variables and parameters, the first-order Markov property, and the triangular dependence of $Y_{i t}^{*}$ on previous components of $Y_{t}$ are not, in themselves, particularly restrictive, as one can approximate any continuous Markov model of form (2) by a form (3) in which $Y_{t}$ is expanded to include transformations and interactions to sufficient order. The normality assumption is also not restrictive in principle. A latent random variable with conditional cumulative distribution function (CDF) $F\left(Y_{1 t}^{*} \mid Y_{t-1}\right)$ and the partial observability transformation (4) can be redefined using the standard normal $\mathrm{CDF} \Phi$ as $Y_{1 t}^{* *}=\Phi^{-1}\left(F\left(Y_{1 t}^{*} \mid Y_{t-1}\right)\right)$ and $Y_{1 t}=$ $\psi_{1}\left(F^{-1}\left(\Phi\left(Y_{1 t}^{* *}\right) \mid Y_{t-1}\right), Y_{1, t-1}\right)$; this gives a version of models (3) and (4) in which the disturbance is standard normal. ${ }^{11}$ The same construction can be

11. For the CDF $F$ of a random variable $Y$, define $F(y-)=\sup _{y^{\prime}<v} F\left(y^{\prime}\right)$ and $F^{-1}(p)=$ $\min \left\{x^{\prime} \mid F\left(x^{\prime}\right) \geq p\right\}$. Define the random variable $Z \equiv h(Y)=\Phi^{-1}\left(F\left(Y^{\prime}\right)+U\left[F(Y)-F\left(Y^{-}\right)\right]\right)$, where $U$ is a uniform $(0,1)$ random variable. Then $Z$ is a.s. standard normal. Define $Y^{*}=$ $F^{-1}(\Phi(Z))$. Then, $Y^{*}=Y$ a.s., so that $Y$ is given a.s. by a nondecreasing transformation of a standard normal random variable. 
applied to the remaining components of $Y_{t}$. The causal chain assumption is innocuous when the time interval is too short for most causal actions to operate, and the components of $Y_{t}$ are conditionally independent. However, the causal chain assumption is a more substantive restriction when the time interval is long enough for multiple events to occur, as it precludes even the feedbacks that would appear in multiple iterations of a true causal chain. Of course, the generally nonrestrictive approximation properties of models (3) and (4) do not imply that a particular specification chosen for an application is accurate, and failures of tests for invariance can also be interpreted as diagnostics for inadequate specifications.

In models (3) and (4), a binomial component $i$ of $Y_{t}$ with the partial observability mapping $\max \left\{Y_{i, t-1}, 1\left(Y_{i t}^{*} \geq 0\right)\right\}$ and the identifying restriction $\sigma_{i}=1$ satisfies $Y_{i t}=1$ if $Y_{i, t-1}=1$, and otherwise is one with the probit probability

$$
\begin{aligned}
& f_{i}\left(Y_{i t}=1 \mid Y_{1 t}, \ldots, Y_{i-1, t}, Y_{t-1}\right) \\
& \quad=\Phi\left(Y_{1, t} \alpha_{1 i}+\ldots+Y_{i-1, t} \alpha_{i-1, i}+Y_{t-1}^{\prime} \beta_{i}+\delta_{i}\right) .
\end{aligned}
$$

Analogous expressions can be developed for ordered or continuous components.

\subsubsection{Measurement Issues}

A feature of the panel we use is that the waves are separated by several years, and the interviews within a wave are spread over many months, with the months between waves differing across households. If model (2) applies to short intervals, say months, then the transition from one wave in month $t$ to another in month $t+s$ is described by the probability model

$$
f\left(Y_{t+s} \mid Y_{t}\right)=\sum_{Y_{t+1}, \ldots, Y_{t+s-1}} f\left(Y_{t+1} \mid Y_{t}\right) \cdot \ldots \cdot f\left(Y_{t+s} \mid Y_{t+s-1}\right) .
$$

Direct computation of these probabilities will generally be intractable, although analysis using simulation methods is possible.

A major additional complication in our panel is that interview timing appears to be related to health status, with household or proxy interviews delayed for individuals who have died or have serious health conditions. This introduces a spurious correlation between apparent time at risk and health status that will bias estimation of structural parameters. To study empirical approximations to (6) and corrections for spurious correlation, we consider a simple model of interview delay. Let $p=\Phi(\alpha+\beta x)$ denote the monthly survival probability for an individual who was alive at the previous wave interview, where $x$ is a single time-invariant covariate that takes the value $-1,0,+1$, each with probability $1 / 3$. Counting from the time of the previous wave interview, let $k$ denote the number of months this individual lives, and $c$ denote the month that interviews begin for the current 
wave. ${ }^{12}$ There is a distribution of initial contact times; let $q$ denote the probability of a month passing without being contacted, and let $m$ denote the month of initial contact. Assume that an individual who is living at the time of initial contact is interviewed immediately, but for individuals who have died by the time of initial contact, there is an interview delay, with $r$ denoting the probability of an additional month passing without a completed interview with a household member or proxy. Let $n$ denote the number of months of delay in this event. Assume that $m$ and $n$ are not observed, but the actual interwave interval $t$, equal to $m$ if the individual is alive at time of initial contact, and equal to $m+n$ otherwise, is observed. The density of $k$ is $p^{k-1}(1-p)$ for $k \geq 1$. The density of $m$ is $q^{m-c}(1-q)$ for $m \geq c$. Let $d$ be an indicator for the event that the individual is dead at the time of initial contact. The probability of $t$ and $d=0$ is $h(0, t)=q^{t-c}(1-q) p^{t}$, the product of the probability of contact at $t$ and the probability of being alive at $t$. The probability of $t$ and $d=1$, denoted $h(1, t)$, is the sum of the probabilities that the individual is dead at an initial contact month $m$, with $c \leq m \leq t$, and the subsequent interview delay is $n=t-m$, or

$$
h(1, t)=\sum_{m=c}^{t}\left(1-p^{m}\right) q^{m-c}(1-q) r^{t-m}(1-r) .
$$

If $r<p q$, then $h(1, t)=(1-q)(1-r)\left\{\left(q^{t-c+1}-r^{t-c+1}\right) /(q-r)-p^{c}\left((p q)^{t-c+1}-\right.\right.$ $\left.\left.r^{t-c+1}\right) /(p q-r)\right\}$. Then, the probability of an observed interwave interval $t$ is $h(t)=h(0, t)+h(1, t)$, and the conditional probability of $d=1$, given $t$, is $P(1 \mid t)=h(1, t) / h(t)$. Absent interview delay, the conditional probability of $d=1$ given $t$ would be simply $p^{t-1}(1-p)$. The parameter values $\alpha=-$ $2.47474, \beta=0.3, c=22, q=0.85$, and $r=0.5$ roughly match our panel. For these values, the median interwave interval is 25.5 months, and at $t=$ 34,87 percent of the interviews have been completed.

Figure 11.2 plots the inverse normal transformations of the true death rate $p^{t-1}(1-p)$ and the apparent death rate $P(1 \mid t)$ against $\log (t)$ for each value of the covariate $x$. The true relationship is to a reasonable empirical approximation linear in $x$ and in $\log (t)$. Then, in the absence of interview delay, one could approximate $p$, given $x$, with reasonable accuracy by estimating a probit model for death of the form $\Phi(\theta+\gamma x+\lambda \log (t))$, and then estimating $p$ using the transformation $p=(1-\Phi(\theta+\gamma x+\lambda \log (t)))^{1 / t}$ for the observed interwave interval $t \cdot{ }^{13}$ However, the figure shows that interview delay induces a sharp gradient of apparent mortality hazard with interwave interval, so that an estimated model will not extrapolate to realistic mortality hazards over shorter periods. A simple imputation of time at

12. It does not matter for the example if the previous wave interview month is fixed or has a distribution, provided the relative interwave interval $c$ is fixed, and current wave outcomes are independent of the timing of the previous wave interview.

13. A Box-Cox transformation of time at risk, $z=4\left(t^{1 / 4}-1\right)$, gives a somewhat better approximation in the probit model than $\log (t)$, but has no appreciable effect on the accuracy of estimated monthly transition probabilities. 


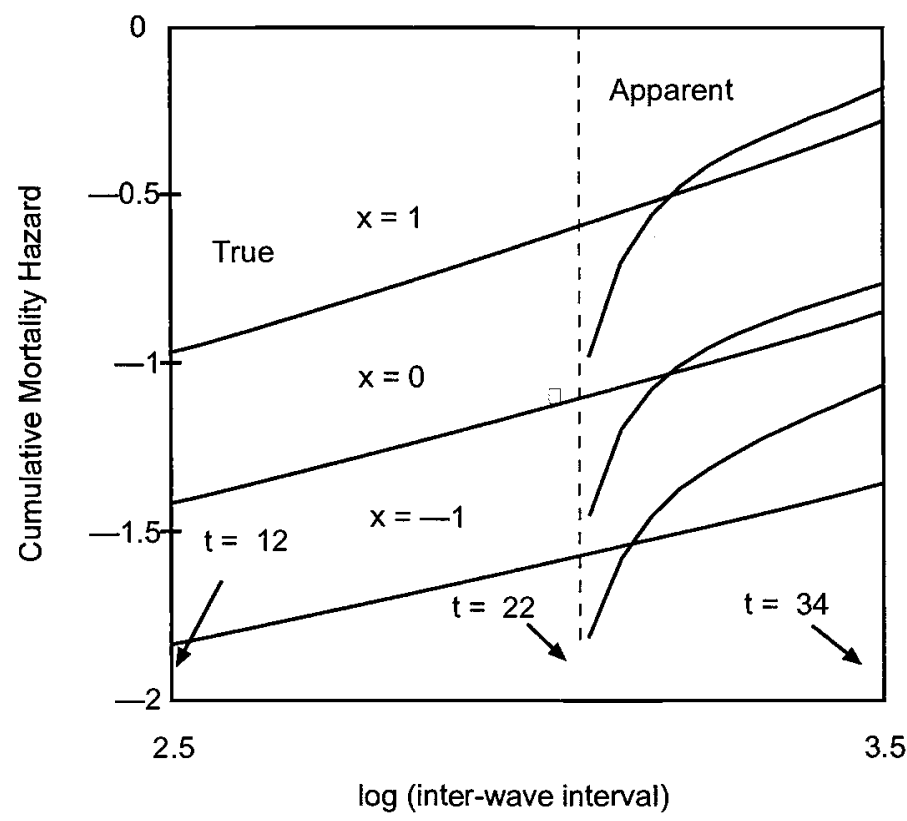

Fig. 11.2 Effect of interview delay (cumulative mortality hazard $=\Phi^{-1}$ [death probability])

risk up to initial contact leads again to models that work well with the procedure just outlined for estimation of $p$ conditioned on $x$. A simple imputed time of initial contact for those who have died is the observed interwave interval less the difference in the mean interwave interview times for dead and living respondents. This imputation can be adjusted further so that the extrapolated annual death rate, $\Phi(\theta+\lambda \log (12)+\gamma x)$, matches the sample average mortality rate. We do the additional adjustment for our panel, with results that are almost identical to the simple imputation of time of initial contact.

We conducted a Monte Carlo calculation of the approximations above in a sample of 50,000. In this simulation, the empirical approximation to observed mortality in the absence of interview delay is $\Phi(-3.1053+$ $0.5327 x+0.652 \log (t))$. With interview delay and the simple imputation described above, $\Phi(-2.9900+0.5349 x+0.6174 \log (t))$ is the empirical approximation. ${ }^{14}$ Table 11.1 gives the annual mortality rates implied by these approximations. From these results, we conclude first that in the absence of interview delay, the probit model $\Phi(\theta+\lambda \log (t)+\gamma x)$ provides an adequate approximation to exact annual mortality rates as a function of time

14. The model estimated with interview delay and without imputation, is $\Phi(-4.6639+$ $0.5349 x+1.1178 \log (t))$. 
Approximation Accuracy with Interview Delay (\%)

\begin{tabular}{|c|c|c|c|c|c|}
\hline$x$ & $\begin{array}{l}\text { Exact } \\
\text { Annual } \\
\text { Mortality } \\
\text { Rate }\end{array}$ & $\begin{array}{c}\text { Approximate } \\
\text { Annual Mortality } \\
\text { Rate without } \\
\text { Interview Delay }\end{array}$ & Error & $\begin{array}{l}\text { Approximate Annual } \\
\text { Mortality Rate with } \\
\text { Interview Delay and } \\
\text { Imputed Contact Time }\end{array}$ & Error \\
\hline 0 & 7.71 & 7.90 & 2.41 & 7.93 & 2.79 \\
\hline-1 & 3.27 & 3.06 & -6.55 & 3.07 & -6.03 \\
\hline+1 & 16.41 & 16.71 & 1.80 & 16.75 & 2.05 \\
\hline Avg. & 9.13 & 9.22 & 0.98 & 9.25 & 1.34 \\
\hline
\end{tabular}

Note: The approximate annual mortality rate is given by $1-(1-\Phi(\theta+\gamma x+\lambda \log (t)))^{12 / t}$, where $t$ is the exact or imputed initial contact time and the model is estimated from the data generated by the Monte Carlo experiment.

at risk, across values of the covariate $x$ that substantially change relative risk, and second that this remains true in the presence of interview delay when one imputes the initial contact time for dead subjects.

These conclusions on the accuracy of the approximation should extend to the exact interwave transition probabilities (6) in our Markov model, supporting use of the probit approximation

$$
\begin{aligned}
& f_{i}\left(Y_{i, t+s}=1 \mid Y_{1 t+s}, \ldots, Y_{i-1, t+s}, Y_{t}\right) \\
& \quad=\Phi\left(Y_{1, t+s} \alpha_{1 i}+\ldots+Y_{i-1, t+s} \alpha_{i-1, i}+Y_{t}^{\prime} \beta_{i}+\delta_{i}+\lambda_{i} \log (s)\right)
\end{aligned}
$$

where $s=t_{i 2}-t_{i 1}$ is the imputed months between initial contact for a wave and previous wave interview, for estimation of incidence between waves. For simulation of yearly transitions, we use the approximation

$$
\begin{aligned}
& f_{i}\left(Y_{i, t+12}=1 \mid Y_{1 t+12}, \ldots, Y_{i-1, t+12}, Y_{t}\right) \\
& \quad=1-\left(1-\Phi\left(Y_{1, t+1} \alpha_{1 i}+\ldots+Y_{i-1, t+1} \alpha_{i-1, i}+Y_{t}^{\prime} \beta_{i}+\delta_{i}+\lambda_{i} \log (s)\right)\right)^{12 / s} \\
& \quad \approx \Phi\left(Y_{1, t+1} \alpha_{1 i}+\ldots+Y_{i-1, t+1} \alpha_{i-1, i}+Y_{t}^{\prime} \beta_{i}+\delta_{i}+\lambda_{i} \log (s)\right) 12 / s
\end{aligned}
$$

where $s$ is the median interwave interval, and the final approximation holds when the probability of a transition is small. Formula (9) generalizes to any probability of a transition from the status quo, with the probability of remaining at the initial state defined so that all the transition probabilities sum to one. We expect this formula to approximate well the probabilities of no new health conditions in a sample population over periods corresponding to the observed interwave intervals.

Estimation of models based on (2)-(8) is straightforward. Because of the independence assumption on the disturbances and the absence of common parameters across equations, the estimation separates into a probit, ordered probit, or ordinary least-squares regression for each component of $Y$, depending on whether the partial observability mapping is binary, 
ordered, or linear. Conventional likelihood ratio tests can be used for the significance of explanatory variables.

\subsection{The AHEAD Panel Data}

\subsubsection{Sample Characteristics}

Our data come from the Asset and Health Dynamics among the Oldest Old (AHEAD) study. ${ }^{15}$ This is a panel of individuals born in 1923 or earlier and their spouses. At baseline in 1993 the AHEAD panel contained 8,222 individuals representative of the noninstitutionalized population, except for oversamples of blacks, Hispanics and Floridians. Of these subjects, 7,638 were over age sixty-nine; the remainder were younger spouses. There were 6,052 households, including individuals living alone or with others, in the sample. The wave 1 surveys took place between October 1993 and August 1994, with half the total completed interviews finished before December 1993. The wave 2 surveys took place approximately twenty-four months later, between November 1995 and June 1996, with half the total completed interviews finished by the beginning of February 1996. The wave 3 surveys took place approximately twenty-seven months after that, between January 1998 and December 1998, with half the total completed interviews finished near the beginning of March 1998. In each wave, there was a long but thin tail of late interviews, heavily weighted with subjects who had moved, or required proxy interviews due to death or institutionalization. Subjects never interviewed, directly or by proxy, are excluded from the calculation of the distribution of interview months. The AHEAD is a continuing panel, but it has now been absorbed into the larger Health and Retirement Study (HRS), which is being interviewed on a three-year cycle.

The AHEAD panel has substantial attrition, with death being the primary, but not the only, cause. A significant effort has been made to track attritors, and identify those who have died through the National Death Register. Figure 11.3 describes outcomes for the full age-eligible sample. For subjects where a proxy interview was possible, an "exit interview" gives information on whether decedents had a new occurrence of cancer, heart attack, or stroke since the previous wave. From the 6,743 age-eligible individuals who did not attrit prior to death, we formed a working sample for analysis consisting of 6,489 by excluding 254 additional individuals with critical missing information. Figure 11.4 describes their outcomes. In a few cases, attritors in wave 2 rejoined the sample in wave 3, but we treat these as permanent attritors because the missing interview makes the observation unusable.

15. The AHEAD survey is conducted by the University of Michigan Survey Research Center for the National Institute on Aging; see Soldo et al. (1997). 
AHEAD Age-Eligible Sample, Wave 1 (7638)

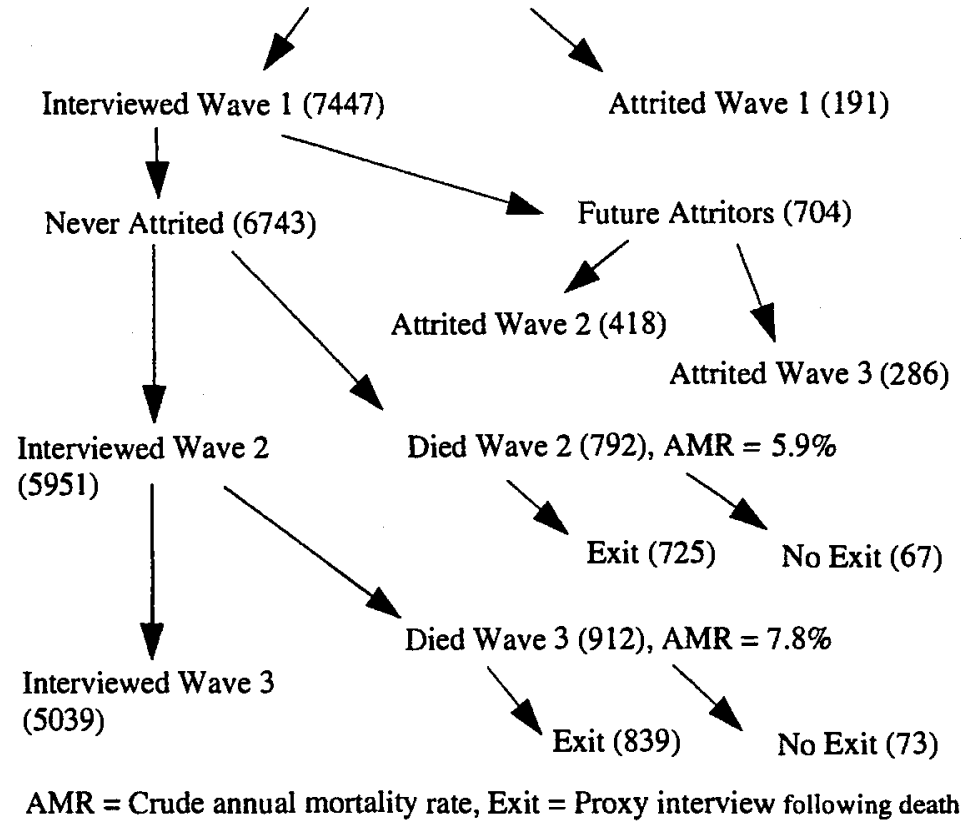

Fig. 11.3 Age-eligible sample outcomes

AHEAD Age-Eligible Sample, Wave 1 (7638)

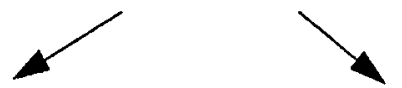

Working Sample Wave 1 (6489) Attritor or Unusable Record (1149)

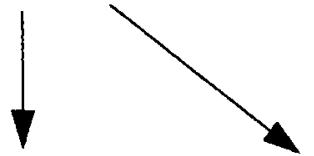

Interviewed Wave 2

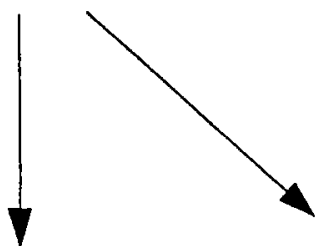

Died Wave 2 (748), AMR $=5.7 \%$

(5741)

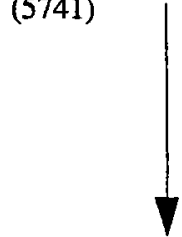

Interviewed Wave 3

(4867)

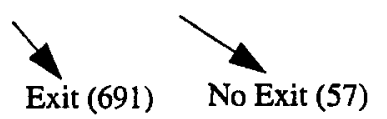

Died Wave 3 (874), AMR $=7.8 \%$

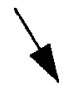

Exit (818)

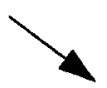

No Exit (56)

$A M R=$ Crude annual mortality rate, Exit $=$ Proxy interview following death

Fig. 11.4 Working sample outcomes 


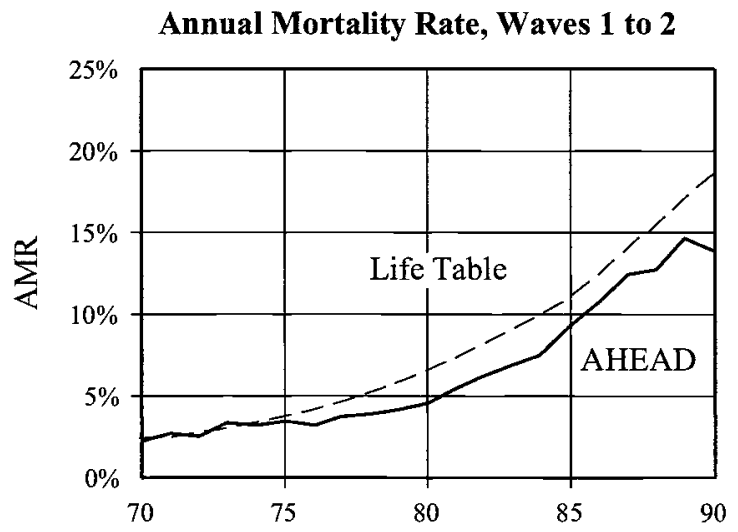

Starting Age for Five-Year Average

Annual Mortality Rate, Waves 2 to 3

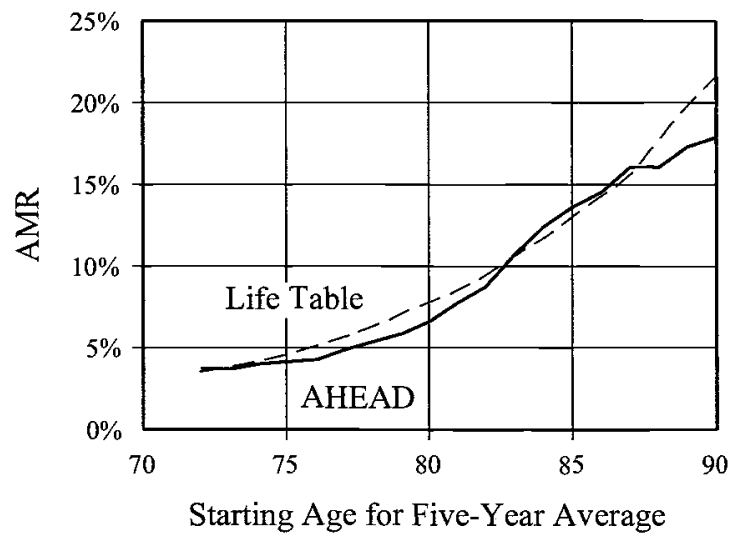

Fig. 11.5 Mortality hazard for AHEAD white females

The restriction of the AHEAD panel to the noninstitutionalized elderly in wave 1 selects against those with the highest mortality risk, particularly at the oldest ages, but the impact of this selection attenuates over time. For white females, figure 11.5 compares the observed annual mortality rate in the AHEAD panel with the expected annual mortality rate from the 1997 life tables for the United States (U.S. Census 1999). ${ }^{16}$ Between waves 1 and 2 , the AHEAD mortality risk is substantially below the life table for ages above seventy-five, reflecting the selection effect of noninstitutionalization.

16. The AMR for the AHEAD sample is the actual death rate between waves for each fiveyear segment of ages in the initial wave, annualized using the median 25.5 month interval between the waves. The AMR from the life tables is obtained by applying life table death rates by month to the actual months at risk for each individual in the five-year segment of ages in 


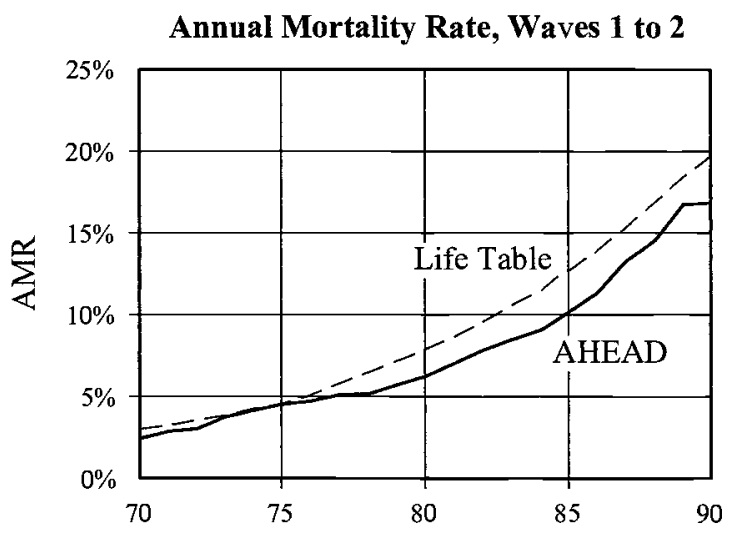

Starting Age for Five-Year Average

Annual Mortality Rate, Waves 2 to 3

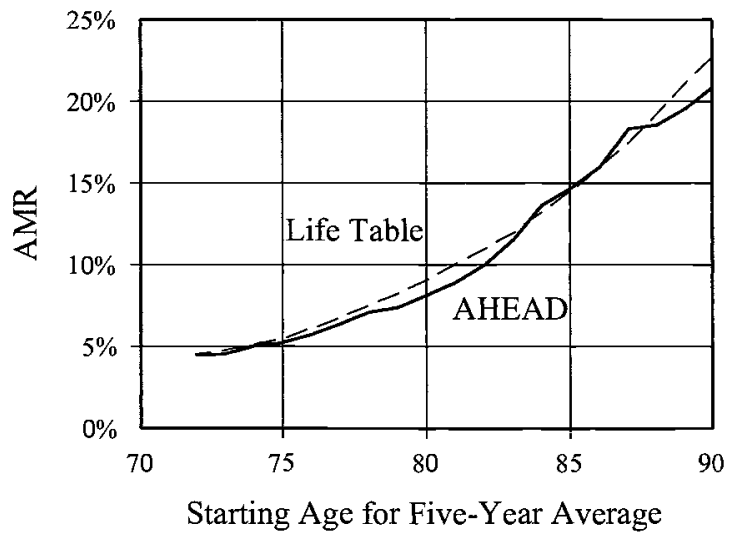

Fig. 11.6 Mortality hazard for AHEAD working sample

Between waves 2 and 3, this effect has essentially disappeared. There is a persistent divergence of the mortality risks above age ninety. In this range, the AHEAD data is sparse, so the curve is imprecisely determined. However, the life tables derived from historical mortality experience may overstate current mortality risk at advanced ages. Figure 11.6 makes the same mortality experience comparisons for the full AHEAD working sample and draws the same conclusions. ${ }^{17}$

the initial wave to calculate expected deaths between waves. This is annualized. For these calculations, the distribution of months at risk for decedents is assumed to be the same as that for survivors.

17. The construction mimics figure 11.5, with life table rates applied using the age, sex, and race of each subject. 


\subsubsection{Descriptive Statistics}

The AHEAD survey provides data on health and socioeconomic status, as well as background demographics. A list of the health conditions we study, with summary statistics, is given in table 11.2. A list of the socioeconomic conditions and demographic variables we use is given in table 11.3. Table 11A.2 lists the variable transformations used in our statistical analysis. ${ }^{18}$ In setting up causality tests, using the framework set out in section 11.2, we will use the health conditions, followed by the socioeconomic conditions, in the order given in these tables. We list cancer, heart disease, and stroke first because they may be instantaneously causal for death, and because we have information from decedent's exit interviews on new occurrence of these diseases. We group the remaining health conditions by degenerative and chronic conditions, then accidents, then mental conditions, because if there is any contemporaneous causality, it will plausibly flow in this order. Similarly, if there is contemporaneous causality between health and socioeconomic conditions, it plausibly flows from the former to the latter.

\subsubsection{Constructed Variables}

The collection and processing of some of the variables requires comment. The AHEAD has an extensive battery of questions about health conditions, including mental health. Most health conditions are asked for in the form "Has a doctor ever told you that you had . . . ?" However, for cancer, heart disease, and stroke, subjects are also asked if there was a new occurrence since the previous interview, and for some conditions such as arthritis, incontinence, and falls, the questions in wave 1 ask for an occurrence in the past twelve months. We note that there are some major groups of health conditions that were not investigated in AHEAD: degenerative neurological diseases, kidney and liver diseases, immunological disorders other than arthritis, sight and hearing problems, back problems, and accidents other than falls. The body mass index (BMI) index is calculated from self-reported height and weight. Information is collected on the number of limitations for six activities of daily living (ADL), and on the number of limitations for five instrumental activities of daily living (IADL). A high ADL limitation count indicates that the individual has difficulty with personal self-care, while a high IADL limitation count indicates difficulty in household management. The study collects data on self-assessed health status, where the subject is asked to rate his or her health as excellent, very good, good, fair or poor. We use an indicator for a poor/fair response. No reference is made to other groups such as "people your age." The study contains the Center for Epidemiologic Studies Depression scale (CESD) 


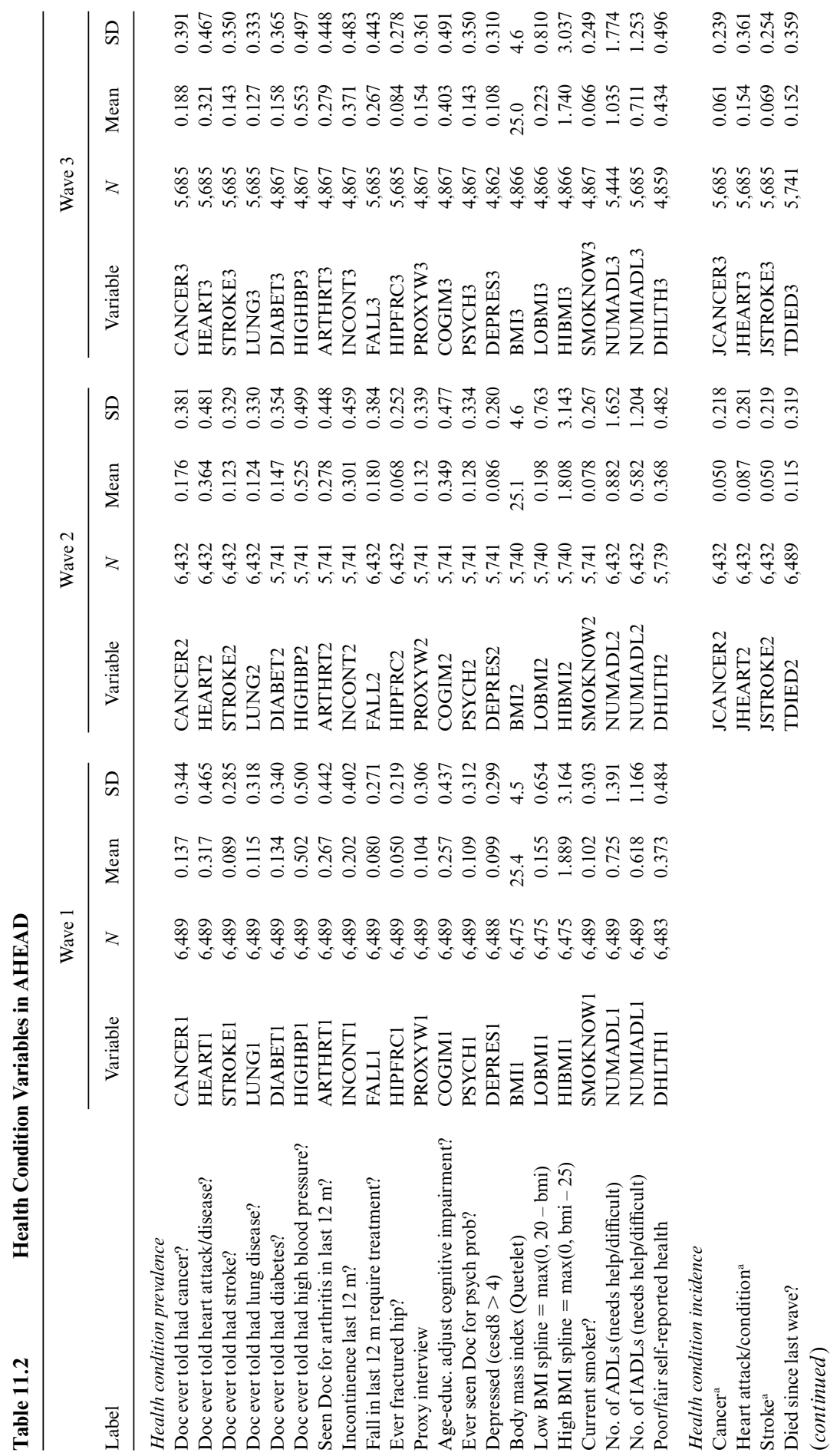




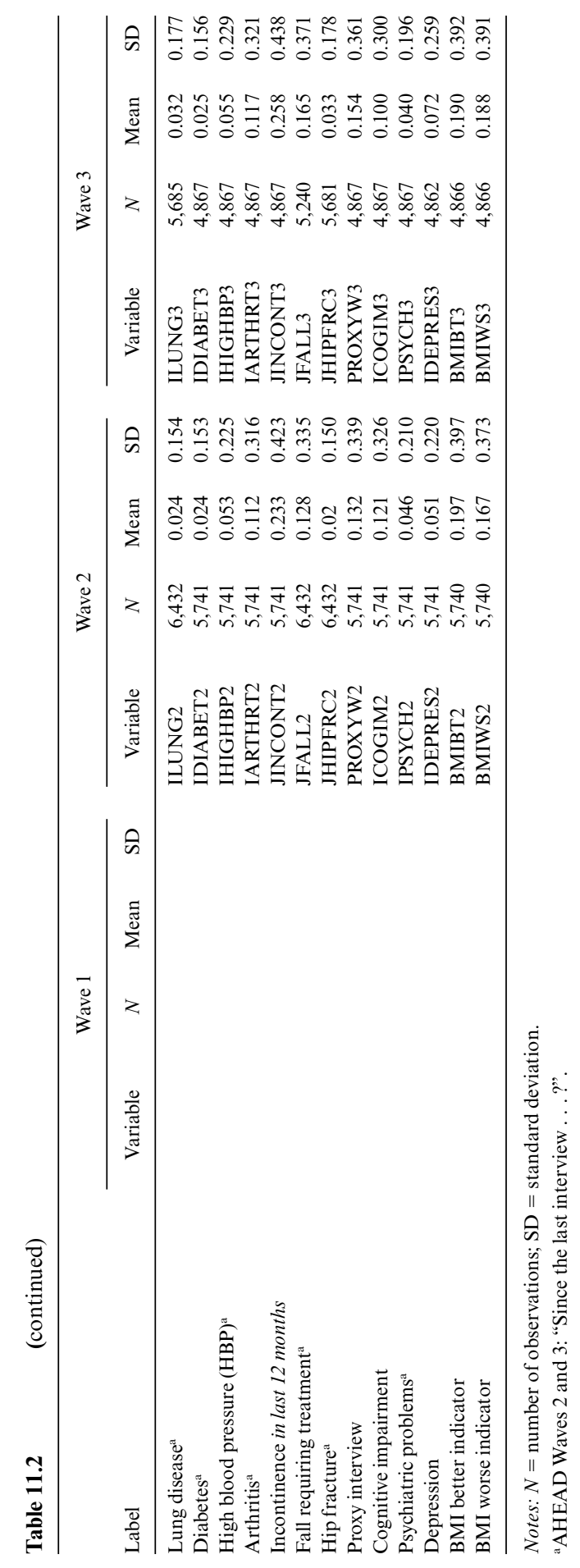




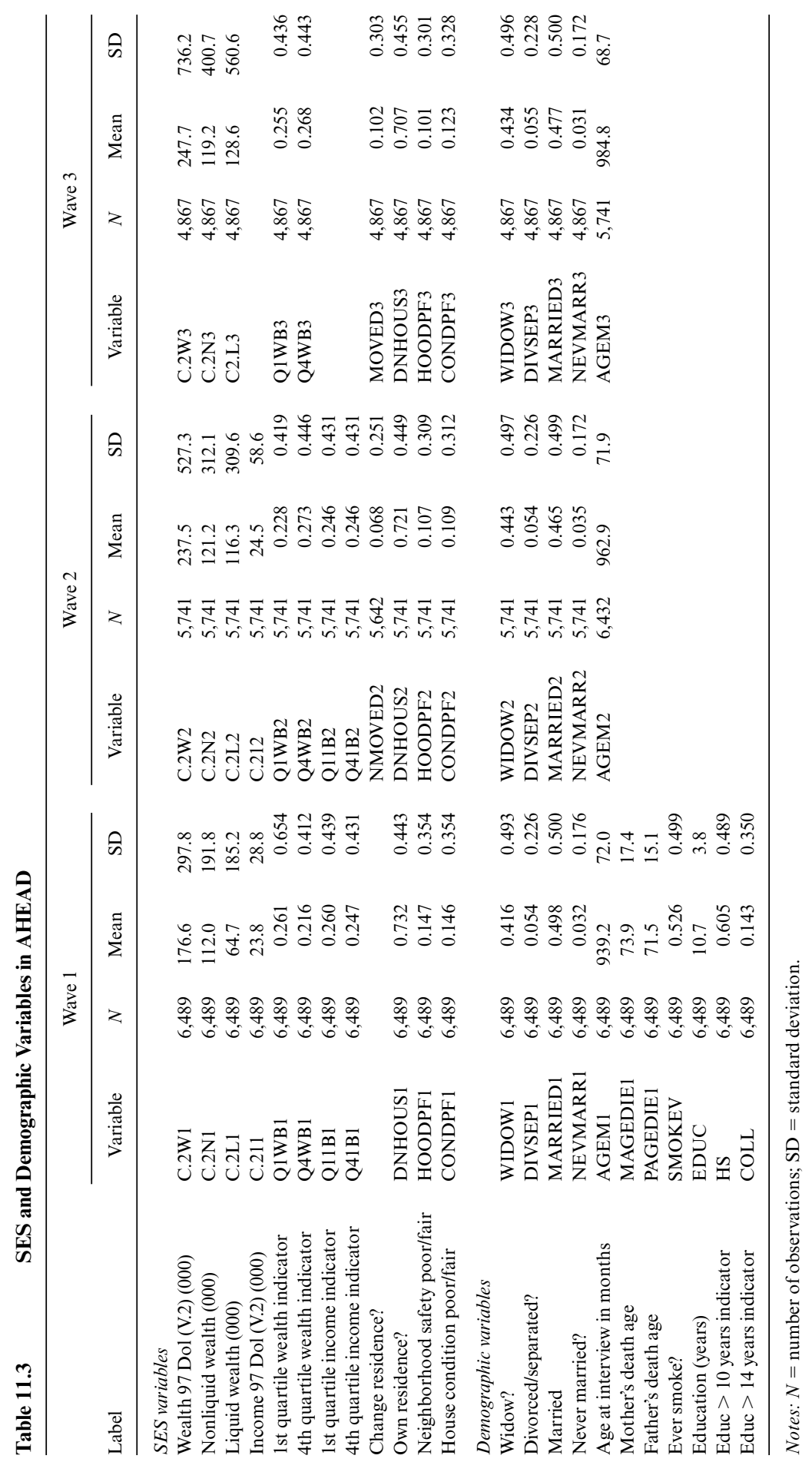


battery of questions measuring general mood, and from this we form an indicator for depression.

The AHEAD is linked to Medicare records. There is insufficient detail to permit reconciliation of self-reports on objective health conditions against diagnoses in the medical records, but errors in self-reports are an issue. We find small, but significant, inconsistencies across waves of AHEAD in reported chronic conditions. A study of Canadian data for a younger population finds substantial discrepancies between self-reported conditions and diagnoses from medical records, particularly for chronic conditions such as arthritis; see Baker, Stabile, and Deri (2001). These authors also find support for a "self-justification" hypothesis that nonworkers are more likely to make false positive claims for health conditions. If this reporting behavior carries into old age, then the reduction in SES as a consequence of spotty employment would induce an artifactual association of self-reported health conditions and SES.

The study measures cognition using a battery of questions which test several domains (Herzog and Wallace 1997): Learning and memory are assessed by immediate and delayed recall from a list of ten words that were read to the subject; reasoning, orientation, and attention are assessed from serial $7 \mathrm{~s}$, counting backwards by 1 , and the naming of public figures, dates, and objects. ${ }^{19}$ This score reflects both long-term native ability and healthrelated impairments due to health events. We carry out the following statistical analysis to reduce the effect of native ability so that we can concentrate on health-related loss of cognitive function. First, we analyze a "nonimpaired" sample of younger individuals, born between 1942 and 1947, who were administered the same cognitive battery in the 1998 Health and Retirement Study (HRS) as were the AHEAD subjects. For these younger individuals, where health-related impairment of cognitive function is rare, we carry out a least absolute deviation (LAD) regression of the cognitive score on education level, sex, and race. We use this fitted regression to predict a "baseline" nonimpaired cognitive score for each member of the AHEAD sample. An additional adjustment is required because average education levels were rising rapidly early in the twentieth century, due to changes in child labor laws and introduction of compulsory education. We assign each AHEAD subject a "1923 cohort equivalent" education level by first regressing education on sex, race, and birth cohort, using a specification search to find interactions and nonlinearities, and then adding to their actual years of education the difference in the mean years of education for their sex-race cohort and the corresponding 1923 sexrace cohort. We then calculate for each AHEAD sample member the deviation of their cognitive score from this adjusted baseline. As a normaliza-

19. Serial $7 \mathrm{~s}$ asks the subject to subtract 7 from 100 , and then to continue subtracting from each successive difference for a total of five subtractions. 
tion, we assign a threshold such that 15 percent of AHEAD subjects aged seventy-seventy-four in wave 1 fall below the threshold. We then use the same threshold in other age groups and other waves to define an indicator for cognitive impairment. ${ }^{20}$

\subsubsection{Measurement of Wealth}

The AHEAD individuals and couples are asked for a complete inventory of assets and debts, and about income sources. Subjects are asked first if they have any assets in a specified category, and, if so, they are asked for the amount. A nonresponse to the amount is followed by unfolding bracket questions to bound the quantity in question, and this may result in complete or incomplete bracket responses. Through the use of unfolding brackets, full nonresponse to asset values was reduced to levels usually less than 5 percent, much lower than would be found in a typical household survey. Generally, median responses among full respondents for an asset category are comparable to other economic surveys, such as the Survey of Consumer Finance (SCF). However, changes in reported assets between waves contain outliers that suggest significant response errors between waves. For couples, where both members are asked the questions on assets, there is also substantial intersubject response variation. It is possible that these repeated reports could be used to control statistically for response error in couples. However, there are systematic differences between respondents, and we use the asset responses only from the individual that a couple says manages the household finances. There may also be an issue of bias in responses recovered by unfolding brackets. Hurd et al. (1998) used experimental variation in the bracket sequences for two financial questions on wave 2 of AHEAD, and found that anchoring to the bracket quantities was significant.

For complete or incomplete bracket responses in an asset category, we impute continuous quantities using hot deck methods. In wave 1, if information on ownership of an asset is missing for a subject, but this subject does give ownership status in wave 2 , then we impute wave 1 ownership by drawing from the conditional empirical distribution of those who have the same response in wave 2 and give a response in wave 1. For subjects missing ownership in both waves 1 and 2, we draw an ownership pair from the empirical distribution of ownership pairs for those giving responses. Given ownership and complete or incomplete bracket information, we draw from the empirical distribution of wave 1 continuous responses that are consistent with the subject's bracket. In later waves, we have adopted a first-order

20. When an interview was done with a proxy, the cognitive battery was not given, but the interviewee was asked if the respondent was cognitively impaired. In our analysis, we treat proxy interview status as a component of the state that appears as a contemporaneous explanation of cognitive impairment; the coefficient on this variable compensates for differences in the definitions of cognitive impairment. 
Markov cross-wave hot deck imputation procedure that assigns a continuous quantity within the given response bracket. First, missing ownership is imputed by choosing randomly from respondents, conditional on ownership in the previous wave. Then, given ownership, we impute a quantitative change in the item from the previous wave by drawing from the empirical distribution of subjects with complete responses that fall in the corresponding brackets in the current and the previous wave. This assures that imputed changes will have the same empirical distribution as observed changes, given the conditioning information available. This procedure does not revise previous wave imputations, so analyses based on earlier waves are not affected. We have experimented with cross-item imputation methods, where bracket information on some asset categories would be used to refine the conditioning used in the imputation of other asset categories. We have found that this has very little effect on the imputed variables or on the results obtained from analyses that use these variables. Therefore, we carry out all imputations one item at a time.

Measured wealth is accumulated over eleven asset categories, including imputed items. We distinguish liquid wealth, composed of IRA balances, stocks, bonds, checking accounts, and certificates of deposit, less debt; and nonliquid wealth, composed of net homeowner equity, other real estate, vehicles and other transportation equipment, businesses, and other assets. The variation in reported wealth of AHEAD households by asset category is substantial from wave to wave, suggesting that in addition to real volatility and reallocation of wealth portfolios, there are serious reporting problems with assets. Values of businesses owned and real estate are problematic items, because current market valuations may be unavailable to respondents, and subjective valuations may be unreliable. Suppose that $W_{t}$ is measured wealth of household in wave $t$, in 1997 dollars, and that $W_{t}=$ $W_{t}^{*}+\eta_{t}$, where $W_{t}^{*}$ is true wealth and $\eta_{t}$ is reporting error. To minimize the impact of extreme outliers in wealth and wealth changes, which we believe are a particular problem due to gross reporting errors, our statistical analysis will use bounded transformations of measured wealth.

The equations of motion for real wealth satisfy $\mathrm{d} W_{i}^{*} / \mathrm{d} t=r W_{i}^{*}+S_{i}$, where $i=T, N, L$ indexes total wealth or its nonliquid and liquid components, $r$ is the instantaneous real rate of return, including unrealized capital gains, and $S_{i}$ is the flow of savings to the wealth component. Make the logistic transformation $Z_{i}=1 /\left(1+\exp \left(-c_{i} W_{i}+d_{i}\right)\right)$, where $c_{i}$ and $d_{i}$ are chosen so that in AHEAD wave 1 the median and the semi-interquartile range of $Z_{i}$ are one-half. Then, $Z_{i}$ is a monotone transformation of measured wealth that is less sensitive to extremes. The equation of motion for $Z_{i}$ is $\mathrm{d} Z_{i} / \mathrm{d} t-r Z_{i}\left(1-Z_{i}\right)\left(\log \left(Z_{i} /\left(1-Z_{i}\right)\right)+d_{i}\right)=c_{i} Z_{i}\left(1-Z_{i}\right) S_{i}+c_{i} Z_{i}(1-$ $\left.Z_{i}\right)(\mathrm{d} \eta / \mathrm{d} t-r \eta)$. We assume that over an inter-wave interval, this equation of motion can be approximated by 


$$
\begin{aligned}
& \frac{Z_{i t}-Z_{i, t-1}-R_{t-1} Z_{i, t-1}\left(1-Z_{i, t-1}\right)\left(\log \left(Z_{i, t-1} /\left(1-Z_{i, t-1}\right)\right)+d_{i}\right)}{m_{t}} \\
& =S_{i t}^{\#}+\sigma v_{i t},
\end{aligned}
$$

where $t$ indexes the wave, $m_{t}$ is the interval in months between waves $t-1$ and $t, R_{t}$ is the $\mathrm{S} \& \mathrm{P}$ real rate of return over the given interval, $\mathrm{S}_{i t}^{\#}$ is the measured part of $c_{i} Z_{i, t-1}\left(1-Z_{i, t-1}\right) S_{i, t-1}$, attenuated at extreme values of $Z_{i, t-1}$, and the disturbance $v_{i t}$ includes the measurement error $c_{i} Z_{i, t-1}\left(1-Z_{i, t-1}\right)\left(\left(\eta_{i t}\right.\right.$ $\left.\left.\eta_{i, t-1}\right) / m_{t-1}-r \eta_{t-1}\right)$ and the unmeasured part of $c_{i} Z_{i, t-1}\left(1-Z_{i, t-1}\right) S_{i, t-1}$. We assume $v$ is homoskedastic. This is consistent with a measurement error in observed wealth that is heteroskedastic, with gross measurement errors more likely when true wealth is near its extremes. ${ }^{21}$ The disturbance in (10) may be serially correlated; however, we have not incorporated this into our analysis. The effect of the transformation is to substantially reduce the influence of outliers in the distribution of changes in measured wealth. In application, we specify $\mathrm{S}_{i t}^{\#}$ to be a linear function of transformed nonliquid and liquid wealth, $Z_{T, t-1}\left(1-Z_{T, t-1}\right) \log \left(Z_{N, t-1} /\left(1-Z_{N, t-1}\right)\right)$ and $Z_{T, t-1}(1-$ $\left.Z_{T, t-1}\right) \log \left(Z_{L, t-1} /\left(1-Z_{L, t-1}\right)\right)$, and of other SES, demographic, and health variables, scaled by $Z_{T, t-1}\left(1-Z_{T, t-1}\right)$.

\subsubsection{Mortality and Observed Wealth Change}

A problem with the analysis of wealth changes is that terminal wealth is not observed following the death of a single, or the death of both members of a household, introducing a selection effect. A second problem is that a household death may have a direct impact on the wealth of a survivor, due to the expenses associated with a death and the disposition of the estate. There are also severe wealth measurement problems following a household death, because a death typically requires a valuation of assets, and in many cases changes the financially responsible respondent. For this reason, we will analyze separately wealth changes for singles and for couples, allow a regime shift following the death of one member of a couple, and account for the selection that occurs when there are no survivors.

For a single female, we adopt a bivariate selection model,

$$
\begin{aligned}
& Y_{f t}^{*}=Y_{f, t-1} \beta_{f}+\varepsilon, \quad y_{f t}=\mathbf{1}\left(Y_{f t}^{*}>0\right), \quad Y_{w t}=Y_{w, t-1} \beta_{w}+Y_{w, t}^{\prime} \gamma_{w}+\lambda \varepsilon+\kappa \eta, \\
& Y_{w t} \text { observed if } y_{f t}=1,
\end{aligned}
$$

21. Heteroskedasticity in (10) will arise from selection effects, described later, as well as possibly from a failure of the transformation to fully control the effects of gross reporting errors. When working with this model, we use standard error estimates that are robust with respect to heteroskedasticity of unknown form and do not attempt direct tests of the implicit error specification underlying transformation (10). 
where the first latent equation determines survival, $y_{f t}=1$, the second equation corresponds to the transformed wealth change equation (10) with dependence on the previous state $Y_{w, t-1}$ and the previously determined components $Y_{w, t}^{\prime}$ of the current state, with the wealth change observed for survivors. The disturbance $\varepsilon_{f}$ has mean zero, variance one, and a density $f(\varepsilon)$. The disturbance $\eta$ is independent of $\varepsilon$, and has mean zero and variance one. The correlation of the disturbances in the selection and wealth change equations is $\rho=\lambda /\left(\lambda^{2}+\kappa^{2}\right)^{1 / 2}$, and the unconditional variance of the wealth change equation is $\sigma^{2}=\lambda^{2}+\kappa^{2}$. When $\varepsilon$ and $\eta$ are standard normal, this is the conventional bivariate normal selection model. However, specification tests for normality fail, and for robustness we adopt a more flexible specification, approximating the density $f(\varepsilon)$ by an Edgeworth expansion,

$$
f(\varepsilon)=\sum_{j=0}^{J} \gamma_{j} H_{j}(\varepsilon) \phi(\varepsilon),
$$

where the $\gamma_{j}$ are parameters and $H_{j}(\varepsilon)$ are Hermite orthogonal polynomials; see Newey, Powell, and Walker (1990). Let $\Psi_{j k}(a)=\int_{a}^{\infty} \varepsilon^{k} H_{j}(\varepsilon) \phi(\varepsilon) \mathrm{d} \varepsilon$. Then, the polynomials $H_{j}(\varepsilon)$ and the partial moment functions $\Psi_{j k}(a)$ can be constructed using the recursions

$$
\begin{aligned}
H_{0}(\varepsilon)= & 1, H_{1}(\varepsilon)=\varepsilon, \text { and } H_{j}(\varepsilon)=\varepsilon H_{j-1}(\varepsilon)-(j-1) H_{j-2}(\varepsilon) \text { for } j>1, \\
\Psi_{00}(a)= & \Phi(-a), \quad \Psi_{01}(a)=\phi(a), \quad \text { and } \\
\Psi_{0 k}(a)= & a^{k-1} \phi(a)+(k-1) \Psi_{0, k-2}(a) \text { for } k>1, \\
\Psi_{j 0}(a)= & H_{j-1}(a) \phi(a) \text { and } \Psi_{j k}(a)=a^{k} H_{j-1}(a) \phi(a)+k \Psi_{j-1, k-1}(a) \\
& \text { for } k>0, \text { for } j>0 .
\end{aligned}
$$

Table 11A.1 derives these results and gives the leading terms for $H_{j}$ and $\Psi_{j k}$ : We require that $f$ integrate to one and have unconditional mean zero and variance one; this forces $\gamma_{0}=1, \gamma_{1}=0$, and $\gamma_{2}=0$. The free parameters $\gamma_{j}$ for $j>2$ determine higher-order moments of $\varepsilon$. For example, skewness and kurtosis are determined by $E \varepsilon^{3}=6 \gamma_{3}$ and $E \varepsilon^{4}=3+24 \gamma_{4}$. With these restrictions, we have, finally

$$
\begin{aligned}
\mathrm{E}(\varepsilon \mid \varepsilon>a) & =\frac{\phi(a)+\sum_{j=3}^{j} \gamma_{j} \Psi_{j 1}(a)}{\Phi(-a)+\sum_{j=3}^{J} \gamma_{j} \Psi_{j 0}(a)} \text { and } \\
\mathrm{E}\left(\varepsilon^{2} \mid \varepsilon>a\right) & =\frac{\Phi(-a)+a \phi(a)+\sum_{j=3}^{j} \gamma_{j} \Psi_{j 2}(a)}{\Phi(-a)+\sum_{j=3}^{j} \gamma_{j} \Psi_{j 0}(a)} .
\end{aligned}
$$

We use the Edgeworth approximation and these conditional expectations with $J=4$. We then have 
(15)

$$
\begin{aligned}
& \mathrm{E}\left(Y_{w t}^{*} \mid \varepsilon>-Y_{f, t-1} \beta_{f}\right) \\
& \quad=Y_{w, t-1} \beta_{w}+Y_{w, t}^{\prime} \gamma_{w}+\lambda \frac{\phi\left(Y_{f, t-1} \beta_{f}\right)+\sum_{j=3}^{4} \gamma_{j} \Psi_{j 1}\left(-Y_{f, t-1} \beta_{f}\right)}{\Phi\left(Y_{f, t-1} \beta_{f}\right)+\sum_{j=3}^{4} \gamma_{j} \Psi_{j 0}\left(-Y_{f, t-1} \beta_{f}\right)} .
\end{aligned}
$$

We estimate this conditional expectation in a two-step procedure. First, the parameters $\beta_{f}$ of the selection equation are estimated by maximum likelihood, and substituted into expression (15) for the expectation of the wealth change equation..$^{22}$ Then, the parameters in this conditional expectation are estimated using nonlinear least squares. The disturbance $\zeta=\lambda \varepsilon+\kappa \eta$ $-\mathrm{E}\left(\varepsilon \mid \varepsilon>-Y_{f, t-1} \beta_{f}\right)$ has mean zero and variance:

$$
\begin{aligned}
& \mathrm{E}\left(\zeta^{2} \mid \varepsilon>-Y_{f, t-1} \beta_{f}\right) \\
& =\kappa^{2}+\lambda^{2}\left(\frac{\sum_{j=0}^{J} \gamma_{j} \Psi_{j 2}\left(-Y_{f, t-1} \beta_{f}\right)}{\sum_{j=0}^{J} \gamma_{j} \Psi_{j 0}\left(-Y_{f, t-1} \beta_{f}\right)}-\left[\frac{\sum_{j=0}^{J} \gamma_{j} \Psi_{j 1}\left(-Y_{f, t-1} \beta_{f}\right)}{\sum_{j=0}^{J} \gamma_{j} \Psi_{j 0}\left(-Y_{f, t-1} \beta_{f}\right)}\right]^{2}\right) .
\end{aligned}
$$

We regress the squared residuals from the estimation of (15) on the righthand-side variables in (16) to obtain an estimate of $\kappa^{2}$. Finally, we estimate the covariance matrix for the parameter estimates using the generalized method of moments "sandwich" formula, with the Eicker-White procedure used for robustness against heteroskedasticity of unknown form, and the delta method used to incorporate the effects of variance in the firststage selection parameter estimates.

Next consider the effects of death and selection on couples. We adopt a trivariate selection model with selection equations

$$
\begin{aligned}
& Y_{f t}^{*}=Y_{f, t-1} \beta_{f}+\varepsilon_{f}, Y_{m t}^{*}=Y_{m, t-1} \beta_{m}+\varepsilon_{m}, \quad y_{f t}=\mathbf{1}\left(Y_{f t}^{*}>0\right), \\
& y_{m t}=\mathbf{1}\left(Y_{m t}^{*}>0\right)
\end{aligned}
$$

for the female and male members of the couple, respectively, where $\varepsilon_{f}$ and $\varepsilon_{m}$ are assumed to be independent with zero mean and unit variance, and densities $g_{f}\left(\varepsilon_{f}\right)$ and $g_{m}\left(\varepsilon_{m}\right)$. The independence assumption could fail if there are hidden common factors in mortality risk for both household members; for example, indirect effects of smoking. However, the frequency of multiple deaths in a household between waves is sufficiently rare in the AHEAD data so that mortality risk interactions are empirically not identified. We distinguish three regimes $\left(y_{f}, y_{m}\right)$ in which wealth change is observed: intact couples where both members survive $(1,1)$, the female survives the death of her spouse $(1,0)$, and the male survives the death of his

22. We find that the coefficients of the index in the mortality model are not sensitive to the Edgeworth generalization, and in estimation of the model for wealth change use the first-stage probit models for mortality estimated earlier, with invariance imposed, to obtain the indices that appear in the selection effects. 
spouse $(0,1)$. We will let $Y_{t}^{0}=\left[Y_{h t-1} Y_{m t-1} y_{f t} \cdot Y_{f t}^{\prime} y_{m t} \cdot Y_{m t}^{\prime}\right]$ denote the vector of variables that explain wealth change, where $Y_{h t-1}, Y_{f t-1}$, and $Y_{m t-1}$ are, respectively, previous wave common, female, and male variables, $Y_{f t}^{\prime}$ are previously determined components of the current state for females, observed only for survivors and hence zeroed out for nonsurvivors, and $Y_{m t}^{\prime}$ are the analogous previously determined components of the current state for males, again observed only for survivors. We assume that in an observed regime $j k$ the wealth change model takes the form

$$
Y_{w t}=Y_{t}^{0} \beta_{w j k}+\left(\lambda_{f}-\theta_{f} \mathbf{1}(j+k=1)\right) \varepsilon_{f}+\left(\lambda_{m}-\theta_{m} \mathbf{1}(j+k=1)\right) \varepsilon_{m}+\kappa_{j k} \eta,
$$

where $\eta$ is independent of $\varepsilon_{f}$ and $\varepsilon_{m}$, with zero mean and unit variance. For intact couples, unobserved dependence of wealth change on selection is reflected in the parameters $\lambda_{f}$ and $\lambda_{m}$, a direct extension of the bivariate selection model to the trivariate case with two independent selection effects. For intact couples, the correlations of the disturbances in the selection and wealth change equations are $\rho_{f}=\lambda_{f} /\left(\kappa_{11}^{2}+\lambda_{f}^{2}+\lambda_{m}^{2}\right)^{1 / 2}$ and $\rho_{m}=\lambda_{m} /\left(\kappa_{11}^{2}+\right.$ $\left.\lambda_{f}^{2}+\lambda_{m}^{2}\right)^{1 / 2}$. The coefficients $\beta_{j k}$ and the standard deviation $\kappa_{j k}$ are allowed to vary by regime, to capture the observed and unobserved economic effects of a death on valuation and reporting of assets. In addition, the selection effects are allowed to shift, from $\lambda_{f}$ to $\lambda_{f}-\theta_{f}$ for the female selection disturbance, and from $\lambda_{m}$ to $\lambda_{m}-\theta_{m}$ for the male selection disturbance. We incorporate these effects to accommodate an apparent interaction in which unexpected survival of a couple (for example, $\varepsilon_{f}$ and $\varepsilon_{m}$ large positive) increases dissaving, perhaps due to additional medical and living expenses linked to overcoming high mortality hazards, but the unexpected death of a spouse (for example, $\varepsilon_{f}$ large negative) also increases dissaving, perhaps because revaluations of assets tend to be more drastic in circumstances where mortality hazard is low.

We adopt the Edgeworth approximation (12) for each of the densities $g_{f}\left(\varepsilon_{f}\right)$ and $g_{m}\left(\varepsilon_{m}\right)$. In regime $j k$ with $j+k>0$, letting $s_{f}=2 y_{f}-1$ and $s_{m}=$ $2 y_{m}-1$, one has

$$
\begin{aligned}
\mathrm{E}\left(Y_{w t} \mid j k\right)= & Y_{t}^{0} \beta_{w j k}+s_{f}\left(\lambda_{f}-y_{f} \theta_{f}\right) \\
& \cdot \frac{\phi\left(Y_{f, t-1} \beta_{f}\right)+\sum_{j=3}^{4} \gamma_{j} \Psi_{j 1}\left(-Y_{f t-1} \beta_{f}\right)}{\Phi\left(s_{f} Y_{f, t-1} \beta_{f}\right)+s_{f} \sum_{j=3}^{4} \gamma_{j} \Psi_{j 0}\left(-Y_{f, t-1} \beta_{f}\right)} \\
& +s_{m}\left(\lambda_{m}-Y_{m} \theta_{m}\right) \\
& \cdot \frac{\phi\left(Y_{m, t-1} \beta_{m}\right)+\sum_{j=3}^{4} \gamma_{j} \Psi_{j 1}\left(-Y_{m, t-1} \beta_{m}\right)}{\Phi\left(s_{m} Y_{m, t-1} \beta_{m}\right)+s_{m} \sum_{j=3}^{4} \gamma_{j} \Psi_{j 0}\left(-Y_{m, t-1} \beta_{m}\right)} .
\end{aligned}
$$

As in the case of singles, we estimate the conditional expectation (19) by nonlinear least squares after plugging in estimates of $\beta_{f}$ and $\beta_{m}$ from the earlier mortality models. A final stage, analogous to (16), regresses the 
squared residuals from (19) for each regime on an intercept, $\mathrm{E}\left(\varepsilon_{f}^{2} \mid s_{f}\right)$ $\left(\mathrm{E}\left(\varepsilon_{f} \mid s_{f}\right)\right)^{2}$, and $\mathrm{E}\left(\varepsilon_{m}^{2} \mid s_{m}\right)-\left(\mathrm{E}\left(\varepsilon_{m} \mid s_{m}\right)\right)^{2}$; the coefficient on the intercept is an estimate of $\kappa_{j k}^{2}$. Because the number of deaths among couples is relatively small, we impose the constraints $\beta_{w 10}=\beta_{w 01}$ for empirical identification.

Household income in AHEAD is also susceptible to measurement error, and to minimize its effect, we use income quartiles as explanatory variables. These are obtained by converting all incomes to 1997 dollars, determining the quartiles for the pooled incomes of all subjects in all waves, and using the thresholds thus established to classify each observed subject income. AHEAD respondents rate the safety of their neighborhood and the condition of their dwelling on a five-point scale, from poor to excellent; we use indicators for poor or fair responses.

\subsection{Socioeconomic Status and Prevalence of Health Conditions}

\subsubsection{Descriptive Statistics}

We first give some descriptive statistics on the prevalence of health conditions in the AHEAD population. Table 11.4 shows prevalence rates in the AHEAD sample in wave 1, classified by age and sex, for the health conditions listed in table 11.2. Generally, prevalence of health conditions does not show a strong age gradient, indicating broadly that morbidity rates among survivors do not increase much with age. Selection effects from initial noninstitutionalization and from mortality may be responsible. The major exception is cognitive impairment, which rises as age increases. The prevalence of acute and degenerative conditions among survivors fall after about age eighty, reflecting the effect of selection due to deaths from these conditions. Males have higher prevalence of acute and degenerative diseases than do females, but females have higher prevalence of mental and chronic conditions, and accidents.

Figure 11.7 shows the age gradients of wealth, income, and education in wave 1 of the AHEAD sample. These gradients reflect substantial cohort effects, as well as life-cycle and composition effects. Work, income, and asset accumulation patterns of the AHEAD population were impacted by World War II, and those over age eighty experienced the Great Depression during their prime working years. The United States was substantially rural when the AHEAD population was born, and education was truncated for work for many members of this population. In addition to cohort effects, the curve for assets reflects life-cycle decumulation of assets through the retirement years, and the curve for income reflects the rising proportion of widows in the survivors to older ages. There is an additional compositional effect from the association of SES and mortality: Higher SES is selected preferentially among survivors. However, in aggregate cross section, the life-cycle and cohort effects dominate the compositional effects. 
Table 11.4

Prevalence of Health Conditions, by Age and Sex

\begin{tabular}{|c|c|c|c|c|c|c|c|c|c|c|}
\hline \multirow[b]{2}{*}{ Condition } & \multicolumn{5}{|c|}{ White Females } & \multicolumn{5}{|c|}{ White Males } \\
\hline & $70-74$ & $75-79$ & $80-84$ & $85-89$ & $90+$ & $70-74$ & $75-79$ & $80-84$ & $85-89$ & $90+$ \\
\hline Cancer $^{\mathrm{a}}$ & 0.122 & 0.137 & 0.168 & 0.141 & 0.127 & 0.132 & 0.185 & 0.202 & 0.187 & 0.093 \\
\hline Heart disease $^{\mathrm{a}}$ & 0.244 & 0.275 & 0.361 & 0.339 & 0.370 & 0.361 & 0.390 & 0.423 & 0.368 & 0.296 \\
\hline Stroke $^{\mathrm{a}}$ & 0.051 & 0.069 & 0.104 & 0.121 & 0.133 & 0.066 & 0.12 & 0.102 & 0.130 & 0.148 \\
\hline Lung disease ${ }^{a}$ & 0.109 & 0.123 & 0.108 & 0.082 & 0.055 & 0.151 & 0.171 & 0.173 & 0.093 & 0.056 \\
\hline Diabetes $^{\mathrm{a}}$ & 0.121 & 0.097 & 0.107 & 0.088 & 0.055 & 0.133 & 0.145 & 0.112 & 0.104 & 0.074 \\
\hline $\begin{array}{l}\text { High blood } \\
\text { pressure }^{\mathrm{a}}\end{array}$ & 0.481 & 0.510 & 0.537 & 0.582 & 0.448 & 0.433 & 0.477 & 0.418 & 0.321 & 0.167 \\
\hline Arthritis ${ }^{\mathrm{b}}$ & 0.222 & 0.285 & 0.267 & 0.328 & 0.254 & 0.167 & 0.205 & 0.196 & 0.161 & 0.167 \\
\hline Incontinence $^{\mathrm{b}}$ & 0.228 & 0.263 & 0.266 & 0.331 & 0.365 & 0.085 & 0.138 & 0.145 & 0.161 & 0.259 \\
\hline Fall $^{\mathrm{b}}$ & 0.082 & 0.096 & 0.116 & 0.138 & 0.133 & 0.044 & 0.046 & 0.048 & 0.088 & 0.056 \\
\hline Hip fracture ${ }^{\mathrm{a}}$ & 0.032 & 0.052 & 0.079 & 0.127 & 0.138 & 0.020 & 0.031 & 0.041 & 0.067 & 0.056 \\
\hline $\begin{array}{l}\text { Cognitive } \\
\text { impairment }\end{array}$ & 0.120 & 0.149 & 0.338 & 0.452 & 0.635 & 0.137 & 0.173 & 0.291 & 0.446 & 0.500 \\
\hline $\begin{array}{l}\text { Psychiatric } \\
\text { disease }^{\mathrm{a}}\end{array}$ & 0.149 & 0.137 & 0.105 & 0.082 & 0.044 & 0.094 & 0.092 & 0.071 & 0.036 & 0.056 \\
\hline Depression & 0.070 & 0.117 & 0.131 & 0.099 & 0.116 & 0.048 & 0.050 & 0.071 & 0.083 & 0.093 \\
\hline $\begin{array}{l}\text { Smoker } \\
\text { ADL }\end{array}$ & 0.133 & 0.095 & 0.058 & 0.040 & 0.017 & 0.142 & 0.123 & 0.082 & 0.041 & 0.093 \\
\hline $\begin{array}{l}\text { impairment } \\
\end{array}$ & 0.375 & 0.544 & 0.829 & 1.266 & 2.16 & 0.285 & 0.499 & 0.691 & 1.114 & 1.444 \\
\hline $\begin{array}{l}\text { 1ADpairment } \\
\text { impal }\end{array}$ & 0.293 & 0.340 & 0.662 & 1.099 & 2.011 & 0.304 & 0.422 & 0.658 & 0.964 & 1.426 \\
\hline $\begin{array}{l}\text { Self-reported } \\
\text { health }\end{array}$ & 0.273 & 0.348 & 0.387 & 0.393 & 0.42 & 0.263 & 0.364 & 0.437 & 0.332 & 0.296 \\
\hline
\end{tabular}

aAHEAD 1993 (wave 1) question: "Has a doctor ever told you . . . /Do you have . . . /Have you ever ...?"”

'AHEAD 1993 (wave 1) question: "During the last 12 months, have you ... ?".

${ }^{\mathrm{c} A v e r a g e ~ n u m b e r ;} \max (\mathrm{ADL})=6, \max (\mathrm{IADL})=5$.

\subsubsection{Models of Association}

To examine the association of SES and health conditions, we estimate a series of binomial probit models of the form

$$
P\left(Y_{i t}=1 \mid Y_{1 t}, \ldots, Y_{i-1, t}, W_{t}, X_{t}\right),
$$

where the $Y_{i t}$ are indicators for the prevalence of various health conditions, $W_{t}$ denotes a vector of SES conditions, and $X_{t}$ denotes other demographic variables. The health conditions appear in the same sequence as in table 11.2 , with previous conditions in (20) providing information on association among health conditions. Included in $W_{t}$ are indicators for the top and bottom quartiles of wealth and income, indicators for ten or more years of education (high school) and for fourteen or more years of education (college), and indicators for poor or fair neighborhood safety and dwelling condition. 


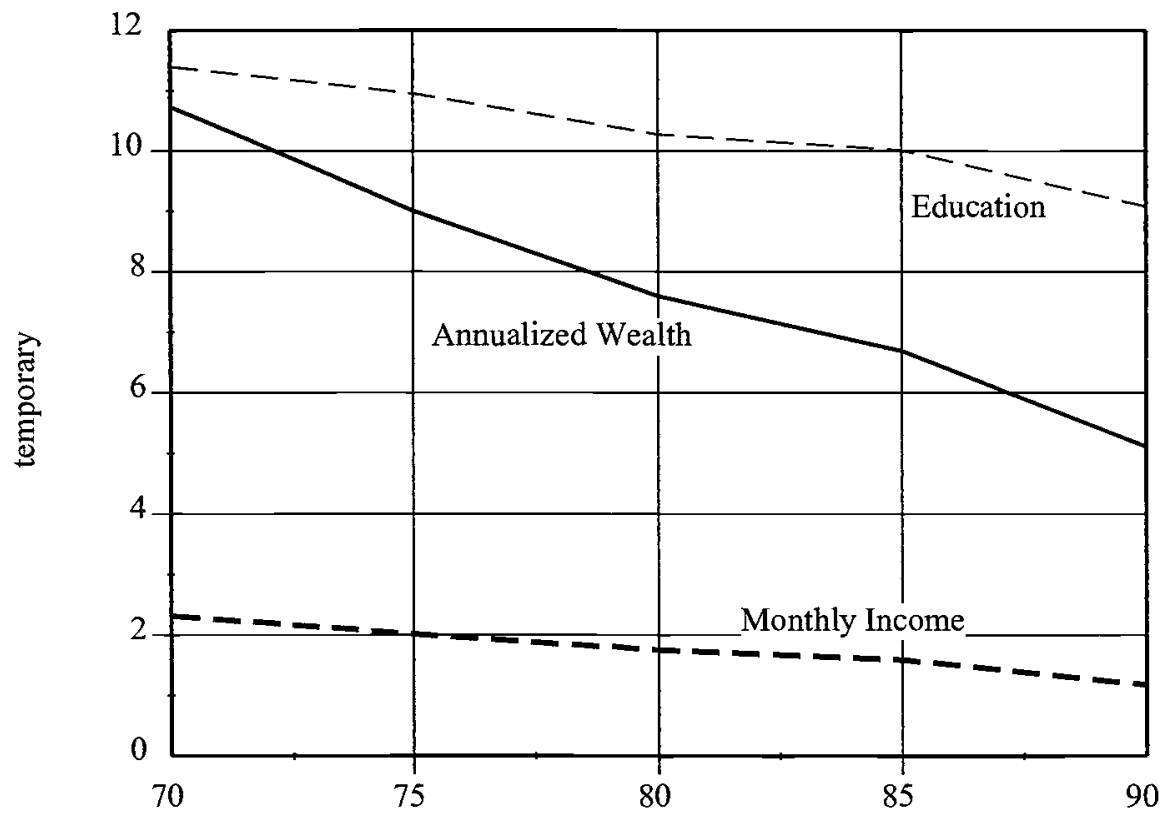

Start of 5-year Age Bracket

Fig. 11.7 Cohort gradients (education, wealth, and income)

The detailed estimation results can be found at http://elsa.berkeley.edu/ $\mathrm{wp} / \mathrm{hww} / \mathrm{hww}$ 202.html. Sample sizes are not adequate for comparable models for non-whites. We find the expected patterns of comorbidity, with a strong association of heart disease, stroke, lung disease, and arthritis, and a strong association of diabetes, heart disease, and high blood pressure. Incontinence is associated with cancer and stroke, and for women with diabetes, high blood pressure, and arthritis. Falls, hip fractures, and strokes are associated. Psychiatric diseases and depression are associated with arthritis and falls. BMI is positively associated with diabetes, high blood pressure, and arthritis, and negatively associated with lung disease. Current smokers have lower BMI, are less likely to have diabetes, and are more likely to be depressed. Numbers of ADLs and IADLs are positively associated with most acute diseases, arthritis, falls, hip fractures, cognitive impairment, and psychiatric disease. A poor or fair self-reported health status is associated with most acute and chronic diseases, with ADLs and IADLs, and with depression.

Some covariates are associated with health conditions, and may be risk factors for these conditions. Widowhood is associated with increased cancer and heart disease for women, increased psychiatric disease for men, and increased lung disease and depression for both men and women. For 
Table 11.5

Summary of Associations of SES and Health Conditions AHEAD Wave 1

\begin{tabular}{|c|c|c|}
\hline SES Association & White Females & White Males \\
\hline 1 percent level & $\begin{array}{l}\text { Heart disease, stroke, lung disease, dia- } \\
\text { betes, cognitive impairment, depression, } \\
\text { BMI, IADL impairment, self-reported } \\
\text { health status }\end{array}$ & $\begin{array}{l}\text { Lung disease, cognitive impairment, } \\
\text { BMI, current smoker, ADL impair- } \\
\text { ment, IADL impairment, self-reported } \\
\text { health status }\end{array}$ \\
\hline 5 percent level & Cancer, HBP, Arthritis & HBP, depression \\
\hline Not significant & $\begin{array}{l}\text { Incontinence, fall, hip fracture, psychi- } \\
\text { atric condition, current smoker, ADL } \\
\text { impairment }\end{array}$ & $\begin{array}{l}\text { Cancer, heart disease, stroke, diabetes, } \\
\text { arthritis, incontinence, fall, hip frac- } \\
\text { ture, psychiatric condition }\end{array}$ \\
\hline
\end{tabular}

Note: $\mathrm{HBP}=$ high blood pressure; $\mathrm{BMI}=$ body mass index (high or low); $\mathrm{ADL}=$ activities of daily living (impairment requiring assistance with personal care); IADL = instrumental activities of daily living (impairment requiring assistance with household management).

women, father's age at death is associated with heart disease, and mother's age at death is associated with high blood pressure. For men, father's age at death is associated with high blood pressure and arthritis.

We generally find a statistically significant association of SES and prevalence of health conditions, as summarized in table 11.5. It is noteworthy that for males the prevalence of the acute diseases, cancer, heart disease, and stroke are not strongly associated with SES, contrary to literature findings for younger populations. This may be the result of early onset of these diseases, particularly among the poor and among smokers, that selects out of the AHEAD population those males most at risk for these diseases. Overall, wealth is the SES component most commonly associated with health conditions. Education, neighborhood rating, and dwelling rating are occasionally significant, and income is almost never significant. Table 11.6 summarizes the SES components that are individually significant in their association with various health conditions and indicates the sign of the correlation. For a number of these conditions, prevalence rates are insufficient to detect the effects of SES components with satisfactory power. However, for heart disease, high blood pressure, arthritis, cognitive impairment, and self-rated health status, sample sizes should guarantee reliable indicators of association.

\subsubsection{Relative Risk}

To provide an indication of the direction and magnitude of the association of health conditions and SES, we calculate relative risk for low SES versus high SES, where the definition of low SES is bottom quartiles for income and wealth, less than a high school education, and a poor/fair neighborhood and dwelling, and the definition of high SES is top quartiles for income and wealth, a college education, and a good or better neighborhood and dwelling. Relative risk is defined as the AHEAD sample average of the ratio of the two probabilities, all other variables remaining at the ob- 


\begin{tabular}{|c|c|c|c|c|c|c|c|c|c|c|}
\hline \multirow[b]{2}{*}{ Condition } & \multicolumn{2}{|c|}{ Wealth } & \multicolumn{2}{|c|}{ Income } & \multicolumn{2}{|c|}{ Education } & \multicolumn{2}{|c|}{$\begin{array}{c}\text { Unsafe } \\
\text { Neighborhood }\end{array}$} & \multicolumn{2}{|c|}{$\begin{array}{l}\text { Dwelling } \\
\text { Poor/Fair }\end{array}$} \\
\hline & $\mathrm{F}$ & $\mathrm{M}$ & $\mathrm{F}$ & $\mathrm{M}$ & $\mathrm{F}$ & $\mathrm{M}$ & $\mathrm{F}$ & $\mathrm{M}$ & $\mathrm{F}$ & M \\
\hline Cancer & & & & & & $\pi$ & $\searrow$ & & & \\
\hline Heart disease & $\searrow \searrow$ & & & & & & & & $\pi \pi$ & \\
\hline Stroke & $\searrow \searrow$ & & & & $\Delta\rangle$ & & & & & \\
\hline Lung disease & & $\searrow$ & & & & & & & & \\
\hline Diabetes & $\searrow$ & $\searrow$ & & $\searrow$ & & & & & & \\
\hline HBP & & & & & & & & & & $\nearrow$ \\
\hline Arthritis & $\searrow$ & $\searrow$ & & & & & & & & \\
\hline Incontinence & & & & & & & $\pi$ & & $\pi$ & $\lambda$ \\
\hline Fall & $\searrow$ & & & & & & $\nearrow$ & & & \\
\hline Hip fracture & & & & & & & & & & \\
\hline $\begin{array}{l}\text { Cognitive } \\
\text { impairment }\end{array}$ & $\searrow \downarrow$ & & $\searrow \downarrow$ & & $\downarrow$ & $\searrow \downarrow$ & & $\nearrow$ & & $\pi$ \\
\hline $\begin{array}{l}\text { Psychiatric } \\
\text { condition }\end{array}$ & & & & & $\searrow$ & & & & & \\
\hline Depression & & & & $\searrow$ & $\searrow$ & & & & $\nearrow \nearrow$ & \\
\hline BMI & $\searrow \searrow$ & & & & $\searrow$ & $\searrow \nu$ & & & & \\
\hline Current smoker & & $\searrow \searrow$ & & & & & & & & $\pi$ \\
\hline ADL impairment & & $\searrow \searrow$ & & & & & & & & \\
\hline IADL impairment & ১ע & & & & $\Delta \searrow$ & & & & & \\
\hline Poor/Fair self-rated & & & & & & & & & & \\
\hline health & $\searrow \searrow$ & & & & $\searrow \downarrow$ & $\searrow$ & & T & $\nearrow \nearrow$ & $\nearrow$ \\
\hline
\end{tabular}

Notes: The table summarizes 180 two-tailed significance tests, so that if the tests were independent, one would expect about 9 of the 41 significant coefficients at the 5 percent level by chance, and about 2 of the 23 significant coefficients at the 1 percent level by chance.

$\nearrow=$ positive at 5 percent level; $\nearrow \nearrow=$ positive at 1 percent level; $\searrow=$ negative at 5 percent level; $\searrow \searrow$ $=$ negative at 1 percent level. See table 11.5 notes for explanations of abbreviations.

Table 11.7 Relative Risk of High vs. Low SES for Various Health Conditions, by Gender

\begin{tabular}{|c|c|c|c|c|c|c|c|c|}
\hline \multirow[b]{2}{*}{ Condition } & \multicolumn{2}{|c|}{ Relative Risk } & \multirow[b]{2}{*}{ Condition } & \multicolumn{2}{|c|}{ Relative Risk } & \multirow[b]{2}{*}{ Condition } & \multicolumn{2}{|c|}{ Relative Risk } \\
\hline & $\mathrm{F}$ & M & & $\mathrm{F}$ & M & & $\mathrm{F}$ & M \\
\hline Cancer & 1.97 & 0.98 & HBP & $0.76^{* *}$ & $0.65^{* *}$ & Cognitive impairment & $0.53^{* *}$ & $0.17^{* *}$ \\
\hline Heart disease & $0.46^{* *}$ & $0.75^{* *}$ & Arthritis & 0.80 & $0.60 * *$ & Psychiatric & 1.14 & 0.64 \\
\hline Stroke & 0.61 & $0.43^{* *}$ & Incontinence & 0.83 & 0.71 & Depression & $0.34^{* *}$ & $0.21 * *$ \\
\hline Lung disease & $0.30^{* *}$ & $0.33 * *$ & Fall & 0.68 & $0.44^{* *}$ & Smoke now & $0.27 * *$ & $0.23^{* *}$ \\
\hline Diabetes & $0.19^{* *}$ & 0.65 & Hip fracture & 0.82 & 0.83 & Health poor/fair & $0.31 * *$ & $0.34^{* *}$ \\
\hline
\end{tabular}

Notes: High SES is defined as top quartile in wealth and income, college education, and good neighborhood and welling; low SES is defined as bottom quartile in wealth and income, less than a high school education, and poor neighborhood and welling. Associations in AHEAD wave 1. See table 11A.3 for an pdated version of these results.

**Relative risks that are significantly different from one at the 5 percent level. 
served levels for the subjects. Table 11.7 summarizes the relative risks for the various health conditions. Note that the prevalence models are describing only association, not causation, so that relative risk numbers cannot be interpreted causally. With the statistically insignificant exception of cancer and psychiatric conditions for females, high SES is associated with lower prevalence. Thus, we confirm in the AHEAD population the literature findings of a systematic association of SES with mortality and morbidity risk and show that this association extends across a variety of acute, degenerative, chronic, and mental health impairments.

\subsection{Incidence of Health Conditions and Tests for Causality in the AHEAD Panel}

\subsubsection{Models of Incidence}

Following the format described in section 11.2, we use the incidence of new health problems (or recurrence of cancer, heart disease, stroke, incontinence, falls, and hip fractures), conditioned on initial demographic, health, and SES status, to test for the absence of direct causal pathways. We define incidence for a group of health conditions to be the occurrence of a condition that was not previously reported, or a recorded reoccurrence in the case of an acute condition (cancer, heart disease, stroke). The descriptive statistics in table 11.2 provide information on rates of incidence of these conditions between waves. ${ }^{23}$

We estimate models for incidence of each health condition, conditioned on previously considered incidences of health conditions, the prevalence of health conditions in the previous wave of the panel, and on SES and demographic variables in the previous wave. The models are binomial probit except for BMI, which is fitted with a linear model using ordinary least squares (OLS), and numbers of ADL and IADL impairments, which are fitted as ordered probits. Detailed parameter estimates can be found at http://elsa.berkeley.edu/wp/hww/hww202.html. Again, the data do not permit the same analysis of nonwhites. The models are estimated by stacking the data for wave 1 to wave 2 transitions above the data for wave 2 to wave 3 transitions. Table 11.8 summarizes the health conditions and covariates that are significant risk factors for the incidence of health conditions. The associations reflect a number of known comorbidities, but show relatively few associations of SES components and incidence of health conditions.

\subsubsection{Causality Tests}

Figure 11.8 gives the structure of the invariance and causality tests we report. We test only whether the model parameters are invariant between the

23. The incidence rates in table 11.2 can be converted to crude annual rates via the formula $0.4706 \cdot \log (1+$ rate $)$. These rates are uncorrected for population composition effects. 


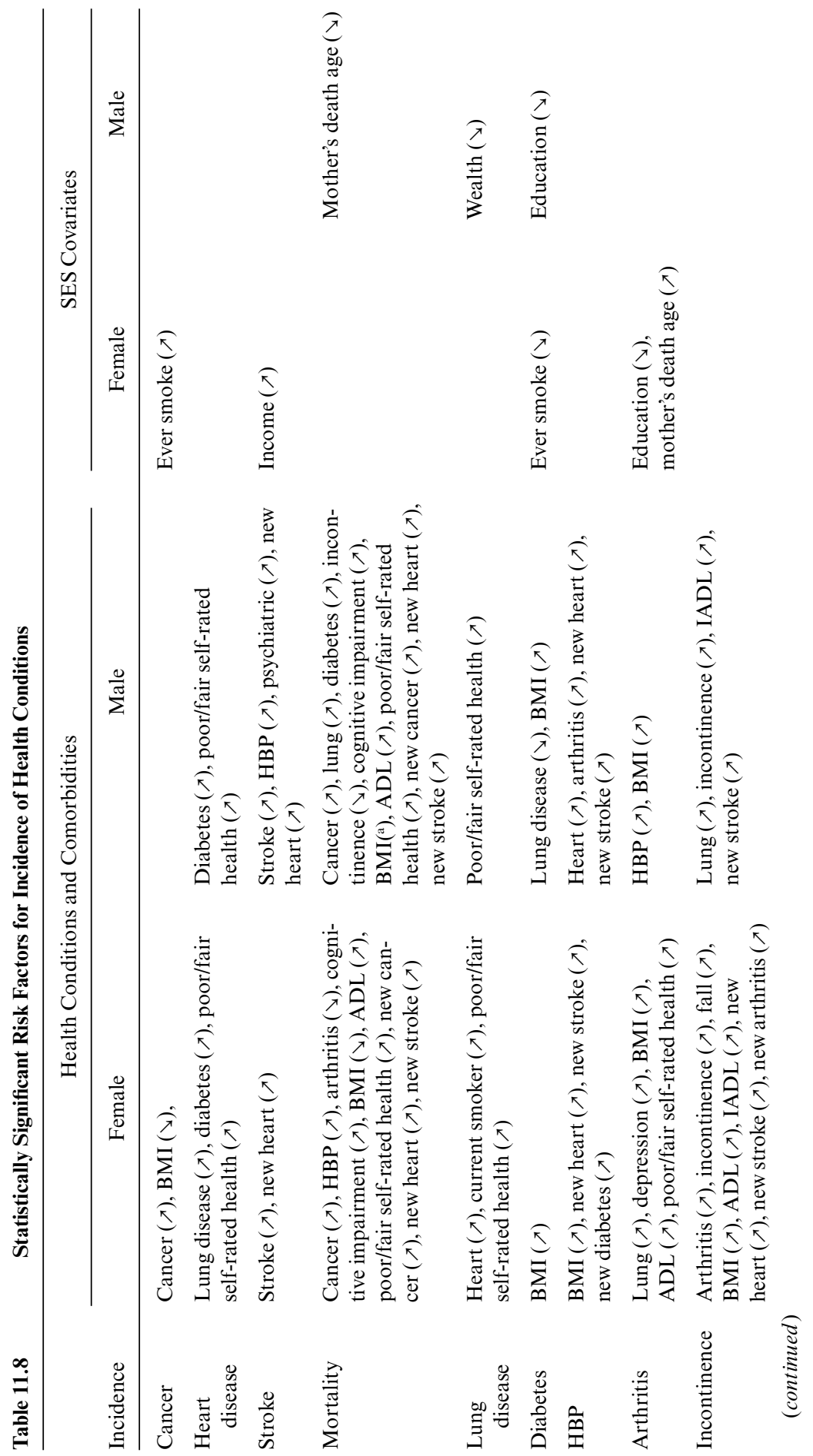




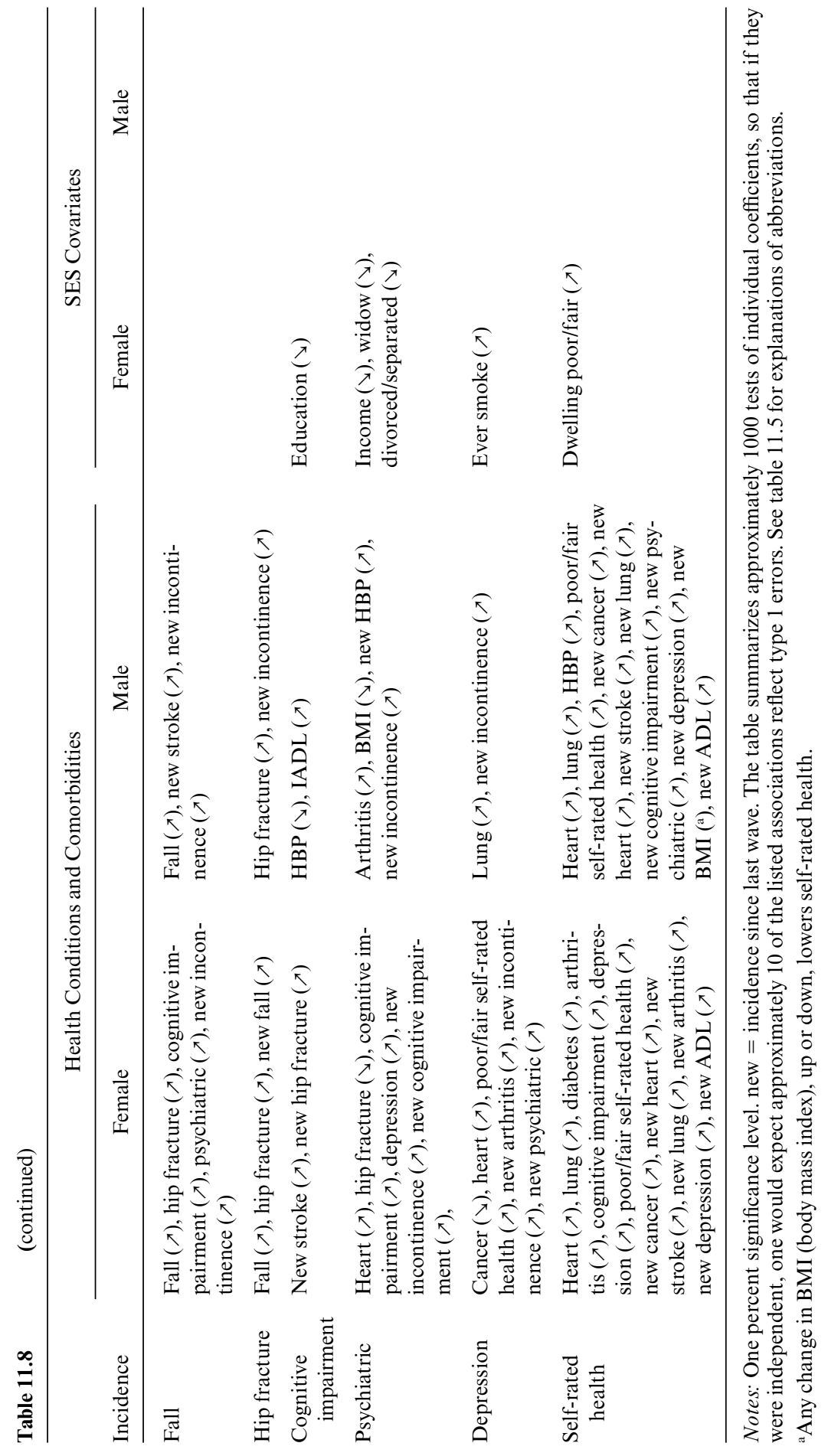




\section{LL(wave 1-2, SES present), LL(wave 2-3, SES present)}

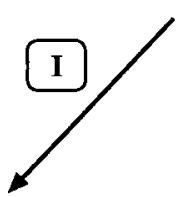

LL(wave 1-2-3, SES present)

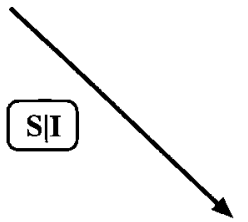

\section{S\&I}

\section{LL(wave 1-2-3, no SES)}

Fig. 11.8 Invariance and causality tests

Note: LL denotes log likelihood for specified condition, an unconditional invariance test is denoted by "I," a conditional test for no direct SES causality, given invariance, is denoted by "S|I" and a joint test of invariance and no direct SES causality is denoted by "S\&I."

wave 1 to 2 transitions and the wave 2 to 3 transitions. We exclude intercepts, age splines, and log of time at risk terms from the invariance test. The reason for doing so is that these terms will capture variations in survey recontact procedure across waves. However, we find in most cases that there is no significant difference in the age spline coefficients across the different transitions. The models are estimated unconstrained, and with the imposition of invariance, noncausality of SES, or both. Likelihood ratio tests are conducted for invariance, with and without noncausality imposed, and for noncausality conditioned on invariance. Because the invariance test without noncausality of SES imposed and the noncausality test conditioned on invariance are nested, they should give the same conclusion, at compatible significance levels, and as a joint test of invariance and noncausality. In accordance with section 11.2, we take acceptance of the joint hypothesis as evidence that there is not a direct causal path from SES to incidence of the given health condition and take this as support for the proposition that differential access to medical care and SES-linked environmental hazards are not causing incidence rates to vary with SES.

The test results are given in table 11.9. The columns of numbers in these tables are, respectively, significance levels for the invariance test with SES variables included, the invariance test with SES variables excluded, the noncausality test conditioned on invariance, and the joint test of invariance and noncausality. The final columns in the table give the relative risk for high versus low SES (see section 11.4.3), and the significance level of a $T$-test of the null hypothesis that the relative risk is one. 


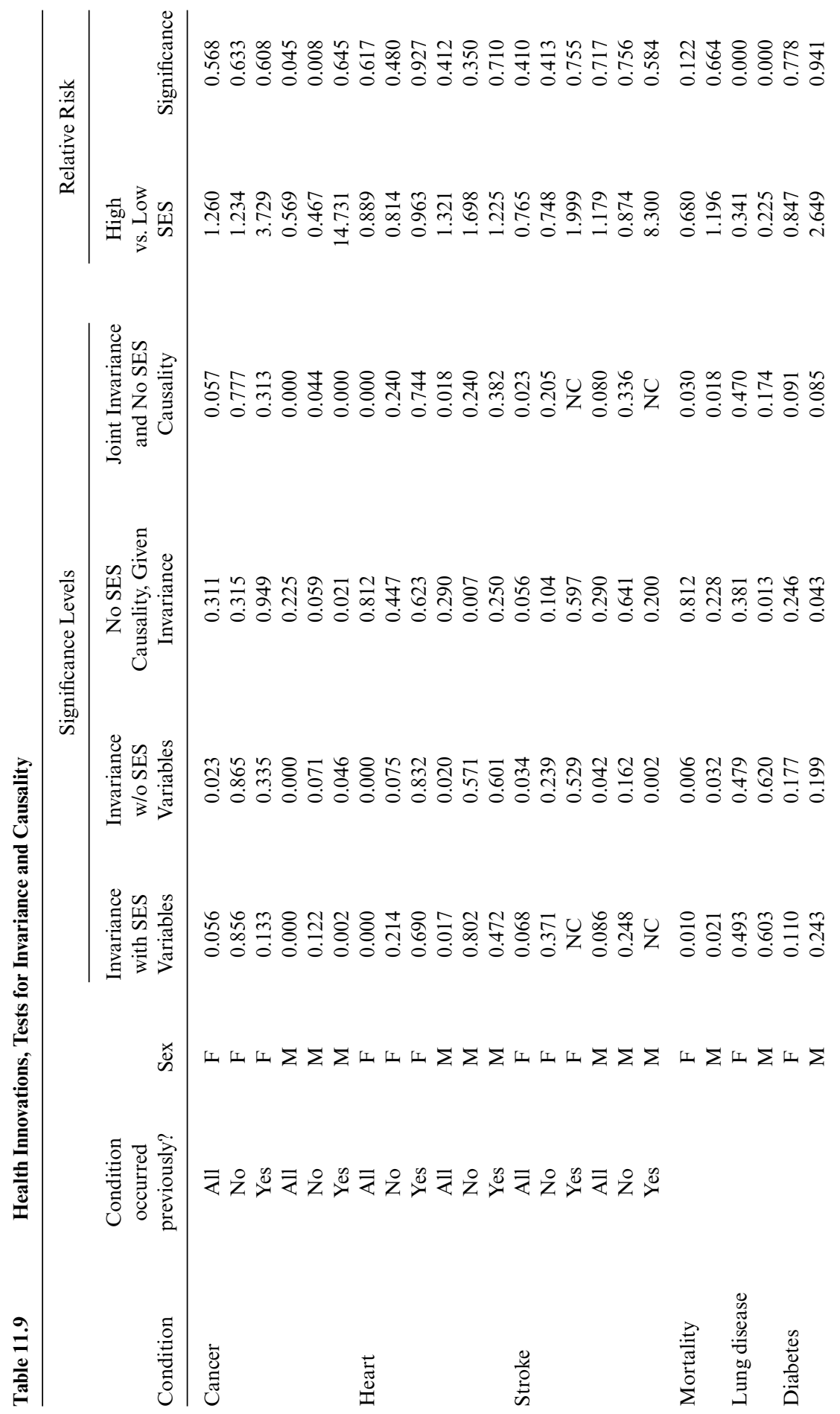




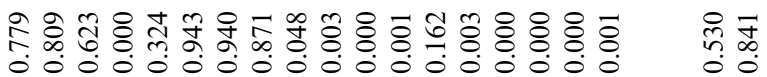

$8:$

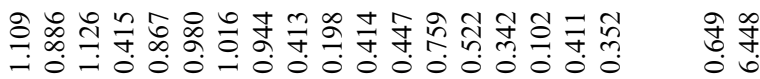

:

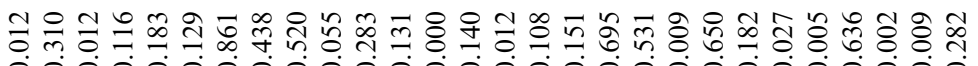

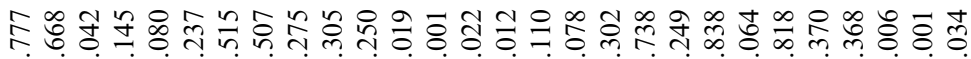

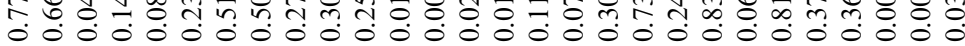

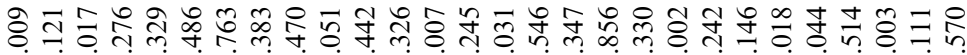

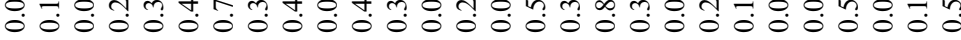

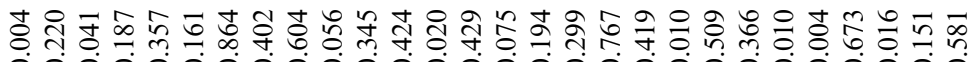

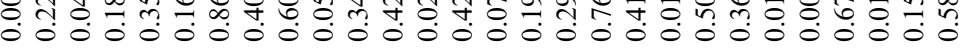

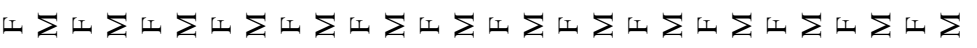

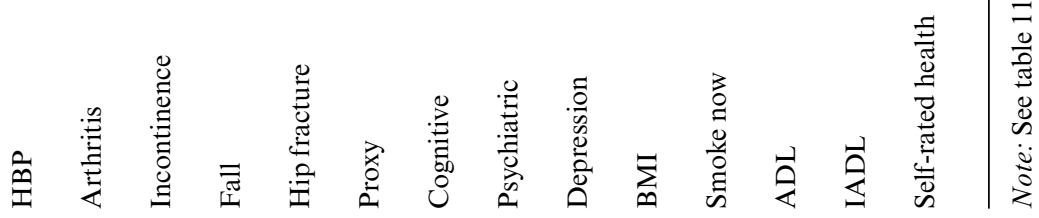


In a majority of cases, our test for invariance is accepted. For cancer and heart disease incidence, it is necessary to separate models for those with and without a previous occurrence of the condition. For females, exceptions where invariance is rejected at the 1 percent level are mortality and ADL count. Exceptions for males are cancer with a previous occurrence, mortality, ADL count, BMI, and IADL count. The failure of the mortality models to satisfy invariance may be related to the initial selection of a noninstitutionalized population in wave 1 of the AHEAD panel. Of course, in addition to the question of the power of our test to detect invariance failures, our single test of invariance across waves falls considerably short of the battery of invariance tests that would be desirable to establish that the model system has the stability and sensitivity required for policy applications.

For females, the tests for noncausality of the SES variables, conditioned on a maintained hypothesis of invariance, are rejected for arthritis and psychiatric disease at the 5 percent level and for cognitive impairment and selfrated health at the 1 percent level. Notably, these are all chronic or mental conditions where Medicare coverage is limited and the cost of drugs or assistance may be substantial. For males, this test for noncausality is rejected for cancer with a previous occurrence, heart disease with no previous occurrence, lung disease, diabetes, cognitive impairment, and self-rated health at the 5 percent level, and for IADL count at the 1 percent level. The results of the joint test for invariance and noncausality are roughly consistent with the separate tests. For conditions such as cancer with a previous occurrence and IADL count for males, cognitive impairment for females, and mortality for both females and males, the noncausality test results may be confounded by the failure of invariance.

The relative risks in table 11.9 should not be interpreted causally, since again the cases where noncausality is rejected and the relative risks are substantially different from one may be due to a common unobserved effect rather than a direct causal link. The pattern of fifteen relative risks exceeding one and eighteen less than one suggests no broad linkage between SES and health changes, given prior health, and the direct links that may be indicated from the significance levels (lung disease and hip fractures for males and females, some cancers and arthritis for males) appear to be related to specific features of poverty, such as smoking history and poor dwelling environment. There are a few cases where the relative risk for high versus low SES is substantially less than one, irrespective of statistical significance, indicating an unproven link of sufficient magnitude to warrant further investigation: lung disease, hip fracture, and the mental diseases for females, and lung disease, diabetes, arthritis, and the mental diseases for males. Large deviations in relative risk from one that are not statistically significant suggest that acceptance of the joint hypothesis of invariance and noncausality could be due to low power. Notably, death shows no re- 
lation to SES, once previous health state is controlled, and the relative risks are insignificantly different from one. This indicates that there are no strong direct causal links from SES to mortality, which at the level of resolution of this study rules out differential access to medical treatment for life-threatening illness. Thus, the association of SES and mortality among the elderly appears to come primarily from variation in the prevalence of health conditions with SES, and more weakly from indirect causal links from SES to incidence of health conditions that increase mortality risk.

The pattern of failures of the noncausality test for mental diseases suggests the possibility of a direct causal link related to differential access. Medicare limits the scope of care for mental conditions, so ability to pay may indeed be an important factor in efficacy of treatments that prevent or control these conditions.

\subsection{Tests for Noncausality from Health Status to Asset Accumulation}

\subsubsection{Models of Incidence}

Health may influence asset accumulation of elderly households because of the cost of medical treatment and related services. Medicare covers acute conditions with limited copayments, but there is the possibility of direct effects from uncovered costs of drugs and living assistance. Also, health conditions may limit the consumption of other goods, and because health status is an indicator of longevity, an individual planning consumption and precautionary reserves over remaining life may adjust target wealth based on altered perceptions of longevity and anticipated medical costs; see Alessie, Lusardi, and Kapteyn (2000), Attanasio and Hoynes (2000), Hurd (1987), Hurd and Wise (1989), Hurd and McGarry (1997), Hurd, McFadden, and Gan (1998). These effects could induce an association of SES and health status even if there were no causal links from SES to health. In the elderly AHEAD population, we will not observe the most likely direct causal link from health status to accumulation among workers, the effect of health on current labor market participation and productivity.

We analyze transitions in wealth from wave to wave using the framework of section 11.2 and model (11) for singles and (17) and (18) for couples, with demographics, previous wave health conditions, and current wave incidence of new health conditions as explanatory variables. Statistically significant selection coefficients are consistent with a direct causal link from death to a change in household wealth, but also consistent with ecological factors that induce an association of mortality risk and SES. Total, nonliquid, and liquid wealth are analyzed separately, with transformation (10) applied to each component.

Tables 11A.5, 11A.6, and 11A.7 give the detailed incidence models for 
total, nonliquid, and liquid wealth change. As in previous studies of savings, we find that most of the variance in wealth changes over the population is not explained by observed economic variables. This remains true after introduction of health conditions. We find dissaving rates out of liquid wealth, before realization of returns calculated from the S\&P 500, that are 5.3 percent for couples, 4.8 percent for singles, and 6.0 percent for survivors whose spouses have died. The dissaving rates from nonliquid wealth, again before realization of returns, are, respectively, 6.9 percent, 6.3 percent, and 8.0 percent for intact couples, singles, and survivors. The higher dissaving rates from nonliquid assets indicates that the wealth portfolios of the elderly are rebalanced to become more liquid as they age. These dissaving rates can be compared to an average rate of dissaving of 8.3 percent of remaining wealth in an age seventy-plus population with life-table survival probabilities who consume the expected annuitized value of their wealth. ${ }^{24}$ Then, observed dissaving rates out of wealth are not grossly lower than would be expected with pure life-cycle consumption averaging over retirement and full pooling of mortality risk. We find that low income couples and individuals have significantly higher dissaving rates than their high income counterparts, but the differences are not quantitatively large. Home ownership is associated with significantly less dissaving for intact couples.

The models for both singles and couples show significant departures from normality in the selection equations. The Edgeworth expansion parameters show positive skewness and smaller than normal kurtosis for female singles, negative skewness and insignificantly different from normal kurtosis for male singles. For couples, both males and females have negative skewness and larger than normal kurtosis. We also find significant selection effects, with $\rho_{f}=-0.49$ for couples and -0.21 for singles, and $\rho_{m}=$ -0.51 for couples and -0.89 for singles. These imply that households that survive despite unfavorable mortality risks have increased dissaving, either because of increased cost of overcoming health problems or because households at elevated risk spend down more rapidly. Equation (18) includes shift parameters that modify the dependence of the wealth change disturbance on the unobserved selection effects in regimes where a spouse dies. These are statistically significant, and sufficiently large to reverse the direction of the intact couple selection effects.

Table 11.10 summarizes the health conditions and other covariates that are individually significant in explaining changes in wealth. For intact couples, we find some acute conditions increase saving, perhaps because they restrict consumption, or perhaps because couples conserve assets for a potential surviving spouse. For the conditions that are associated with in-

24. This calculation is made from the 1996 life tables and assumes the historical S\&P rate of return from 1993 to 1997, and a 7 percent real rate of return on assets after 1997. 
Table 11.10 Statistically Significant Risk Factors for Wealth Changes

\begin{tabular}{|c|c|c|}
\hline Component & Health Conditions & Covariates \\
\hline \multicolumn{3}{|l|}{ Intact couple } \\
\hline Total wealth & $\begin{array}{l}\text { M self-rated health poor/fair }(\nearrow), \mathrm{M} \\
\text { new heart }(\nearrow), \text { M new hip fracture }(\searrow) \text {, } \\
\text { F new cancer }(\nearrow)\end{array}$ & $\begin{array}{l}\text { Nonliquid wealth }(\searrow) \text {, liquid wealth }(\searrow) \text {, } \\
\text { income }(\nearrow) \text {, homeowner }(\nearrow)\end{array}$ \\
\hline $\begin{array}{l}\text { Nonliquid } \\
\text { wealth }\end{array}$ & & $\begin{array}{l}\text { Nonliquid wealth }(\searrow) \text {, liquid wealth }(\nearrow) \text {, } \\
\text { homeowner }(\nearrow)\end{array}$ \\
\hline Liquid wealth & M new heart $(\nearrow)$, M BMI worse $(\searrow)$ & $\begin{array}{l}\text { Nonliquid wealth }(\nearrow) \text {, liquid wealth }(\searrow) \text {, } \\
\text { income }(\nearrow) \text {, dwelling poor/fair }(\searrow)\end{array}$ \\
\hline \multicolumn{3}{|l|}{ Spouse died } \\
\hline Total wealth & & $\begin{array}{l}\text { Nonliquid wealth }(\searrow) \text {, liquid wealth }(\searrow) \text {, } \\
\text { income }(\nearrow)\end{array}$ \\
\hline $\begin{array}{l}\text { Nonliquid } \\
\text { wealth }\end{array}$ & & Nonliquid wealth (১) \\
\hline Liquid wealth & F new stroke $(\searrow)$ & $\begin{array}{l}\text { Nonliquid wealth }(\nearrow) \text {, liquid wealth }(\searrow) \text {, } \\
\text { income }(\nearrow)\end{array}$ \\
\hline \multicolumn{3}{|l|}{ Single } \\
\hline Total wealth & $\begin{array}{l}\text { M new cancer }(\nearrow), F \text { new cancer }(\searrow), F \\
\text { new depression }(\searrow)\end{array}$ & $\begin{array}{l}\text { M,F nonliquid wealth }(\searrow), \text { M,F liquid } \\
\text { wealth }(\searrow), \text { M,F income }(\nearrow)\end{array}$ \\
\hline $\begin{array}{l}\text { Nonliquid } \\
\text { wealth }\end{array}$ & $\begin{array}{l}\text { M hip fracture }(\nearrow), \mathrm{M} \text { new cancer }(\nearrow), \\
\mathrm{M} \text { new heart }(\nearrow)\end{array}$ & $\begin{array}{l}\text { M,F nonliquid wealth }(\searrow), \text { M liquid } \\
\text { wealth }(\nearrow), \mathrm{F} \text { income }(\nearrow), \mathrm{F} \text { home- } \\
\text { owner }(\nearrow)\end{array}$ \\
\hline Liquid wealth & $\begin{array}{l}\text { F cognitive impairment }(\searrow), F \text { new } \\
\text { stroke }(\searrow), F \text { new cognitive impair- } \\
\text { ment }(\searrow)\end{array}$ & $\begin{array}{l}\text { M,F nonliquid wealth }(\nearrow), \mathrm{M}, \mathrm{F} \text { liquid } \\
\text { wealth }(\searrow), \mathrm{M}, \mathrm{F} \text { income }(\nearrow), \mathrm{F} \text { dwel- } \\
\text { ling poor/fair }(\searrow)\end{array}$ \\
\hline
\end{tabular}

Notes: One percent significance level. $\mathrm{M}=$ male; $\mathrm{F}=$ female; new $=$ incidence since last wave; $\nearrow$ indicates increased saving; $\searrow$ indicates decreased saving.

creased dissaving (cognitive impairment and stroke for single females), costs of maintenance associated with these conditions may be directly causal to wealth changes.

\subsubsection{Causality Tests}

Table 11.11 summarizes our tests for invariance and absence of direct causal links. We test for common parameters in the wealth change models between waves 1-2 and waves 2-3, excepting intercepts and age effects to allow for the effects of sample timing. Invariance is convincingly rejected for each demographic group and wealth category, indicating that our model fails to capture the structural determinants of wealth change. As a consequence, our noncausality tests to follow may produce rejections due to model misspecification, confounding the detection of direct causal 
Table 11.11

Wealth Changes, Tests for Invariance and Causality

\begin{tabular}{lcccc}
\hline & \multicolumn{4}{c}{ Significance Levels } \\
\cline { 2 - 5 } & & \multicolumn{3}{c}{ Noncausality } \\
\cline { 2 - 5 } $\begin{array}{l}\text { Demographic Group } \\
\text { Wealth Component }\end{array}$ & Invariance & $\begin{array}{c}\text { Previous Health } \\
\text { Conditions }\end{array}$ & $\begin{array}{c}\text { Current Health } \\
\text { Conditions }\end{array}$ & $\begin{array}{c}\text { All Health } \\
\text { Conditions }\end{array}$ \\
\hline $\begin{array}{l}\text { Intact couple } \\
\text { Total wealth }\end{array}$ & 0.000 & 0.036 & 0.001 & 0.000 \\
Nonliquid wealth & 0.000 & 0.014 & 0.028 & 0.001 \\
Liquid wealth & 0.000 & 0.006 & 0.012 & 0.000 \\
Spouse died & & & & 0.074 \\
Total wealth & 0.000 & 0.811 & 0.776 & 0.037 \\
Nonliquid wealth & 0.000 & 0.071 & 0.456 & 0.023 \\
Liquid wealth & 0.000 & 0.676 & 0.022 & 0.001 \\
Single & & & 0.347 & 0.235 \\
Total wealth & 0.000 & 0.004 & 0.028 & 0.000 \\
Nonliquid wealth & 0.000 & 0.100 & & \\
Liquid wealth & 0.000 & 0.000 & &
\end{tabular}

links. A deconstruction of the invariance failures, detailed in appendix table 11A.8, shows that for nonliquid and liquid wealth, invariance passes for demographic and health prevalence and incidence variables, but fails for female SES variables, and for all male variables including SES taken together. Thus, there was an unexplained regime shift before and after wave 2 of AHEAD. Possible explanations for this are an interaction between the criterion of noninstitutionalization in the initial panel recruitment and economic behavioral response; a wealth-linked interaction in panel retention; problems in the measurement of wealth in the AHEAD population, which exhibits unexplained mean reversion; or a true behavioral shift with age in a single cohort that is not captured accurately by a model that pools wealth change observations across cohorts.

We expect that terminal medical and burial expenses, estate taxes and other estate settlement costs, insurance payments, and bequests will have a substantial impact on the size of a decedent's estate and surviving spouse's reported wealth. We easily reject the hypothesis that the model coefficients for intact couples and for surviving spouses are the same, but note that measurement problems associated with a change in financially responsible respondent could also produce this rejection.

The hypothesis of no direct causality of health conditions for total wealth changes is rejected at the 1 percent level for intact couples and singles. For nonliquid wealth, the hypothesis is rejected for intact couples, and for liquid wealth, the hypothesis is rejected for all demographic groups. 
The failure of the invariance tests, and the possibility of confounding by persistent common factors and selection suggest that conclusions on the health to wealth link be interpreted with caution. Table 11A.9 deconstructs the causality tests and identifies the health conditions and genders responsible for rejections. The pattern of results suggest that if there is indeed a direct causal link, then it is most likely to involve liquid wealth and health conditions that require assisted living.

Table 11A.10 estimates models of income change, given health conditions and other covariates. One would not expect health status to have a significant impact on the incomes of retirees, conditioned on previous wealth, and the empirical results are generally consistent with this expectation. We have not done formal tests of invariance or causality for income. Also included in the state vector $Y_{t}$ that describes individuals are changes in home ownership status, and dwelling and neighborhood conditions. We estimate incidence models for these components; results are in table 11A.11.

\subsection{Simulation of Life Courses under Counterfactual Conditions}

\subsubsection{The Simulation Experiment}

For policy analysis of interventions that alter delivery or cost of medical services, or retirement financing, one would like to trace through the direct and indirect causal links between wealth, health, and mortality. If Markov models of the sort developed in sections 11.2-11.6 satisfy the required invariance properties, then they can be used to simulate the impacts of these interventions on the life courses of a synthetic population. In this section, we develop such a simulation analysis and apply it to illustrative interventions. Because we have not uniformly accepted invariance, and in a number of cases find associations that may be either direct causal links or hidden common factors, this simulation analysis assumes more than our estimates support. It should be interpreted only as an exercise that shows how a model of this general structure might be used in a policy application to unravel the dynamics of comorbidities and forecast condition-specific morbidity and mortality and life expectancy.

We simulate the life courses of a synthetic population in which heads of household are initially aged seventy-seventy-four. To synthesize this population, we start from the 1,612 households in AHEAD wave 1 whose heads are white and aged seventy-seventy-four. Using the SES and demographic variables for each household in this subsample, we make ten Monte Carlo draws from the prevalence models in section 11.4 to create synthetic initial health profiles for the household head, and spouse if present. This gives an initial synthetic sample of 16,120 households. We then 
create life courses for the members of each household by drawing recursively from the Markov incidence models in sections 11.5 and 11.6, adjusted to annual transitions using (9) to approximate the probabilities of moving to new states.

We first consider a base scenario $(\mathrm{S} 0)$ in which initial prevalence and incidence transitions are given by our models estimated on the AHEAD data. We note that the simulation outcomes can be expected to differ to some degree from the cross-cohort patterns found in AHEAD, because the distribution of conditions at ages seventy-seventy-four will differ from the distributions of prevalence that actually prevailed for older individuals in AHEAD when they were aged seventy-seventy-four. They should also differ to some degree from the actual experience that the aged seventy-seventy-four cohort in AHEAD will have through the remainder of their lives, because the simulation cannot anticipate the realized future distribution of exogenous variables and because our models do not allow for drift-in disease incidence or condition-specific mortality hazards that will result from changes in medical care. Historically, these drifts have been very significant, reducing morbidities and increasing life expectancies. If these trends continue, then the baseline simulations will underestimate actual survival experience.

We next consider two stylized policy interventions. The first alternative scenario (S1) examines the impact on life courses of the introduction of a hypothetical medical treatment that cures diabetes, for example, by stem cell and immune system therapy that rejuvenates the pancreas for both type I and type II diabetics. In this scenario, we assume that prevalence of diabetes at the start of the simulated panel drops to zero, and that there is zero incidence of this condition as the cohort ages. We do not alter the historical prevalence of conditions associated with diabetes. Thus, we assume that the historical impact on individuals of type I diabetes, notably increased prevalence of heart disease and stroke at ages seventy-seventyfour, is not altered. The second alternative scenario (S2) examines the impact on life courses of reducing the entire population from their current SES to our definition of a low-SES individual: bottom quartile for wealth and income, less than a high school education, and a poor or fair neighborhood and dwelling. This alternative is obviously hypothetical and is not even a stylized approximation to any real policy alternative. However, it provides an extreme in which the interactions of health and SES are permitted maximum play, giving an upper bound on the effect that SES could possibly have on health outcomes, and providing a finger exercise that tests the plausibility of our model system.

\subsubsection{Baseline Simulation}

Table 11.12 summarizes the survival probabilities and prevalence of health conditions among survivors in the simulated cohort as it ages, under 


\begin{tabular}{|c|c|c|c|c|c|c|c|}
\hline & \multirow[b]{2}{*}{ Scenario } & \multicolumn{6}{|c|}{ Age } \\
\hline & & 70 & 75 & 80 & 85 & 90 & 95 \\
\hline \multicolumn{8}{|l|}{ White females } \\
\hline \multirow{3}{*}{ Survival probability } & S0 & 1.000 & 0.905 & 0.743 & 0.500 & 0.240 & 0.079 \\
\hline & S1 & 1.000 & 0.906 & 0.757 & 0.517 & 0.257 & 0.087 \\
\hline & $\mathrm{S} 2$ & 1.000 & 0.884 & 0.662 & 0.359 & 0.125 & 0.027 \\
\hline \multirow[t]{3}{*}{ Cancer $^{\mathrm{b}}$} & S0 & 0.112 & 0.174 & 0.219 & 0.245 & 0.257 & 0.262 \\
\hline & S1 & 0.112 & 0.169 & 0.217 & 0.243 & 0.258 & 0.252 \\
\hline & $\mathrm{S} 2$ & 0.112 & 0.208 & 0.273 & 0.298 & 0.302 & 0.336 \\
\hline \multirow[t]{3}{*}{ Heart disease ${ }^{\mathrm{b}}$} & So & 0.224 & 0.322 & 0.442 & 0.538 & 0.588 & 0.594 \\
\hline & S1 & 0.224 & 0.321 & 0.429 & 0.515 & 0.569 & 0.608 \\
\hline & S2 & 0.224 & 0.344 & 0.495 & 0.608 & 0.663 & 0.679 \\
\hline \multirow[t]{3}{*}{ Stroke ${ }^{b}$} & So & 0.042 & 0.105 & 0.191 & 0.272 & 0.326 & 0.341 \\
\hline & S1 & 0.042 & 0.104 & 0.186 & 0.260 & 0.317 & 0.351 \\
\hline & $\mathrm{S} 2$ & 0.042 & 0.105 & 0.196 & 0.274 & 0.320 & 0.366 \\
\hline \multirow[t]{3}{*}{ Lung disease ${ }^{\mathrm{b}}$} & S0 & 0.105 & 0.151 & 0.179 & 0.190 & 0.168 & 0.143 \\
\hline & $\mathrm{S} 1$ & 0.105 & 0.150 & 0.183 & 0.190 & 0.175 & 0.154 \\
\hline & S2 & 0.105 & 0.193 & 0.258 & 0.278 & 0.276 & 0.286 \\
\hline \multirow[t]{3}{*}{ Diabetes $^{\mathrm{b}}$} & So & 0.114 & 0.161 & 0.198 & 0.199 & 0.170 & 0.157 \\
\hline & S1 & 0.114 & 0.000 & 0.000 & 0.000 & 0.000 & 0.000 \\
\hline & S2 & 0.114 & 0.181 & 0.231 & 0.233 & 0.207 & 0.231 \\
\hline \multirow[t]{3}{*}{ High Blood Pressure ${ }^{\mathrm{b}}$} & So & 0.467 & 0.583 & 0.678 & 0.738 & 0.761 & 0.778 \\
\hline & S1 & 0.467 & 0.585 & 0.678 & 0.742 & 0.783 & 0.804 \\
\hline & $\mathrm{S} 2$ & 0.467 & 0.597 & 0.701 & 0.764 & 0.786 & 0.810 \\
\hline \multirow[t]{3}{*}{ Arthritis ${ }^{\mathrm{b}}$} & So & 0.232 & 0.501 & 0.677 & 0.791 & 0.857 & 0.901 \\
\hline & S1 & 0.232 & 0.501 & 0.670 & 0.784 & 0.856 & 0.905 \\
\hline & S2 & 0.232 & 0.567 & 0.769 & 0.876 & 0.925 & 0.965 \\
\hline \multirow[t]{3}{*}{ Incontinence $^{\mathrm{b}}$} & S0 & 0.232 & 0.416 & 0.601 & 0.751 & 0.843 & 0.891 \\
\hline & S1 & 0.232 & 0.427 & 0.611 & 0.749 & 0.844 & 0.906 \\
\hline & $\mathrm{S} 2$ & 0.232 & 0.444 & 0.664 & 0.814 & 0.891 & 0.917 \\
\hline \multirow[t]{3}{*}{ Fall $^{\mathrm{b}}$} & S0 & 0.071 & 0.271 & 0.464 & 0.635 & 0.759 & 0.837 \\
\hline & S1 & 0.071 & 0.268 & 0.456 & 0.628 & 0.754 & 0.846 \\
\hline & S2 & 0.071 & 0.260 & 0.460 & 0.640 & 0.759 & 0.822 \\
\hline \multirow[t]{3}{*}{ Hip fracture ${ }^{b}$} & So & 0.030 & 0.046 & 0.070 & 0.109 & 0.153 & 0.215 \\
\hline & S1 & 0.030 & 0.043 & 0.069 & 0.109 & 0.156 & 0.190 \\
\hline & $\mathrm{S} 2$ & 0.030 & 0.056 & 0.104 & 0.160 & 0.224 & 0.258 \\
\hline \multirow[t]{3}{*}{ Proxy interview } & So & 0.038 & 0.056 & 0.103 & 0.163 & 0.230 & 0.294 \\
\hline & S1 & 0.038 & 0.063 & 0.095 & 0.155 & 0.222 & 0.271 \\
\hline & $\mathrm{S} 2$ & 0.038 & 0.103 & 0.211 & 0.316 & 0.409 & 0.521 \\
\hline \multirow[t]{3}{*}{ Cognitive impairment ${ }^{\mathrm{b}}$} & So & 0.104 & 0.253 & 0.437 & 0.609 & 0.736 & 0.818 \\
\hline & S1 & 0.104 & 0.251 & 0.435 & 0.602 & 0.722 & 0.803 \\
\hline & S2 & 0.104 & 0.405 & 0.669 & 0.838 & 0.910 & 0.952 \\
\hline \multirow[t]{3}{*}{ Psychiatric disease ${ }^{\mathrm{b}}$} & So & 0.154 & 0.215 & 0.307 & 0.376 & 0.421 & 0.434 \\
\hline & S1 & 0.154 & 0.219 & 0.305 & 0.379 & 0.416 & 0.426 \\
\hline & S2 & 0.154 & 0.316 & 0.508 & 0.634 & 0.704 & 0.762 \\
\hline \multirow[t]{3}{*}{ Depression $^{\mathrm{b}}$} & So & 0.068 & 0.183 & 0.305 & 0.429 & 0.515 & 0.575 \\
\hline & S1 & 0.068 & 0.179 & 0.305 & 0.424 & 0.521 & 0.596 \\
\hline & $\mathrm{S} 2$ & 0.068 & 0.247 & 0.434 & 0.574 & 0.665 & 0.749 \\
\hline
\end{tabular}

(continued) 


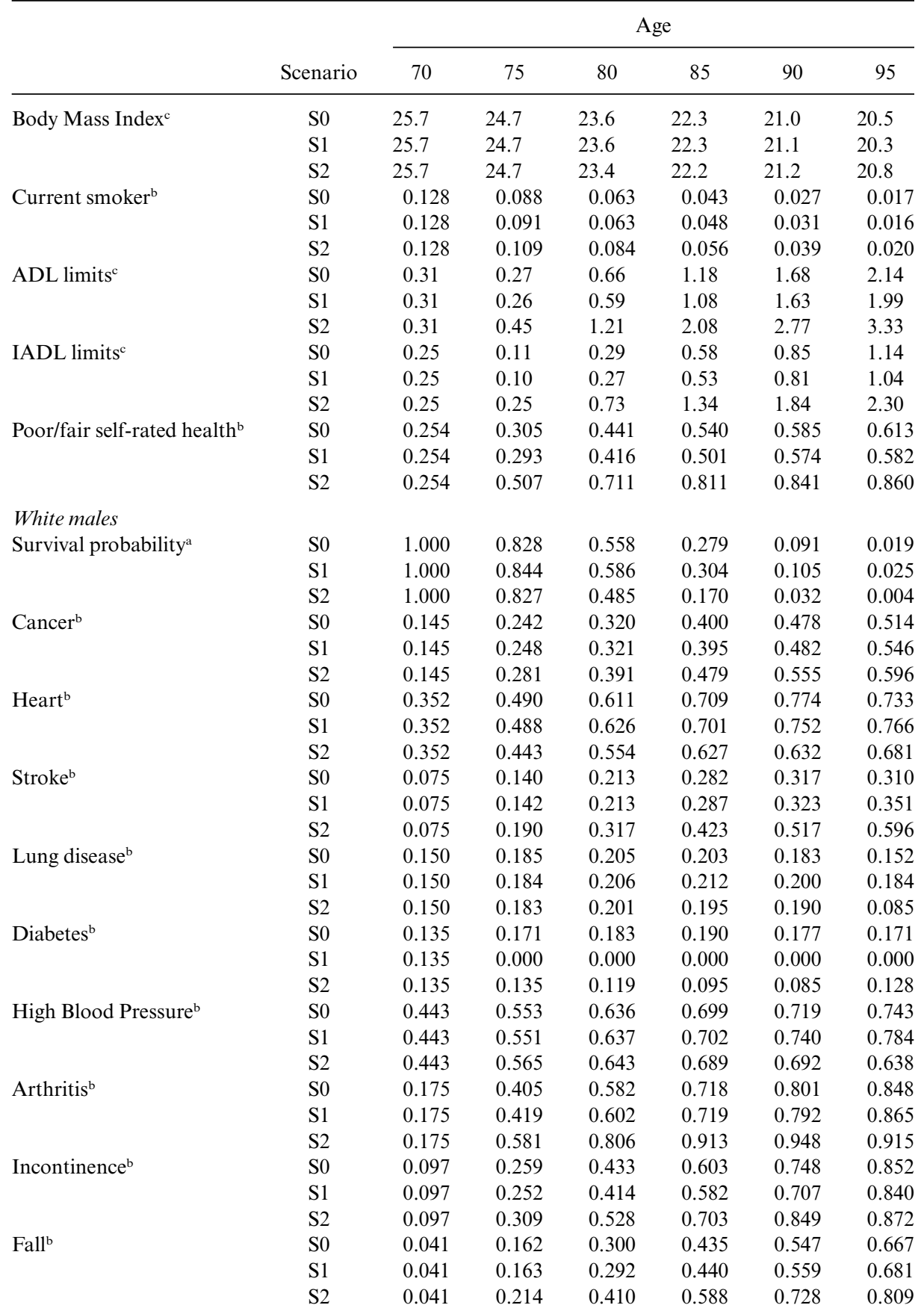




\begin{tabular}{|c|c|c|c|c|c|c|c|}
\hline & \multirow[b]{2}{*}{ Scenario } & \multicolumn{6}{|c|}{ Age } \\
\hline & & 70 & 75 & 80 & 85 & 90 & 95 \\
\hline \multirow[t]{3}{*}{ Hip fracture ${ }^{\mathrm{b}}$} & S0 & 0.025 & 0.032 & 0.044 & 0.066 & 0.119 & 0.167 \\
\hline & S1 & 0.025 & 0.030 & 0.044 & 0.068 & 0.108 & 0.138 \\
\hline & S2 & 0.025 & 0.076 & 0.147 & 0.247 & 0.357 & 0.447 \\
\hline \multirow[t]{3}{*}{ Proxy Interview } & S0 & 0.111 & 0.110 & 0.114 & 0.125 & 0.155 & 0.157 \\
\hline & S1 & 0.111 & 0.109 & 0.120 & 0.147 & 0.170 & 0.170 \\
\hline & $\mathrm{S} 2$ & 0.111 & 0.223 & 0.303 & 0.382 & 0.429 & 0.468 \\
\hline \multirow[t]{3}{*}{ Cognitive impairment $\mathrm{t}^{\mathrm{b}}$} & S0 & 0.146 & 0.326 & 0.505 & 0.662 & 0.768 & 0.857 \\
\hline & S1 & 0.146 & 0.329 & 0.509 & 0.657 & 0.772 & 0.897 \\
\hline & S2 & 0.146 & 0.484 & 0.743 & 0.881 & 0.934 & 0.936 \\
\hline \multirow[t]{3}{*}{ Psychiatric disease $^{\mathrm{b}}$} & S0 & 0.085 & 0.133 & 0.186 & 0.240 & 0.268 & 0.291 \\
\hline & S1 & 0.085 & 0.135 & 0.187 & 0.240 & 0.263 & 0.319 \\
\hline & $\mathrm{S} 2$ & 0.085 & 0.237 & 0.430 & 0.557 & 0.621 & 0.660 \\
\hline \multirow[t]{3}{*}{ Depression $^{\mathrm{b}}$} & S0 & 0.038 & 0.105 & 0.184 & 0.233 & 0.262 & 0.281 \\
\hline & S1 & 0.038 & 0.110 & 0.196 & 0.259 & 0.263 & 0.344 \\
\hline & S2 & 0.038 & 0.199 & 0.344 & 0.421 & 0.445 & 0.404 \\
\hline \multirow[t]{3}{*}{ Body Mass Index ${ }^{\mathrm{c}}$} & S0 & 26.1 & 25.5 & 24.9 & 24.6 & 24.4 & 24.4 \\
\hline & S1 & 26.1 & 25.6 & 25.0 & 24.7 & 24.6 & 24.1 \\
\hline & S2 & 26.1 & 24.6 & 23.6 & 23.2 & 23.2 & 22.9 \\
\hline \multirow[t]{3}{*}{ Current smoker ${ }^{\mathrm{b}}$} & S0 & 0.131 & 0.063 & 0.035 & 0.015 & 0.009 & 0.005 \\
\hline & S1 & 0.131 & 0.061 & 0.041 & 0.014 & 0.003 & 0.000 \\
\hline & $\mathrm{S} 2$ & 0.131 & 0.075 & 0.038 & 0.013 & 0.000 & 0.000 \\
\hline \multirow[t]{3}{*}{ ADL limits ${ }^{c}$} & S0 & 0.33 & 0.36 & 0.75 & 1.33 & 1.84 & 2.45 \\
\hline & S1 & 0.33 & 0.38 & 0.79 & 1.37 & 1.88 & 2.46 \\
\hline & S2 & 0.33 & 0.94 & 2.11 & 3.24 & 4.15 & 4.51 \\
\hline \multirow[t]{3}{*}{ IADL limits ${ }^{\mathrm{c}}$} & S0 & 0.34 & 0.16 & 0.33 & 0.63 & 0.94 & 1.24 \\
\hline & S1 & 0.34 & 0.15 & 0.34 & 0.64 & 0.95 & 1.23 \\
\hline & $\mathrm{S} 2$ & 0.34 & 0.52 & 1.22 & 2.00 & 2.65 & 2.85 \\
\hline \multirow[t]{3}{*}{ Poor/fair self-rated health ${ }^{\mathrm{b}}$} & S0 & 0.282 & 0.355 & 0.445 & 0.487 & 0.514 & 0.543 \\
\hline & S1 & 0.282 & 0.352 & 0.448 & 0.488 & 0.482 & 0.500 \\
\hline & S2 & 0.282 & 0.586 & 0.760 & 0.818 & 0.871 & 0.830 \\
\hline
\end{tabular}

Notes: $\mathrm{S} 0=$ baseline; $\mathrm{S} 1=$ no diabetes; $\mathrm{S} 2=$ all low SES. See table 11.5 for explanation of abbreviations. aProportion of age 70 population surviving to the specified age.

${ }^{b}$ Proportion of surviving population at specified age who ever had condition.

${ }^{\mathrm{c}}$ Mean in surviving population.

the baseline scenario (S0), the no-diabetes scenario (S1), and the low-SES scenario (S2). Keeping in mind that we expect the simulation model to differ from the historical cross-cohort record in AHEAD, the success of this model in plausibly mimicking observed conditions in the AHEAD population can be judged by comparing the results for scenario $\mathrm{S} 0$ with life table survival probabilities. Life expectancy for a cohort of white females aged seventy-seventy-four is 13.15 years from the 1996 life tables and 14.36 years in our baseline simulation. The life table probability of survival for 
fifteen years for the aged seventy-seventy-four cohort is 0.535 , while the corresponding survival probability in the simulation model is 0.500 . For white males, the life expectancy at age seventy is 11.31 years from the life tables and 10.81 years from the S0 simulation. The fifteen-year survival probability is 0.381 from the life tables and 0.279 from the simulation model. Thus, relative to the life tables, the simulation model underpredicts female mortality and overpredicts male mortality. The comparison of annual mortality rates for white females given in figure 11.5 indicates that actual AHEAD mortality experience was more favorable than the life tables between waves 1 and 2, presumably due to selection in panel recruitment, and very close to the life tables between waves 2 and 3 . Then, the baseline simulation appears to reproduce relatively accurately the cross-cohort survival experience in AHEAD. This provides a reality check for the simulation model, but also suggests that if the survival experience of a current cohort differs from the historical cross-cohort pattern, then the simulation model will miss the drift in mortality hazards that a single cohort will face in the future.

A comparison of prevalence rates for various health conditions among survivors of various ages can be made between AHEAD at wave 1, given in table 11.4, and the baseline simulation in table 11.12. There are issues of comparability in the definition of prevalence for some conditions, but the pattern that emerges is that the simulated prevalences are systematically higher than the historical prevalences and increasingly so at older ages. For example, for white females aged eighty-eighty-four, the historical and simulated prevalence rates are 0.168 versus 0.219 for cancer, 0.361 versus 0.442 for heart disease, and 0.338 versus 0.437 for cognitive impairment. One possible explanation for this is that the links from morbidity to mortality are stronger than the mortality model detects, perhaps because of underreporting of health conditions that arise prior to death, so that the simulation model underestimates the selection effect of mortality that reduces prevalence among survivors. A second possible explanation is that there is strong unobserved heterogeneity in susceptibility to various health conditions, so that cumulative prevalence is overestimated by our first-order Markov models which describe prevalence for most conditions as the result of one or more positives in a series of Bernoulli trials. It is possible to test for persistent unobserved heterogeneity by asking whether the frequency of a negative for a condition between waves 1 and 3 of AHEAD is the product of the frequencies of a negative between successive waves. When we do this, we do not find persistent unobserved heterogeneity. However, the power of the test is modest, and it is possible that even a limited degree of persistent unobserved heterogeneity is enough to explain the differences in AHEAD and the simulation.

A comparison is given in table 11.13 between median wealth and income by age in the AHEAD panel and in the baseline simulation. The historical 
Table 11.13

Wealth and Income in AHEAD and in the Baseline Scenario, by Age

\begin{tabular}{|c|c|c|c|c|c|}
\hline & $70-74$ & $75-79$ & $80-84$ & $85-89$ & $90+$ \\
\hline \multicolumn{6}{|c|}{ AHEAD cross-cohort data } \\
\hline \multicolumn{6}{|c|}{ Total wealth $(000)$} \\
\hline 1st quartile & 64.38 & 46.92 & 32.76 & 14.05 & 2.17 \\
\hline Median & 144.04 & 112.76 & 94.35 & 71.34 & 40.13 \\
\hline 3rd quartile & 314.27 & 242.68 & 203.20 & 185.91 & 117.93 \\
\hline \multicolumn{6}{|c|}{ Nonliquid wealth $(000)$} \\
\hline 1st quartile & 47.72 & 28.20 & 10.81 & 0.86 & 0.00 \\
\hline Median & 94.94 & 80.48 & 62.01 & 44.19 & 5.44 \\
\hline 3rd quartile & 178.96 & 151.68 & 113.88 & 109.12 & 65.47 \\
\hline \multicolumn{6}{|c|}{ Liquid wealth (000) } \\
\hline 1st quartile & 2.18 & 1.31 & 0.54 & 0.33 & 0.00 \\
\hline Median & 26.19 & 15.97 & 11.89 & 9.73 & 5.40 \\
\hline 3rd quartile & 98.21 & 70.93 & 70.93 & 55.31 & 37.83 \\
\hline \multicolumn{6}{|l|}{ Income $(000)$} \\
\hline 1st quartile & 14.15 & 11.97 & 9.76 & 8.68 & 6.74 \\
\hline Median & 22.78 & 19.59 & 15.26 & 13.77 & 9.76 \\
\hline 3rd quartile & 34.92 & 31.65 & 28.06 & 25.10 & 15.29 \\
\hline \multicolumn{6}{|c|}{ Baseline simulation data } \\
\hline \multicolumn{6}{|c|}{ Total wealth $(000)$} \\
\hline 1st quartile & 56.67 & 65.69 & 37.07 & 16.08 & 8.22 \\
\hline Median & 136.20 & 121.43 & 79.94 & 51.86 & 41.59 \\
\hline 3rd quartile & 299.13 & 206.63 & 136.38 & 91.16 & 74.29 \\
\hline \multicolumn{6}{|c|}{ Nonliquid wealth (000) } \\
\hline 1st quartile & 42.72 & 37.39 & 17.56 & 2.97 & -3.77 \\
\hline Median & 91.53 & 74.34 & 47.13 & 29.17 & 21.21 \\
\hline 3rd quartile & 171.34 & 118.09 & 78.90 & 55.44 & 45.07 \\
\hline \multicolumn{6}{|c|}{ Liquid wealth (000) } \\
\hline 1st quartile & 1.64 & 19.16 & 10.91 & 4.96 & 3.61 \\
\hline Median & 22.79 & 43.77 & 31.16 & 22.01 & 19.38 \\
\hline 3rd quartile & 95.90 & 80.05 & 58.58 & 42.39 & 36.69 \\
\hline \multicolumn{6}{|l|}{ Income $(000)$} \\
\hline 1st quartile & 13.56 & 13.57 & 11.25 & 8.62 & 7.92 \\
\hline Median & 21.82 & 18.19 & 15.89 & 13.58 & 11.92 \\
\hline 3rd quartile & 34.70 & 29.58 & 23.12 & 17.81 & 15.85 \\
\hline
\end{tabular}

cross-cohort data shows sharply declining wealth and income with age, and a less liquid portfolio with age, reflecting strong cohort effects as well as life-cycle and selection effects. The simulation results, which exclude cohort effects, nevertheless show even more sharply declining wealth with age and a strong shift toward a more liquid portfolio mix. If the simulation is correctly describing portfolio balance of a single cohort over its life course, then there is a strong cross-cohort effect, with older cohorts starting from retirement portfolios that are more heavily invested in housing equity and other nonliquid forms. The simulated semi-interquartile range is narrower than its historical counterpart, particularly for older households. In the 
simulation, variability (defined as the ratio of the semi-interquartile range divided by the median) falls with age, whereas in the historical cross-cohort data variability rises with age. This suggests that in addition to crosscohort effects, that there may be persistent heterogeneity in savings behavior that is not captured in our model.

\subsubsection{Alternative Scenarios}

Table 11.12 gives the survival probabilities and prevalences of various health conditions under our alternative no-diabetes scenario (S1) and the low-SES scenario (S2). In the no-diabetes simulation, the direct mortality risk from diabetes, and the incidence of comorbidities with diabetes are eliminated, although our simulated population will display elevated prevalence of heart disease and stroke at age seventy among former diabetics. Life expectancy at age seventy under this scenario increases from 14.36 to 14.69 years for females, and from 10.81 to 11.26 years for males. These rates imply in turn that a former diabetic's life expectancy increases by 2.72 years for females and 3.32 years for males. Other health condition prevalences that fall in the absence of diabetes are heart disease, stroke, cognitive impairment, ADL and IADL impairment, and poor/fair self-rated health. While reduction in mortality risk from one source must as a matter of accounting eventually lead to more deaths from competing risks, there are no substantial movements in prevalences of the remaining health conditions.

The alternative low-SES scenario reduces our entire aged seventy simulated population to the bottom quartile for wealth and income, gives them less than a high school education and places them in a dwelling in poor condition in an unsafe neighborhood. They are kept in this low-SES status for the remainder of their lives; that is, there is no opportunity in this simulation for households to escape low SES by a lucky change in wealth or income. However, our population displays the patterns of prevalence of health conditions established in their earlier lives with their historical SES status. This scenario is quite artificial, but it demonstrates the holistic effect on the broad spectrum of health conditions of low SES. Life expectancies at age seventy in this scenario drop dramatically, from 14.36 to 12.27 years for females, and from 10.81 to 9.56 years for males. Prevalences of cancer, heart disease, lung disease, diabetes, arthritis, incontinence, hip fractures, cognitive impairment, psychiatric disease, and depression all increase sharply, as do the number of ADL and IADL impairments. Conditions whose prevalence is not affected substantially by low SES are stroke, high blood pressure, and falls. These results indicate that if the associations of SES and incidence of health conditions that we find in AHEAD were entirely the result of direct causal links from wealth to health, then the protective effect of the prevailing pattern of higher SES is 1.26-2.08 years of 
added life expectancy. Thus, our findings that for most health conditions the evidence is against direct causal links from SES to incidence do not appear to rule out a substantial cumulative effect of SES over conditions and time that induce a noticeable SES gradient in mortality. Given our specific findings against direct causal links from SES to incidence of acute conditions and mortality, the most obvious possible source for this gradient are SES-linked differences in genetic susceptibility and behavior.

We have emphasized that our stylized, hypothetical policy intervention and the changes in health they produce over the life course are strictly illustrative and should be interpreted with great caution. These finger exercises cannot be used to draw conclusions about any real policy initiatives. This is particularly true since we have included within our model system components that fail the invariance tests that we have emphasized must be met by a valid policy model, and because in many cases our models display some wealth or income gradients for incidence that we cannot with our statistical methods identify as the sole result of direct causal links. While most of these effects are not statistically significant, it is possible that in a larger or longer panel with greater statistical power, they will prove to be significant. Then, it is essential to turn to the more advanced statistical methods of Heckman (2001) and others to identify the direct causal components in these incidence associations and improve the models to achieve invariance. Only after this is done, and realistically detailed policy scenarios are considered, could policy makers take our model system seriously as a policy tool. However, we believe that our results do demonstrate that it would be useful for health policy analysis to utilize a system of invariant models with a causal chain structure to simulate policy impacts, in a framework that takes into account indirect impacts, competing hazards, and direct causal links between SES and health. We believe that analysis of the broad sweep of comorbidities and wealth effects over the life course is an important complement to the diseasecentric orientation of many medical and epidemiological studies of health outcomes.

\subsection{Summary and Speculations for Further Research}

This paper has used innovations in health conditions and in wealth in the AHEAD panel to carry out tests for the absence of direct causal links from SES to health, and from health conditions to wealth. By advancing beyond the detection of association to a framework in which there is some possibility of detecting the absence of causal links, this paper provides a methodology that may be useful in winnowing the list of possible direct causal mechanisms, or delimiting their domain of action. For the AHEAD sample, a panel of U.S. elderly aged seventy and older in 1993, we conclude generally that for mortality and for acute, sudden-onset diseases, the hy- 
pothesis of no causal link from SES is accepted, and for incidence of mental problems the hypothesis is rejected. The results for chronic and degenerative diseases are mixed. We generally reject the hypothesis of no direct causal link from health conditions to total wealth changes but cannot rule out confounding of the test by invariance failures.

The pattern of results suggests that incidence of acute, sudden onset health conditions, conditioned on existing health conditions, does not exhibit a significant SES gradient, while incidence of some mental, chronic, and degenerative conditions appear to have an association to SES due to some combination of direct causal links and common unobserved behavioral or genetic factors. The results suggest that there may be an SES gradient in seeking treatment for the second class of conditions that may influence detection, or for maintaining preventative regimens that may maintain some conditions below the reporting thresholds. Our findings are not inconsistent with the possibility that for mental and chronic illnesses where the acute care procedures covered by Medicare are often inapplicable, ability to pay may be a causal factor in seeking and receiving treatment. We do not find systematic persuasive associations of health conditions and changes in total wealth, except for surviving spouses. Problems in measuring and modeling wealth changes suggest caution in concluding from these results that there is generally no direct causal link from health conditions to wealth changes.

We emphasize that our results apply only to elderly individuals in the United States, where Medicare and Medicaid programs limit out-ofpocket medical costs, particularly for acute care, and where retired status eliminates a possible direct causal link from health status to ability to work. Further, in an elderly population, common factors may be manifest in prior health conditions and economic status, so they have little impact once incidence is conditioned on prior state. Our results provide no evidence on the nature of the causal links at younger ages, during the stages of life where association of health and wealth is emerging as a consequence of some causal structure.

Future waves of the AHEAD (HRS) panel will allow the hypotheses of invariance and noncausality to be tested with greater power. This will particularly be the case when full tracking of decedents, and determination of cause of death from medical records, become part of the data. It seems likely that some of the associations we have found between changes in health and wealth will survive more detailed analysis, and that suitably defined natural or designed experiments are likely to be needed to fully unravel the causal structure underlying these associations.

The modeling structure used in this paper is parametric, and the high dimensionality of the vector of possible explanatory variables and the relatively limited information contained in binomial outcomes in the AHEAD panel make it difficult to move to a more robust nonparametric analysis. 
However, we have been flexible in specifying the variable transformations that appear in our models, and we interpret our analysis as conforming in spirit, if hardly in fact, to a method of sieves approach to nonparametric analysis. One of the major limitations of our models, which would be likely to lead them to fail invariance tests in situations where a sharp test is possible, is that they do not account adequately for the multiple risk structure of health conditions and its implications for the duration patterns that can emerge, particularly over the relatively long intervals between waves. Some outcomes, such as mortality and nonfatal heart disease, are competing risks, while others, like diabetes and heart conditions, are complementary risks. For future research, we are investigating hidden Markov models in which a latent vector of propensities for all health and SES conditions follows a first-order Markov process, conditioned on demographic state, and all possible causal links across the components of this latent vector appear in the model. Given thresholds that trigger observed states, this model provides a consistent but computationally demanding data generation process for the vector of Markov states month-by-month. Within this model, it is possible to carry out joint tests for the absence of classes of causal links. The next wave of this research, incorporating wave 4 of AHEAD, will include full development of flexible multiple-risk duration models. 


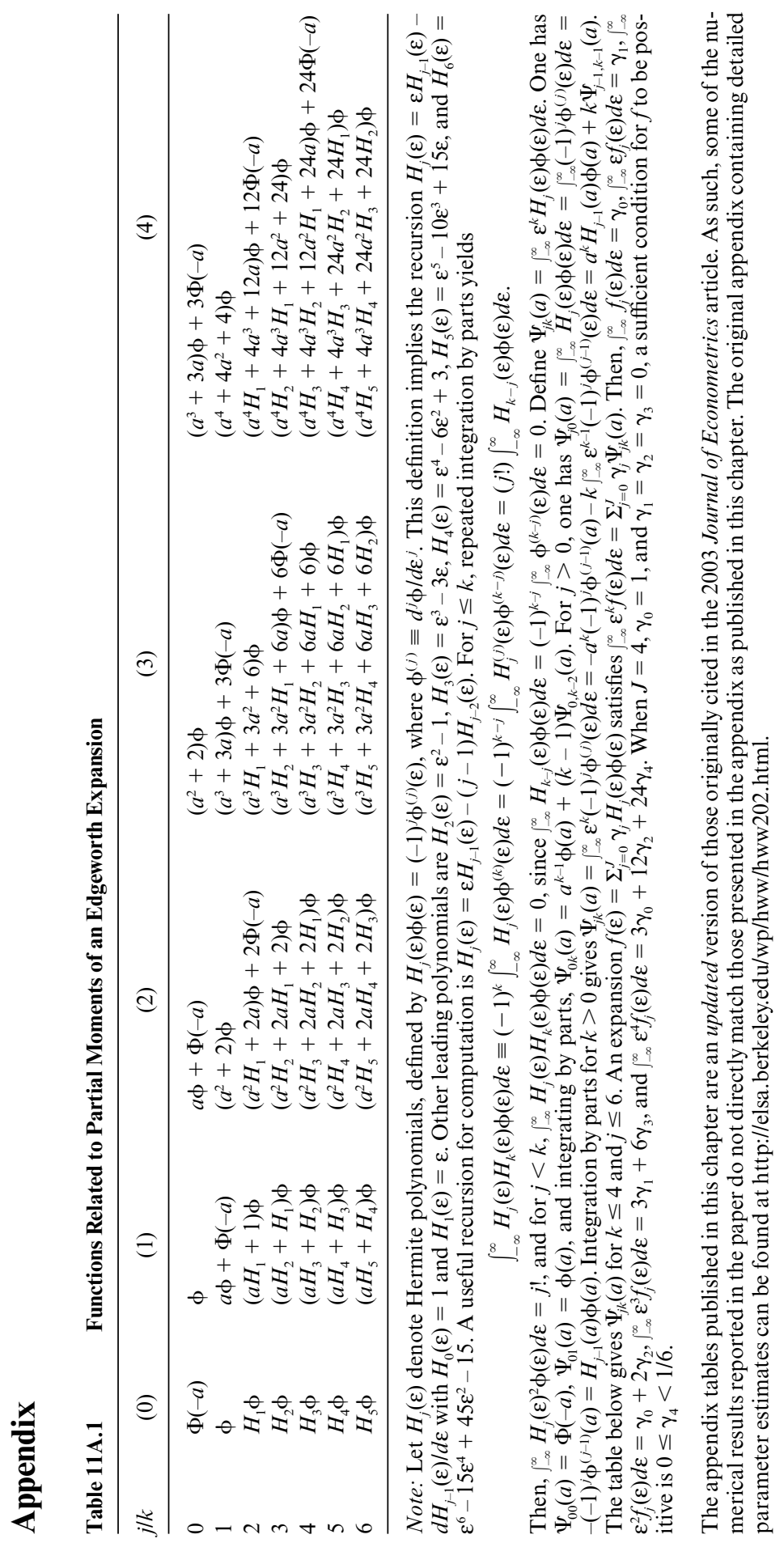




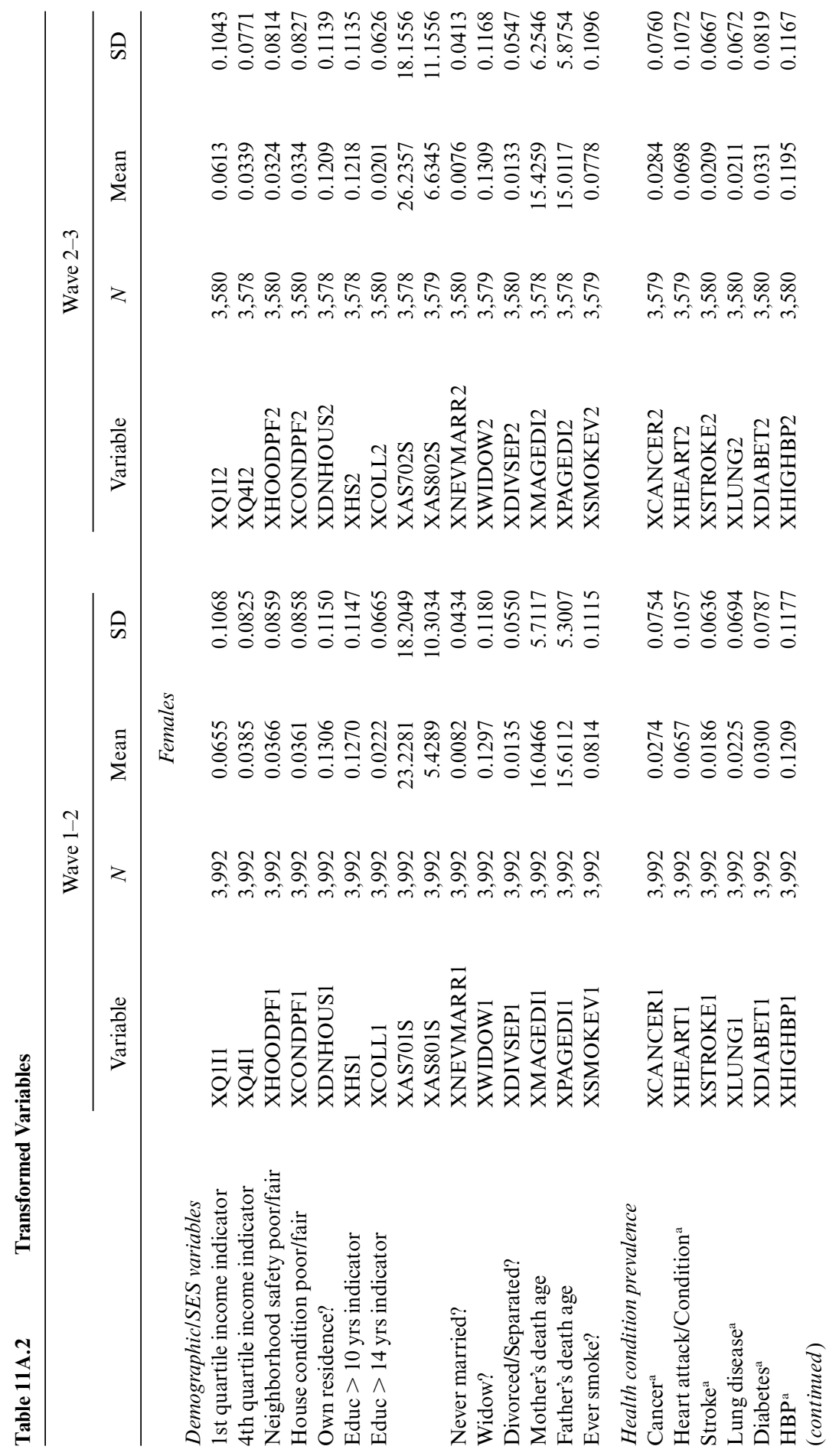




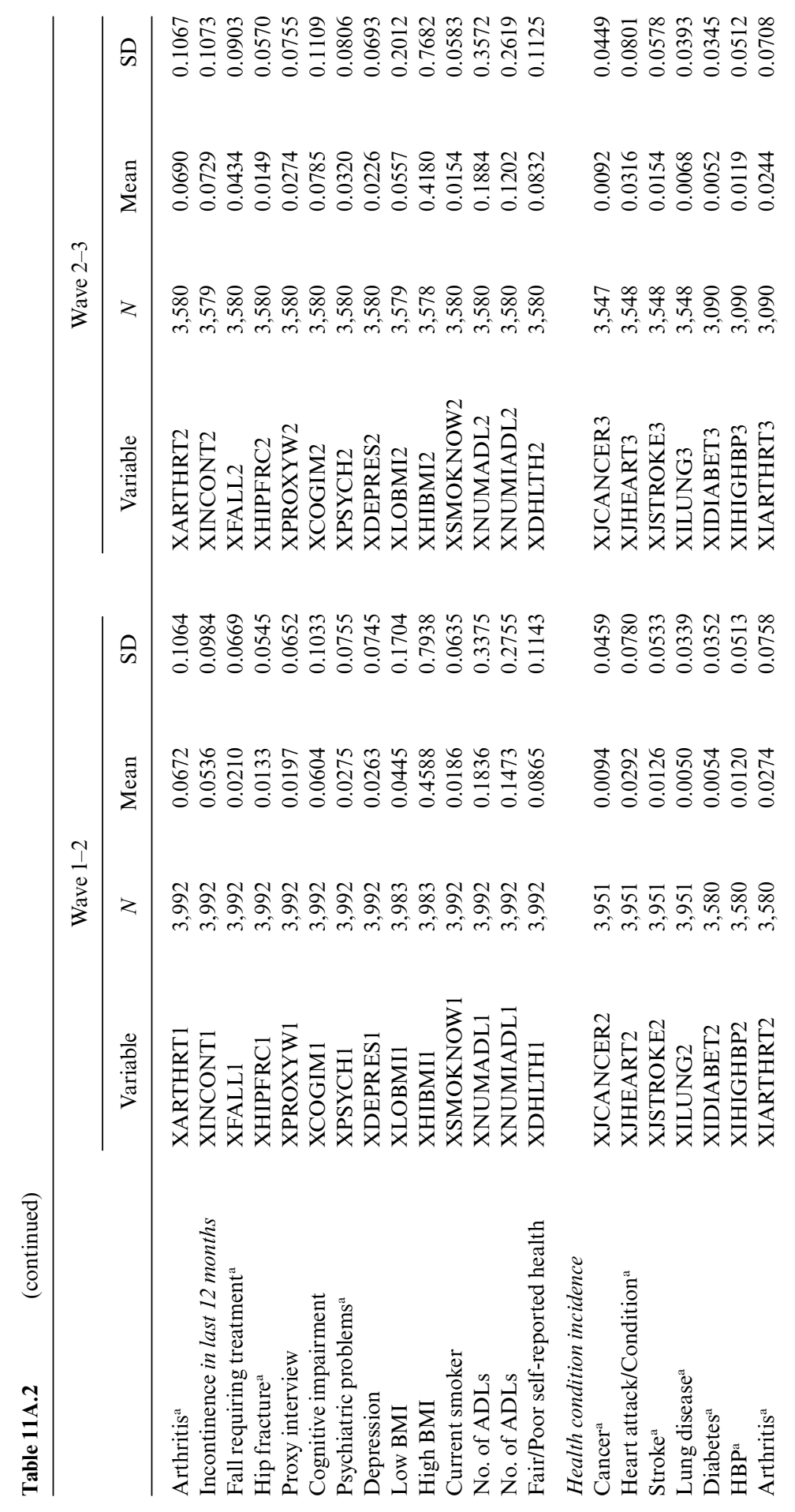




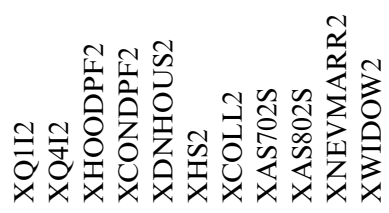

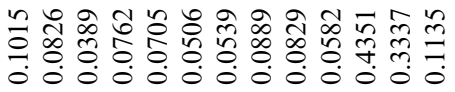

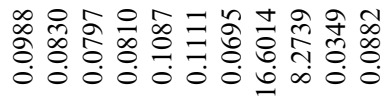

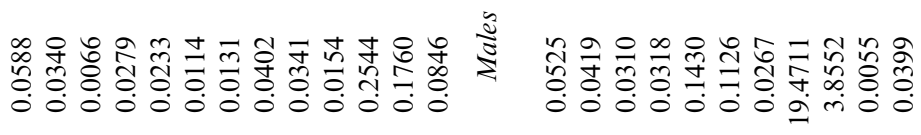

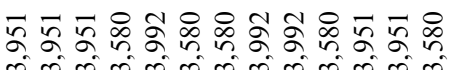

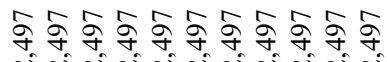
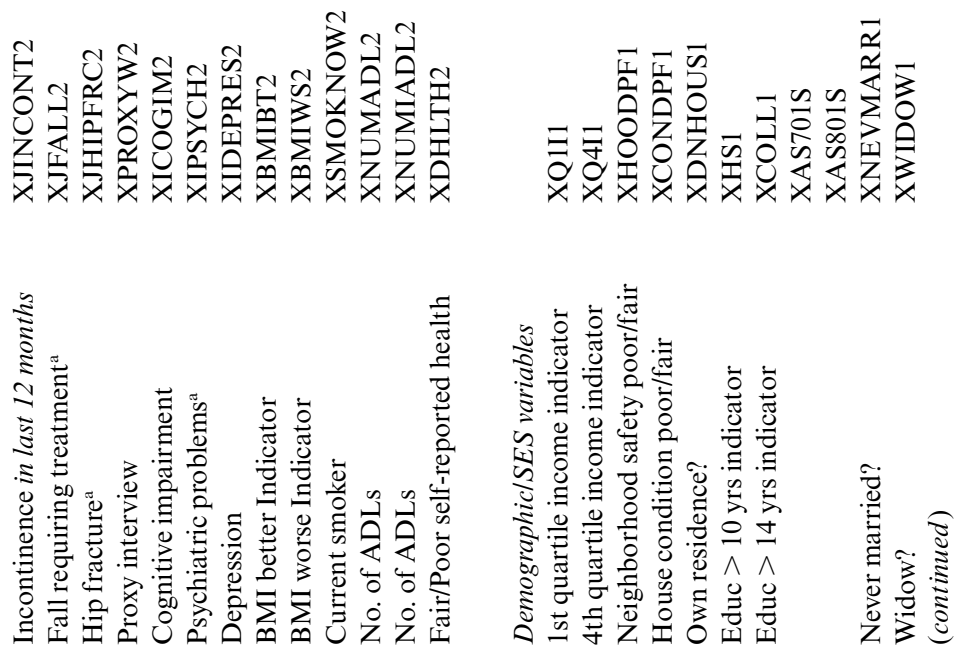


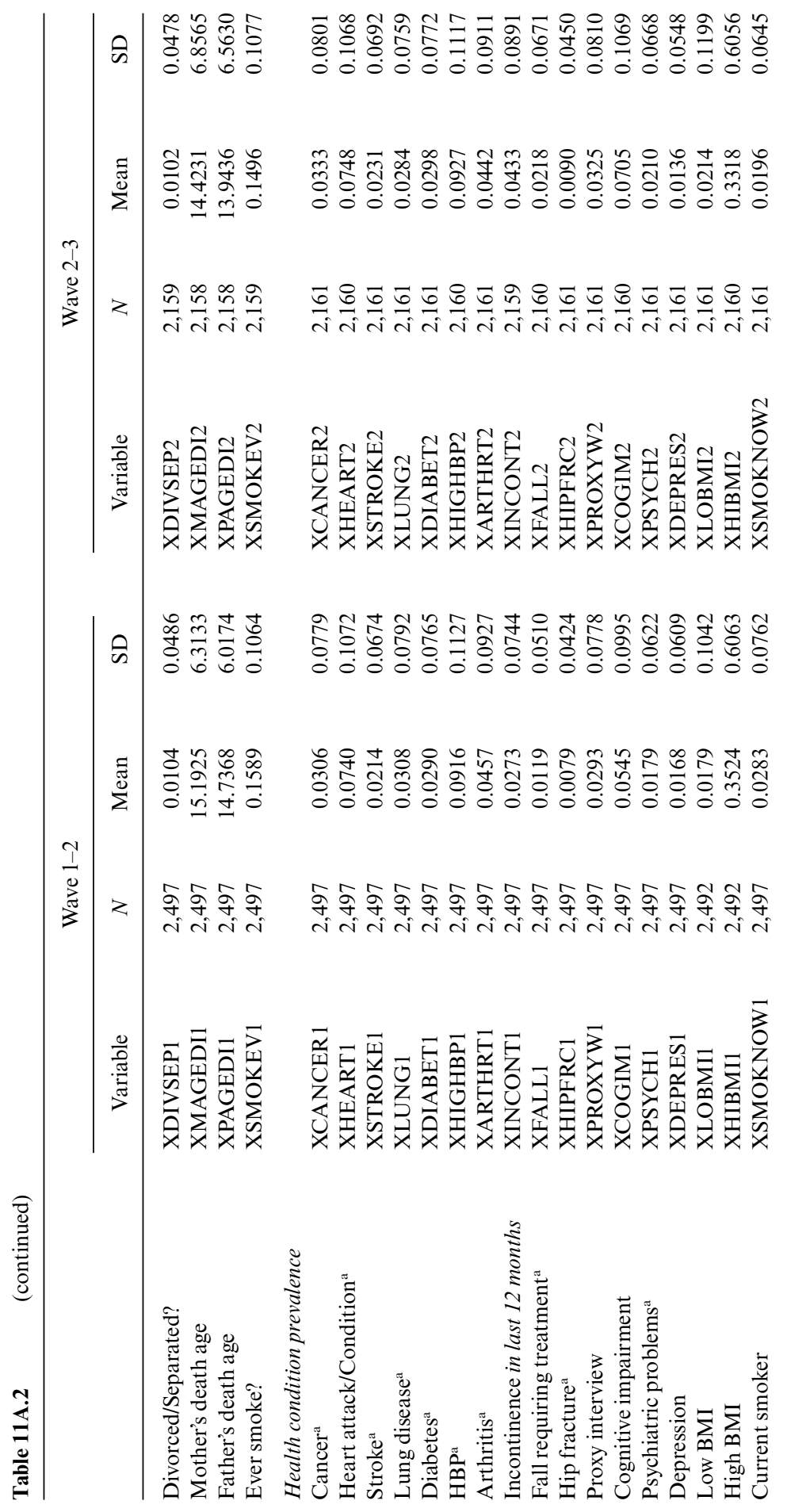




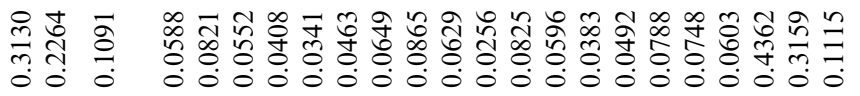

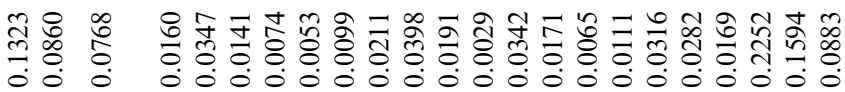

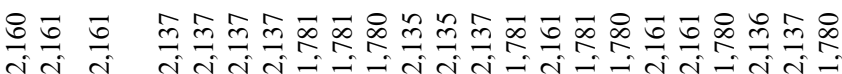

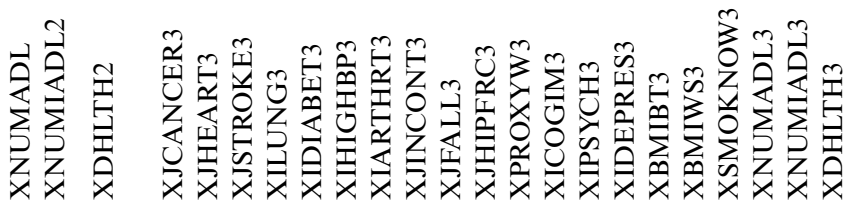

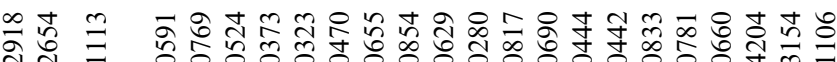
त. 0000000000000000000000000

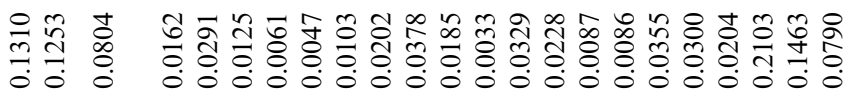

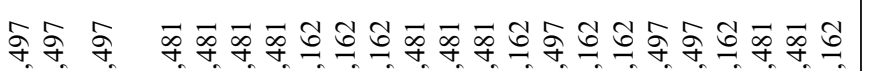

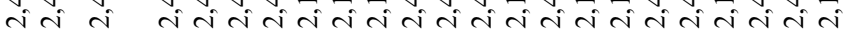

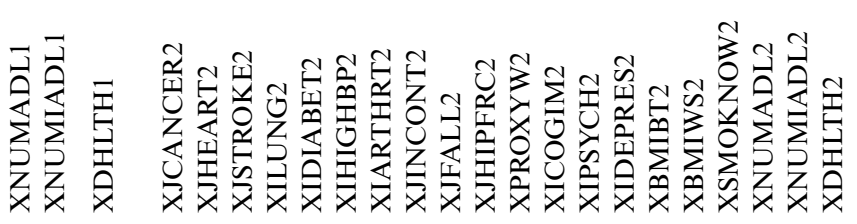

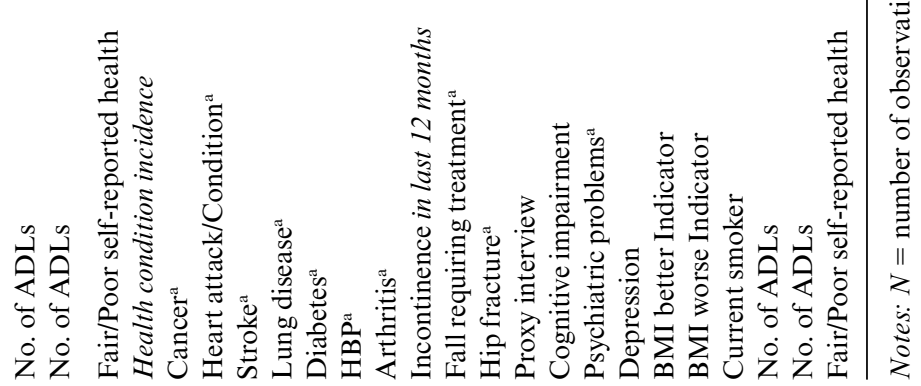




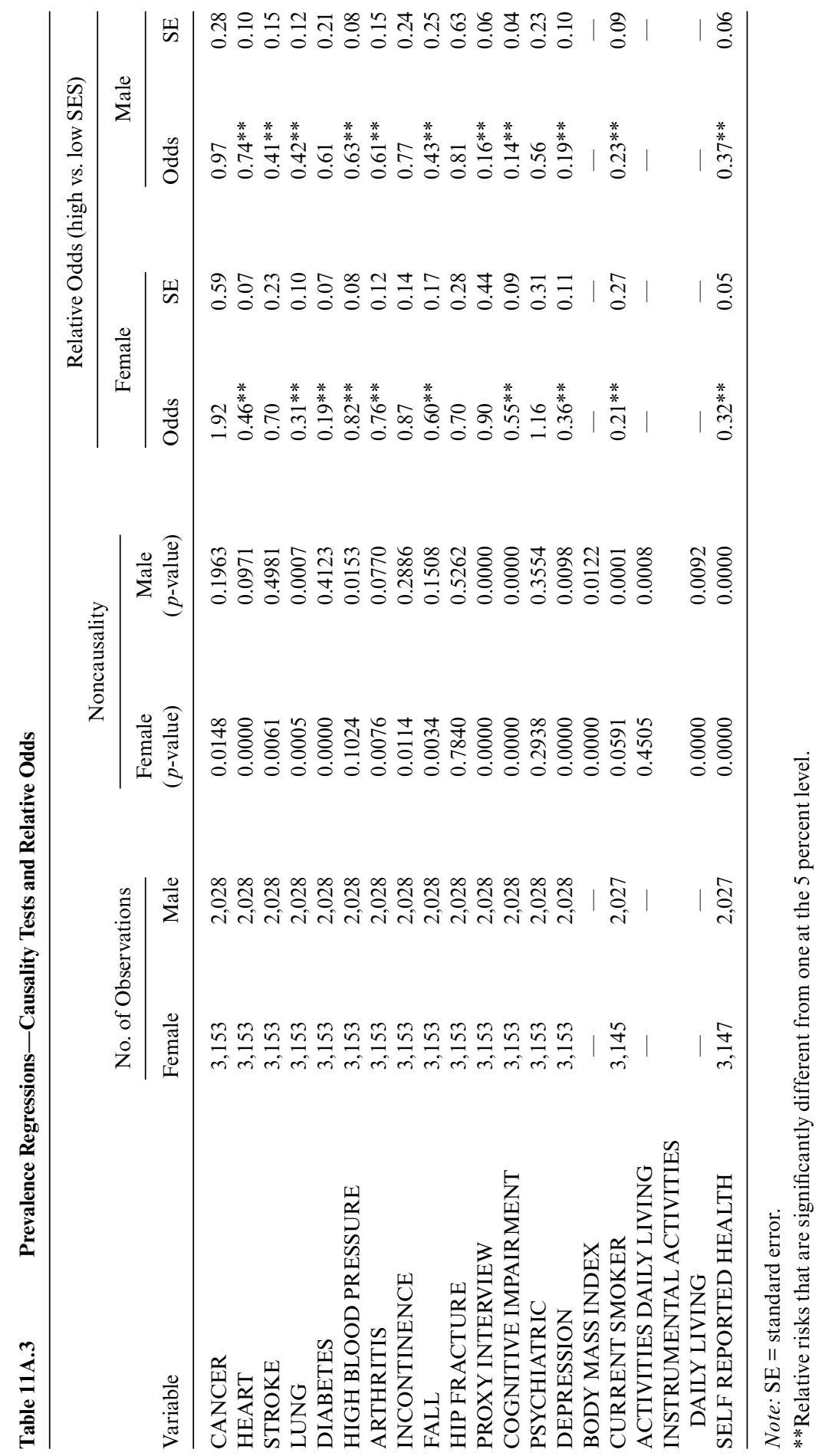




\begin{tabular}{|c|c|c|c|c|}
\hline \multirow[b]{3}{*}{ Variable } & \multicolumn{4}{|c|}{ Invariance } \\
\hline & \multicolumn{2}{|c|}{ With SES } & \multicolumn{2}{|c|}{ Without SES } \\
\hline & Female & Male & Female & Male \\
\hline CANCER & 0.5275 & 0.0155 & 0.3088 & 0.0071 \\
\hline CANCER - no previous & 0.8573 & 0.1291 & 0.8116 & 0.0639 \\
\hline CANCER — previous & 0.0682 & 0.0443 & 0.0789 & 0.0835 \\
\hline HEART & 0.0854 & 0.6901 & 0.0517 & 0.6188 \\
\hline HEART - no previous & 0.1704 & 0.8228 & 0.0604 & 0.4982 \\
\hline HEART — previous & 0.5468 & 0.6925 & 0.4918 & 0.7248 \\
\hline STROKE & 0.3842 & 0.2036 & 0.2663 & 0.1351 \\
\hline STROKE-no previous & 0.1719 & 0.2584 & 0.1603 & 0.1799 \\
\hline STROKE—previous & 0.9073 & 0.0448 & 0.7838 & 0.0866 \\
\hline MORTALITY & 0.2212 & 0.3777 & 0.3153 & 0.4915 \\
\hline LUNG & 0.5518 & 0.6892 & 0.4825 & 0.5021 \\
\hline DIABETES & 0.1893 & 0.2340 & 0.2810 & 0.1282 \\
\hline HIGH BLOOD PRESSURE & 0.0066 & 0.3934 & 0.0244 & 0.1718 \\
\hline ARTHRITIS & 0.0461 & 0.0709 & 0.0319 & 0.1665 \\
\hline INCONTINENCE & 0.7809 & 0.3505 & 0.5968 & 0.6817 \\
\hline INCONTINENCE_-no previous & 0.7057 & 0.1019 & 0.4261 & 0.5548 \\
\hline INCONTINENCE_-previous & 0.9620 & 0.7931 & 0.8921 & 0.7303 \\
\hline FALL & 0.9035 & 0.2626 & 0.7904 & 0.2072 \\
\hline FALL_-no previous & 0.7918 & 0.1401 & 0.6119 & 0.1332 \\
\hline FALL_-previous & 0.3649 & 0.0000 & 0.3576 & 0.0000 \\
\hline HIP FRACTURE & 0.4915 & 0.1261 & 0.2803 & 0.0530 \\
\hline HIP FRACTURE_-no previous & 0.9297 & 0.2997 & 0.7237 & 0.1227 \\
\hline PROXY INTERVIEW & 0.3008 & 0.5908 & 0.4646 & 0.3777 \\
\hline PROXY INTERVIEW — no previous & 0.1275 & 0.7948 & 0.4442 & 0.6064 \\
\hline COGNITIVE IMPAIRMENT & 0.0053 & 0.2878 & 0.0083 & 0.1425 \\
\hline PSYCHIATRIC & 0.1266 & 0.2949 & 0.0516 & 0.3647 \\
\hline DEPRESSION & 0.2109 & 0.9437 & 0.2989 & 0.9343 \\
\hline BODY MASS INDEX & 0.2599 & 0.0089 & 0.2511 & 0.0020 \\
\hline CURRENT SMOKER & 0.4203 & 0.7097 & 0.2140 & 0.5042 \\
\hline CURRENT SMOKER — no previous & 0.1331 & 0.0328 & 0.0783 & 0.0401 \\
\hline CURRENT SMOKER — previous & 0.7966 & & 0.7332 & \\
\hline ACTIVITIES DAILY LIVING & 0.0010 & 0.0211 & 0.0069 & 0.0377 \\
\hline \multicolumn{5}{|l|}{ INSTRUMENTAL ACTIVITIES } \\
\hline DAILY LIVING & 0.6031 & 0.0077 & 0.3883 & 0.0027 \\
\hline SELF RATED HEALTH & 0.3761 & 0.6342 & 0.3408 & 0.6065 \\
\hline SELF RATED HEALTH—no previous & 0.5144 & 0.2515 & 0.5578 & 0.2151 \\
\hline SELF RATED HEALTH—previous & 0.2395 & 0.1652 & 0.1763 & 0.1886 \\
\hline
\end{tabular}
(continued) 


\begin{tabular}{|c|c|c|c|c|c|c|}
\hline & \multicolumn{6}{|c|}{ Noncausality } \\
\hline & \multicolumn{2}{|c|}{ Wave $1-2$} & \multicolumn{2}{|c|}{ Wave $2-3$} & \multicolumn{2}{|c|}{ Wave $1-3$} \\
\hline & Female & Male & Female & Male & Female & Male \\
\hline CANCER & 0.9874 & 0.5883 & 0.4080 & 0.1653 & 0.6133 & 0.1980 \\
\hline CANCER — no previous & 0.7038 & 0.6584 & 0.2886 & 0.1730 & 0.3130 & 0.1658 \\
\hline CANCER — previous & 0.1428 & 0.2277 & 0.4719 & 0.0168 & 0.2989 & 0.0359 \\
\hline HEART & 0.5398 & 0.0538 & 0.3963 & 0.9964 & 0.3978 & 0.2430 \\
\hline HEART_no previous & 0.8722 & 0.3444 & 0.7495 & 0.4118 & 0.7360 & 0.0393 \\
\hline HEART — previous & 0.1040 & 0.0707 & 0.1533 & 0.7372 & 0.0192 & 0.1716 \\
\hline STROKE & 0.7567 & 0.8367 & 0.5845 & 0.0278 & 0.6573 & 0.0593 \\
\hline STROKE-no previous & 0.4147 & 0.9546 & 0.6708 & 0.0639 & 0.7128 & 0.2035 \\
\hline STROKE-previous & 0.8239 & 0.3012 & 0.8819 & 0.1548 & 0.7986 & 0.3827 \\
\hline MORTALITY & 0.0980 & 0.2753 & 0.8830 & 0.3056 & 0.6516 & 0.3636 \\
\hline LUNG & 0.1657 & 0.1739 & 0.8663 & 0.1224 & 0.3431 & 0.0097 \\
\hline DIABETES & 0.6152 & 0.1413 & 0.0197 & 0.2361 & 0.1096 & 0.0250 \\
\hline HIGH BLOOD PRESSURE & 0.3422 & 0.9956 & 0.0831 & 0.9409 & 0.5339 & 0.9897 \\
\hline ARTHRITIS & 0.1786 & 0.0285 & 0.2423 & 0.7129 & 0.0848 & 0.3947 \\
\hline INCONTINENCE & 0.7627 & 0.0191 & 0.2536 & 0.7999 & 0.1628 & 0.4632 \\
\hline INCONTINENCE_-no previous & 0.9140 & 0.0369 & 0.6018 & 0.1970 & 0.4530 & 0.6408 \\
\hline INCONTINENCE—previous & 0.8996 & 0.2471 & 0.1675 & 0.6643 & 0.1490 & 0.2440 \\
\hline FALL & 0.5325 & 0.6875 & 0.953 & 0.4539 & 0.6003 & 0.5918 \\
\hline FALL_no previous & 0.5015 & 0.6973 & 0.9435 & 0.2509 & 0.5576 & 0.5321 \\
\hline FALL_-previous & 0.3286 & 0.0000 & 0.8034 & 0.0000 & 0.6959 & 0.0529 \\
\hline HIP FRACTURE & 0.6125 & 0.5974 & 0.3700 & 0.6656 & 0.1586 & 0.4304 \\
\hline HIP FRACTURE - no previous & 0.4606 & 0.4610 & 0.7058 & 0.7249 & 0.1277 & 0.2344 \\
\hline PROXY INTERVIEW & 0.0172 & 0.4856 & 0.8700 & 0.1267 & 0.2540 & 0.0317 \\
\hline PROXY INTERVIEW — no previous & 0.0016 & 0.7935 & 0.5408 & 0.1207 & 0.0874 & 0.0732 \\
\hline COGNITIVE IMPAIRMENT & 0.0007 & 0.2587 & 0.2591 & 0.1995 & 0.0016 & 0.0262 \\
\hline PSYCHIATRIC & 0.0428 & 0.2376 & 0.2138 & 0.0685 & 0.0036 & 0.0649 \\
\hline DEPRESSION & 0.0071 & 0.1433 & 0.2605 & 0.3770 & 0.0113 & 0.0653 \\
\hline BODY MASS INDEX & 0.1876 & 0.8388 & 0.9308 & 0.7108 & 0.6729 & 0.6640 \\
\hline CURRENT SMOKER & 0.6031 & 0.2821 & 0.9741 & 0.6927 & 0.6251 & 0.1286 \\
\hline CURRENT SMOKER - no previous & 0.3355 & 0.1965 & 0.8744 & 0.9802 & 0.5148 & 0.9615 \\
\hline CURRENT SMOKER — previous & 0.3750 & 0.3248 & 0.5473 & 0.3248 & 0.2736 & 0.0249 \\
\hline ACTIVITIES DAILY LIVING & 0.0771 & 0.0137 & 0.3460 & 0.9714 & 0.8278 & 0.3577 \\
\hline \multicolumn{7}{|l|}{ INSTRUMENTAL ACTIVITIES } \\
\hline DAILY LIVING & 0.3738 & 0.0510 & 0.8166 & 0.2426 & 0.2408 & 0.0085 \\
\hline SELF RATED HEALTH & 0.0133 & 0.0476 & 0.0996 & 0.3006 & 0.0013 & 0.0204 \\
\hline SELF RATED HEALTH—no previous & 0.0149 & 0.1874 & 0.2022 & 0.1210 & 0.0071 & 0.0337 \\
\hline SELF RATED HEALTH—previous & 0.2250 & 0.1955 & 0.5565 & 0.2555 & 0.1934 & 0.1752 \\
\hline
\end{tabular}




\begin{tabular}{|c|c|c|c|c|c|c|}
\hline & \multirow{2}{*}{\multicolumn{2}{|c|}{$\begin{array}{l}\text { Joint (Invariance } \\
+ \text { Noncausality) }\end{array}$}} & \multicolumn{4}{|c|}{ Relative Odds (high vs. low SES) } \\
\hline & & & \multicolumn{2}{|c|}{ Female } & \multicolumn{2}{|c|}{ Male } \\
\hline & Female & Male & Odds & SE & Odds & SE \\
\hline CANCER & 0.5999 & 0.0124 & 1.3099 & 0.4606 & 0.7316 & 0.2699 \\
\hline CANCER - no previous & 0.7778 & 0.0844 & 1.2423 & 0.4835 & 0.6733 & 0.2934 \\
\hline CANCER_previous & 0.0666 & 0.0110 & 5.8494 & 7.7533 & 2.6866 & 3.4206 \\
\hline HEART & 0.0986 & 0.5708 & 0.9739 & 0.2107 & 1.0196 & 0.2379 \\
\hline HEART_-no previous & 0.2780 & 0.4464 & 0.8190 & 0.2525 & 1.3003 & 0.5022 \\
\hline HEART — previous & 0.1686 & 0.5161 & 1.1323 & 0.3180 & 0.8778 & 0.2629 \\
\hline STROKE & 0.4812 & 0.0800 & 0.7308 & 0.2537 & 0.9363 & 0.3517 \\
\hline STROKE_-no previous & 0.2711 & 0.1893 & 0.6787 & 0.2666 & 0.8182 & 0.3603 \\
\hline STROKE-previous & 0.9477 & 0.0537 & 1.1538 & 0.9298 & 1.6050 & 1.2472 \\
\hline MORTALITY & 0.3076 & 0.3596 & 0.6881 & 0.2069 & 1.1677 & 0.4066 \\
\hline LUNG & 0.5039 & 0.2032 & 0.3272 & 0.1731 & 0.5043 & 0.4315 \\
\hline DIABETES & 0.1013 & 0.0622 & 0.6932 & 0.4119 & 1.4837 & 3.1948 \\
\hline HIGH BLOOD PRESSURE & 0.0127 & 0.6660 & 0.8959 & 0.2884 & 0.7425 & 0.3568 \\
\hline ARTHRITIS & 0.0204 & 0.0816 & 1.0309 & 0.2177 & 0.5433 & 0.1596 \\
\hline INCONTINENCE & 0.6148 & 0.3733 & 0.8501 & 0.1268 & 1.1093 & 0.3031 \\
\hline INCONTINENCE_no previous & 0.6954 & 0.1583 & 0.7738 & 0.1983 & 1.0196 & 0.3574 \\
\hline INCONTINENCE—previous & 0.8574 & 0.6836 & 0.9398 & 0.0903 & 1.1258 & 0.2871 \\
\hline FALL & 0.9133 & 0.3285 & 0.9845 & 0.1947 & 0.9228 & 0.3132 \\
\hline FALL—no previous & 0.8079 & 0.1809 & 1.0259 & 0.2536 & 0.8638 & 0.3220 \\
\hline FALL_previous & 0.4700 & 0.0000 & 1.0032 & 0.2718 & 89.6130 & 267.8210 \\
\hline HIP FRACTURE & 0.3475 & 0.1434 & 0.3270 & 0.2205 & 0.2096 & 0.2770 \\
\hline HIP FRACTURE — no previous & 0.7845 & 0.2381 & 0.2289 & 0.1690 & 0.1397 & 0.1924 \\
\hline PROXY INTERVIEW & 0.2482 & 0.2610 & 0.4587 & 0.1610 & 0.4756 & 0.1750 \\
\hline PROXY INTERVIEW — no previous & 0.0610 & 0.5310 & 0.2666 & 0.1094 & 0.3992 & 0.2009 \\
\hline COGNITIVE IMPAIRMENT & 0.0002 & 0.0888 & 0.7795 & 0.1721 & 0.5920 & 0.1852 \\
\hline PSYCHIATRIC & 0.0123 & 0.1372 & 0.3942 & 0.1529 & 0.1589 & 0.1243 \\
\hline DEPRESSION & 0.0422 & 0.7534 & 0.3753 & 0.1453 & 0.2856 & 0.1530 \\
\hline BODY MASS INDEX & 0.3452 & 0.0190 & & & & \\
\hline CURRENT SMOKER & 0.4918 & 0.5276 & 0.4609 & 0.3702 & 0.9187 & 1.1083 \\
\hline CURRENT SMOKER — no previous & 0.1652 & 0.0970 & 0.1055 & 0.1581 & 19.9184 & 132.7460 \\
\hline CURRENT SMOKER — previous & 0.7141 & & 0.9262 & 0.1595 & 0.9499 & 0.1758 \\
\hline ACTIVITIES DAILY LIVING & 0.0036 & 0.0240 & & & & \\
\hline \multicolumn{7}{|l|}{ INSTRUMENTAL ACTIVITIES } \\
\hline DAILY LIVING & 0.5089 & 0.0008 & & & & \\
\hline SELF RATED HEALTH & 0.0444 & 0.2784 & 0.6749 & 0.0780 & 0.6445 & 0.0919 \\
\hline SELF RATED HEALTH—no previous & 0.1380 & 0.0907 & 0.5892 & 0.1224 & 0.5066 & 0.1290 \\
\hline SELF RATED HEALTH—previous & 0.1773 & 0.1159 & 0.8500 & 0.0754 & 0.9227 & 0.0824 \\
\hline
\end{tabular}

Notes: $\mathrm{SE}=$ standard error. $\mathrm{NC}=$ nonconvergence. 


\begin{tabular}{|c|c|c|c|c|c|c|}
\hline \multirow[b]{2}{*}{ Variable } & \multicolumn{2}{|c|}{ Couples } & \multicolumn{2}{|c|}{ Spouse Died } & \multicolumn{2}{|c|}{ Single } \\
\hline & Estimate & $t$-statistic & Estimate & $t$-statistic & Estimate & $t$-statistic \\
\hline XONE1 & 0.0610 & 12.72 & 0.0917 & 5.35 & 0.0552 & 4.70 \\
\hline XONE2 & 0.0487 & 9.94 & 0.0755 & 3.46 & 0.0430 & 3.45 \\
\hline XLWLTH12 & -0.0528 & -10.98 & -0.530 & -4.23 & -0.0503 & -7.93 \\
\hline XNWLTH12 & -0.0673 & -8.23 & -0.1033 & -5.61 & -0.0629 & -5.52 \\
\hline XQ1I12 & -0.0037 & -3.88 & -0.0052 & -1.58 & -0.0014 & -0.53 \\
\hline XQ4I12 & 0.0098 & 6.98 & 0.0040 & 0.58 & 0.0066 & 2.68 \\
\hline XHOODPF12 & -0.0001 & -0.05 & 0.0066 & 1.59 & 0.0030 & 1.02 \\
\hline XCONDPF12 & -0.0031 & -2.48 & -0.0027 & -0.52 & 0.0000 & 0.01 \\
\hline XDNHOUS12 & 0.0085 & 5.29 & 0.0124 & 2.74 & 0.0015 & 0.66 \\
\hline M_XHS12 & 0.0007 & 0.79 & 0.0019 & 0.51 & 0.0035 & 1.67 \\
\hline M_XCOLL12 & 0.0008 & 0.57 & 0.0034 & 0.62 & 0.0034 & 0.86 \\
\hline M_XAS701S & 0.0000 & 1.69 & 0.0001 & 0.67 & 0.0001 & 1.94 \\
\hline M_XAS801S & 0.0000 & -0.80 & 0.0000 & 0.05 & -0.0001 & -1.29 \\
\hline M_XAS702S & 0.0000 & 1.22 & 0.0000 & -0.37 & 0.0001 & 1.82 \\
\hline M_XAS802S & 0.0000 & -0.58 & 0.0001 & 0.47 & -0.0001 & -0.76 \\
\hline M_XNEVMARR12 & & & & & 0.0131 & 1.62 \\
\hline M_XWIDOW12 & & & & & 0.0123 & 1.64 \\
\hline M_XDIVSEP12 & & & & & 0.0138 & 1.73 \\
\hline M_XMAGEDI12 & 0.0000 & 1.24 & -0.0001 & -1.06 & 0.0000 & -0.89 \\
\hline M_XPAGEDI12 & 0.0000 & -0.10 & 0.0001 & 0.86 & -0.0001 & -1.40 \\
\hline M_XSMOKEV12 & -0.0012 & -1.17 & -0.0046 & -1.40 & 0.0012 & 0.44 \\
\hline M_XCANCER12 & 0.0003 & 0.24 & 0.0025 & 0.76 & 0.0004 & 0.15 \\
\hline M_XHEART12 & -0.0004 & -0.45 & 0.0009 & 0.28 & -0.0007 & -0.33 \\
\hline M_XSTROKE12 & -0.0003 & -0.16 & -0.0024 & -0.47 & -0.0015 & -0.49 \\
\hline M_XLUNG12 & 0.0039 & 2.15 & -0.0057 & -1.51 & -0.0009 & -0.33 \\
\hline M_XDIABET12 & -0.0013 & -1.13 & -0.0004 & -0.11 & 0.0024 & 0.91 \\
\hline M_XHIGHBP12 & -0.0003 & -0.36 & 0.0035 & 1.19 & -0.0002 & -0.09 \\
\hline M_XARTHRT12 & -0.0007 & -0.56 & 0.0015 & 0.41 & -0.0011 & -0.54 \\
\hline M_XINCONT12 & 0.0012 & 0.87 & -0.0061 & -1.77 & -0.0008 & -0.30 \\
\hline M_XFALL12 & -0.0018 & -1.26 & -0.0021 & -0.39 & -0.0051 & -0.151 \\
\hline M_XHIPFRC12 & -0.0029 & -0.84 & 0.0042 & 0.57 & 0.0059 & 1.49 \\
\hline M_XPROXYW12 & -0.0004 & -0.20 & -0.0027 & -0.69 & 0.0055 & 1.04 \\
\hline M_XCOGIM12 & 0.0011 & 0.88 & -0.0048 & -1.69 & -0.0024 & -1.10 \\
\hline M_XPSYCH12 & -0.0012 & -0.61 & 0.0055 & 1.25 & 0.0015 & 0.43 \\
\hline M_XDEPRES12 & -0.0001 & -0.02 & 0.0033 & 0.69 & -0.0015 & -0.54 \\
\hline M_XLOBMI12 & -0.0009 & -0.20 & -0.0002 & -0.09 & 0.0020 & 0.99 \\
\hline M_XHIBMI12 & 0.0000 & 0.25 & 0.0002 & 0.44 & -0.0003 & -0.88 \\
\hline M_XSMOKNOW12 & -0.0029 & -1.71 & -0.0030 & -0.54 & -0.0045 & -1.59 \\
\hline M_XNUMADL12 & 0.0001 & 0.17 & -0.0001 & -0.03 & -0.0010 & -1.05 \\
\hline M_XNUMIADL12 & -0.0010 & -0.93 & 0.0002 & 0.05 & 0.0014 & 1.16 \\
\hline M_XDHLTH12 & 0.0000 & -0.04 & 0.0022 & 0.53 & 0.0039 & 1.62 \\
\hline M_XJCANCER23 & 0.0007 & 0.22 & 0.0011 & 0.10 & 0.0091 & 2.21 \\
\hline M_XJHEART23 & 0.0007 & 0.29 & -0.0023 & -0.19 & 0.0029 & 1.00 \\
\hline M_XJSTROKE23 & 0.0043 & 1.22 & -0.0024 & -0.22 & 0.0051 & 1.33 \\
\hline M_XILUNG23 & -0.0021 & -1.08 & -0.0051 & -0.35 & -0.0033 & -1.22 \\
\hline M_XIDIABET23 & -0.0012 & -0.48 & 0.0250 & 1.94 & -0.0015 & -0.35 \\
\hline M_XIHIGHBP23 & -0.0006 & -0.18 & -0.0174 & -1.15 & 0.0009 & 0.34 \\
\hline M_XIARTHRT23 & -0.0008 & -0.53 & -0.0016 & -0.25 & -0.0020 & -0.67 \\
\hline
\end{tabular}


(continued)

\begin{tabular}{|c|c|c|c|c|c|c|}
\hline \multirow[b]{2}{*}{ Variable } & \multicolumn{2}{|c|}{ Couples } & \multicolumn{2}{|c|}{ Spouse Died } & \multicolumn{2}{|c|}{ Single } \\
\hline & Estimate & $t$-statistic & Estimate & $t$-statistic & Estimate & $t$-statistic \\
\hline M_XJINCONT23 & -0.0006 & -0.39 & 0.0015 & 0.17 & 0.0007 & 0.31 \\
\hline M_XJFALL23 & 0.0003 & 0.24 & 0.0048 & 0.34 & -0.0029 & -1.30 \\
\hline M_XJHIPFRC23 & -0.0044 & -0.57 & -0.0006 & -0.02 & -0.0009 & -0.14 \\
\hline M_XPROXYW23 & -0.0005 & -0.29 & 0.0017 & 0.20 & -0.0010 & -0.27 \\
\hline M_XICOGIM23 & 0.0001 & 0.06 & -0.0057 & -0.48 & 0.0020 & 0.84 \\
\hline M_XIPSYCH23 & -0.0003 & -0.18 & 0.0008 & 0.06 & 0.0046 & 1.54 \\
\hline M_XIDEPRES23 & -0.0016 & -0.72 & 0.0009 & 0.11 & -0.0032 & -1.07 \\
\hline M_XBMIBT23 & 0.0004 & 0.36 & -0.0020 & -0.26 & 0.0022 & 1.14 \\
\hline M_XBMIWS23 & -0.0013 & -1.00 & -0.0031 & -0.34 & 0.0008 & 0.39 \\
\hline M_XSMOKNOW23 & 0.0040 & 2.08 & -0.0069 & -0.38 & -0.0006 & -0.24 \\
\hline M_XNUMADL23 & -0.0001 & -0.12 & -0.0055 & -1.63 & -0.0003 & -0.56 \\
\hline M_XNUMIADL23 & 0.0004 & 0.41 & 0.0006 & 0.20 & -0.0008 & -1.06 \\
\hline M_XDHLTH23 & -0.0007 & -0.67 & -0.0118 & -1.32 & 0.0015 & 0.90 \\
\hline F_XONE1 & & & & & 0.0753 & 12.84 \\
\hline F_XONE2 & & & & & 0.0656 & 10.87 \\
\hline F_XLWLTH12 & & & & & -0.0503 & -16.12 \\
\hline F_XNWLTH12 & & & & & -0.0640 & -11.29 \\
\hline F_XQ1I12 & & & & & -0.0006 & -0.81 \\
\hline F_XQ4I12 & & & & & 0.0089 & 7.79 \\
\hline F_XHOODPF12 & & & & & -0.0010 & -1.12 \\
\hline F_XCONDPF12 & & & & & -0.0012 & -1.36 \\
\hline F_XDNHOUS12 & & & & & 0.0035 & 3.54 \\
\hline F_XHS12 & 0.0008 & 0.75 & 0.0069 & 1.66 & 0.0016 & 2.16 \\
\hline F_XCOLL12 & 0.0019 & 1.34 & 0.0029 & 0.49 & 0.0026 & 1.80 \\
\hline F_XAS701S & 0.0000 & 1.14 & -0.0001 & -0.83 & 0.0000 & -0.09 \\
\hline F_XAS801S & -0.0001 & -0.75 & 0.0000 & 0.04 & 0.0000 & 0.04 \\
\hline F_XAS702S & 0.0000 & -1.88 & 0.0000 & 0.66 & 0.0000 & -0.35 \\
\hline F_XAS802S & 0.0001 & 1.96 & -0.0001 & -0.37 & 0.0000 & 0.51 \\
\hline F_XNEVMARR12 & & & & & 0.0023 & 0.50 \\
\hline F_XWIDOW12 & & & & & 0.0010 & 0.23 \\
\hline F_XDIVSEP12 & & & & & 0.0001 & 0.01 \\
\hline F_XMAGEDI12 & 0.0000 & 1.08 & 0.0000 & -0.02 & 0.0000 & 0.44 \\
\hline F_XPAGEDI12 & 0.0000 & -0.79 & 0.0000 & -0.40 & 0.0000 & -0.47 \\
\hline F_XSMOKEV12 & 0.0024 & 2.58 & 0.0007 & 0.17 & 0.0007 & 0.88 \\
\hline F_XCANCER 12 & -0.0012 & -0.87 & -0.0049 & -0.86 & -0.0007 & -0.69 \\
\hline F_XHEART12 & 0.0002 & 0.21 & -0.0025 & -0.77 & -0.0010 & -1.42 \\
\hline F_XSTROKE12 & -0.0010 & -0.52 & 0.0021 & 0.29 & -0.0002 & -0.20 \\
\hline F_XLUNG12 & 0.0002 & 0.10 & -0.0033 & -0.71 & -0.0015 & -1.48 \\
\hline F_XDIABET12 & -0.0027 & -1.99 & 0.0041 & 0.86 & -0.0018 & -1.89 \\
\hline F_XHIGHBP12 & 0.0006 & 0.61 & 0.0047 & 1.55 & -0.0010 & -1.35 \\
\hline F_XARTHRT12 & 0.0008 & 0.73 & -0.0018 & -0.40 & 0.0004 & 0.44 \\
\hline F_XINCONT12 & -0.0013 & -1.01 & 0.0001 & 0.03 & 0.0006 & 0.66 \\
\hline F_XFALL12 & 0.0001 & 0.09 & -0.0002 & -0.05 & 0.0010 & 0.99 \\
\hline F_XHIPFRC12 & 0.0011 & 0.33 & 0.0018 & 0.28 & -0.0005 & -0.40 \\
\hline F_XPROXYW12 & -0.0013 & -0.40 & -0.0013 & -0.20 & -0.0004 & -0.25 \\
\hline F_XCOGIM12 & -0.0003 & -0.17 & -0.0050 & -1.11 & -0.0023 & -2.70 \\
\hline
\end{tabular}


(continued)

\begin{tabular}{|c|c|c|c|c|c|c|}
\hline \multirow[b]{2}{*}{ Variable } & \multicolumn{2}{|c|}{ Couples } & \multicolumn{2}{|c|}{ Spouse Died } & \multicolumn{2}{|c|}{ Single } \\
\hline & Estimate & $t$-statistic & Estimate & $t$-statistic & Estimate & $t$-statistic \\
\hline F_XPSYCH12 & -0.0005 & -0.44 & 0.0007 & 0.14 & -0.0010 & -0.97 \\
\hline F_XDEPRES12 & -0.0016 & -0.91 & -0.0012 & -0.24 & -0.0007 & -0.61 \\
\hline F_XLOBMI12 & 0.0007 & 0.34 & 0.0013 & 0.58 & 0.0001 & 0.10 \\
\hline F_XHIBMI12 & -0.0003 & -1.79 & -0.0011 & -2.61 & -0.0002 & -1.47 \\
\hline F_XSMOKNOW12 & -0.0014 & -0.60 & -0.0013 & -0.20 & -0.0026 & -1.48 \\
\hline F_XNUMADL12 & 0.0013 & 1.58 & 0.0015 & 0.63 & -0.0005 & -1.64 \\
\hline F_XNUMIADL12 & 0.0002 & 0.20 & -0.0016 & -1.00 & -0.0006 & -1.37 \\
\hline F_XDHLTH12 & 0.0002 & 0.15 & -0.0012 & -0.21 & -0.0004 & -0.44 \\
\hline F_XJCANCER23 & 0.0019 & 0.71 & -0.0002 & -0.01 & -0.0077 & -3.19 \\
\hline F_XJHEART23 & 0.0033 & 1.69 & -0.0045 & -0.80 & -0.0023 & -2.00 \\
\hline F_XJSTROKE23 & 0.0041 & 1.77 & -0.0185 & -2.60 & -0.0034 & -1.98 \\
\hline F_XILUNG23 & 0.0044 & 1.15 & -0.0039 & -0.49 & -0.0004 & -0.26 \\
\hline F_XIDIABET23 & -0.0011 & -0.37 & -0.0002 & -0.03 & 0.0000 & 0.02 \\
\hline F_XIHIGHBP23 & 0.0023 & 1.09 & 0.0010 & 0.15 & 0.0001 & 0.06 \\
\hline F_XIARTHRT23 & 0.0012 & 0.81 & 0.0029 & 0.44 & 0.0010 & 1.09 \\
\hline F_XJINCONT23 & 0.0024 & 2.50 & -0.0009 & -0.24 & 0.0011 & 1.37 \\
\hline F_XJFALL23 & -0.0011 & -0.60 & -0.0036 & -0.75 & 0.0003 & 0.35 \\
\hline F_XJHIPFRC23 & 0.0010 & 0.27 & 0.0067 & 0.82 & 0.0006 & 0.036 \\
\hline F_XPROXYW23 & -0.0017 & -0.67 & -0.0036 & -0.52 & -0.0011 & -0.82 \\
\hline F_XICOGIM23 & -0.0001 & -0.05 & -0.0023 & -0.48 & -0.0024 & -2.42 \\
\hline F_XIPSYCH 23 & -0.0014 & -0.70 & -0.0158 & -2.49 & 0.0012 & 0.93 \\
\hline F_XIDEPRES23 & -0.0026 & -1.52 & 0.0005 & 0.07 & -0.0011 & -0.78 \\
\hline F_XBMIBT23 & 0.0006 & 0.39 & 0.0017 & 0.34 & -0.0001 & -0.19 \\
\hline F_XBMIWS23 & -0.0001 & -0.10 & 0.0013 & 0.22 & 0.0001 & 0.11 \\
\hline F_XSMOKNOW23 & -0.0038 & -1.56 & 0.0013 & 0.13 & 0.0012 & 0.70 \\
\hline F_XNUMADL23 & -0.0002 & -0.33 & 0.0020 & 1.22 & -0.0002 & -0.93 \\
\hline F_XNUMIADL23 & 0.0006 & 0.73 & -0.0014 & -0.65 & -0.0003 & -0.84 \\
\hline F_XDHLTH23 & -0.0032 & -2.68 & -0.0028 & -0.60 & -0.0003 & -0.33 \\
\hline $\mathrm{CF} 4$ & -0.2411 & -0.18 & -0.2411 & -0.18 & -0.0128 & -0.27 \\
\hline CF3 & -1.1433 & -1.38 & -1.1433 & -1.38 & 0.5102 & 6.01 \\
\hline CM4 & 0.1903 & 1.40 & 0.1903 & 1.40 & -0.1306 & -1.97 \\
\hline CM3 & -0.3582 & -2.24 & -0.3582 & -2.24 & -0.4368 & -3.62 \\
\hline $\mathrm{AM}$ & -0.0025 & -1.87 & 0.0012 & 2.80 & -0.0076 & -4.39 \\
\hline $\mathrm{AF}$ & -0.0008 & -0.30 & 0.0004 & 0.45 & -0.0019 & -10.04 \\
\hline $\mathrm{C}$ & 0.0000 & 21.10 & 0.0000 & 7.74 & 0.0000 & 6.11 \\
\hline VARM & 0.0000 & -0.88 & 0.0000 & -0.89 & 0.0000 & -0.81 \\
\hline VARF & 0.0000 & -2.53 & 0.0000 & 1.20 & 0.0000 & 0.48 \\
\hline SIGMA & 0.0043 & 42.20 & 0.0000 & 7.74 & 0.0088 & 6.12 \\
\hline THETA & 2.4733 & 19.10 & & & & \\
\hline RHOM & -0.4882 & -6.31 & & & -0.8641 & -17.28 \\
\hline RHOF & -0.1606 & -3.11 & & & -0.2103 & -5.32 \\
\hline
\end{tabular}

Notes: Prefixes $\mathrm{M}_{-}$and $\mathrm{F}_{-}$refer to males and females, respectively. For couples and spouse died regressions household-level variables are common for males and females. We report the estimates under the male section. CF3, CF4 = third/fourth order Edgeworth expansion terms for females; CM3, CM4 = third/fourth order Edgeworth expansion terms for males; AF, AM = estimates of $\lambda$ in equations (15) and (19); $\mathrm{C}=$ estimate of $\mathrm{k}^{2}$ in equation (16); VARM, VARF = estimates of $\lambda^{2}$ in equation (16) for males and females; SIGMA = estimate of $\sigma$ as defined in page 440 of paper; THETA $=$ estimate of $\theta$ in equation (19); RHOF, RHOM = estimate of $\rho$ as defined in page 442 of paper. 


\begin{tabular}{|c|c|c|c|c|c|c|}
\hline \multirow[b]{2}{*}{ Variable } & \multicolumn{2}{|c|}{ Couples } & \multicolumn{2}{|c|}{ Spouse Died } & \multicolumn{2}{|c|}{ Single } \\
\hline & Estimate & $t$-statistic & Estimate & $t$-statistic & Estimate & $t$-statistic \\
\hline XONE1 & 0.0582 & 14.64 & 0.0752 & 4.68 & 0.0482 & 4.74 \\
\hline XONE2 & 0.0459 & 11.33 & 0.0655 & 3.13 & 0.0438 & 3.94 \\
\hline XLWLTH12 & 0.0046 & 1.03 & 0.0041 & 0.40 & 0.0128 & 2.56 \\
\hline XNWLTH12 & -0.1311 & -15.98 & -0.1646 & -8.65 & -0.1138 & -8.91 \\
\hline XQ1I12 & -0.0010 & -1.19 & -0.0011 & -0.37 & -0.0012 & -0.50 \\
\hline XQ4I12 & 0.0021 & 2.17 & 0.0032 & 0.53 & 0.0015 & 0.66 \\
\hline XHOODPF12 & -0.0017 & -1.47 & 0.0050 & 1.27 & 0.0002 & 0.07 \\
\hline XCONDPF12 & -0.0014 & -1.19 & -0.0008 & -0.17 & -0.0001 & -0.03 \\
\hline XDNHOUS12 & 0.0068 & 4.45 & 0.0074 & 1.80 & 0.0013 & 0.50 \\
\hline M_XHS12 & 0.0000 & 0.04 & 0.0005 & 0.14 & 0.0010 & 0.47 \\
\hline M_XCOLL12 & 0.0000 & -0.01 & 0.0021 & 0.44 & -0.0008 & -0.25 \\
\hline M_XAS701S & 0.0000 & 0.22 & 0.0001 & 0.82 & 0.0001 & 2.71 \\
\hline M_XAS801S & -0.0001 & -1.73 & -0.0001 & -0.43 & -0.0001 & -1.88 \\
\hline M_XAS702S & 0.0000 & 0.48 & 0.0000 & 0.10 & 0.0001 & 2.01 \\
\hline M_XAS802S & 0.0000 & -1.16 & 0.0000 & -0.19 & -0.0001 & -0.91 \\
\hline M_XNEVMARR12 & & & & & 0.0078 & 1.13 \\
\hline M_XWIDOW12 & & & & & 0.0078 & 1.26 \\
\hline M_XDIVSEP12 & & & & & 0.0101 & 1.45 \\
\hline M_XMAGEDI12 & 0.0000 & 0.33 & -0.0001 & -1.63 & -0.0001 & -1.64 \\
\hline M_XPAGEDI12 & 0.0000 & 0.23 & 0.0000 & 0.37 & -0.0001 & -1.20 \\
\hline M_XSMOKEV12 & -0.0011 & -1.33 & -0.0044 & -1.36 & -0.0016 & -0.67 \\
\hline M_XCANCER12 & -0.0004 & -0.35 & 0.0037 & 1.44 & 0.0032 & 1.20 \\
\hline M_XHEART12 & 0.0003 & 0.36 & -0.0011 & -0.42 & 0.0002 & 0.10 \\
\hline M_XSTROKE12 & 0.0015 & 0.83 & -0.0013 & -0.29 & 0.0012 & 0.44 \\
\hline M_XLUNG12 & 0.0022 & 1.30 & -0.0018 & -0.50 & 0.0001 & 0.05 \\
\hline M_XDIABET12 & -0.0019 & -1.89 & 0.0024 & 0.83 & 0.0044 & 1.87 \\
\hline M_XHIGHBP12 & -0.0005 & -0.71 & 0.0041 & 1.52 & 0.0007 & 0.37 \\
\hline M_XARTHRT12 & 0.0019 & 1.62 & 0.0052 & 1.52 & -0.0012 & -0.60 \\
\hline M_XINCONT12 & 0.0004 & 0.33 & -0.0040 & -1.48 & -0.0034 & -1.29 \\
\hline M_XFALL12 & -0.0002 & -0.14 & -0.0025 & -0.50 & -0.0059 & -1.90 \\
\hline M_XHIPFRC12 & -0.0015 & -0.48 & 0.0068 & 0.91 & 0.0100 & 2.32 \\
\hline M_XPROXYW12 & 0.0025 & 1.43 & -0.0049 & -1.35 & 0.0057 & 1.14 \\
\hline M_XCOGIM12 & 0.0024 & 2.07 & -0.0018 & -0.71 & 0.0017 & 0.81 \\
\hline M_XPSYCH12 & -0.0007 & -0.41 & -0.0058 & -1.62 & 0.0009 & 0.35 \\
\hline M_XDEPRES12 & 0.0018 & 0.48 & -0.0027 & -0.65 & 0.0018 & 0.57 \\
\hline M_XLOBMI12 & 0.0010 & 0.21 & -0.0025 & -1.25 & 0.0061 & 2.21 \\
\hline M_XHIBMI12 & 0.0003 & 2.04 & 0.0002 & 0.32 & -0.0003 & -0.70 \\
\hline M_XSMOKNOW12 & -0.0006 & -0.44 & 0.0006 & 0.10 & -0.0050 & -1.98 \\
\hline M_XNUMADL12 & -0.0002 & -0.24 & 0.0010 & 0.49 & 0.0004 & 0.51 \\
\hline M_XNUMIADL12 & -0.0013 & -1.31 & 0.0007 & 0.22 & 0.0008 & 0.76 \\
\hline M_XDHLTH12 & -0.0017 & -1.53 & -0.0029 & -0.81 & 0.0033 & 1.37 \\
\hline M_XJCANCER23 & 0.0012 & 0.42 & 0.0022 & 0.22 & 0.0170 & 3.07 \\
\hline M_XJHEART23 & 0.0020 & 0.93 & 0.0046 & 0.40 & 0.0097 & 2.51 \\
\hline M_XJSTROKE23 & 0.0024 & 0.69 & -0.0077 & -0.65 & 0.0066 & 1.62 \\
\hline M_XILUNG23 & -0.0025 & -1.54 & -0.0010 & -0.07 & -0.0062 & -2.39 \\
\hline $\begin{array}{l}\text { M_XIDIABET23 } \\
\text { (continued) }\end{array}$ & 0.0001 & 0.06 & 0.0212 & 2.97 & -0.0003 & -0.07 \\
\hline
\end{tabular}


(continued)

\begin{tabular}{|c|c|c|c|c|c|c|}
\hline \multirow[b]{2}{*}{ Variable } & \multicolumn{2}{|c|}{ Couples } & \multicolumn{2}{|c|}{ Spouse Died } & \multicolumn{2}{|c|}{ Single } \\
\hline & Estimate & $t$-statistic & Estimate & $t$-statistic & Estimate & $t$-statistic \\
\hline M_XIHIGHBP23 & -0.0025 & -0.80 & -0.0254 & -1.90 & 0.0004 & 0.16 \\
\hline M_XIARTHRT23 & -0.0010 & -0.80 & 0.0058 & 0.96 & -0.0023 & -0.82 \\
\hline M_XJINCONT23 & 0.0000 & 0.00 & -0.0069 & -0.97 & 0.0014 & 0.78 \\
\hline M_XJFALL23 & 0.0000 & 0.01 & -0.0034 & -0.23 & -0.0009 & -0.49 \\
\hline M_XJHIPFRC23 & -0.0038 & -0.50 & 0.0221 & 0.91 & -0.0040 & -1.09 \\
\hline M_XPROXYW23 & 0.0002 & 0.11 & -0.0017 & -0.23 & 0.0012 & 0.34 \\
\hline M_XICOGIM23 & 0.0008 & 0.59 & -0.0026 & -0.20 & -0.0013 & -0.70 \\
\hline M_XIPSYCH 23 & -0.0004 & -0.27 & 0.0027 & 0.28 & 0.0036 & 1.37 \\
\hline M_XIDEPRES 23 & -0.0007 & -0.36 & -0.0088 & -1.15 & -0.0001 & -0.04 \\
\hline M_XBMIBT23 & -0.0001 & -0.15 & -0.0057 & -0.86 & 0.0005 & 0.31 \\
\hline M_XBMIWS23 & -0.0004 & -0.29 & -0.0078 & -0.97 & 0.0014 & 0.78 \\
\hline M_XSMOKNOW23 & 0.0015 & 0.97 & -0.0128 & -0.64 & 0.0038 & 1.72 \\
\hline M_XNUMADL23 & 0.0004 & 0.53 & -0.0070 & -2.30 & -0.0005 & -0.87 \\
\hline M_XNUMIADL23 & -0.0002 & -0.15 & 0.0037 & 1.36 & -0.0008 & -1.17 \\
\hline M_XDHLTH23 & -0.0005 & -0.55 & -0.0044 & -0.52 & 0.0015 & 0.92 \\
\hline F_XONE1 & & & & & 0.0688 & 12.20 \\
\hline F_XONE2 & & & & & 0.0619 & 10.64 \\
\hline F_XLWLTH12 & & & & & 0.0033 & 1.42 \\
\hline F_XNWLTH12 & & & & & -0.1257 & -20.66 \\
\hline F_XQ1I12 & & & & & 0.0004 & 0.59 \\
\hline F_XQ4I12 & & & & & 0.0030 & 3.13 \\
\hline F_XHOODPF12 & & & & & -0.0010 & -1.21 \\
\hline F_XCONDPF 12 & & & & & 0.0002 & 0.26 \\
\hline F_XDNHOUS12 & & & & & 0.0045 & 4.66 \\
\hline F_XHS12 & 0.0004 & 0.41 & 0.0034 & 0.89 & 0.0001 & 0.21 \\
\hline F_XCOLL12 & 0.0005 & 0.44 & 0.0095 & 1.88 & 0.0016 & 1.36 \\
\hline F_XAS701S & 0.0000 & -0.51 & 0.0000 & -0.32 & 0.0000 & -1.70 \\
\hline F_XAS801S & 0.0000 & 0.69 & -0.0001 & -0.81 & 0.0000 & 0.28 \\
\hline F_XAS702S & 0.0000 & -0.45 & 0.0000 & 0.45 & 0.0000 & -1.09 \\
\hline F_XAS $802 S$ & 0.0001 & 1.26 & 0.0000 & 0.03 & 0.0000 & 0.54 \\
\hline F_XNEVMARR 12 & & & & & 0.0001 & 0.02 \\
\hline F_XWIDOW12 & & & & & 0.0000 & 0.01 \\
\hline F_XDIVSEP12 & & & & & -0.0001 & -0.01 \\
\hline F_XMAGEDI12 & 0.0000 & 0.64 & 0.0000 & 0.73 & 0.0000 & 0.74 \\
\hline F_XPAGEDI12 & 0.0000 & -0.31 & 0.0000 & 0.32 & 0.0000 & 0.47 \\
\hline F_XSMOKEV12 & -0.0003 & -0.40 & -0.0025 & -0.63 & 0.0001 & 0.20 \\
\hline F_XCANCER 12 & 0.0007 & 0.57 & -0.0052 & -1.00 & 0.0001 & 0.07 \\
\hline F_XHEART12 & -0.0009 & -0.89 & -0.0046 & -1.51 & -0.0006 & -0.96 \\
\hline F_XSTROKE12 & 0.0029 & 1.83 & 0.0010 & 0.13 & -0.0005 & -0.44 \\
\hline F_XLUNG12 & 0.0000 & -0.01 & -0.0008 & -0.20 & -0.0012 & -1.45 \\
\hline F_XDIABET 12 & -0.0002 & -0.13 & 0.0064 & 1.36 & -0.0012 & -1.38 \\
\hline F_XHIGHBP12 & 0.0001 & 0.15 & 0.0046 & 1.82 & -0.0014 & -2.16 \\
\hline F_XARTHRT12 & -0.0002 & -0.18 & 0.0029 & 0.68 & 0.0004 & 0.59 \\
\hline F_XINCONT12 & 0.0000 & -0.02 & -0.0014 & -0.42 & 0.0000 & 0.02 \\
\hline F_XFALL12 & 0.0005 & 0.33 & 0.0012 & 0.31 & 0.0010 & 1.12 \\
\hline F_XHIPFRC12 & 0.0039 & 1.29 & -0.0018 & -0.33 & -0.0008 & -0.69 \\
\hline F_XPROXYW12 & -0.0007 & -0.24 & -0.0011 & -0.19 & -0.0005 & -0.32 \\
\hline
\end{tabular}


(continued)

\begin{tabular}{|c|c|c|c|c|c|c|}
\hline \multirow[b]{2}{*}{ Variable } & \multicolumn{2}{|c|}{ Couples } & \multicolumn{2}{|c|}{ Spouse Died } & \multicolumn{2}{|c|}{ Single } \\
\hline & Estimate & $t$-statistic & Estimate & $t$-statistic & Estimate & $t$-statistic \\
\hline F_XCOGIM12 & 0.0005 & 0.33 & -0.0043 & -1.04 & -0.0014 & -1.70 \\
\hline F_XPSYCH12 & 0.0000 & -0.01 & 0.0033 & 0.66 & -0.0013 & -1.48 \\
\hline F_XDEPRES12 & 0.0006 & 0.40 & -0.0025 & -0.51 & -0.0008 & -0.83 \\
\hline F_XLOBMI12 & 0.0017 & 0.90 & 0.0004 & 0.20 & -0.0004 & -1.16 \\
\hline F_XHIBMI12 & 0.0000 & 0.17 & -0.0012 & -3.19 & -0.0001 & -0.87 \\
\hline F_XSMOKNOW12 & -0.0004 & -0.18 & 0.0038 & 0.61 & -0.0033 & -2.14 \\
\hline F_XNUMADL12 & 0.0001 & 0.18 & 0.0011 & 0.49 & -0.0004 & -1.28 \\
\hline F_XNUMIADL12 & 0.0008 & 0.89 & 0.0000 & 0.00 & 0.0003 & 0.89 \\
\hline F_XDHLTH12 & 0.0006 & 0.47 & -0.0011 & -0.21 & -0.0008 & -1.00 \\
\hline F_XJCANCER23 & -0.0010 & -0.46 & 0.0028 & 0.33 & -0.0063 & -2.60 \\
\hline F_XJHEART23 & 0.0007 & 0.38 & -0.0039 & -0.79 & -0.0019 & -1.76 \\
\hline F_XJSTROKE23 & 0.0015 & 0.83 & -0.0032 & -0.44 & -0.0022 & -1.33 \\
\hline F_XILUNG23 & 0.0060 & 1.74 & -0.0070 & -1.11 & -0.0019 & -1.41 \\
\hline F_XIDIABET23 & -0.0028 & -1.41 & -0.0050 & -0.58 & -0.0005 & -0.31 \\
\hline F_XIHIGHBP23 & 0.0002 & 0.09 & -0.0009 & -0.15 & 0.0002 & 0.14 \\
\hline F_XIARTHRT23 & 0.0004 & 0.27 & 0.0001 & 0.01 & 0.0010 & 1.14 \\
\hline F_XJINCONT23 & 0.0007 & 0.86 & -0.0006 & -0.17 & 0.0005 & 0.78 \\
\hline F_XJFALL23 & -0.0006 & -0.32 & -0.0042 & -1.04 & -0.0005 & -0.73 \\
\hline F_XJHIPFRC23 & -0.0045 & -1.86 & -0.0025 & -0.39 & -0.0003 & -0.23 \\
\hline F_XPROXYW23 & 0.0006 & 0.23 & -0.0043 & -0.61 & -0.0008 & -0.61 \\
\hline F_XICOGIM23 & -0.0007 & -0.41 & -0.0016 & -0.34 & -0.0016 & -1.98 \\
\hline F_XIPSYCH23 & -0.0005 & -0.28 & -0.0047 & -0.65 & -0.0001 & -0.08 \\
\hline F_XIDEPRES23 & 0.0007 & 0.42 & -0.0041 & -0.65 & -0.0010 & -0.88 \\
\hline F_XBMIBT23 & 0.0033 & 0.24 & 0.0044 & 1.00 & 0.0024 & 0.61 \\
\hline F_XBMIWS23 & 0.0001 & 0.06 & 0.0026 & 0.44 & -0.0004 & -0.62 \\
\hline F_XSMOKNOW23 & -0.0013 & -0.56 & -0.0075 & -0.88 & 0.0033 & 2.22 \\
\hline F_XNUMADL23 & -0.0006 & -0.91 & 0.0019 & 1.06 & -0.0003 & -1.45 \\
\hline F_XNUMIADL23 & 0.0002 & 0.22 & -0.0021 & -1.02 & -0.0007 & -2.34 \\
\hline F_XDHLTH 23 & -0.0027 & -2.52 & 0.0032 & 0.76 & 0.0005 & 0.65 \\
\hline CF4 & 0.1230 & 0.09 & 0.1230 & 0.09 & 0.0191 & 0.36 \\
\hline CF3 & -0.2322 & -0.28 & -0.2322 & -0.28 & 0.4650 & 4.71 \\
\hline CM4 & 0.1776 & 1.30 & 0.1776 & 1.30 & -0.1248 & -2.74 \\
\hline CM3 & -0.2742 & -1.71 & -0.2742 & -1.71 & -0.3308 & -3.87 \\
\hline $\mathrm{AM}$ & -0.0015 & -1.16 & 0.0006 & 2.09 & -0.0118 & -3.52 \\
\hline $\mathrm{AF}$ & -0.0004 & -0.15 & 0.0001 & 0.30 & -0.0015 & -7.26 \\
\hline $\mathrm{C}$ & 0.0000 & 23.59 & 0.0000 & 0.00 & 0.0000 & 5.84 \\
\hline VARM & 0.0000 & 1.34 & 0.0000 & 0.00 & 0.0000 & -0.56 \\
\hline VARF & 0.0000 & -0.12 & 0.0000 & 0.00 & 0.0000 & -0.23 \\
\hline SIGMA & 0.0041 & 47.19 & 0.0000 & 0.00 & 0.0125 & 4.00 \\
\hline THETA & 2.3623 & 11.32 & & & & \\
\hline RHOM & -0.3532 & -3.29 & & & -0.9434 & -31.26 \\
\hline RHOF & -0.0939 & -1.65 & & & -0.1164 & -3.53 \\
\hline
\end{tabular}

Notes: See table 11A.5. 


\begin{tabular}{|c|c|c|c|c|c|c|}
\hline \multirow[b]{2}{*}{ Variable } & \multicolumn{2}{|c|}{ Couples } & \multicolumn{2}{|c|}{ Spouse Died } & \multicolumn{2}{|c|}{ Single } \\
\hline & Estimate & $t$-statistic & Estimate & $t$-statistic & Estimate & $t$-statistic \\
\hline XONE1 & 0.0819 & 12.94 & 0.1150 & 5.73 & 0.0802 & 5.66 \\
\hline XONE2 & 0.0705 & 10.88 & 0.1021 & 4.35 & 0.0652 & 4.39 \\
\hline XLWLTH12 & -0.1474 & -22.15 & -0.1581 & -9.33 & -0.1583 & -13.68 \\
\hline XNWLTH12 & 0.0222 & 2.68 & 0.0058 & 0.42 & 0.0272 & 2.55 \\
\hline XQ1I12 & -0.0077 & -6.24 & -0.0100 & -2.50 & -0.0012 & -0.43 \\
\hline XQ4I12 & 0.0103 & 5.38 & 0.0032 & 0.40 & 0.0108 & 3.44 \\
\hline XHOODPF12 & -0.0014 & -0.86 & 0.0069 & 1.31 & 0.0032 & 0.91 \\
\hline XCONDPF12 & -0.0038 & -2.58 & -0.0066 & -1.20 & 0.0010 & 0.30 \\
\hline XDNHOUS12 & 0.0008 & 0.47 & 0.0104 & 2.36 & -0.0007 & -0.25 \\
\hline M_XHS12 & 0.0003 & 0.28 & 0.0044 & 1.00 & 0.0037 & 1.46 \\
\hline M_XCOLL12 & 0.0016 & 0.83 & 0.0061 & 0.88 & 0.0080 & 1.53 \\
\hline M_XAS701S & 0.0000 & 0.85 & -0.0001 & -1.13 & 0.0000 & 0.67 \\
\hline M_XAS801S & 0.0000 & 0.90 & 0.0003 & 1.62 & 0.0000 & 0.42 \\
\hline M_XAS702S & 0.0000 & 0.12 & -0.0001 & -0.90 & 0.0001 & 1.12 \\
\hline M_XAS802S & 0.0001 & 1.90 & 0.0003 & 1.69 & 0.0000 & -0.28 \\
\hline M_XNEVMARR12 & & & & & 0.0078 & 0.90 \\
\hline M_XWIDOW12 & & & & & 0.0083 & 1.04 \\
\hline M_XDIVSEP12 & & & & & 0.0069 & 0.81 \\
\hline M_XMAGEDI12 & 0.0000 & 0.86 & 0.0000 & -0.36 & 0.0000 & -0.03 \\
\hline M_XPAGEDI12 & 0.0000 & -0.34 & 0.0000 & -0.16 & -0.0001 & -1.02 \\
\hline M_XSMOKEV12 & 0.0007 & 0.49 & -0.0026 & -0.68 & 0.0016 & 0.52 \\
\hline M_XCANCER 12 & 0.0027 & 1.72 & 0.0011 & 0.28 & -0.0002 & -0.08 \\
\hline M_XHEART12 & -0.0007 & -0.63 & -0.0042 & -1.11 & -0.0007 & -0.28 \\
\hline M_XSTROKE12 & 0.0013 & 0.55 & -0.0051 & -0.92 & -0.0036 & -1.06 \\
\hline M_XLUNG12 & 0.0045 & 2.16 & -0.0056 & -1.22 & -0.0047 & -1.76 \\
\hline M_XDIABET12 & -0.0023 & -1.47 & -0.0059 & -1.39 & -0.0015 & -0.46 \\
\hline M_XHIGHBP12 & 0.0011 & 0.98 & 0.0021 & 0.66 & -0.0017 & -0.71 \\
\hline M_XARTHRT12 & -0.0039 & -2.48 & 0.0024 & 0.56 & 0.0002 & 0.09 \\
\hline M_XINCONT12 & -0.0003 & -0.15 & -0.0015 & -0.35 & 0.0005 & 0.19 \\
\hline M_XFALL12 & -0.0025 & -1.12 & 0.0076 & 1.22 & -0.0007 & -0.22 \\
\hline M_XHIPFRC12 & -0.0021 & -0.57 & -0.0069 & -0.81 & 0.0005 & 0.11 \\
\hline M_XPROXYW12 & -0.0022 & -1.00 & 0.0030 & 0.63 & 0.0006 & 0.13 \\
\hline M_XCOGIM12 & -0.0002 & -0.11 & -0.0089 & -2.49 & -0.0070 & -2.77 \\
\hline M_XPSYCH12 & 0.0004 & 0.17 & 0.0087 & 1.47 & 0.0044 & 1.07 \\
\hline M_XDEPRES12 & -0.0064 & -1.55 & 0.0109 & 1.99 & -0.0034 & -1.05 \\
\hline M_XLOBMI12 & -0.0003 & -0.05 & 0.0008 & 0.34 & 0.0024 & 0.95 \\
\hline M_XHIBMI12 & -0.0003 & -1.56 & 0.0012 & 1.76 & 0.0001 & 0.27 \\
\hline M_XSMOKNOW12 & -0.0021 & -0.85 & -0.0057 & -0.96 & 0.0002 & 0.05 \\
\hline M_XNUMADL12 & 0.0014 & 1.57 & -0.0020 & -0.89 & -0.0011 & -1.02 \\
\hline M_XNUMIADL12 & -0.0022 & -1.90 & 0.0005 & 0.14 & 0.0001 & 0.09 \\
\hline M_XDHLTH12 & 0.0031 & 2.01 & 0.0052 & 1.15 & 0.0030 & 1.10 \\
\hline M_XJCANCER23 & 0.0011 & 0.32 & 0.0015 & 0.11 & -0.0010 & -0.24 \\
\hline M_XJHEART23 & 0.0032 & 1.30 & -0.0052 & -0.45 & 0.0003 & 0.10 \\
\hline M_XJSTROKE23 & 0.0012 & 0.30 & 0.0079 & 0.71 & 0.0045 & 1.09 \\
\hline M_XILUNG23 & 0.0004 & 0.15 & -0.0257 & -1.76 & -0.0024 & -0.61 \\
\hline M_XIDIABET23 & -0.0030 & -0.90 & 0.0105 & 0.84 & -0.0007 & -0.11 \\
\hline M_XIHIGHBP23 & 0.0026 & 0.68 & 0.0003 & 0.02 & -0.0064 & -1.59 \\
\hline
\end{tabular}


(continued)

\begin{tabular}{|c|c|c|c|c|c|c|}
\hline \multirow[b]{2}{*}{ Variable } & \multicolumn{2}{|c|}{ Couples } & \multicolumn{2}{|c|}{ Spouse Died } & \multicolumn{2}{|c|}{ Single } \\
\hline & Estimate & $t$-statistic & Estimate & $t$-statistic & Estimate & $t$-statistic \\
\hline M_XIARTHRT23 & -0.0011 & -0.59 & -0.0086 & -1.40 & -0.0046 & -1.53 \\
\hline M_XJINCONT23 & -0.0005 & -0.25 & 0.0043 & 0.50 & -0.0023 & -0.92 \\
\hline M_XJFALL23 & 0.0021 & 1.05 & 0.0224 & 1.55 & -0.0033 & -1.05 \\
\hline M_XJHIPFRC23 & -0.0075 & -0.94 & -0.0264 & -1.00 & 0.0093 & 0.97 \\
\hline M_XPROXYW23 & -0.0018 & -0.83 & 0.0069 & 0.86 & -0.0038 & -1.12 \\
\hline M_XICOGIM23 & -0.0008 & -0.47 & -0.0046 & -0.41 & 0.0008 & 0.28 \\
\hline M_XIPSYCH23 & 0.0010 & 0.51 & -0.0156 & -0.74 & 0.0071 & 1.86 \\
\hline M_XIDEPRES23 & 0.0009 & 0.32 & 0.0041 & 0.55 & -0.0053 & -1.24 \\
\hline M_XBMIBT23 & -0.0027 & -2.02 & -0.0038 & -0.50 & 0.0004 & 0.15 \\
\hline M_XBMIWS23 & -0.0038 & -2.47 & -0.0055 & -0.53 & -0.0014 & -0.55 \\
\hline M_XSMOKNOW23 & 0.0020 & 0.68 & 0.0047 & 0.25 & -0.0082 & -2.11 \\
\hline M_XNUMADL23 & -0.0004 & -0.46 & -0.0011 & -0.37 & -0.0006 & -0.86 \\
\hline M_XNUMIADL23 & 0.0003 & 0.28 & -0.0077 & -2.41 & 0.0004 & 0.42 \\
\hline M_XDHLTH23 & 0.0000 & 0.01 & -0.0046 & -0.51 & 0.0000 & -0.02 \\
\hline F_XONE1 & & & & & 0.0680 & 10.83 \\
\hline F_XONE2 & & & & & 0.0547 & 8.51 \\
\hline F_XLWLTH12 & & & & & -0.1280 & -20.62 \\
\hline F_XNWLTH12 & & & & & 0.0203 & 4.26 \\
\hline F_XQ1I12 & & & & & -0.0020 & -2.31 \\
\hline F_XQ4I12 & & & & & 0.0118 & 7.73 \\
\hline F_XHOODPF12 & & & & & -0.0008 & -0.69 \\
\hline F_XCONDPF12 & & & & & -0.0031 & -2.93 \\
\hline F_XDNHOUS12 & & & & & 0.0014 & 1.31 \\
\hline F_XHS12 & 0.0022 & 1.55 & 0.0103 & 2.16 & 0.0025 & 2.84 \\
\hline F_XCOLL12 & 0.0027 & 1.35 & -0.0007 & -0.09 & 0.0036 & 1.96 \\
\hline F_XAS701S & 0.0001 & 2.35 & 0.0000 & 0.33 & 0.0000 & 0.55 \\
\hline F_XAS801S & -0.0002 & -2.04 & -0.0002 & -0.82 & 0.0000 & 0.15 \\
\hline F_XAS702S & 0.0000 & -1.16 & -0.0001 & -0.79 & 0.0000 & 1.63 \\
\hline F_XAS802S & 0.0000 & 0.30 & 0.0000 & 0.24 & 0.0000 & -0.81 \\
\hline F_XNEVMARR12 & & & & & 0.0114 & 2.38 \\
\hline F_XWIDOW12 & & & & & 0.0087 & 1.97 \\
\hline F_XDIVSEP12 & & & & & 0.0061 & 1.33 \\
\hline F_XMAGEDI12 & 0.0000 & 0.71 & 0.0000 & -0.39 & 0.0000 & 0.66 \\
\hline F_XPAGEDI12 & 0.0000 & -1.31 & -0.0001 & -1.07 & 0.0000 & 0.36 \\
\hline F_XSMOKEV12 & 0.0034 & 2.76 & 0.0063 & 1.38 & 0.0011 & 1.10 \\
\hline F_XCANCER 12 & -0.0019 & -1.10 & -0.0024 & -0.38 & -0.0010 & -0.82 \\
\hline F_XHEART12 & -0.0006 & -0.41 & 0.0038 & 1.01 & 0.0001 & 0.15 \\
\hline F_XSTROKE12 & -0.0013 & -0.52 & 0.0032 & 0.43 & -0.0009 & -0.67 \\
\hline F_XLUNG12 & -0.0001 & -0.03 & -0.0068 & -1.28 & -0.0011 & -0.85 \\
\hline F_XDIABET12 & -0.0028 & -1.66 & -0.0027 & -0.51 & -0.0015 & -1.27 \\
\hline F_XHIGHBP12 & -0.0010 & -0.82 & 0.0094 & 2.55 & -0.0006 & -0.63 \\
\hline F_XARTHRT12 & 0.0019 & 1.43 & -0.0053 & -1.13 & -0.0005 & -0.55 \\
\hline F_XINCONT12 & 0.0004 & 0.22 & 0.0012 & 0.26 & -0.0003 & -0.29 \\
\hline F_XFALL12 & 0.0026 & 1.28 & 0.0000 & 0.01 & 0.0003 & 0.27 \\
\hline $\begin{array}{l}\text { F_XHIPFRC12 } \\
\text { (continued) }\end{array}$ & 0.0034 & 0.89 & -0.0001 & -0.01 & 0.0030 & 1.80 \\
\hline
\end{tabular}


(continued)

\begin{tabular}{|c|c|c|c|c|c|c|}
\hline \multirow[b]{2}{*}{ Variable } & \multicolumn{2}{|c|}{ Couples } & \multicolumn{2}{|c|}{ Spouse Died } & \multicolumn{2}{|c|}{ Single } \\
\hline & Estimate & $t$-statistic & Estimate & $t$-statistic & Estimate & $t$-statistic \\
\hline F_XPROXYW12 & -0.0023 & -0.62 & -0.0017 & -0.25 & -0.0032 & -1.54 \\
\hline F_XCOGIM12 & -0.0011 & -0.56 & -0.0064 & -1.24 & -0.0034 & -3.27 \\
\hline F_XPSYCH12 & -0.0015 & -0.99 & -0.0009 & -0.15 & 0.0017 & 1.31 \\
\hline F_XDEPRES12 & -0.0016 & -0.74 & 0.0031 & 0.56 & -0.0020 & -1.59 \\
\hline F_XLOBMI12 & -0.0006 & -0.31 & 0.0021 & 0.96 & 0.0002 & 0.32 \\
\hline F_XHIBMI12 & -0.0005 & -2.31 & -0.0005 & -0.88 & -0.0003 & -2.14 \\
\hline F_XSMOKNOW12 & -0.0016 & -0.43 & -0.0136 & -1.83 & -0.0035 & -1.71 \\
\hline F_XNUMADL12 & 0.0023 & 2.35 & 0.0005 & 0.20 & -0.0006 & -1.44 \\
\hline F_XNUMIADL12 & 0.0006 & 0.48 & -0.0046 & -2.31 & -0.0011 & -2.45 \\
\hline F_XDHLTH12 & -0.0019 & -1.13 & 0.0003 & 0.05 & -0.0006 & -0.60 \\
\hline F_XJCANCER23 & 0.0073 & 2.04 & -0.0026 & -0.21 & -0.0066 & -2.41 \\
\hline F_XJHEART23 & 0.0029 & 1.36 & -0.0038 & -0.57 & -0.0024 & -1.77 \\
\hline F_XJSTROKE23 & 0.0012 & 0.45 & -0.0235 & -2.53 & -0.0041 & -2.04 \\
\hline F_XILUNG23 & -0.0052 & -1.48 & -0.0040 & -0.32 & 0.0012 & 0.62 \\
\hline F_XIDIABET23 & -0.0050 & -1.26 & 0.0031 & 0.28 & 0.0012 & 0.54 \\
\hline F_XIHIGHBP23 & -0.0024 & -0.93 & 0.0024 & 0.32 & -0.0007 & -0.44 \\
\hline F_XIARTHRT23 & 0.0015 & 0.79 & 0.0077 & 1.14 & 0.0006 & 0.46 \\
\hline F_XJINCONT23 & 0.0034 & 2.59 & 0.0041 & 0.86 & 0.0017 & 1.71 \\
\hline F_XJFALL23 & -0.0010 & -0.48 & -0.0074 & -1.16 & 0.0017 & 1.56 \\
\hline F_XJHIPFRC23 & 0.0034 & 0.69 & 0.0198 & 1.68 & -0.0005 & -0.26 \\
\hline F_XPROXYW23 & -0.0015 & -0.50 & -0.0001 & -0.01 & -0.0001 & -0.04 \\
\hline F_XICOGIM23 & -0.0017 & -0.67 & 0.0007 & 0.10 & -0.0036 & -2.86 \\
\hline F_XIPSYCH23 & -0.0015 & -0.60 & -0.0192 & -2.81 & 0.0014 & 0.81 \\
\hline F_XIDEPRES23 & -0.0027 & -1.22 & 0.0030 & 0.41 & -0.0023 & -1.46 \\
\hline F_XBMIBT23 & 0.0007 & 0.41 & -0.0001 & -0.02 & -0.0001 & -0.11 \\
\hline F_XBMIWS23 & -0.0010 & -0.67 & 0.0018 & 0.25 & 0.0005 & 0.56 \\
\hline F_XSMOKNOW23 & -0.0060 & -1.59 & 0.0168 & 1.60 & 0.0013 & 0.64 \\
\hline F_XNUMADL23 & -0.0017 & -2.52 & 0.0037 & 1.84 & -0.0002 & -0.46 \\
\hline F_XNUMIADL23 & 0.0022 & 2.35 & -0.0035 & -1.29 & 0.0006 & 1.42 \\
\hline F_XDHLTH23 & -0.0002 & -0.16 & -0.0094 & -1.81 & 0.0007 & 0.75 \\
\hline $\mathrm{CF} 4$ & 0.0801 & 0.06 & 0.0801 & 0.06 & -0.0320 & -0.50 \\
\hline $\mathrm{CF} 3$ & -0.1813 & -0.22 & -0.1813 & -0.22 & 0.5701 & 5.63 \\
\hline CM4 & 0.1603 & 1.18 & 0.1603 & 1.18 & 0.0101 & 0.07 \\
\hline CM3 & -0.3138 & -1.97 & -0.3138 & -1.97 & -0.5973 & -2.35 \\
\hline $\mathrm{AM}$ & -0.0027 & -2.09 & 0.0014 & 3.13 & -0.0038 & -2.89 \\
\hline $\mathrm{AF}$ & -0.0018 & -0.66 & 0.0009 & 0.93 & -0.0016 & -10.38 \\
\hline $\mathrm{C}$ & 0.0000 & 24.84 & 0.0000 & 4.23 & 0.0000 & 6.13 \\
\hline VARM & 0.0000 & -0.51 & 0.0000 & 0.72 & 0.0000 & -1.45 \\
\hline VARF & 0.0000 & -0.38 & 0.0000 & -0.67 & 0.0000 & 1.75 \\
\hline SIGMA & 0.0055 & 49.68 & 0.0000 & 4.23 & 0.0061 & 7.47 \\
\hline THETA & 2.5207 & 18.63 & & & & \\
\hline RHOM & -0.4243 & -7.48 & & & -0.6292 & -5.06 \\
\hline RHOF & -0.2826 & -5.64 & & & -0.2579 & -6.27 \\
\hline
\end{tabular}

Notes: See table 11A.5. 


\begin{tabular}{|c|c|c|c|c|c|c|c|}
\hline & \multirow{2}{*}{$\begin{array}{l}\text { Wealth } \\
\text { (DF) }\end{array}$} & \multicolumn{2}{|c|}{ Total } & \multicolumn{2}{|c|}{ Nonliquid } & \multicolumn{2}{|c|}{ Liquid } \\
\hline & & CHISQ & $p$-value & CHISQ & $p$-value & CHISQ & $p$-value \\
\hline \multicolumn{8}{|l|}{ Couples } \\
\hline All & 97 & 468.6 & 0.000 & 355.1 & 0.000 & 377.2 & 0.000 \\
\hline All less SES & 90 & 219.4 & 0.0000 & 168.1 & 0.0000 & 243.9 & 0.0000 \\
\hline All male & 52 & 279.7 & 0.0000 & 232.5 & 0.0000 & 215.9 & 0.0000 \\
\hline All male less SES & 45 & 109.1 & 0.0000 & 80.0 & 0.0010 & 117.4 & 0.0000 \\
\hline All female & 52 & 277.2 & 0.0000 & 218.9 & 0.0000 & 200.1 & 0.0000 \\
\hline All female less SES & 45 & 90.0 & 0.0001 & 76.9 & 0.0021 & 104.9 & 0.0000 \\
\hline All less prevalence & 57 & 301.2 & 0.0000 & 224.6 & 0.0000 & 223.8 & 0.0000 \\
\hline All less incidence & 57 & 358.4 & 0.0000 & 259.8 & 0.0000 & 266.1 & 0.0000 \\
\hline Only SES & 7 & 123.4 & 0.0000 & 119.6 & 0.0000 & 69.8 & 0.0000 \\
\hline Only male demographic & 5 & 6.9 & 0.2292 & 4.1 & 0.5382 & 8.9 & 0.1129 \\
\hline Only female demographic & 5 & 5.2 & 0.3971 & 10.6 & 0.0590 & 4.9 & 0.4261 \\
\hline Only male prevalence & 20 & 58.8 & 0.0000 & 34.2 & 0.0246 & 69.9 & 0.0000 \\
\hline Only female prevalence & 20 & 57.2 & 0.0000 & 33.3 & 0.0310 & 45.8 & 0.0009 \\
\hline Only male incidence & 20 & 38.9 & 0.0070 & 33.2 & 0.0324 & 44.0 & 0.0015 \\
\hline Only female incidence & 20 & 31.1 & 0.0540 & 22.7 & 0.3060 & 53.5 & 0.0001 \\
\hline \multicolumn{8}{|l|}{ Spouse died } \\
\hline All & 97 & 672.2 & 0.0000 & 682.7 & 0.0000 & 700.2 & 0.0000 \\
\hline All less SES & 90 & 524.0 & 0.0000 & 645.3 & 0.0000 & 576.9 & 0.0000 \\
\hline All male & 52 & 268.2 & 0.0000 & 370.0 & 0.0000 & 224.6 & 0.0000 \\
\hline All male less SES & 45 & 244.1 & 0.0000 & 350.1 & 0.0000 & 161.4 & 0.0000 \\
\hline All female & 52 & 250.0 & 0.0000 & 181.5 & 0.0000 & 358.8 & 0.0000 \\
\hline All female less SES & 45 & 164.7 & 0.0000 & 142.7 & 0.0000 & 256.6 & 0.0000 \\
\hline All less prevalence & 57 & 223.4 & 0.0000 & 269.2 & 0.0000 & 361.1 & 0.0000 \\
\hline All less incidence & 57 & 240.4 & 0.0000 & 234.9 & 0.0000 & 277.3 & 0.0000 \\
\hline Only SES & 7 & 60.0 & 0.0000 & 34.2 & 0.0000 & 37.0 & 0.0000 \\
\hline Only male demographic & 5 & 7.8 & 0.1692 & 8.2 & 0.1473 & 12.7 & 0.0259 \\
\hline Only female demographic & 5 & 7.3 & 0.2020 & 5.6 & 0.3479 & 16.2 & 0.0063 \\
\hline Only male prevalence & 20 & 69.5 & 0.0000 & 65.8 & 0.0000 & 66.3 & 0.0000 \\
\hline Only female prevalence & 20 & 56.0 & 0.0000 & 49.9 & 0.0002 & 38.2 & 0.0085 \\
\hline Only male incidence & 20 & 71.7 & 0.0000 & 105.5 & 0.0000 & 41.5 & 0.0021 \\
\hline Only female incidence & 20 & 74.6 & 0.0000 & 65.0 & 0.0000 & 115.2 & 0.0000 \\
\hline \multicolumn{8}{|l|}{ Singles } \\
\hline All & 110 & 384.8 & 0.0000 & 353.6 & 0.0000 & 301.4 & 0.0000 \\
\hline All less SES & 96 & 118.5 & 0.0594 & 139.9 & 0.0023 & 129.8 & 0.0124 \\
\hline All male & 55 & 129.2 & 0.0000 & 139.4 & 0.0000 & 91.2 & 0.0015 \\
\hline All male less SES & 48 & 43.3 & 0.6639 & 60.3 & 0.1094 & 59.4 & 0.1261 \\
\hline All female & 55 & 255.6 & 0.0000 & 214.1 & 0.0000 & 210.1 & 0.0000 \\
\hline All female less SES & 48 & 75.2 & 0.0073 & 79.6 & 0.0028 & 70.4 & 0.0192 \\
\hline All less prevalence & 70 & 307.3 & 0.0000 & 296.7 & 0.0000 & 201.4 & 0.0000 \\
\hline All less incidence & 70 & 287.4 & 0.0000 & 275.7 & 0.0000 & 222.0 & 0.0000 \\
\hline Only Male SES & 7 & 30.2 & 0.0001 & 47.0 & 0.0000 & 16.4 & 0.0215 \\
\hline Only female SES & 7 & 153.3 & 0.0000 & 129.3 & 0.0000 & 89.8 & 0.0000 \\
\hline Only male demographic & 8 & 4.1 & 0.8446 & 6.5 & 0.5875 & 5.8 & 0.6742 \\
\hline Only female demographic & 8 & 13.9 & 0.0842 & 14.9 & 0.0603 & 16.3 & 0.0379 \\
\hline Only male prevalence & 20 & 19.0 & 0.5251 & 30.6 & 0.0613 & 30.8 & 0.0580 \\
\hline Only female prevalence & 20 & 26.4 & 0.1536 & 30.6 & 0.0601 & 26.3 & 0.1559 \\
\hline Only male incidence & 20 & 19.4 & 0.4955 & 23.3 & 0.2747 & 19.7 & 0.4759 \\
\hline Only female incidence & 20 & 41.0 & 0.0037 & 40.7 & 0.0040 & 30.2 & 0.0663 \\
\hline
\end{tabular}




\begin{tabular}{|c|c|c|c|c|c|c|c|}
\hline & \multirow{2}{*}{$\begin{array}{c}\text { Wealth } \\
\text { (DF) }\end{array}$} & \multicolumn{2}{|c|}{ Total } & \multicolumn{2}{|c|}{ Nonliquid } & \multicolumn{2}{|c|}{ Liquid } \\
\hline & & CHISQ & $p$-value & CHISQ & $p$-value & CHISQ & $p$-value \\
\hline \multicolumn{8}{|l|}{ Incidence } \\
\hline \multicolumn{8}{|l|}{ Couple } \\
\hline Male & 20 & 20.01 & 0.4575 & 16.03 & 0.7146 & 18.04 & 0.5847 \\
\hline Female & 20 & 36.65 & 0.0129 & 33.87 & 0.0270 & 37.47 & 0.0103 \\
\hline Male \& female & 40 & 59.47 & 0.0243 & 51.44 & 0.1061 & 57.55 & 0.0356 \\
\hline \multicolumn{8}{|l|}{ Spouse died } \\
\hline Male & 20 & 22.65 & 0.3061 & 51.36 & 0.0001 & 50.99 & 0.0002 \\
\hline Female & 20 & 23.02 & 0.2878 & 16.99 & 0.6533 & 30.71 & 0.0591 \\
\hline Male \& female & 40 & 62.86 & 0.0120 & 75.29 & 0.0006 & 88.09 & 0.0000 \\
\hline \multicolumn{8}{|l|}{ Single } \\
\hline Male & 20 & 18.78 & 0.5362 & 30.01 & 0.0696 & 24.38 & 0.2263 \\
\hline Female & 20 & 32.65 & 0.0369 & 53.88 & 0.0001 & 33.03 & 0.0335 \\
\hline Male \& female & 40 & 51.43 & 0.1064 & 83.89 & 0.0001 & 57.41 & 0.0366 \\
\hline \multicolumn{8}{|l|}{ Prevalence } \\
\hline \multicolumn{8}{|l|}{ Couple } \\
\hline Male & 20 & 27.85 & 0.1130 & 47.88 & 0.0004 & 45.58 & 0.0009 \\
\hline Female & 20 & 24.73 & 0.2120 & 14.50 & 0.8041 & 38.30 & 0.0081 \\
\hline Male \& female & 40 & 58.87 & 0.0275 & 72.18 & 0.0014 & 111.42 & 0.0000 \\
\hline \multicolumn{8}{|l|}{ Spouse died } \\
\hline Male & 20 & 20.72 & 0.4137 & 29.71 & 0.0746 & 32.32 & 0.0401 \\
\hline Female & 20 & 13.58 & 0.8511 & 16.95 & 0.6559 & 34.18 & 0.0249 \\
\hline Male \& female & 40 & 49.79 & 0.1607 & 74.75 & 0.0007 & 76.24 & 0.0005 \\
\hline \multicolumn{8}{|l|}{ Single } \\
\hline Male & 20 & 17.67 & 0.6093 & 18.07 & 0.5830 & 19.62 & 0.4818 \\
\hline Female & 20 & 35.84 & 0.0161 & 27.75 & 0.1155 & 53.83 & 0.0001 \\
\hline Male \& female & 40 & 53.51 & 0.0749 & 45.82 & 0.2436 & 73.45 & 0.0010 \\
\hline \multicolumn{8}{|c|}{ Incidence and prevalence } \\
\hline \multicolumn{8}{|c|}{ Couple } \\
\hline Male & 40 & 50.91 & 0.1157 & 70.14 & 0.0022 & 78.51 & 0.0003 \\
\hline Female & 40 & 72.00 & 0.0014 & 54.30 & 0.0651 & 88.95 & 0.0000 \\
\hline Male \& female & 80 & 126.80 & 0.0007 & 124.70 & 0.0010 & 191.82 & 0.0000 \\
\hline \multicolumn{8}{|l|}{ Spouse died } \\
\hline Male & 40 & 61.81 & 0.0150 & 104.07 & 0.0000 & 100.39 & 0.0000 \\
\hline Female & 40 & 51.95 & 0.0977 & 37.35 & 0.5904 & 70.08 & 0.0023 \\
\hline Male \& female & 80 & 122.23 & 0.0017 & 174.89 & 0.0000 & 190.94 & 0.0000 \\
\hline \multicolumn{8}{|l|}{ Single } \\
\hline Male & 40 & 35.35 & 0.6796 & 40.58 & 0.4448 & 49.87 & 0.1362 \\
\hline Female & 40 & 80.77 & 0.0001 & 84.39 & 0.0001 & 79.31 & 0.0002 \\
\hline Male \& female & 80 & 116.11 & 0.0052 & 124.96 & 0.0010 & 129.18 & 0.0004 \\
\hline
\end{tabular}


Income Regressions-( $t$-statistics)

\begin{tabular}{|c|c|c|c|c|c|c|}
\hline \multirow[b]{2}{*}{ Variable } & \multicolumn{2}{|c|}{ Couples } & \multicolumn{2}{|c|}{ Spouse Died } & \multicolumn{2}{|c|}{ Single } \\
\hline & Estimate & $t$-statistic & Estimate & $t$-statistic & Estimate & $t$-statistic \\
\hline ONE & -0.1417 & -5.75 & -0.0864 & -0.79 & -0.1386 & -2.23 \\
\hline WLTH12 & 0.1077 & 6.82 & 0.1249 & 1.41 & 0.1061 & 2.57 \\
\hline Q1I12 & 0.0799 & 12.32 & 0.1009 & 3.42 & 0.0388 & 2.15 \\
\hline Q4I12 & -0.0882 & -14.25 & -0.1171 & -3.05 & -0.0908 & -6.83 \\
\hline HOODPF12 & 0.0019 & 0.23 & -0.0054 & -0.13 & 0.0261 & 1.55 \\
\hline CONDPF12 & -0.0028 & -0.34 & -0.0904 & -2.31 & -0.0304 & -1.79 \\
\hline DNHOUS12 & 0.0019 & 0.29 & 0.0191 & 0.60 & 0.0051 & 0.39 \\
\hline M_HS12 & -0.0013 & -0.22 & 0.0210 & 0.70 & 0.0053 & 0.41 \\
\hline M_COLL12 & 0.0293 & 4.59 & 0.0177 & 0.46 & 0.0040 & 0.23 \\
\hline M_AS70S & 0.0000 & 0.49 & 0.0000 & 0.09 & -0.0001 & -0.56 \\
\hline M_AS80S & 0.0001 & 0.52 & -0.0004 & -0.56 & -0.0002 & -0.65 \\
\hline M_NEVMARR 12 & & & & & 0.0925 & 2.18 \\
\hline M_WIDOW12 & & & & & 0.1141 & 2.85 \\
\hline M_DIVSEP12 & & & & & 0.1032 & 2.47 \\
\hline M_MAGEDI12 & 0.0002 & 1.27 & -0.0010 & -1.56 & 0.0000 & -0.13 \\
\hline M_PAGEDI12 & 0.0001 & 0.49 & -0.0002 & -0.26 & 0.0003 & 0.94 \\
\hline M_SMOKEV12 & 0.0087 & 1.60 & 0.0223 & 0.75 & -0.0190 & -1.47 \\
\hline M_CANCER 12 & 0.0073 & 1.19 & 0.0109 & 0.36 & 0.0331 & 2.18 \\
\hline M_HEART12 & -0.0008 & -0.17 & -0.0304 & -1.16 & 0.0014 & 0.12 \\
\hline M_STROKE12 & -0.0107 & -1.20 & -0.0404 & -1.08 & -0.0122 & -0.62 \\
\hline M_LUNG12 & -0.0005 & -0.07 & -0.0307 & -0.99 & -0.0072 & -0.49 \\
\hline M_DIABET12 & 0.0032 & 0.44 & -0.0709 & -2.28 & -0.0145 & -0.88 \\
\hline M_HIGHBP12 & 0.0134 & 2.82 & 0.0456 & 1.89 & 0.0010 & 0.08 \\
\hline M_ARTHRT12 & 0.0045 & 0.73 & -0.0212 & -0.65 & 0.0211 & 1.52 \\
\hline M_INCONT12 & -0.0017 & -0.20 & -0.0273 & -0.82 & -0.0006 & -0.03 \\
\hline M_FALL12 & -0.0061 & -0.52 & 0.0800 & 1.75 & -0.0021 & -0.09 \\
\hline M_HIPFRC12 & -0.0015 & -0.11 & -0.0192 & -0.30 & -0.0121 & -0.41 \\
\hline M_PROXYW12 & -0.0193 & -2.19 & -0.0173 & -0.57 & -0.0052 & -0.14 \\
\hline M_COGIM12 & 0.0047 & 0.66 & 0.0041 & 0.15 & 0.0083 & 0.54 \\
\hline M_PSYCH12 & 0.0056 & 0.66 & -0.0334 & -0.77 & -0.0060 & -0.33 \\
\hline M_DEPRES12 & -0.0245 & -1.77 & 0.0050 & 0.12 & -0.0187 & -1.02 \\
\hline M_LOBMI12 & -0.0063 & -0.70 & -0.0262 & -1.50 & -0.0244 & -1.55 \\
\hline M_HIBMI12 & 0.0006 & 0.67 & 0.0031 & 0.67 & -0.0016 & -0.69 \\
\hline M_SMOKNOW12 & 0.0139 & 1.20 & 0.0429 & 1.08 & 0.0316 & 1.37 \\
\hline M_NUMADL12 & -0.0054 & -1.67 & -0.0037 & -0.34 & 0.0013 & 0.19 \\
\hline M_NUMIADL12 & 0.0000 & -0.01 & 0.0103 & 0.86 & 0.0059 & 0.66 \\
\hline M_DHLTH12 & -0.0090 & -1.47 & 0.0394 & 1.30 & -0.0117 & -0.81 \\
\hline M_JCANCER23 & -0.0018 & -0.18 & -0.0330 & -0.21 & -0.0077 & -0.35 \\
\hline M_JHEART23 & -0.0042 & -0.56 & 0.1318 & 1.59 & 0.0118 & 0.64 \\
\hline M_JSTROKE23 & -0.0072 & -0.59 & 0.0482 & 0.25 & -0.0149 & -0.59 \\
\hline M_JLUNG23 & -0.0041 & -0.30 & 0.0001 & 0.00 & 0.0210 & 0.62 \\
\hline M_IDIABET23 & -0.0216 & -1.50 & -0.3218 & -1.49 & -0.0335 & -0.93 \\
\hline M_IHIGHBP23 & -0.0123 & -1.17 & 0.1396 & 0.83 & 0.0081 & 0.36 \\
\hline M_IARTHRT23 & -0.0161 & -2.10 & -0.2789 & -3.54 & 0.0138 & 0.69 \\
\hline $\begin{array}{l}\text { M_JINCONT23 } \\
\text { (continued) }\end{array}$ & -0.0043 & -0.58 & 0.0622 & 0.84 & 0.0032 & 0.20 \\
\hline
\end{tabular}



(continued)

\begin{tabular}{|c|c|c|c|c|c|c|}
\hline \multirow[b]{2}{*}{ Variable } & \multicolumn{2}{|c|}{ Couples } & \multicolumn{2}{|c|}{ Spouse Died } & \multicolumn{2}{|c|}{ Single } \\
\hline & Estimate & $t$-statistic & Estimate & $t$-statistic & Estimate & $t$-statistic \\
\hline M_JFALL23 & -0.0018 & -0.21 & 0.1214 & 0.98 & -0.0080 & -0.40 \\
\hline M_JHIPFRC23 & -0.0315 & -1.44 & -0.0491 & -0.34 & 0.0231 & 0.51 \\
\hline M_PROXYW23 & -0.0028 & -0.30 & 0.1074 & 1.70 & 0.0230 & 0.88 \\
\hline M_ICOGIM23 & 0.0042 & 0.58 & 0.0835 & 1.09 & 0.0199 & 1.17 \\
\hline M_IPSYCH 23 & 0.0048 & 0.56 & 0.0548 & 0.47 & -0.0164 & -0.40 \\
\hline M_IDEPRES 23 & -0.0119 & -0.91 & -0.0135 & -0.23 & 0.0261 & 0.96 \\
\hline M_BMIBT23 & 0.0068 & 1.09 & -0.0380 & -0.86 & 0.0219 & 1.53 \\
\hline M_BMIWS23 & -0.0026 & -0.39 & 0.0709 & 0.87 & -0.0108 & -0.77 \\
\hline M_SMOKNOW23 & -0.0117 & -0.85 & -0.1375 & -1.68 & -0.0327 & -1.32 \\
\hline M_NUMADL23 & -0.0036 & -1.18 & -0.0188 & -0.61 & -0.0154 & -2.58 \\
\hline M_NUMIADL23 & 0.0081 & 2.05 & -0.0286 & -0.97 & 0.0131 & 1.76 \\
\hline M_DHLTH23 & 0.0015 & 0.25 & 0.0011 & 0.02 & -0.0138 & -1.02 \\
\hline F_ONE & & & & & -0.1196 & -3.13 \\
\hline F_WLTH12 & & & & & 0.0869 & 4.05 \\
\hline F_Q1I12 & & & & & 0.0395 & 6.34 \\
\hline F_Q4I12 & & & & & -0.0967 & -14.66 \\
\hline F_HOODPF12 & & & & & 0.0012 & 0.16 \\
\hline F_CONDPF12 & & & & & -0.0037 & -0.49 \\
\hline F_DNHOUS12 & & & & & 0.0056 & 0.98 \\
\hline F_HS12 & 0.0044 & 0.69 & 0.0250 & 0.88 & 0.0184 & 3.33 \\
\hline F_COLL12 & 0.0126 & 1.89 & 0.0601 & 1.43 & 0.0275 & 3.54 \\
\hline F_AS70S & 0.0000 & 0.08 & -0.0002 & -0.47 & 0.0000 & 0.14 \\
\hline F_AS 80 S & 0.0000 & -0.19 & 0.0007 & 0.78 & 0.0001 & 0.68 \\
\hline F_NEVMARR12 & & & & & 0.0724 & 2.16 \\
\hline F_WIDOW 12 & & & & & 0.0589 & 1.84 \\
\hline F_DIVSEP12 & & & & & 0.0552 & 1.67 \\
\hline F_MAGEDI12 & 0.0002 & 1.17 & 0.0004 & 0.72 & 0.0002 & 1.14 \\
\hline F_PAGEDI12 & 0.0002 & 1.26 & 0.0002 & 0.26 & -0.0001 & -0.47 \\
\hline F_SMOKEV12 & 0.0059 & 1.17 & -0.0297 & -1.10 & 0.0079 & 1.44 \\
\hline F_CANCER 12 & 0.0104 & 1.47 & -0.0399 & -1.08 & 0.0105 & 1.57 \\
\hline F_HEART12 & 0.0070 & 1.24 & -0.0061 & -0.22 & -0.0016 & -0.29 \\
\hline F_STROKE12 & 0.0271 & 2.57 & -0.0160 & -0.37 & -0.0008 & -0.09 \\
\hline F_LUNG12 & -0.0058 & -0.70 & 0.0561 & 1.41 & 0.0031 & 0.39 \\
\hline F_DIABET12 & 0.0144 & 1.83 & 0.0003 & 0.01 & 0.0021 & 0.26 \\
\hline F_HIGHBP12 & 0.0093 & 1.98 & -0.0234 & -0.96 & 0.0003 & 0.07 \\
\hline F_ARTHRT12 & 0.0063 & 1.11 & -0.0663 & -2.31 & 0.0006 & 0.10 \\
\hline F_INCONT12 & 0.0042 & 0.70 & 0.0280 & 0.84 & -0.0005 & -0.08 \\
\hline F_FALL12 & 0.0117 & 1.40 & -0.0098 & -0.22 & 0.0008 & 0.10 \\
\hline F_HIPFRC12 & 0.0435 & 3.59 & -0.0526 & -0.97 & -0.0031 & -0.32 \\
\hline F_PROXYW12 & 0.0007 & 0.06 & -0.0636 & -1.14 & -0.0005 & -0.04 \\
\hline F_COGIM12 & 0.0183 & 2.32 & -0.0273 & -0.93 & 0.0010 & 0.15 \\
\hline F_PSYCH12 & 0.0027 & 0.41 & -0.0275 & -0.68 & 0.0082 & 1.07 \\
\hline F_DEPRES12 & -0.0043 & -0.46 & -0.0404 & -0.99 & -0.0010 & -0.13 \\
\hline F_LOBMI12 & 0.0039 & 0.99 & -0.0079 & -0.58 & 0.0017 & 0.46 \\
\hline F_HIBMI12 & -0.0006 & -0.89 & -0.0017 & -0.28 & 0.0006 & 0.66 \\
\hline F_SMOKNOW12 & 0.0079 & 0.44 & -0.0286 & -0.49 & -0.0013 & -0.11 \\
\hline F_NUMADL12 & 0.0036 & 1.10 & 0.0289 & 1.73 & -0.0026 & -0.94 \\
\hline
\end{tabular}


(continued)

\begin{tabular}{|c|c|c|c|c|c|c|}
\hline \multirow[b]{2}{*}{ Variable } & \multicolumn{2}{|c|}{ Couples } & \multicolumn{2}{|c|}{ Spouse Died } & \multicolumn{2}{|c|}{ Single } \\
\hline & Estimate & $t$-statistic & Estimate & $t$-statistic & Estimate & $t$-statistic \\
\hline F_NUMIADL12 & -0.0074 & -1.73 & -0.0039 & -0.25 & 0.0001 & 0.04 \\
\hline F_DHLTH12 & -0.0050 & -0.77 & 0.0368 & 1.21 & 0.0027 & 0.42 \\
\hline F_JCANCER 23 & 0.0064 & 0.47 & -0.0632 & -0.89 & -0.0025 & -0.18 \\
\hline F_JHEART23 & -0.0165 & -1.92 & -0.0496 & -1.10 & -0.0163 & -2.08 \\
\hline F_JSTROKE23 & -0.0189 & -1.46 & -0.0688 & -0.95 & 0.0083 & 0.64 \\
\hline F_JLUNG23 & -0.0075 & -0.43 & 0.0216 & 0.18 & -0.0003 & -0.02 \\
\hline F_IDIABET23 & -0.0025 & -0.14 & 0.0516 & 0.58 & -0.0036 & -0.23 \\
\hline F_IHIGHBP23 & 0.0221 & 1.98 & -0.0730 & -1.32 & 0.0091 & 0.86 \\
\hline F_IARTHRT23 & 0.0095 & 1.24 & 0.0417 & 0.80 & -0.0062 & -0.85 \\
\hline F_JINCONT23 & -0.0037 & -0.64 & -0.0334 & -0.91 & 0.0056 & 0.89 \\
\hline F_JFALL23 & 0.0009 & 0.13 & 0.0384 & 0.87 & -0.0040 & -0.58 \\
\hline F_JHIPFRC23 & -0.0325 & -1.46 & -0.0973 & -0.95 & 0.0070 & 0.49 \\
\hline F_PROXYW23 & 0.0005 & 0.05 & 0.1906 & 3.18 & -0.0135 & -1.29 \\
\hline F_ICOGIM23 & -0.0009 & -0.10 & -0.0727 & -1.75 & -0.0039 & -0.53 \\
\hline F_IPSYCH23 & -0.0023 & -0.25 & -0.0264 & -0.66 & -0.0016 & -0.13 \\
\hline F_IDEPRES23 & -0.0082 & -0.71 & 0.0403 & 0.95 & 0.0091 & 0.85 \\
\hline F_BMIBT23 & -0.0172 & -2.74 & 0.0032 & 0.09 & 0.0008 & 0.11 \\
\hline F_BMIWS23 & -0.0084 & -1.33 & 0.0236 & 0.63 & -0.0035 & -0.53 \\
\hline F_SMOKNOW23 & -0.0056 & -0.30 & 0.0571 & 0.73 & -0.0128 & -0.97 \\
\hline F_NUMADL23 & -0.0025 & -0.87 & -0.0088 & -0.64 & 0.0006 & 0.24 \\
\hline F_NUMIADL23 & -0.0010 & -0.26 & -0.0165 & -0.93 & 0.0049 & 1.61 \\
\hline F_DHLTH23 & -0.0016 & -0.25 & -0.0665 & -1.86 & -0.0124 & -1.95 \\
\hline
\end{tabular}


Table 11A.11 Mobility, Ownership, Neighborhood, and Dwelling Condition Regressions-( $t$-statistics)

\begin{tabular}{|c|c|c|c|c|}
\hline \multirow[b]{2}{*}{ Variable } & \multicolumn{2}{|c|}{ Females } & \multicolumn{2}{|c|}{ Males } \\
\hline & Coefficient & $t$-statistic & Coefficient & $t$-statistic \\
\hline \multicolumn{5}{|c|}{ Changed Residence Regressions } \\
\hline one1 & -8.0824 & -5.1883 & -8.4228 & -5.5322 \\
\hline one2 & -3.5406 & -3.2190 & -3.3344 & -3.0886 \\
\hline $\operatorname{logm} 1$ & 2.0472 & 4.1790 & 2.1521 & 4.4979 \\
\hline $\log m 2$ & 0.5848 & 1.7574 & 0.5224 & 1.6023 \\
\hline q1wb12 & 0.2458 & 4.1263 & 0.2213 & 3.7980 \\
\hline q4wb12 & -0.1640 & -2.5800 & -0.1952 & -3.1669 \\
\hline q1ib12 & 0.0881 & 1.5198 & 0.0965 & 1.7090 \\
\hline q4ib12 & 0.1086 & 1.8830 & 0.1300 & 2.3259 \\
\hline hoodpf12 & 0.0351 & 0.4949 & 0.0246 & 0.3560 \\
\hline condpf12 & -0.0950 & -1.3343 & -0.0855 & -1.2402 \\
\hline cwlth23 & -0.5547 & -2.9274 & -0.5864 & -3.1662 \\
\hline male12 & -0.0706 & -1.0036 & -0.0728 & -1.0355 \\
\hline single12 & 0.3399 & 4.9781 & 0.3471 & 4.1435 \\
\hline spdied 23 & 0.4072 & 3.1407 & 0.4890 & 3.3585 \\
\hline mspdie23 & 0.2545 & 1.4573 & 0.2889 & 1.6484 \\
\hline adl12 & -0.0159 & -0.6746 & -0.0410 & -1.7200 \\
\hline iadl12 & 0.0643 & 2.2692 & 0.0382 & 1.3670 \\
\hline dhlth12 & -0.0307 & -0.5561 & 0.0888 & 1.6706 \\
\hline adl23 & 0.0454 & 2.3124 & 0.0549 & 2.8570 \\
\hline iadl23 & 0.0429 & 1.8005 & 0.0539 & 2.2981 \\
\hline dhlth23 & 0.0003 & 0.0062 & -0.0551 & -1.0606 \\
\hline hmown 23 & & & & \\
\hline hoodpf 23 & & & & \\
\hline sadl12 & 0.0097 & 0.2181 & 0.0437 & 1.0901 \\
\hline siadl12 & -0.1377 & -2.4472 & -0.0614 & -1.1688 \\
\hline sdhlth12 & 0.1103 & 1.1330 & -0.2603 & -2.6730 \\
\hline $\operatorname{sad} 123$ & 0.0389 & 0.7989 & 0.0780 & 1.7261 \\
\hline siadl23 & 0.0597 & 0.9476 & -0.0663 & -1.0395 \\
\hline sdhlth23 & -0.0846 & -0.7577 & 0.1738 & 1.6609 \\
\hline Likelihood & \multicolumn{2}{|c|}{$-2,080.6$} & \multicolumn{2}{|c|}{$-2,187.5$} \\
\hline \multicolumn{5}{|l|}{ Observations } \\
\hline Negative & \multicolumn{2}{|c|}{$5,395(88.47)$} & \multicolumn{2}{|c|}{$6,019(89.21)$} \\
\hline Positive & \multicolumn{2}{|c|}{$703(11.53)$} & \multicolumn{2}{|c|}{728 (10.79) } \\
\hline \multicolumn{5}{|c|}{ Home Ownership_Regressions } \\
\hline one1 & 7.6815 & 1.7802 & 5.1103 & 1.1990 \\
\hline one2 & -2.1898 & -0.7730 & -1.2400 & -0.4581 \\
\hline $\operatorname{logm} 1$ & -2.3714 & -1.7483 & -1.5396 & -1.1488 \\
\hline $\log 2$ & 0.6749 & 0.7907 & 0.4041 & 0.4973 \\
\hline q1wb12 & -1.0613 & -5.2262 & -1.1041 & -5.4193 \\
\hline q4wb12 & 1.1765 & 7.0422 & 1.0881 & 6.7074 \\
\hline q1ib12 & -0.0290 & -0.1684 & -0.0662 & -0.3924 \\
\hline q4ib12 & 0.0937 & 0.6125 & 0.1012 & 0.6812 \\
\hline hoodpf12 & -0.1658 & -0.7884 & -0.1677 & -0.8208 \\
\hline condpf 12 & 0.2148 & 1.0574 & 0.2051 & 1.0496 \\
\hline cwlth23 & 2.3604 & 5.2032 & 2.1317 & 4.8227 \\
\hline
\end{tabular}


Table 11A.11

(continued)

\begin{tabular}{|c|c|c|c|c|}
\hline \multirow[b]{2}{*}{ Variable } & \multicolumn{2}{|c|}{ Females } & \multicolumn{2}{|c|}{ Males } \\
\hline & Coefficient & $t$-statistic & Coefficient & $t$-statistic \\
\hline male12 & 0.0218 & 0.1130 & -0.0011 & -.0058 \\
\hline single12 & -0.8657 & -5.5954 & -0.8716 & -4.0723 \\
\hline spdied 23 & -0.0252 & -0.0885 & -0.0496 & -0.1491 \\
\hline mspdie23 & -0.5329 & -1.2507 & -0.5408 & -1.2679 \\
\hline adl12 & -0.0116 & -0.1682 & -0.0333 & -0.4443 \\
\hline iadl12 & -0.1099 & -1.2344 & -0.1499 & -1.5601 \\
\hline dhlth12 & -0.0646 & -0.4219 & 0.0686 & 0.4644 \\
\hline $\operatorname{ad} 123$ & 0.0338 & 0.6406 & 0.0291 & 0.5583 \\
\hline $\operatorname{iadl} 23$ & -0.1331 & -1.9536 & -0.1406 & -2.0826 \\
\hline dhlth23 & -0.1977 & -1.3659 & -0.2537 & -1.7724 \\
\hline \multicolumn{5}{|l|}{ hmown 23} \\
\hline \multicolumn{5}{|l|}{ hoodpf23 } \\
\hline \multicolumn{5}{|l|}{ sadl12 } \\
\hline \multicolumn{5}{|l|}{ siadl12 } \\
\hline \multicolumn{5}{|l|}{ sdhlth12 } \\
\hline \multicolumn{5}{|l|}{$\operatorname{sad} 23$} \\
\hline \multicolumn{5}{|l|}{$\operatorname{siad123}$} \\
\hline \multicolumn{5}{|l|}{ sdhlth23 } \\
\hline Likelihood & \multicolumn{2}{|c|}{-297.19} & \multicolumn{2}{|c|}{-312.63} \\
\hline \multicolumn{5}{|l|}{ Observations } \\
\hline Negative & \multicolumn{2}{|c|}{$510(72.55)$} & \multicolumn{2}{|c|}{$521(71.57)$} \\
\hline Positive & \multicolumn{2}{|c|}{$193(27.45)$} & \multicolumn{2}{|c|}{$207(28.43)$} \\
\hline \multicolumn{5}{|c|}{ Neighborhood_Regressions } \\
\hline one1 & -5.1638 & -1.0797 & -4.5901 & -0.9643 \\
\hline one2 & 0.2757 & 0.0596 & 2.9740 & 0.6733 \\
\hline $\log m 1$ & 0.8645 & 0.5791 & 0.7609 & 0.5103 \\
\hline $\operatorname{logm} 2$ & -0.8698 & -0.6188 & -1.6126 & -1.1976 \\
\hline q1wb12 & 0.1013 & 0.5063 & 0.0948 & 0.4845 \\
\hline q4wb12 & -0.2939 & -0.9384 & -0.3117 & -1.0448 \\
\hline q1ib12 & 0.1348 & 0.7182 & 0.1480 & 0.8100 \\
\hline q4ib12 & -0.1193 & -0.4647 & -0.1579 & -0.6348 \\
\hline hoodpf12 & 0.8861 & 4.6151 & 0.8985 & 4.8188 \\
\hline condpf12 & -0.2322 & -0.9571 & -0.2772 & -1.1564 \\
\hline cwlth23 & -0.7506 & -0.9264 & -0.7756 & -0.9988 \\
\hline male12 & 0.0804 & 0.3313 & 0.0758 & 0.3122 \\
\hline single12 & 0.6373 & 2.0210 & 0.4454 & 1.3979 \\
\hline spdied 23 & 0.4967 & 1.1126 & 0.3041 & 0.6549 \\
\hline mspdie23 & -0.2941 & -0.4464 & -0.2635 & -0.3990 \\
\hline adl12 & 0.0176 & 0.2351 & -0.0175 & -0.2305 \\
\hline iadl12 & -0.0031 & -0.0374 & 0.0065 & 0.0787 \\
\hline dhlth12 & 0.0773 & 0.4279 & 0.0041 & 0.0231 \\
\hline $\operatorname{adl} 23$ & 0.0088 & 0.1523 & 0.0196 & 0.3490 \\
\hline $\operatorname{iadl} 23$ & 0.0110 & 0.1594 & -0.0004 & -0.0062 \\
\hline dhlth23 & 0.3240 & 1.7316 & 0.3610 & 1.9610 \\
\hline hmown23 & 0.2023 & 0.8696 & 0.1511 & 0.6839 \\
\hline hoodpf 23 & & & & \\
\hline
\end{tabular}




\begin{tabular}{|c|c|c|c|c|}
\hline \multirow[b]{2}{*}{ Variable } & \multicolumn{2}{|c|}{ Females } & \multicolumn{2}{|c|}{ Males } \\
\hline & Coefficient & $t$-statistic & Coefficient & $t$-statistic \\
\hline $\begin{array}{l}\text { sad112 } \\
\text { siadl12 } \\
\text { sdhlth12 } \\
\text { sadl23 } \\
\text { siadl23 } \\
\text { sdhlth23 }\end{array}$ & & & & \\
\hline Likelihood & \multicolumn{2}{|c|}{-151.63} & \multicolumn{2}{|c|}{-161.16} \\
\hline $\begin{array}{c}\text { Observations } \\
\text { Negative } \\
\text { Positive }\end{array}$ & & ) & & ) \\
\hline \multicolumn{5}{|c|}{ Dwelling Condition-Regressions } \\
\hline one1 & -5.1743 & -1.0939 & -6.9663 & -1.4421 \\
\hline one2 & -3.5792 & -0.8303 & -4.2874 & -0.9590 \\
\hline $\log m 1$ & 0.8286 & 0.5609 & 1.1817 & 0.7866 \\
\hline $\operatorname{logm} 2$ & 0.2552 & 0.1961 & 0.2502 & 0.1862 \\
\hline q1wb12 & 0.4419 & 2.2384 & 0.3250 & 1.5940 \\
\hline q4wb12 & 0.1381 & 0.5095 & 0.1553 & 0.5661 \\
\hline q1ib12 & 0.2242 & 1.2029 & 0.3016 & 1.5771 \\
\hline q4ib12 & 0.0068 & 0.0291 & 0.0496 & 0.2087 \\
\hline hoodpf12 & -0.1940 & -0.8174 & -0.1418 & -0.5920 \\
\hline condpf12 & 1.2251 & 6.3478 & 1.2447 & 6.3933 \\
\hline cwlth23 & 0.3107 & 0.4315 & 0.2390 & 0.3295 \\
\hline male12 & 0.0589 & 0.2455 & 0.0409 & 0.1712 \\
\hline single12 & 0.5441 & 1.9046 & 1.2591 & 2.8052 \\
\hline spdied 23 & 0.3015 & 0.7117 & 1.0219 & 1.8470 \\
\hline mspdie23 & 0.2957 & 0.5383 & 0.3331 & 0.6089 \\
\hline $\operatorname{adl12}$ & 0.0211 & 0.2795 & -0.0030 & -0.0375 \\
\hline iadl12 & 0.0308 & 0.3609 & 0.0119 & 0.1350 \\
\hline dhlth12 & 0.1629 & 0.8842 & 0.0696 & 0.3692 \\
\hline adl23 & -0.0349 & -0.5898 & -0.0153 & -0.2606 \\
\hline iadl23 & -0.0493 & -0.6871 & -0.0471 & -0.6488 \\
\hline dhlth23 & 0.1229 & 0.6586 & 0.1519 & 0.7975 \\
\hline hmown 23 & 0.4304 & 2.0561 & 0.4232 & 1.9598 \\
\hline hoodpf 23 & 0.7158 & 2.8877 & 0.7217 & 2.8960 \\
\hline \multicolumn{5}{|l|}{ sadl12 } \\
\hline \multicolumn{5}{|l|}{ siadl12 } \\
\hline \multicolumn{5}{|l|}{ sdhlth12 } \\
\hline \multicolumn{5}{|l|}{ sadl23 } \\
\hline \multicolumn{5}{|l|}{ siadl23 } \\
\hline \multicolumn{5}{|l|}{ sdhlth23 } \\
\hline Likelihood & \multicolumn{2}{|c|}{-160.73} & \multicolumn{2}{|c|}{-153.66} \\
\hline \multicolumn{5}{|l|}{ Observations } \\
\hline Negative & \multicolumn{2}{|c|}{$644(91.61)$} & & \\
\hline Positive & & & & \\
\hline
\end{tabular}

Note: Numbers in parentheses are percentages. 


\section{References}

Adler, N., and J. Ostrove. 1999. Socioeconomic status and health: What we know and what we don't. Socioeconomic Status and Health in Industrialized Nations: Annals of the New York Academy of Sciences 896:3-15.

Alessie, R., A. Lusardi, and A. Kapteyn. 2000. Savings after retirement: Evidence from three different surveys. Labour Economics 6 (2): 277-310.

Angrist, J., G. Imbens, and D. Rubin. 1996. Identification of causal effects using instrumental variables. Journal of the American Statistical Association 91:444-72.

Attanasio, O., and H. Hoynes. 2000. Differential mortality and wealth accumulation. Journal of Human Resources 35 (1): 1-29.

Backlund, E., P. Sorlie, and N. Johnson. 1999. A comparison of the relationships of education and income with mortality: The National Longitudinal Mortality Study. Social Science and Medicine 49:1373-84.

Baker, M., M. Stabile, and C. Deri. 2001. What do self-reported objective measures of health measure? NBER Working Paper no. 8419. Cambridge, Mass.: National Bureau of Economic Research, August.

Barsky, R., T. Juster, M. Kimball, and M. Shapiro. 1997. Preference parameters and behavioral heterogeneity: An experimental approach in the Health and Retirement Survey. Quarterly Journal of Economics 112:537-79.

Bosma, H., M. G. Marmot, H. Hemingway, A. C. Nicholson, E. Brunner, and S. A. Stansfeld. 1997. Low job control and risk of coronary heart disease in Whitehall II (prospective cohort) Study. British Medical Journal 314:558-565.

Chandola, T. 1998. Social inequality in coronary heart disease: A comparison of occupational classifications. Social Science and Medicine 47:525-33.

- Social class differences in mortality using the new UK National Statistics Socio-Economic Classification. Social Science and Medicine 50:641-49.

Chapman, K., and G. Hariharran. 1994. Controlling for causality in the link from income to mortality. Journal of Risk and Uncertainty 8 (1): 85-93.

Chay, K., and M. Greenstone. 1998. Does air quality matter? Evidence from the housing market. NBER Working Paper no. 6826. Cambridge, Mass.: National Bureau of Economic Research, December.

Davey-Smith, G., D. Blane, and M. Bartley. 1994. Explanations for socio-economic differentials in mortality: Evidence from Britain and elsewhere. European Journal of Public Health 4:131-44.

Dawid, A. 2000. Causal inference without counterfactuals. Journal of the American Statistical Association 95:407-48.

Dohrenwend, B. P., I. Levav, P. E. Shrout, S. Schwartz, G. Naveh, B. G. Link, A. E. Skodal, and A. Stueve. 1992. Socioeconomic status and psychiatric disorders: A test of the social causation-social selection issue. Science 255:946-52.

Drever, F., and M. Whitehead. 1997. Health inequalities. London: ONS.

Ecob, R., and G. Smith. 1999. Income and health: What is the nature of the relationship. Social Science and Medicine 48:693-705.

Elo, I., and S. Preston. 1996. Educational differences in mortality: United States, 1979-85. Social Science and Medicine 42 (1): 47-57.

Engle, R., D. Hendry, and J. Richard. 1983. Exogeneity. Econometrica 51:277-304.

Ettner, S. 1996. New evidence on the relationship between income and wealth. Journal of Health Economics 15:67-85.

Evans, A. 1978. Causation and disease: A chronological journey. American Journal of Epidemiology 108:249-58.

Feigl, H. 1953. Notes on causality. In Readings in the philosophy of science, ed. H. Feigl and M. Brodbeck, 408-18. New York: Appleton-Century-Crofts. 
Feinstein, J. 1992. The relationship between socioeconomic status and health: A review of the literature. The Millbank Quarterly 71 (2): 279-322.

Felitti, V. J, R. F. Anda, D. Nordenberg, D. F. Williamson, A. M. Spitz, V. Edwards, M. P. Koss, and J. S. Marks. 1998. Relationship of childhood abuse and household dysfunction to many of the leading causes of death in adults: The Adverse Childhood Experiences (ACE) Study. American Journal of Preventative Medicine 14:245-58.

Fitzpatrick, R., M. Bartley, B. Dodgeon, D. Firth, and K. Lynch. 1997. Social variations in health: Relationship of mortality to the interim revised social classification. In Constructing classes, ed. D. Rose and K. O'Reily. Swindon, England: ESRC/ONS.

Fitzpatrick, J., and G. Dollamore. 1999. Examining adult mortality rates using the National Statistics Socio-Economic Classification. Health Statistics Quarterly 2:33-40.

Florens, J. P., and J. Heckman. 2001. Conditioning versus fixing: Definitions of causality in static and dynamic models. Paper presented at DC2 conferences: CORE. 13 December, Louvain-la-Neuve, Belgium.

Fox, A., P. Goldblatt, and D. Jones. 1985. Social class mortality differentials: Artifact, selection, or life circumstances? Journal of Epidemiology and Community Health 39:1-8.

Freedman, D. 1985. Statistics and the scientific method. In Cohort analysis in social research, ed. W. Mason and S. Feinberg, 343-90. New York: Springer.

2001. On specifying graphical models for causation and the identification problem. University of California, Berkeley, Department of Statistics. Working Paper.

Fuchs, V. 1993. Poverty and health: Asking the right questions. In Medical care and the health of the poor, ed. D. Rogers and E. Ginzberg, 9-20. Boulder, Colo.: Westview Press.

Geweke, J. 1984. Inference and causality in economic time series models. In Handbook of econometrics, Vol. 2, ed. Z. Griliches and M. Intriligator, 1101-44. Amsterdam: North-Holland.

Gill, R., and J. Robins. 2001. Causal inference of complex longitudinal data: The continuous case. Annals of Statistics, 29:1785-811.

Goldblatt, P. O. 1990. Longitudinal study, mortality, and social organization. London: HMSO.

Goldman, N. 1994. Social factors and health: The causation-selection issue revisited. Proceedings of the National Academy of Sciences 91:1251-55.

2001. Social inequalities in health: Disentangling the underlying mechanisms. Strengthening the Dialogue between Epidemiology and Demography: Annals of the New York Academy of Science 954:118-39.

Granger, C. 1969. Investigating causal relations by econometric models and crossspectral methods. Econometrica 37:424-38.

Haynes, R. 1991. Inequalities in health and health service use: Evidence from the General Household Survey. Social Science and Medicine 33:361-68.

Heckman, J. 2000. Causal parameters and policy analysis in econometrics: A twentieth century retrospective. Quarterly Journal of Econometrics 105:45-97.

2001. Econometrics counterfactuals and causal models. University of Chicago, International Statistical Institute. Working Paper.

2003. Conditioning, causality and policy analysis. Journal of Econometrics 112 (1): 73-78.

Hendry, D., and G. Mizon. 1999. The pervasiveness of Granger causality in econometrics. In Cointegration, causality, and forecasting, ed. R. Engle and H. White, 102-34. Oxford: Oxford University Press. 
Hertzman, C. 1999. Population health and human development. In Developmental health and the wealth of nations, ed. D. Keating and C. Hertzman. New York: Guilford Press.

Herzog, R., and R. Wallace. 1997. Measures of cognitive functioning in the AHEAD Study. Journal of Gerontology B ser., 52:37-48.

Holland, P. 1986. Statistics and causal inference. Journal of the American Statistical Association 81:945-60.

1988. Causal inference, path analysis, and recursive structural equation models. In Sociological methodology, ed. C. Clogg, 449-84. Washington, D.C.: American Sociological Association.

Hoover, K. 2001. Causality in macroeconomics. Cambridge, U.K.: Cambridge University Press.

. 2003. Some causal lessons from macroeconomics. Joural of Econometrics 112 (1): 121-125.

Humphries, K., and E. van Doorslaer. 2000. Income related health inequality in Canada. Social Science and Medicine 50 (5): 663-71.

Hurd, M. 1987. Savings of the elderly and desired bequests. American Economic Review 77:298-312.

Hurd, M., D. McFadden, and L. Gan. 1998. Subjective survival curves and life cycle behavior. In Inquiries in the economics of aging, ed. D. Wise, 259-305. Chicago: University of Chicago Press.

Hurd, M., D. McFadden, L. Gan, A. Merrill, and M. Roberts. 1998. In Frontiers in the economics of aging, ed. D. Wise, 353-87. Chicago: University of Chicago Press.

Hurd, M., and K. McGarry. 1997. Evaluation of the subjective probabilities of survival in the Health and Retirement Survey. Journal of Human Resources 30: S268-92.

Hurd, M., and D. Wise. 1989. Wealth depletion and life cycle consumption by the elderly. In Topics in the economics of aging, ed. D. Wise, 135-60. Chicago: University of Chicago Press.

Kaplan, J., and S. Manuck. 1999. Status, stress, and arteriosclerosis: The role of environment and individual behaviour. Socioeconomic Status and Health in Industrialized Nations: Annals of the New York Academy of Science 896:145-61.

Karasek, R. A., T. Theorell, J. Schwartz, P. Schnell, C. Peiper, and J. Michela. 1988. Job characteristics in relation to the prevalence of myocardial infarction in the US Health Examination Survey (HES) and the Health and Nutrition Examination Survey (NHANES). American Journal of Public Health 78:910-18.

Kelley, S., C. Hertzman, and M. Daniels. 1997. Searching for the biological pathways between stress and health. Annual Review of Public Health 18:437-62.

Kitagawa, E., and P. Hauser. 1973. Differential mortality in the United States: A study in socioeconomic epidemiology. Cambridge, Mass.: Harvard University Press.

Kunsch, H., S. Geman, and A. Kehagias. 1995. Hidden Markov random fields. Annals of Applied Probability 5:577-602.

Leigh, J., and R. Dhir. 1997. Schooling and frailty among seniors. Economics of Education Review 16 (1): 45-57.

Lewis, G., P. Bebbington, T. Brugha, M. Farell, B. Gill, R. Jenkins, and H. Meltzer. 1998. Socioeconomic status, standard of living and neurotic disorder. Lancet 352:605-09.

Luft, H. 1978. Poverty and health: Economic causes and consequences of health problems. Cambridge, Mass.: Ballinger.

Marmot, M. G., G. D. Smith, S. Stansfeld, C. Patel, F. North, J. Head, I. White, E. Brunner, and E. Feeney. 1991. Health inequalities among British civil servants: The Whitehall II Study. Lancet 337:1387-93. 
Marmot, M., M. Bobak, and G. Davey-Smith. 1995. Explanations for social inequalities in health. In Society and health, ed. B. Amick, S. Levine, A. R. Tarlov, and D. C. Walsh, 172-210 New York: Oxford University Press.

Marmot, M., H. Bosma, H. Hemingway, E. Brunner, and S. Stansfeld. 1997. Contribution of job control and other risk factors to social variations in coronary heart disease incidence. Lancet 350:235-39.

Martin, L., and S. Preston. 1994. Demography of aging. Washington, D.C.: National Academy Press.

Martin, L., and B. Soldo. 1997. Racial and ethnic differences in the health of older Americans. Washington, D.C.: National Academy Press.

McDonough, P., G. Duncan, D. Williams, and J. House. 1997. Income dynamics and adult mortality in the United States. American Journal of Public Health 87:1476-83.

McEwen, B., and E. Stellar. 1993. Stress and the individual: Mechanisms leading to disease. Archives of Internal Medicine 153:2093-2101.

Meer, J., D. Miller, and H. Rosen. 2001. Exploring the health-wealth nexus. Princeton University. Working Paper.

Murray, C. J. L., G. Yang, and X. Qiao. 1992. Adult mortality: Levels, patterns, and causes. In The health of adults in the developing world, ed. R. G. Feachem, T. Kjellstrom, C. J. L. Murray, M. Over, and M. Phillips, 23-111. New York: Oxford University Press.

Newey, W., J. Powell, and J. Walker. 1990. Semiparametric estimation of selection models: Some empirical results. American Economic Review 80:324-28.

Nozick, R. 2001. Invariance: The structure of the objective world. Cambridge, Mass.: Harvard University Press.

Pearl, J. 2000. Causality: Models, reasoning, and inference. Cambridge, Mass.: Harvard University Press.

Power, C., and S. Matthews. 1998. Accumulation of health risks across social groups in a national longitudinal study. In Human biology and social inequality, ed. S. Strickland and P. Shetty, 36-57. Cambridge, U.K.: Cambridge University Press.

Power, C., S. Matthews, and O. Manor. 1996. Inequalities in self-rated health in the 1958 birth cohort: Life time social circumstances or social mobility? British Medical Journal 313:449-53.

Preston, S., and P. Taubman. 1994. Socioeconomic differences in adult mortality and health status. In Demography of aging, ed. L. Martin and S. Preston, 279318. Washington, D.C.: National Academy Press.

Robins, J. 1999. Association, causation, and marginal structural models. Synthese 121:151-79.

Rodgers, B. 1991. Socio-economic status, employment and neurosis. Social Psychiatry and Psychiatric Epidemiology 26:104-14.

Ross, C., and J. Mirowsky. 2000. Does medical insurance contribute to socioeconomic differentials in health? The Millbank Quarterly 78:291-321.

Schnall, P., P. Landsbergis, and D. Baker. 1994. Job strain and cardiovascular disease. Annual Review of Public Health 15:381-411.

Seeman, T., B. Singer, G. Love, and L. Levy-Storms. 2002. Social relationships, gender, and allostatic load across two age cohorts. Psychosomatic Medicine 64:395-406.

Shorrocks, A. 1975. The age-wealth relationship: A cross-section and cohort analysis. Review of Economics and Statistics 57:155-63.

Sims, C. 1972. Money, income, and causality. American Economic Review 65: $540-52$. 
Smith, J. 1998. Socioeconomic status and health. American Economic Review 88: 192-96.

. 1999. Healthy bodies and thick wallets: The dual relation between health and economic status. Journal of Economic Perspectives 13:145-66.

Smith, J., and R. Kington. 1997a. Demographic and economic correlates of health in old age. Demography 34 (1): 159-70.

1997b. Race, socioeconomic status, and health in late life. In Racial and ethnic differences in the health of older Americans, ed. L. Martin and B. Soldo, 106-62. Washington, D.C.: National Academy Press.

Sobel, M. 1997. Measurement, causation, and local independence in latent variable models. In Latent variable modeling and applications to causality, ed. M. Berkane, 11-28. Berlin: Springer.

-2000. Causal inference in the social sciences. Journal of the American Statistical Association 95:647-51.

Soldo, B., M. Hurd, W. Rodgers, and R. Wallace. 1997. Asset and health dynamics among the oldest old: An overview of the AHEAD Study. Journal of Gerontology B ser., 52:1-20.

Staiger, D., and J. Stock. 1997. Instrumental variables regression with weak instruments. Econometrica 64:556-86.

Stern, J. 1983. Social mobility and the interpretation of social class mortality differentials. Journal of Social Policy 12:27-49.

Swert, W. 1979. Tests of causality. In Three aspects of policy and policymaking, ed. K. Brunner and A. Meltzer, 55-96. Amsterdam: North-Holland.

U.S. Bureau of the Census. 1999. National vital statistics reports: United States life tables, 1997, Vol. 47. Washington, D.C.: GPO.

Wadsworth, M. 1991. The imprint of time: Childhood, history, and adult life. Oxford, Clarendon Press.

Whitehead, M. 1988. The health divide. London: Penguin.

Wilkinson, R. 1998. Equity, social cohesion, and health. In Human biology and social inequity, ed. S. Strickland and P. Shetty. Cambridge: Cambridge University Press.

Woodward, J. 1999. Causal interpretation in systems of equations. Synthese 212: 199-247.

Woodward, M., M. Shewry, C. Smith, and H. Tunstall-Pedoe. 1992. Social status and coronary heart disease: Results from the Scottish Heart Health Study. Preventive Medicine 21:136-48.

Zellner, A. 1979. Causality and econometrics. In Three aspects of policy and policymaking, ed. K. Brunner and A. Meltzer, 9-54. Amsterdam: North-Holland.

\section{Addendum}

This addendum describes updates in data and analysis since the publication of this paper in the Journal of Econometrics (2003), 112, 3-53. The differences result from correcting some coding errors, producing a new dataset with revised imputations, and a new treatment of the simulation of wealth evolution. We also include in this addendum results from Lagrange multiplier (LM) tests of the Wold causal chain assumption that we impose on the 
system of innovation equations. We comment on each of these points in turn.

We have corrected a health condition coding problem in the AHEAD data, described in "Data alert: Correction to F1156 [B7. Heart Condition]," from the HRS webpage. This coding problem produced a significant undercount of heart attack prevalence in wave 3 . We have also corrected a problem in our count of new incidences, given existing previous condition, for the variables heart attack, cancer, and stroke, which was producing undercounts for the incidence variables. Updated tables $11.2 \mathrm{R}$ and $11.3 \mathrm{R}$ give summary statistics for the revised variables. These changes do not produce significant alterations to our overall results, but there are some differences in the coefficients of the incidence regressions. Table 11.8 in the published paper is updated in table $11.8 \mathrm{R}$, which summarizes the coefficients that are now significant. A notable change is that, with the exception of cancer for males, we now obtain invariance of the models over time for the first three health conditions: cancer, heart disease, and stroke. The updated invariance and noncausality tests are given in table $11.9 \mathrm{R}$. The wealth revisions have some impact on simulation results, which are updated in tables $11.12 \mathrm{R}$ and $11.13 \mathrm{R}$.

In revising our code, we fixed the seed for the random number generator and produced a data set in which all imputations can be replicated. However, numerical imputations have changed, particularly imputed asset values. The tables listed above reflect these changes. The numerical differences from the previous published results are minor, and all the same results are obtained.

The simulations of wealth paths were producing, in some instances, unreasonable results in the first few years of simulation, with excessive increases in wealth observed in some cases. Our simulations start from a baseline population of seventy-seventy-five-year-olds in the first wave of the AHEAD, and these changes in wealth in the initial years of simulation are inconsistent with changes for the same population observed in subsequent waves. The observed pattern of wealth decrease is reproduced in the simulation after a few years, leading us to postulate, in loose terms, that our imputations and estimates capture the correct dynamics, but the wrong initial state of the baseline population. This is consistent with the findings of other researchers that wealth appears to be undercounted in AHEAD wave 1, due to undercounting of the categories in which assets are held. We therefore attempted to adjust to the correct initial state. We did this by calibrating the constant term of the wealth regressions using a crossvalidation procedure. We calibrated the intercept so that the first year of simulated wealth changes (in terms of rate of change) matched, at the median, the observed transition for our baseline population. The changes in the intercept required to obtain this match are minor, as can be seen from table 11.14. Although we effectively force the prediction to match the 


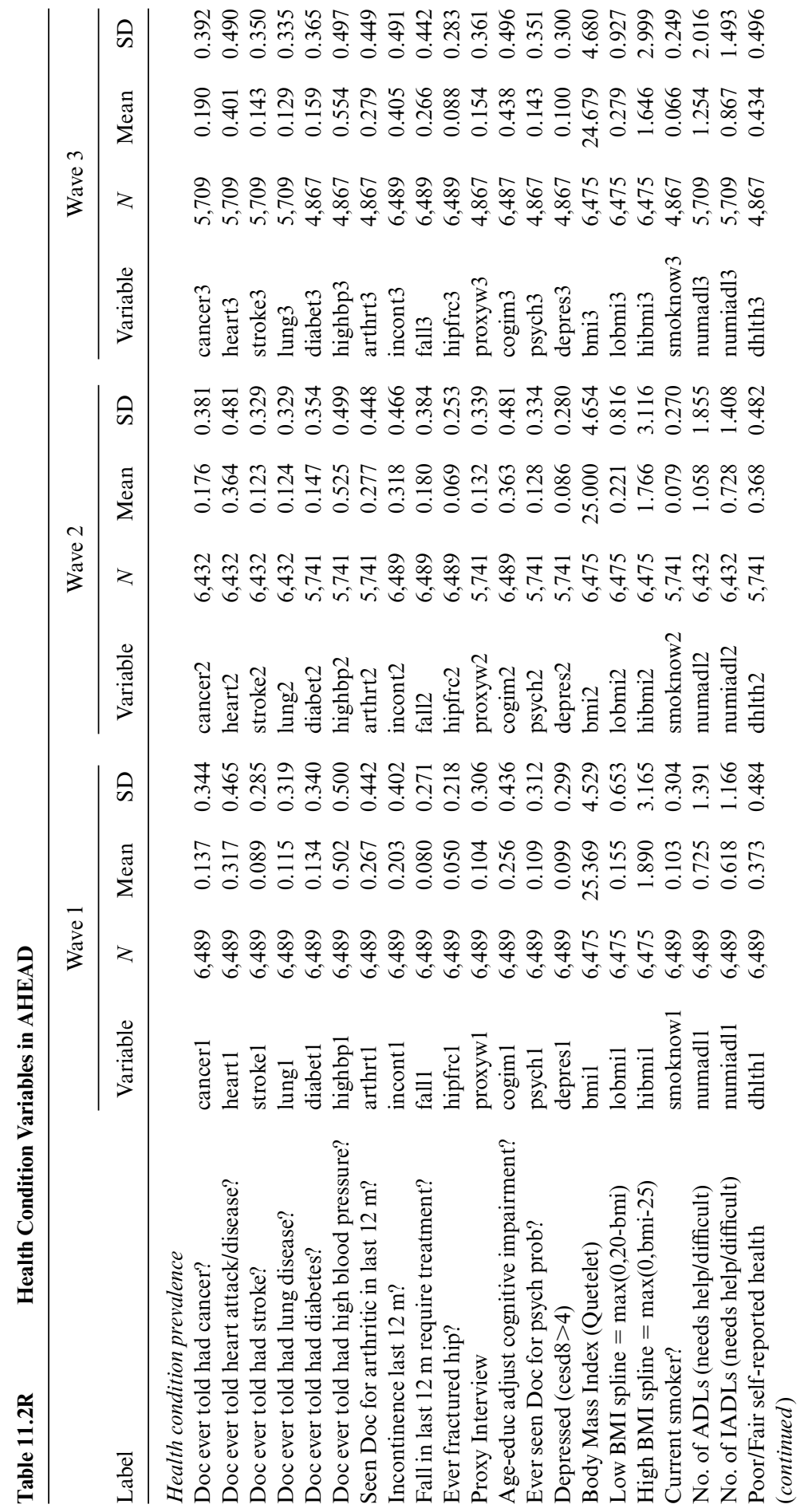




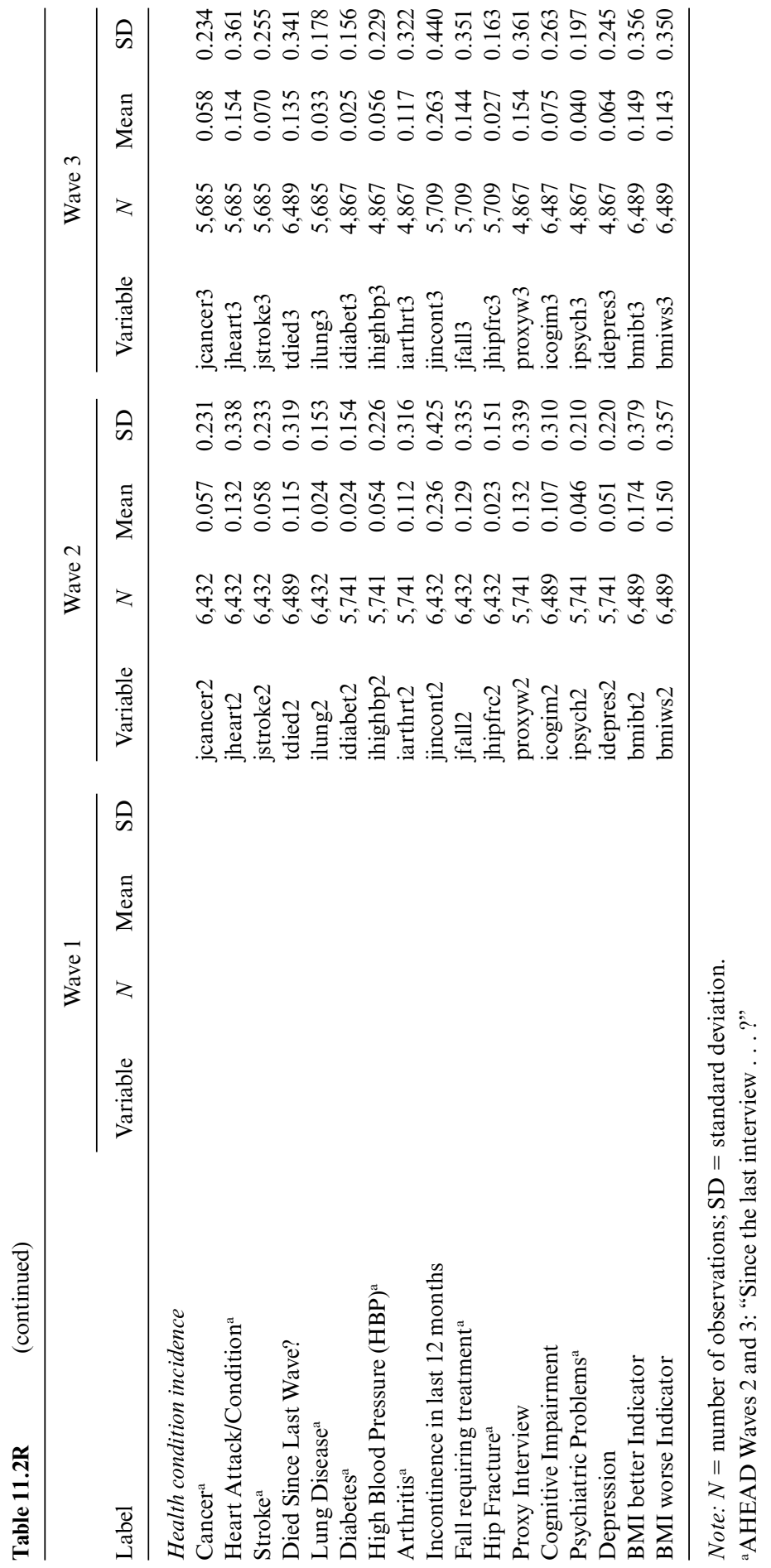




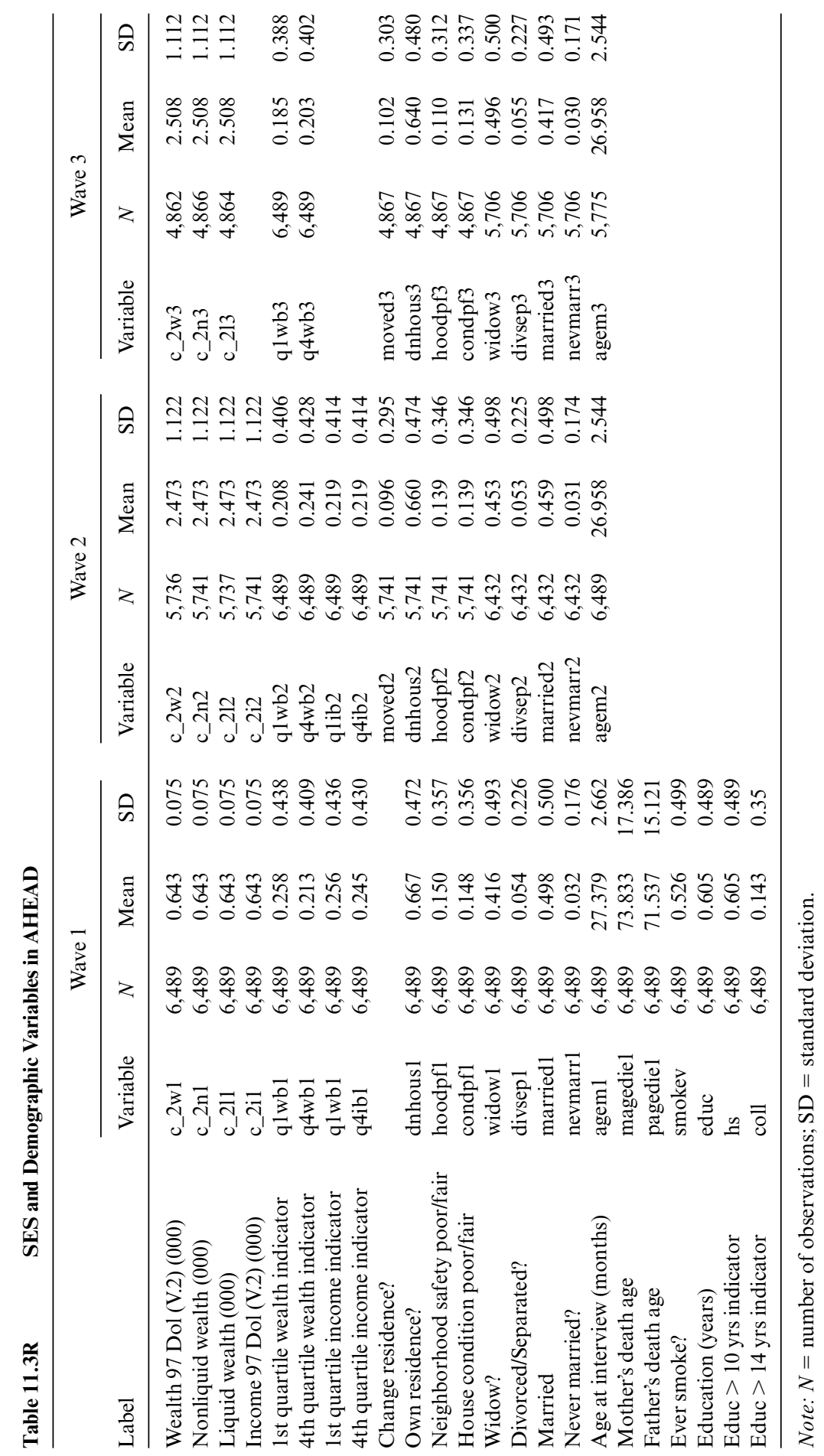




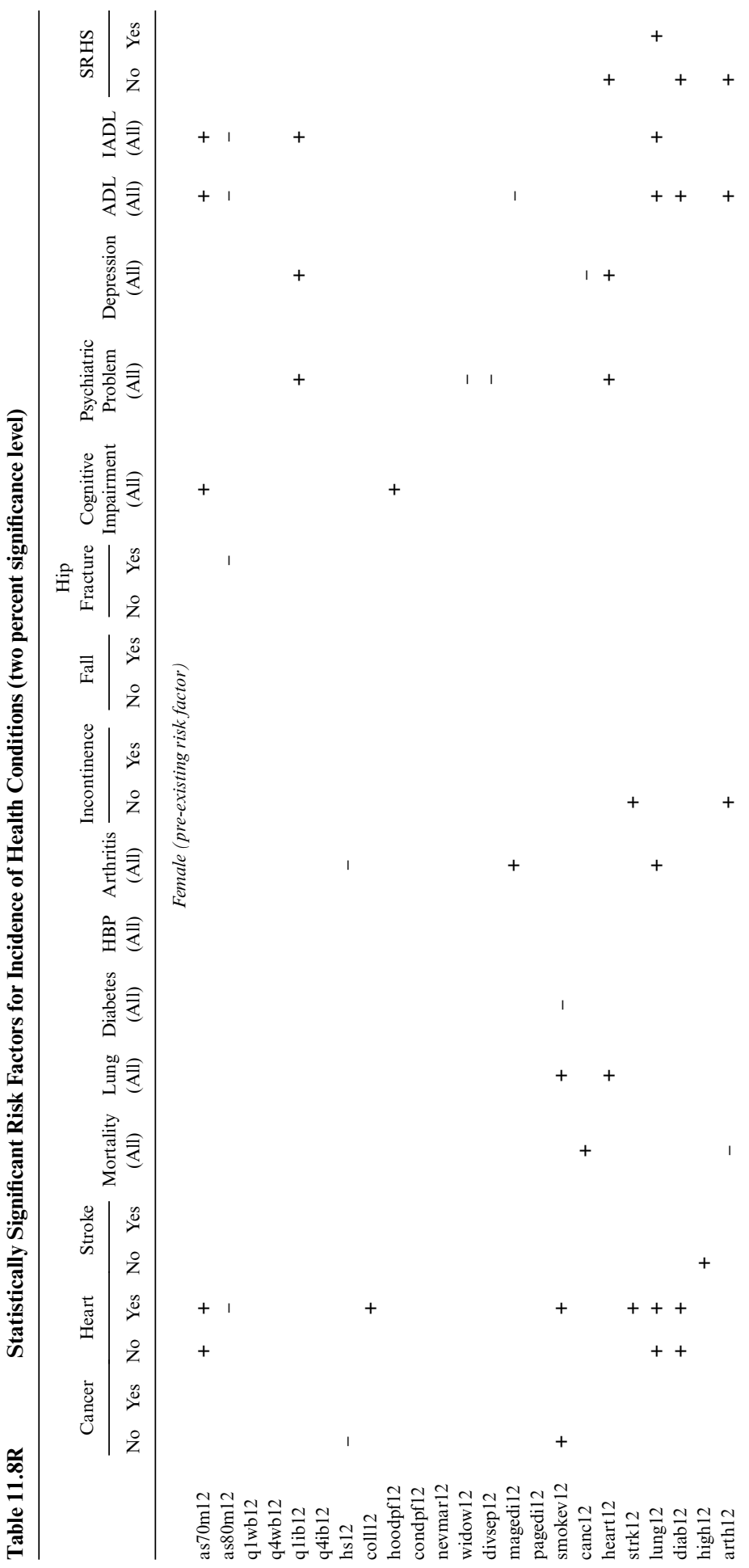




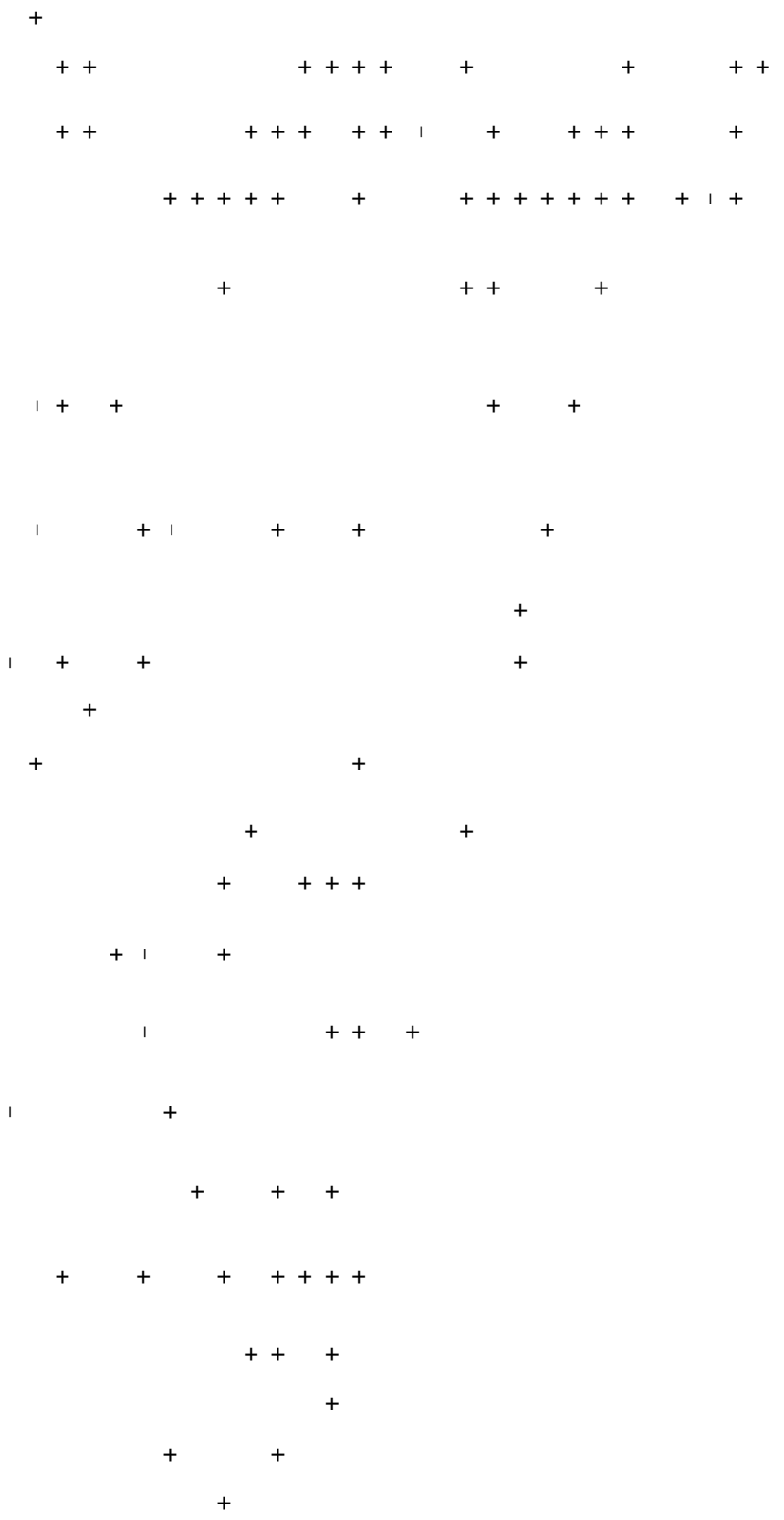

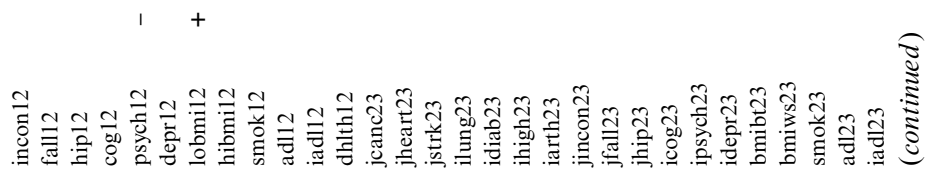




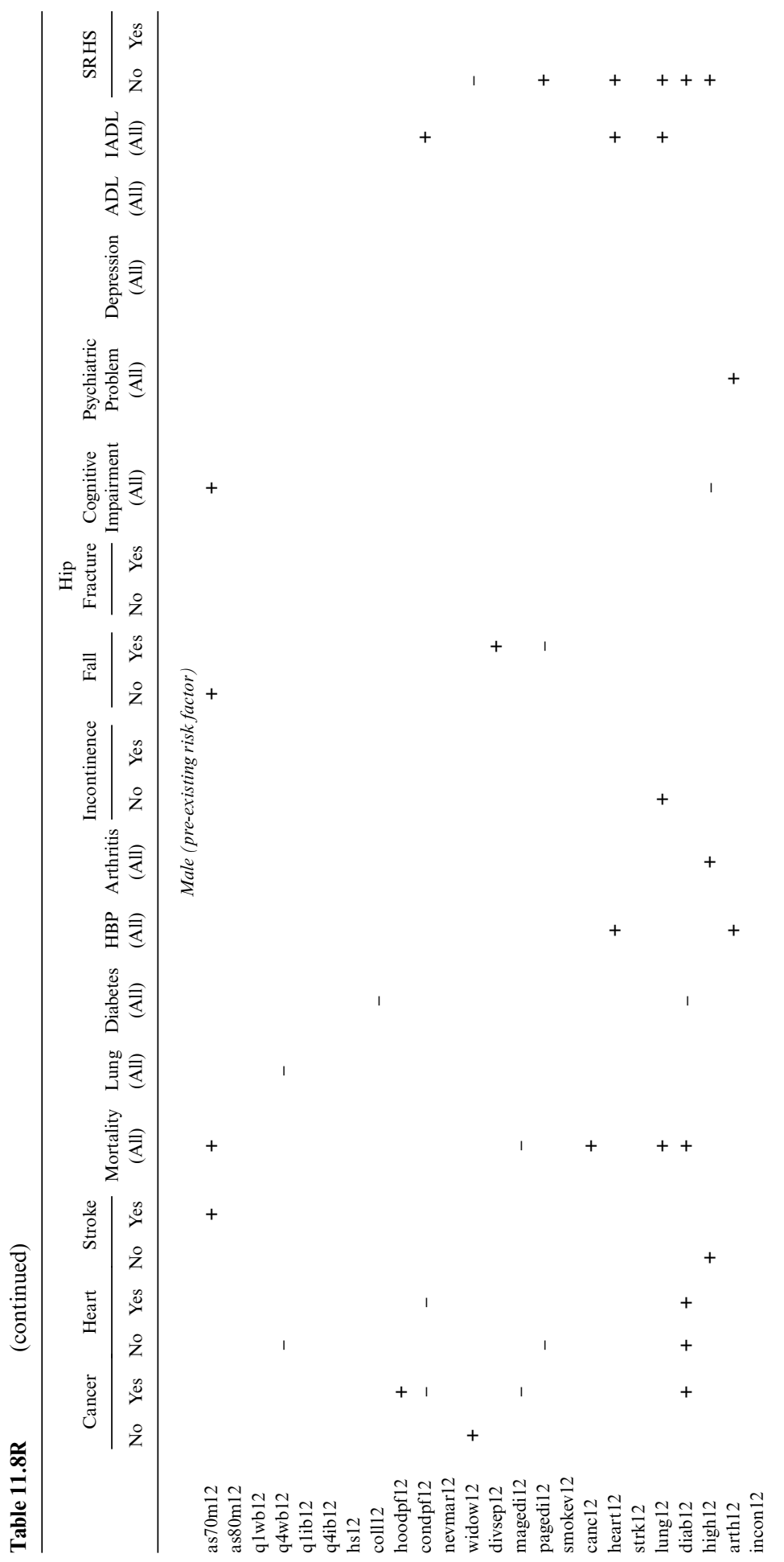




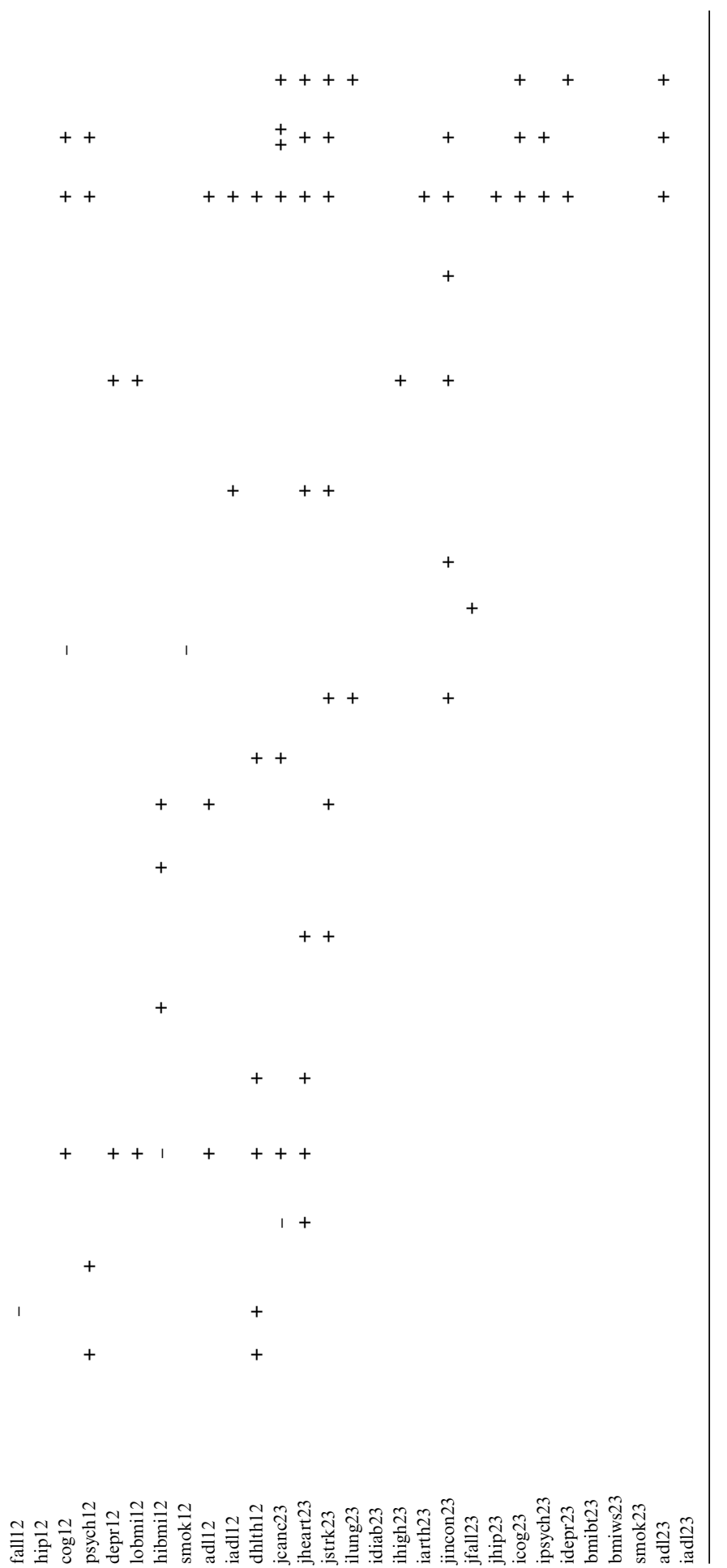




\begin{tabular}{|c|c|c|c|c|}
\hline \multirow[b]{3}{*}{ Variable } & \multicolumn{4}{|c|}{ Invariance } \\
\hline & \multicolumn{2}{|c|}{ With SES } & \multicolumn{2}{|c|}{ Without SES } \\
\hline & Female & Male & Female & Male \\
\hline CANCER & 0.528 & 0.016 & 0.309 & 0.007 \\
\hline CANCER - no previous & 0.867 & 0.129 & 0.812 & 0.064 \\
\hline CANCER - previous & 0.068 & 0.044 & 0.079 & 0.083 \\
\hline HEART & 0.085 & 0.690 & 0.052 & 0.619 \\
\hline HEART - no previous & 0.170 & 0.823 & 0.060 & 0.498 \\
\hline HEART_-previous & 0.547 & 0.692 & 0.492 & 0.725 \\
\hline STROKE & 0.384 & 0.204 & 0.266 & 0.135 \\
\hline STROKE—no previous & 0.172 & 0.258 & 0.160 & 0.180 \\
\hline STROKE—previous & 0.907 & 0.045 & 0.784 & 0.087 \\
\hline MORTALITY & 0.221 & 0.378 & 0.315 & 0.491 \\
\hline LUNG & 0.552 & 0.689 & 0.483 & 0.502 \\
\hline DIABETES & 0.189 & 0.234 & 0.281 & 0.128 \\
\hline HIGH BLOOD PRESSURE & 0.007 & 0.393 & 0.024 & 0.172 \\
\hline ARTHRITIS & 0.046 & 0.071 & 0.032 & 0.167 \\
\hline INCONTINENCE & 0.781 & 0.351 & 0.597 & 0.682 \\
\hline INCONTINENCE—no previous & 0.706 & 0.102 & 0.426 & 0.555 \\
\hline INCONTINENCE—previous & 0.962 & 0.793 & 0.892 & 0.730 \\
\hline FALL & 0.904 & 0.263 & 0.790 & 0.207 \\
\hline FALL—no previous & 0.792 & 0.140 & 0.612 & 0.133 \\
\hline FALL_previous & 0.365 & 0.000 & 0.358 & 0.000 \\
\hline HIP FRACTURE & 0.491 & 0.126 & 0.280 & 0.053 \\
\hline HIP FRACTURE — no previous & 0.930 & 0.300 & 0.724 & 0.123 \\
\hline \multicolumn{5}{|l|}{ HIP FRACTURE—previous } \\
\hline PROXY INTERVIEW & 0.301 & 0.591 & 0.465 & 0.378 \\
\hline PROXY INTERVIEW—no previous & 0.127 & 0.795 & 0.444 & 0.606 \\
\hline \multicolumn{5}{|l|}{ PROXY INTERVIEW—previous } \\
\hline COGNITIVE IMPAIRMENT & 0.005 & 0.288 & 0.008 & 0.143 \\
\hline PSYCHIATRIC & 0.127 & 0.295 & 0.052 & 0.365 \\
\hline DEPRESSION & 0.211 & 0.944 & 0.299 & 0.934 \\
\hline BODY MASS INDEX & 0.260 & 0.009 & 0.251 & 0.002 \\
\hline CURRENT SMOKER & 0.420 & 0.710 & 0.214 & 0.504 \\
\hline CURRENT SMOKER - no previous & 0.133 & 0.033 & 0.078 & 0.040 \\
\hline CURRENT SMOKER — previous & 0.797 & & 0.733 & \\
\hline ADL & 0.001 & 0.021 & 0.007 & 0.038 \\
\hline IADL & 0.603 & 0.008 & 0.388 & 0.003 \\
\hline SELF RATED HEALTH & 0.376 & 0.634 & 0.341 & 0.607 \\
\hline SELF RATED HEALTH—no previous & 0.514 & 0.251 & 0.558 & 0.215 \\
\hline SELF RATED HEALTH—previous & 0.239 & 0.165 & 0.176 & 0.189 \\
\hline
\end{tabular}


(continued)

\begin{tabular}{|c|c|c|c|c|c|c|}
\hline & \multicolumn{6}{|c|}{ Noncausality } \\
\hline & \multicolumn{2}{|c|}{ Wave $1-2$} & \multicolumn{2}{|c|}{ Wave $2-3$} & \multicolumn{2}{|c|}{ Wave $1-3$} \\
\hline & Female & Male & Female & Male & Female & Male \\
\hline CANCER & 0.987 & 0.588 & 0.408 & 0.165 & 0.613 & 0.198 \\
\hline CANCER - no previous & 0.704 & 0.658 & 0.289 & 0.173 & 0.313 & 0.166 \\
\hline CANCER — previous & 0.143 & 0.228 & 0.472 & 0.017 & 0.299 & 0.036 \\
\hline HEART & 0.540 & 0.054 & 0.396 & 0.996 & 0.398 & 0.243 \\
\hline HEART — no previous & 0.872 & 0.344 & 0.750 & 0.412 & 0.736 & 0.039 \\
\hline HEART — previous & 0.104 & 0.071 & 0.153 & 0.737 & 0.019 & 0.172 \\
\hline STROKE & 0.757 & 0.837 & 0.584 & 0.028 & 0.657 & 0.059 \\
\hline STROKE_-no previous & 0.415 & 0.955 & 0.671 & 0.064 & 0.713 & 0.203 \\
\hline STROKE_-previous & 0.824 & 0.301 & 0.882 & 0.155 & 0.799 & 0.383 \\
\hline MORTALITY & 0.098 & 0.275 & 0.883 & 0.306 & 0.652 & 0.364 \\
\hline LUNG & 0.166 & 0.174 & 0.866 & 0.122 & 0.343 & 0.010 \\
\hline DIABETES & 0.615 & 0.141 & 0.020 & 0.236 & 0.110 & 0.025 \\
\hline HIGH BLOOD PRESSURE & 0.342 & 0.996 & 0.083 & 0.941 & 0.534 & 0.990 \\
\hline ARTHRITIS & 0.179 & 0.029 & 0.242 & 0.713 & 0.085 & 0.395 \\
\hline INCONTINENCE & 0.763 & 0.019 & 0.254 & 0.800 & 0.163 & 0.463 \\
\hline INCONTINENCE—no previous & 0.914 & 0.037 & 0.602 & 0.197 & 0.453 & 0.641 \\
\hline INCONTINENCE—previous & 0.900 & 0.247 & 0.168 & 0.664 & 0.149 & 0.244 \\
\hline FALL & 0.532 & 0.687 & 0.945 & 0.454 & 0.600 & 0.592 \\
\hline FALL—no previous & 0.501 & 0.697 & 0.944 & 0.251 & 0.558 & 0.532 \\
\hline FALL—previous & 0.329 & 0.000 & 0.803 & 0.000 & 0.696 & 0.053 \\
\hline HIP FRACTURE & 0.613 & 0.597 & 0.370 & 0.666 & 0.159 & 0.430 \\
\hline HIP FRACTURE — no previous & 0.461 & 0.461 & 0.706 & 0.725 & 0.128 & 0.234 \\
\hline \multicolumn{7}{|l|}{ HIP FRACTURE - previous } \\
\hline PROXY INTERVIEW & 0.017 & 0.486 & 0.870 & 0.127 & 0.254 & 0.032 \\
\hline PROXY INTERVIEW — no previous & 0.002 & 0.793 & 0.541 & 0.121 & 0.087 & 0.073 \\
\hline \multicolumn{7}{|l|}{ PROXY INTERVIEW—previous } \\
\hline COGNITIVE IMPAIRMENT & 0.001 & 0.259 & 0.259 & 0.200 & 0.002 & 0.026 \\
\hline PSYCHIATRIC & 0.043 & 0.238 & 0.214 & 0.069 & 0.004 & 0.065 \\
\hline DEPRESSION & 0.007 & 0.143 & 0.261 & 0.377 & 0.011 & 0.065 \\
\hline BODY MASS INDEX & 0.188 & 0.839 & 0.931 & 0.711 & 0.673 & 0.684 \\
\hline CURRENT SMOKER & 0.603 & 0.282 & 0.974 & 0.693 & 0.625 & 0.129 \\
\hline CURRENT SMOKER - no previous & 0.335 & 0.196 & 0.874 & 0.980 & 0.515 & 0.962 \\
\hline CURRENT SMOKER — previous & 0.375 & 0.325 & 0.547 & 0.325 & 0.274 & 0.025 \\
\hline $\mathrm{ADL}$ & 0.077 & 0.014 & 0.346 & 0.971 & 0.828 & 0.358 \\
\hline IADL & 0.374 & 0.051 & 0.817 & 0.243 & 0.241 & 0.009 \\
\hline SELF RATED HEALTH & 0.013 & 0.048 & 0.100 & 0.301 & 0.001 & 0.020 \\
\hline SELF RATED HEALTH—no previous & 0.015 & 0.187 & 0.202 & 0.121 & 0.007 & 0.034 \\
\hline $\begin{array}{l}\text { SELF RATED HEALTH - previous } \\
\text { (continued) }\end{array}$ & 0.225 & 0.195 & 0.557 & 0.256 & 0.193 & 0.175 \\
\hline
\end{tabular}




\begin{tabular}{|c|c|c|c|c|c|c|}
\hline & \multirow{2}{*}{\multicolumn{2}{|c|}{$\begin{array}{l}\text { Joint (Invariance } \\
+ \text { Noncausality) }\end{array}$}} & \multicolumn{4}{|c|}{ Relative Odds (high vs. low SES) } \\
\hline & & & \multicolumn{2}{|c|}{ Female } & \multicolumn{2}{|c|}{ Male } \\
\hline & Female & Male & Odds & SE & Odds & SE \\
\hline CANCER & 0.600 & 0.012 & 1.31 & 0.46 & 0.73 & 0.27 \\
\hline CANCER - no previous & 0.778 & 0.084 & 1.24 & 0.48 & 0.67 & 0.29 \\
\hline CANCER — previous & 0.067 & 0.011 & 5.85 & 7.75 & 2.69 & 3.42 \\
\hline HEART & 0.099 & 0.571 & 0.97 & 0.21 & 1.02 & 0.24 \\
\hline HEART — no previous & 0.278 & 0.446 & 0.82 & 0.25 & 1.30 & 0.50 \\
\hline HEART — previous & 0.169 & 0.516 & 1.13 & 0.32 & 0.88 & 0.26 \\
\hline STROKE & 0.481 & 0.080 & 0.73 & 0.25 & 0.94 & 0.35 \\
\hline STROKE—no previous & 0.271 & 0.189 & 0.68 & 0.27 & 0.82 & 0.36 \\
\hline STROKE—previous & 0.948 & 0.054 & 1.15 & 0.93 & 1.61 & 1.25 \\
\hline MORTALITY & 0.308 & 0.360 & 0.69 & 0.21 & 1.17 & 0.41 \\
\hline LUNG & 0.504 & 0.203 & 0.33 & 0.17 & 0.50 & 0.43 \\
\hline DIABETES & 0.101 & 0.062 & 0.69 & 0.41 & 1.48 & 3.19 \\
\hline HIGH BLOOD PRESSURE & 0.013 & 0.666 & 0.90 & 0.29 & 0.74 & 0.36 \\
\hline ARTHRITIS & 0.020 & 0.082 & 1.03 & 0.22 & 0.54 & 0.16 \\
\hline INCONTINENCE & 0.615 & 0.373 & 0.85 & 0.13 & 1.11 & 0.30 \\
\hline INCONTINENCE—no previous & 0.695 & 0.158 & 0.77 & 0.20 & 1.02 & 0.36 \\
\hline INCONTINENCE—previous & 0.858 & 0.684 & 0.94 & 0.09 & 1.13 & 0.29 \\
\hline FALL & 0.913 & 0.328 & 0.98 & 0.19 & 0.92 & 0.31 \\
\hline FALL—no previous & 0.808 & 0.181 & 1.03 & 0.25 & 0.86 & 0.32 \\
\hline FALL—previous & 0.470 & 0.000 & 1.00 & 0.27 & 89.61 & 267.82 \\
\hline HIP FRACTURE & 0.347 & 0.143 & 0.33 & 0.22 & 0.21 & 0.28 \\
\hline HIP FRACTURE—no previous & 0.785 & 0.238 & 0.23 & 0.17 & 0.14 & 0.19 \\
\hline \multicolumn{7}{|l|}{ HIP FRACTURE—previous } \\
\hline PROXY INTERVIEW & 0.248 & 0.261 & 0.46 & 0.16 & 0.48 & 0.17 \\
\hline PROXY INTERVIEW — no previous & 0.061 & 0.531 & 0.27 & 0.11 & 0.40 & 0.20 \\
\hline \multicolumn{7}{|l|}{ PROXY INTERVIEW—previous } \\
\hline COGNITIVE IMPAIRMENT & 0.000 & 0.089 & 0.78 & 0.17 & 0.59 & 0.19 \\
\hline PSYCHIATRIC & 0.012 & 0.137 & 0.39 & 0.15 & 0.16 & 0.12 \\
\hline DEPRESSION & 0.042 & 0.753 & 0.38 & 0.15 & 0.29 & 0.15 \\
\hline BODY MASS INDEX & 0.345 & 0.019 & & & & \\
\hline CURRENT SMOKER & 0.492 & 0.528 & 0.46 & 0.37 & 0.92 & 1.11 \\
\hline CURRENT SMOKER — no previous & 0.165 & 0.097 & 0.11 & 0.16 & 19.92 & 132.75 \\
\hline CURRENT SMOKER — previous & 0.714 & & 0.93 & 0.16 & 0.95 & 0.18 \\
\hline ADL & 0.004 & 0.024 & & & & \\
\hline IADL & 0.509 & 0.001 & & & & \\
\hline SELF RATED HEALTH & 0.044 & 0.278 & 0.67 & 0.08 & 0.64 & 0.09 \\
\hline SELF RATED HEALTH—no previous & 0.138 & 0.091 & 0.59 & 0.12 & 0.51 & 0.13 \\
\hline SELF RATED HEALTH—previous & 0.177 & 0.116 & & & & \\
\hline
\end{tabular}

Notes: $\mathrm{SE}=$ standard error. 


\begin{tabular}{|c|c|c|c|c|c|c|c|}
\hline & Scenario & 70 & 75 & 80 & 85 & 90 & 95 \\
\hline \multicolumn{8}{|c|}{ White Females } \\
\hline \multirow[t]{3}{*}{ Survival probability ${ }^{\mathrm{a}}$} & S0 & 1.000 & 0.907 & 0.747 & 0.502 & 0.247 & 0.082 \\
\hline & S1 & 1.000 & 0.912 & 0.761 & 0.526 & 0.268 & 0.092 \\
\hline & $\mathrm{S} 2$ & 1.000 & 0.887 & 0.664 & 0.354 & 0.117 & 0.024 \\
\hline \multirow[t]{3}{*}{ Cancer $^{\mathrm{b}}$} & So & 0.117 & 0.180 & 0.229 & 0.264 & 0.280 & 0.267 \\
\hline & S1 & 0.117 & 0.174 & 0.222 & 0.257 & 0.275 & 0.259 \\
\hline & $\mathrm{S} 2$ & 0.117 & 0.213 & 0.277 & 0.309 & 0.335 & 0.301 \\
\hline \multirow[t]{3}{*}{ Heart disease $^{b}$} & S0 & 0.225 & 0.329 & 0.457 & 0.561 & 0.630 & 0.667 \\
\hline & S1 & 0.225 & 0.323 & 0.438 & 0.538 & 0.604 & 0.625 \\
\hline & $\mathrm{S} 2$ & 0.225 & 0.361 & 0.521 & 0.635 & 0.701 & 0.733 \\
\hline \multirow[t]{3}{*}{ Stroke $^{\mathrm{b}}$} & So & 0.044 & 0.108 & 0.197 & 0.274 & 0.344 & 0.392 \\
\hline & $\mathrm{S} 1$ & 0.044 & 0.107 & 0.184 & 0.261 & 0.324 & 0.358 \\
\hline & $\mathrm{S} 2$ & 0.044 & 0.119 & 0.223 & 0.311 & 0.393 & 0.458 \\
\hline \multirow[t]{3}{*}{ Lung disease $\mathrm{e}^{\mathrm{b}}$} & So & 0.104 & 0.153 & 0.183 & 0.193 & 0.177 & 0.159 \\
\hline & S1 & 0.104 & 0.147 & 0.174 & 0.183 & 0.174 & 0.142 \\
\hline & $\mathrm{S} 2$ & 0.104 & 0.196 & 0.266 & 0.289 & 0.275 & 0.211 \\
\hline \multirow[t]{3}{*}{ Diabetes $^{\mathrm{b}}$} & S0 & 0.114 & 0.163 & 0.189 & 0.196 & 0.195 & 0.173 \\
\hline & S1 & 0.114 & 0.000 & 0.000 & 0.000 & 0.000 & 0.000 \\
\hline & $\mathrm{S} 2$ & 0.114 & 0.202 & 0.252 & 0.266 & 0.253 & 0.213 \\
\hline \multirow[t]{3}{*}{ High blood pressure ${ }^{\mathrm{b}}$} & So & 0.467 & 0.584 & 0.675 & 0.733 & 0.763 & 0.787 \\
\hline & S1 & 0.467 & 0.581 & 0.672 & 0.740 & 0.769 & 0.809 \\
\hline & $\mathrm{S} 2$ & 0.467 & 0.622 & 0.729 & 0.799 & 0.842 & 0.890 \\
\hline \multirow[t]{3}{*}{ Arthritis ${ }^{\mathrm{b}}$} & So & 0.227 & 0.495 & 0.677 & 0.794 & 0.871 & 0.916 \\
\hline & S1 & 0.227 & 0.506 & 0.676 & 0.800 & 0.874 & 0.935 \\
\hline & S2 & 0.227 & 0.574 & 0.775 & 0.885 & 0.944 & 0.961 \\
\hline \multirow[t]{3}{*}{ Incontinence $^{\mathrm{b}}$} & S0 & 0.231 & 0.410 & 0.591 & 0.732 & 0.831 & 0.892 \\
\hline & S1 & 0.231 & 0.422 & 0.601 & 0.747 & 0.842 & 0.901 \\
\hline & $\mathrm{S} 2$ & 0.231 & 0.438 & 0.646 & 0.796 & 0.879 & 0.938 \\
\hline \multirow[t]{3}{*}{ Fall $^{\mathrm{b}}$} & So & 0.072 & 0.276 & 0.462 & 0.628 & 0.762 & 0.860 \\
\hline & S1 & 0.072 & 0.276 & 0.462 & 0.624 & 0.754 & 0.854 \\
\hline & $\mathrm{S} 2$ & 0.072 & 0.273 & 0.473 & 0.652 & 0.776 & 0.854 \\
\hline \multirow[t]{3}{*}{ Hip fracture ${ }^{\mathrm{b}}$} & S0 & 0.029 & 0.045 & 0.069 & 0.104 & 0.137 & 0.180 \\
\hline & S1 & 0.029 & 0.044 & 0.070 & 0.102 & 0.138 & 0.157 \\
\hline & $\mathrm{S} 2$ & 0.029 & 0.064 & 0.112 & 0.183 & 0.240 & 0.298 \\
\hline \multirow[t]{3}{*}{ Proxy interview } & So & 0.036 & 0.057 & 0.090 & 0.149 & 0.215 & 0.282 \\
\hline & S1 & 0.036 & 0.062 & 0.089 & 0.144 & 0.209 & 0.279 \\
\hline & $\mathrm{S} 2$ & 0.036 & 0.102 & 0.185 & 0.295 & 0.405 & 0.469 \\
\hline \multirow[t]{3}{*}{ Cognitive impairment ${ }^{\mathrm{b}}$} & S0 & 0.108 & 0.254 & 0.440 & 0.619 & 0.741 & 0.812 \\
\hline & S1 & 0.108 & 0.261 & 0.434 & 0.612 & 0.747 & 0.813 \\
\hline & $\mathrm{S} 2$ & 0.108 & 0.403 & 0.678 & 0.845 & 0.921 & 0.963 \\
\hline \multirow[t]{3}{*}{ Psychiatric disease $\mathrm{e}^{\mathrm{b}}$} & S0 & 0.153 & 0.223 & 0.310 & 0.382 & 0.425 & 0.459 \\
\hline & S1 & 0.153 & 0.225 & 0.317 & 0.390 & 0.421 & 0.451 \\
\hline & $\mathrm{S} 2$ & 0.153 & 0.320 & 0.506 & 0.635 & 0.726 & 0.772 \\
\hline \multirow[t]{3}{*}{ Depression $^{\mathrm{b}}$} & S0 & 0.067 & 0.168 & 0.280 & 0.380 & 0.465 & 0.519 \\
\hline & S1 & 0.067 & 0.178 & 0.290 & 0.399 & 0.488 & 0.572 \\
\hline & $\mathrm{S} 2$ & 0.067 & 0.253 & 0.429 & 0.573 & 0.664 & 0.711 \\
\hline \multirow{3}{*}{ Body mass index ${ }^{c}$} & S0 & 25.657 & 24.791 & 23.673 & 22.435 & 21.389 & 20.716 \\
\hline & S1 & 25.657 & 24.781 & 23.640 & 22.413 & 21.375 & 20.384 \\
\hline & $\mathrm{S} 2$ & 25.657 & 24.424 & 23.018 & 21.782 & 20.852 & 20.483 \\
\hline
\end{tabular}

(continued) 
Table 11.12R (continued)

\begin{tabular}{|c|c|c|c|c|c|c|c|}
\hline & Scenario & 70 & 75 & 80 & 85 & 90 & 95 \\
\hline \multirow[t]{3}{*}{ Current smoker ${ }^{\mathrm{b}}$} & S0 & 0.130 & 0.088 & 0.059 & 0.038 & 0.021 & 0.015 \\
\hline & S1 & 0.130 & 0.086 & 0.057 & 0.037 & 0.025 & 0.016 \\
\hline & $\mathrm{S} 2$ & 0.130 & 0.120 & 0.100 & 0.071 & 0.045 & 0.039 \\
\hline \multirow[t]{3}{*}{$\mathrm{ADL}_{\text {limits }}{ }^{\mathrm{c}}$} & S0 & 0.307 & 0.272 & 0.607 & 1.075 & 1.581 & 2.071 \\
\hline & S1 & 0.307 & 0.245 & 0.558 & 1.029 & 1.529 & 2.013 \\
\hline & $\mathrm{S} 2$ & 0.307 & 0.478 & 1.183 & 2.047 & 2.721 & 3.365 \\
\hline \multirow[t]{3}{*}{ IADL limits ${ }^{c}$} & S0 & 0.241 & 0.113 & 0.263 & 0.534 & 0.790 & 1.110 \\
\hline & S1 & 0.241 & 0.106 & 0.257 & 0.503 & 0.770 & 1.096 \\
\hline & $\mathrm{S} 2$ & 0.241 & 0.249 & 0.688 & 1.311 & 1.751 & 2.045 \\
\hline \multirow[t]{3}{*}{ Poor/fair self-rated health ${ }^{\mathrm{b}}$} & S0 & 0.249 & 0.309 & 0.433 & 0.530 & 0.583 & 0.605 \\
\hline & S1 & 0.249 & 0.288 & 0.416 & 0.504 & 0.565 & 0.594 \\
\hline & $\mathrm{S} 2$ & 0.249 & 0.515 & 0.717 & 0.815 & 0.846 & 0.882 \\
\hline \multicolumn{8}{|c|}{ White Males } \\
\hline \multirow[t]{3}{*}{ Survival probability ${ }^{\mathrm{a}}$} & S0 & 1.000 & 0.822 & 0.555 & 0.285 & 0.090 & 0.018 \\
\hline & S1 & 1.000 & 0.838 & 0.592 & 0.313 & 0.116 & 0.026 \\
\hline & $\mathrm{S} 2$ & 1.000 & 0.834 & 0.513 & 0.201 & 0.040 & 0.005 \\
\hline \multirow[t]{3}{*}{ Cancer $^{\mathrm{b}}$} & S0 & 0.138 & 0.235 & 0.319 & 0.402 & 0.491 & 0.631 \\
\hline & S1 & 0.138 & 0.242 & 0.326 & 0.411 & 0.493 & 0.578 \\
\hline & $\mathrm{S} 2$ & 0.138 & 0.233 & 0.309 & 0.391 & 0.480 & 0.660 \\
\hline \multirow[t]{3}{*}{ Heart $^{\mathrm{b}}$} & So & 0.361 & 0.504 & 0.639 & 0.734 & 0.790 & 0.862 \\
\hline & S1 & 0.361 & 0.507 & 0.633 & 0.730 & 0.828 & 0.861 \\
\hline & $\mathrm{S} 2$ & 0.361 & 0.486 & 0.612 & 0.706 & 0.748 & 0.868 \\
\hline \multirow[t]{3}{*}{ Stroke ${ }^{b}$} & S0 & 0.071 & 0.140 & 0.216 & 0.278 & 0.341 & 0.379 \\
\hline & S1 & 0.071 & 0.134 & 0.212 & 0.282 & 0.311 & 0.366 \\
\hline & $\mathrm{S} 2$ & 0.071 & 0.186 & 0.308 & 0.400 & 0.502 & 0.528 \\
\hline \multirow[t]{3}{*}{ Lung disease $\mathrm{e}^{\mathrm{b}}$} & S0 & 0.153 & 0.185 & 0.218 & 0.254 & 0.241 & 0.222 \\
\hline & S1 & 0.153 & 0.184 & 0.224 & 0.242 & 0.241 & 0.272 \\
\hline & $\mathrm{S} 2$ & 0.153 & 0.167 & 0.181 & 0.211 & 0.232 & 0.189 \\
\hline \multirow[t]{3}{*}{ Diabetes $^{\mathrm{b}}$} & S0 & 0.133 & 0.165 & 0.186 & 0.197 & 0.188 & 0.138 \\
\hline & S1 & 0.133 & 0.000 & 0.000 & 0.000 & 0.000 & 0.000 \\
\hline & $\mathrm{S} 2$ & 0.133 & 0.136 & 0.134 & 0.125 & 0.083 & 0.038 \\
\hline \multirow[t]{3}{*}{ High blood pressure ${ }^{\mathrm{b}}$} & S0 & 0.440 & 0.547 & 0.626 & 0.686 & 0.709 & 0.690 \\
\hline & S1 & 0.440 & 0.548 & 0.631 & 0.687 & 0.740 & 0.833 \\
\hline & $\mathrm{S} 2$ & 0.440 & 0.585 & 0.681 & 0.759 & 0.804 & 0.887 \\
\hline \multirow[t]{3}{*}{ Arthritis ${ }^{\mathrm{b}}$} & S0 & 0.175 & 0.398 & 0.576 & 0.706 & 0.782 & 0.803 \\
\hline & S1 & 0.175 & 0.412 & 0.587 & 0.707 & 0.775 & 0.826 \\
\hline & $\mathrm{S} 2$ & 0.175 & 0.512 & 0.732 & 0.857 & 0.944 & 1.000 \\
\hline \multirow[t]{3}{*}{ Incontinence ${ }^{\mathrm{b}}$} & S0 & 0.099 & 0.250 & 0.416 & 0.584 & 0.724 & 0.808 \\
\hline & $\mathrm{S} 1$ & 0.099 & 0.247 & 0.402 & 0.580 & 0.726 & 0.808 \\
\hline & $\mathrm{S} 2$ & 0.099 & 0.294 & 0.501 & 0.684 & 0.846 & 0.962 \\
\hline \multirow[t]{3}{*}{ Fall $^{\mathrm{b}}$} & S0 & 0.041 & 0.157 & 0.288 & 0.419 & 0.536 & 0.601 \\
\hline & $\mathrm{S} 1$ & 0.041 & 0.151 & 0.284 & 0.411 & 0.500 & 0.592 \\
\hline & $\mathrm{S} 2$ & 0.041 & 0.226 & 0.430 & 0.608 & 0.739 & 0.887 \\
\hline \multirow[t]{3}{*}{ Hip fracture } & S0 & 0.024 & 0.032 & 0.042 & 0.067 & 0.094 & 0.148 \\
\hline & S1 & 0.024 & 0.030 & 0.045 & 0.064 & 0.091 & 0.139 \\
\hline & S2 & 0.024 & 0.067 & 0.131 & 0.207 & 0.295 & 0.472 \\
\hline
\end{tabular}


Table 11.12R (continued)

\begin{tabular}{|c|c|c|c|c|c|c|c|}
\hline & Scenario & 70 & 75 & 80 & 85 & 90 & 95 \\
\hline \multirow[t]{3}{*}{ Proxy Interview } & S0 & 0.110 & 0.106 & 0.119 & 0.149 & 0.166 & 0.163 \\
\hline & S1 & 0.110 & 0.119 & 0.129 & 0.144 & 0.184 & 0.171 \\
\hline & S2 & 0.110 & 0.181 & 0.256 & 0.313 & 0.353 & 0.340 \\
\hline \multirow[t]{3}{*}{ Cognitive impairment ${ }^{\mathrm{b}}$} & S0 & 0.144 & 0.323 & 0.505 & 0.660 & 0.768 & 0.837 \\
\hline & S1 & 0.144 & 0.326 & 0.508 & 0.668 & 0.778 & 0.829 \\
\hline & S2 & 0.144 & 0.435 & 0.686 & 0.835 & 0.920 & 0.868 \\
\hline \multirow[t]{3}{*}{ Psychiatric disease $^{\mathrm{b}}$} & S0 & 0.085 & 0.136 & 0.188 & 0.225 & 0.272 & 0.310 \\
\hline & S1 & 0.085 & 0.133 & 0.183 & 0.237 & 0.268 & 0.265 \\
\hline & S2 & 0.085 & 0.188 & 0.323 & 0.429 & 0.498 & 0.604 \\
\hline \multirow[t]{3}{*}{ Depression $^{\mathrm{b}}$} & S0 & 0.039 & 0.098 & 0.169 & 0.240 & 0.263 & 0.291 \\
\hline & S1 & 0.039 & 0.097 & 0.171 & 0.239 & 0.295 & 0.338 \\
\hline & S2 & 0.039 & 0.206 & 0.350 & 0.473 & 0.538 & 0.623 \\
\hline \multirow[t]{3}{*}{ Body mass index ${ }^{c}$} & S0 & 26.113 & 25.608 & 25.125 & 24.654 & 24.542 & 24.734 \\
\hline & S1 & 26.113 & 25.682 & 25.207 & 24.786 & 24.503 & 24.650 \\
\hline & S2 & 26.113 & 24.879 & 23.968 & 23.508 & 23.506 & 25.136 \\
\hline \multirow[t]{3}{*}{ Current smoker ${ }^{\mathrm{b}}$} & S0 & 0.125 & 0.057 & 0.034 & 0.017 & 0.004 & 0.000 \\
\hline & S1 & 0.125 & 0.060 & 0.039 & 0.019 & 0.007 & 0.000 \\
\hline & S2 & 0.125 & 0.085 & 0.060 & 0.031 & 0.011 & 0.000 \\
\hline \multirow[t]{3}{*}{ ADL limits $^{c}$} & S0 & 0.324 & 0.290 & 0.643 & 1.121 & 1.753 & 2.025 \\
\hline & S1 & 0.324 & 0.318 & 0.651 & 1.152 & 1.716 & 2.258 \\
\hline & S2 & 0.324 & 0.734 & 1.741 & 2.773 & 3.938 & 4.340 \\
\hline \multirow[t]{3}{*}{ IADL limits ${ }^{\mathrm{c}}$} & S0 & 0.333 & 0.133 & 0.304 & 0.580 & 0.867 & 1.143 \\
\hline & S1 & 0.333 & 0.135 & 0.311 & 0.570 & 0.959 & 1.303 \\
\hline & $\mathrm{S} 2$ & 0.333 & 0.392 & 0.894 & 1.676 & 2.444 & 2.415 \\
\hline \multirow[t]{3}{*}{ Poor/fair self-rated health ${ }^{\mathrm{b}}$} & S0 & 0.286 & 0.370 & 0.461 & 0.507 & 0.511 & 0.483 \\
\hline & S1 & 0.286 & 0.360 & 0.454 & 0.484 & 0.510 & 0.512 \\
\hline & S2 & 0.286 & 0.598 & 0.745 & 0.812 & 0.819 & 0.849 \\
\hline
\end{tabular}

Notes: $\mathrm{S} 0$ = baseline; $\mathrm{S} 1=$ no diabetes; $\mathrm{S} 2$ = all low SES.

sample values for the first year, this is not so for subsequent years of the simulation, which produces no anomalous results in subsequent waves.

As mentioned in a note added in proof which appeared with our reply to published comments, LM tests for the triangular Wold causal chain structure of our model have been calculated. The results support that assumption in most cases. Table 11.15 reports the $t$-statistics of pairwise independence tests. The notable exceptions to acceptance of the causal chain structure are the mortality, ADL, and IADL equations, whose pairwise independence fails with respect to most of the remaining conditions. The joint test for independences across equations is not rejected for the case of males and is rejected for the case of females. The rejection for females is eliminated by removing the equations for mortality, BMI, ADL, and IADL. 


\begin{tabular}{|c|c|c|c|c|c|}
\hline & $70-74$ & $75-79$ & $80-84$ & $85-89$ & $90+$ \\
\hline \multicolumn{6}{|c|}{ AHEAD cross-cohort data } \\
\hline \multicolumn{6}{|c|}{ Total wealth $(000)$} \\
\hline 1st quartile & 63.51 & 44.07 & 29.28 & 15.13 & 1.64 \\
\hline Median & 144.04 & 110.76 & 90.62 & 71.19 & 38.37 \\
\hline 3rd quartile & 307.29 & 239.41 & 190.23 & 180.84 & 113.49 \\
\hline \multicolumn{6}{|c|}{ Liquid wealth (000) } \\
\hline 1st quartile & 2.18 & 1.09 & 0.54 & 0.32 & 0.00 \\
\hline Median & 27.28 & 15.24 & 10.91 & 8.64 & 4.36 \\
\hline 3rd quartile & 100.39 & 70.93 & 64.85 & 54.15 & 34.21 \\
\hline \multicolumn{6}{|c|}{ Nonliquid wealth (000) } \\
\hline 1st quartile & 38.09 & 15.24 & 5.40 & 0.11 & 0.00 \\
\hline Median & 91.66 & 77.00 & 60.02 & 43.38 & 1.63 \\
\hline 3rd quartile & 176.84 & 147.31 & 110.25 & 108.45 & 63.29 \\
\hline \multicolumn{6}{|l|}{ Income $(000)$} \\
\hline 1st quartile & 14.19 & 12.00 & 9.76 & 8.68 & 6.87 \\
\hline Median & 24.01 & 19.64 & 15.55 & 13.56 & 10.37 \\
\hline 3rd quartile & 37.96 & 32.54 & 28.37 & 23.94 & 15.71 \\
\hline \multicolumn{6}{|c|}{ Baseline simulation data } \\
\hline \multicolumn{6}{|c|}{ Total wealth $(000)$} \\
\hline 1st quartile & 56.61 & 71.59 & 57.48 & 34.76 & 20.62 \\
\hline Median & 136.41 & 121.52 & 98.82 & 69.50 & 52.88 \\
\hline 3rd quartile & 292.45 & 202.94 & 148.19 & 107.54 & 86.91 \\
\hline \multicolumn{6}{|c|}{ Liquid wealth (000) } \\
\hline 1st quartile & 1.64 & 10.24 & 6.68 & 0.98 & -1.74 \\
\hline Median & 25.10 & 29.24 & 22.28 & 14.39 & 10.63 \\
\hline 3rd quartile & 96.35 & 60.16 & 41.96 & 29.10 & 23.25 \\
\hline \multicolumn{6}{|c|}{ Nonliquid wealth $(000)$} \\
\hline 1st quartile & 34.10 & 53.69 & 43.52 & 26.45 & 15.76 \\
\hline Median & 87.84 & 87.54 & 73.89 & 53.80 & 42.45 \\
\hline 3rd quartile & 170.85 & 130.09 & 106.62 & 81.51 & 68.95 \\
\hline \multicolumn{6}{|l|}{ Income $(000)$} \\
\hline 1st quartile & 13.69 & 13.36 & 11.98 & 10.00 & 8.68 \\
\hline Median & 22.22 & 22.99 & 21.59 & 18.89 & 17.01 \\
\hline 3rd quartile & 36.23 & 35.35 & 34.17 & 30.19 & 26.17 \\
\hline
\end{tabular}

Table 11.14

Calibration of Wave 1 Wealth Levels

\begin{tabular}{lccc}
\hline Model & Calibrated Constant & Estimated Constant & Standard Deviation \\
\hline Liquid & & & \\
Couples & 0.0744 & 0.0751 & 0.0078 \\
Spouse died & 0.0876 & 0.0839 & 0.0210 \\
Singles & & & \\
$\quad$ Males & 0.0567 & 0.0708 & 0.0156 \\
$\quad$ Females & 0.0635 & 0.0794 & 0.0061 \\
$\quad$ Nonliquid & & & \\
Couples & 0.0626 & 0.0592 & 0.0046 \\
Spouse died & 0.1062 & 0.0954 & 0.0154 \\
Singles & & & 0.0104 \\
$\quad$ Males & 0.0554 & 0.0632 & 0.0067 \\
$\quad$ Females & 0.0721 & 0.0824 & \\
\hline
\end{tabular}




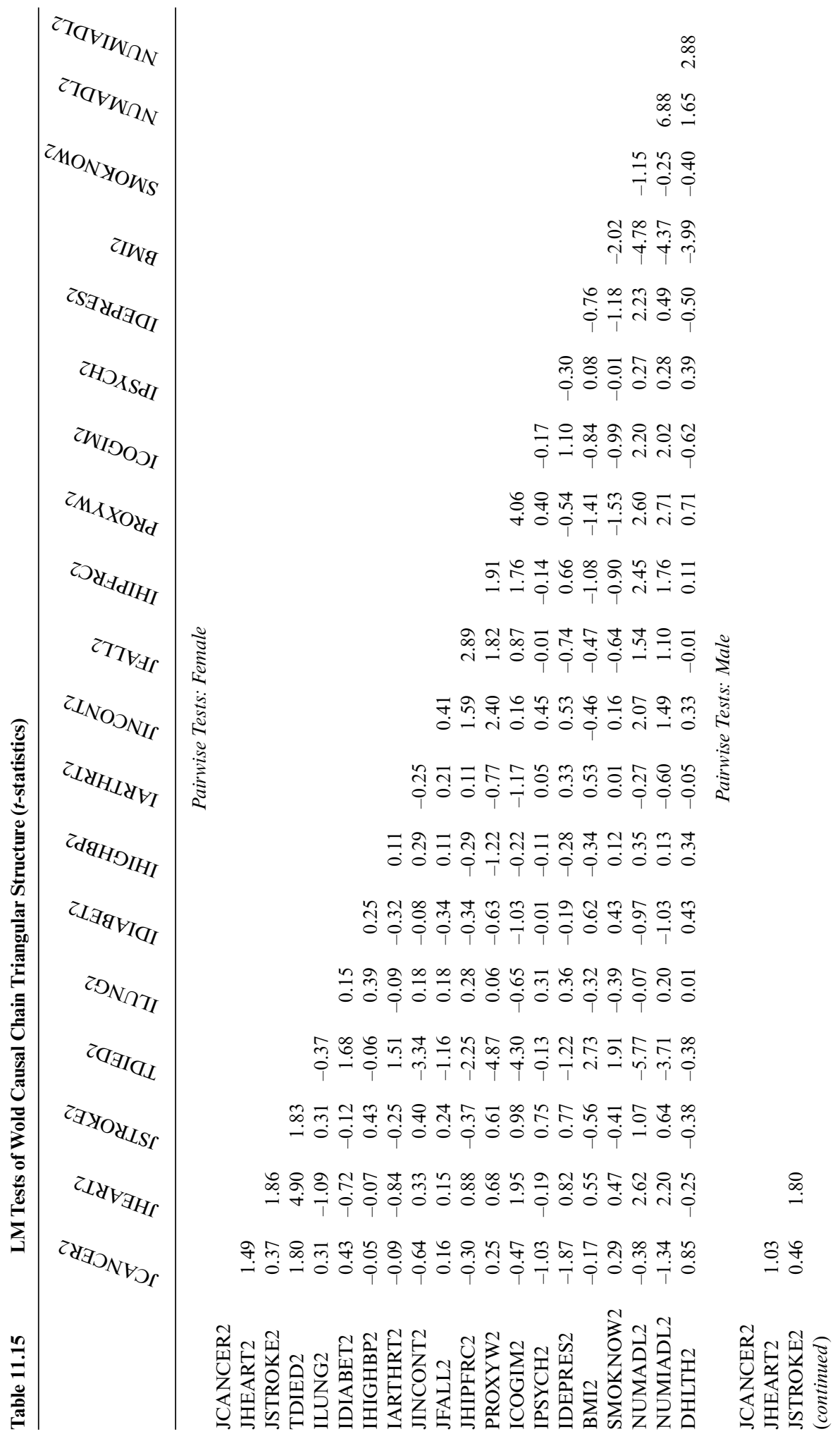




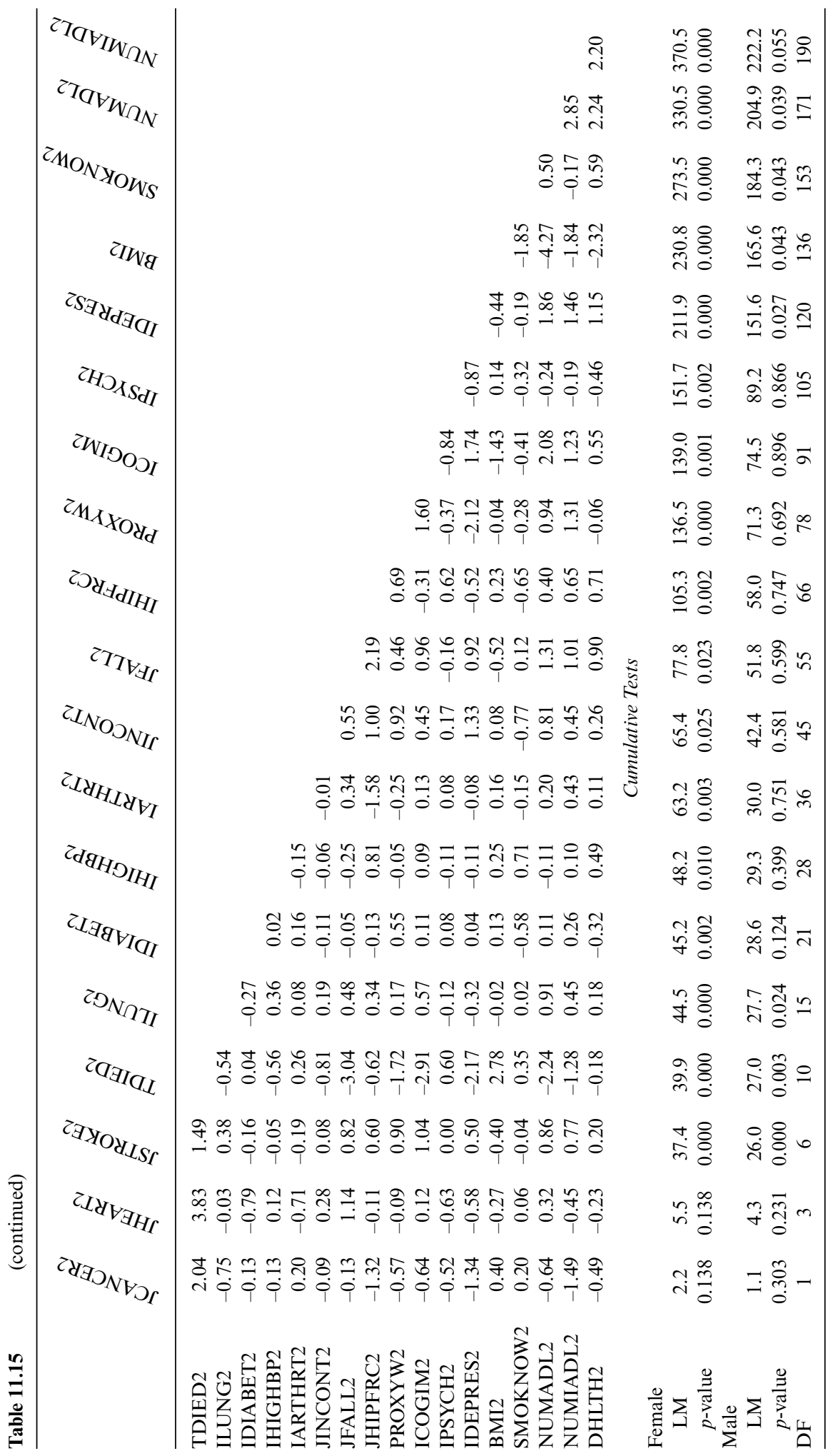




\section{Comment James M. Poterba}

This paper presents a wealth of interesting new information on the relationship between various measures of socioeconomic status (SES) and the health of elderly individuals. While most previous studies of the correlation between SES and health status have relied on cross-sectional data, this paper exploits panel data. Repeated observations on the same individuals make it possible to develop more refined tests than those in past studies. In particular, the authors are able to study how income, wealth, and other socioeconomic conditions are associated with the onset of various health conditions, rather than simply the point-in-time correlation between SES and health status.

The core of the study consists of two related empirical projects. The first explores how SES affects changes in health status, while the second explores the relationship between changes in health status and changes in financial circumstances.

For the first project, the authors develop some "central tendency measures" of socioeconomic status. They find that some of the components of socioeconomic status have greater impact on health than others. Wealth, for example, has a stronger link to health than some of the other components of SES. Many of their findings suggest only modest links between SES and the onset of adverse health conditions. One worry is that by using many different variables to construct a measure of socioeconomic status, the authors have increased the chance of finding weak links between the SES variables and health outcomes. It is always possible to find weak effects by including many marginally influential variables in an empirical analysis. Focusing the analysis on a few key variables relating to socioeconomic status, such as wealth, income, and education, would seem like a natural direction for further analysis. It may ultimately be possible to rank different measures of income, wealth, and other aspects of socioeconomic status in terms of their predictive power for various health events.

One by-product of the study of how SES affects the onset of health conditions is a comparison between measures of the incidence of chronic conditions in the AHEAD sample and the aggregate population. In some cases, there appear to be disparities between the two data sets; this seems like a natural subject for future study. Another related suggestion for further work involves distinguishing between long-term and short-term measures of socioeconomic status. It is possible that transitory shocks to socioeconomic status, such as a temporary decline in income, may have a less important effect on health status than persistent differences due to wealth.

James M. Poterba is the Mitsui Professor of Economics and associate head of the economics department at the Massachusetts Institute of Technology, and the director of the Public Economics Research Program at the National Bureau of Economic Research. 
One of the most important advances in this study is the disaggregate analysis of various measures of health status. By studying acute conditions separately from chronic conditions, and distinguishing mental conditions from acute physical conditions due to accidents and other factors, the paper is able to show that there are important differences in the link between SES and the onset of different long-term health limitations. This is a key insight if one tries to forecast how changes in future economic circumstances will affect the health of the future elderly population.

The second component of this study explores the extent to which changes in socioeconomic status can be explained by changes in health status. Because some changes in health status may require expensive treatment or movement to a nursing home or other costly facility, there is a presumption that health changes might account for some changes in financial circumstances. The results on the link from health status changes to financial status changes are weak. This is one aspect of the paper that could benefit from further data analysis. Disaggregating survey respondents by health insurance status, and focusing on relatively expensive health changes, might reveal a stronger relationship between some types of health status change and subsequent financial changes. For many AHEAD participants, income flows - pensions, Social Security, and related flows - are not affected by health status. It is therefore possible that the links from health changes to income changes for this age group are more muted than the changes for younger elderly.

In addition to its two significant empirical components, the paper also proposes a conceptual framework for analyzing how wealth and other measures of socioeconomic status are related to health. The "invariance" condition proposed here requires that the relationship between SES components and health status must be stable over time. Invariance is stipulated as a logical precondition for a causal relationship between SES and health status. It is not clear that this is a reasonable restriction, however. There are many reasons to suspect that the relationship might change over time, even if there is a true underlying link. For example, medical treatment technology may change. A procedure that was expensive at one point in time may become less expensive and widely available at a later date, thereby changing the relationship between SES and observed health status. Even if income and wealth are positively correlated with access to this procedure at all points in time, a decline in the price of the technology might alter the slope of this relationship. Similarly, there could be changes over time in behavior or other factors that affect health status. These could lead to changes in the measured relationship between health status and socioeconomic status. Once again, the difficulty is that even if higher socioeconomic status is associated with a lower likelihood of chronic conditions at all points during the sample period, a test for the stability of coefficients over time might reject this restriction. The diffusion of exercise or other per- 
sonal behaviors across the socioeconomic spectrum could lead to timevarying coefficients even in the presence of a causal link.

This paper opens a broad new field of inquiry directly at the detailed mapping of links from income, wealth, and other aspects of socioeconomic status to the level of, and changes in, health status. As panel data sets become more common in the study of elderly populations and researchers have increased access to information on both medical conditions and economic circumstances, this research is likely to reveal more and more subtle aspects of these relationships. This paper represents a very important step in this research program.

\section{Response Peter Adams, Michael D. Hurd, Daniel McFadden, Angela Merrill, and Tiago Ribeiro}

The problem of how to describe, detect, and measure causal effects has an importance in economic and social policy analysis that transcends the specifics of our paper, and our discussants provide valuable perspectives on possible approaches. We thank them for their comments. In this response, we identify points in the discussion that we find particularly useful, and try to clarify some issues where there appears to be disagreement.

The comment by Jérôme Adda, Tarani Chandola, and Michael Marmot focuses on the association of health and wealth in panel data. They replicate our statistical analysis on two data sets, the Whitehall II panel in Great Britain and the Swedish Survey of Living Conditions (ULF) and conclude that these replications give similar results. This is extremely valuable, providing a powerful cross-population/cross-institutions test for model invariance. However, their general assessment that our model is transferable to these data sets may be overly generous; a detailed comparison reveals some significant differences whose exploration would be a good starting point for further research. Their finding that mental diseases in the British and Swedish data also fail the test for no direct causality suggests strongly that the sources of this rejection are behavioral factors, rather than our proposal of a possible gradient in affordability of preventative mental health services within Medicare. James Poterba points out that a detailed look at disease-specific therapies and Medicare reimbursement rules may permit a sharper test for a causal link from affordability of preventative care to health outcomes, and changes in medical insurance coverage over

Peter Adams is affiliated with the Department of Economics at the University of California, Berkeley; Michael D. Hurd is affiliated with RAND Corporation; Daniel McFadden is affiliated with the Department of Economics at the University of California, Berkeley; Angela Merrill is affiliated with Mathematica; and Tiago Ribeiro is affiliated with the Department of Economics at the University of California, Berkeley. 
time or with recipient age may induce invariance failures unless they are accounted for explicitly.

Our discussants include central contributors to three major "schools" of causal analysis: time-series prediction criteria, or G-causality, grounded in the empirical tests proposed by Granger and Sims (Clive Granger, John Geweke); the structural or functional approach grounded in econometric simultaneous equations models (Jerry Hausman, Kevin Hoover); and the potential outcomes or counterfactual approach grounded in the statistical analysis of experimental treatments (Jean-Pierre Florens, James Heckman, Fabrizia Mealli, Donald Rubin, and James Robins). As a shorthand, we will refer to the structural approach as $S$-causality and the prospective outcomes approach as $P$-causality. These schools differ substantially in terminology, perspective, and prescription for applications. Nevertheless, there are strong links between them. Pearl (2000, chapter 7) demonstrates a formal equivalence of S-causality and P-causality, and Heckman's comment demonstrates the utility of interweaving the $\mathrm{S}$ and $\mathrm{P}$ formulations. Both the S and P schools are critical of G-causality, arguing that its rather sparse characterization of causal properties is not sufficient to predict the effect of interventions. In the testing scheme we adopt in our paper, we start from G-causality and add invariance tests as a way to addressing this problem. The questions then are whether our invariance requirements are consistent with the more complete $\mathrm{S}$ or $\mathrm{P}$ specifications for causal modeling; whether they are sufficient for the limited causality claims that we make; and, more broadly, whether on the road to a complete causal analysis our approach is a helpful way station or a dangerous diversion.

In linear econometrics, it is common to conduct exogeneity tests for model specification, which can be interpreted as invariance tests for model coefficients when instrumental variables are used, and conditional on acceptance of exogeneity tests, to use simple exclusion tests for the existence of direct effects of explanatory variables. Features of this setup are that the alternatives to exogeneity are vague, an exogeneity test may be rejected for a variety of model misspecification reasons, and the procedure may have zero power against some alternatives in which direct exogeneity failures are confounded by other model failures. Nevertheless, the procedure is a useful diagnostic whose robustness weighs against its lack of optimality against specifically focused alternative structures. The scheme in our paper for testing the absence of direct causal paths has a similar structure, and we argue that it has similar properties.

First, a universally valid causal model in the $\mathrm{S}$ or $\mathrm{P}$ framework will predict successfully given any history, defined broadly to include any changes in geographical or temporal frame and any policy interventions. Each successful prediction constitutes, in our terminology, a model invariance. When one requires only that a more restricted class of invariance conditions be met, there will be a family of S or P models that are not necessar- 
ily universally valid, but which are valid and observationally equivalent for the specified class; see Florens and Heckman (2001). For example, the two directed acyclic graphs (DAGs) in in figure 11.9, only one of which has a direct causal path from $S_{t-1}$ to $H_{t}$, may nevertheless both be valid for a class of invariance conditions that does not include interventions in which the conditional distribution of $S_{t-1}$ given $H_{t-1}$ changes. The fact that a broader class of invariance conditions could distinguish these models is not necessarily important if one is interested only in policy interventions in which the conditional distribution of $S_{t-1}$ given $H_{t-1}$ is itself always invariant. James Heckman makes a related, and even more important point, stating that "Evidence for invariance with respect to one class of manipulations does not necessarily carry over to other classes of manipulations" (2003, 77). The class of invariances tested should be precisely those needed for a targeted policy intervention, and these may or may not include transferability of the model across time periods or locations.

An empirical rejection of a model invariance is evidence against the validity of the family of S or P models that imply this invariance. Our proposed invariance tests are nothing more than the empirical counterpart of the logical relationships common to families of DAGs defining families of $\mathrm{S}$ or P models. We claim that our setup, with suitable articulation, thus provides a language for characterizing the empirical implications of causal analysis in an S or P framework. We strongly support the suggestion that DAGs and a full S or P analysis be used to map out the invariances that need to be satisfied by a valid model for predicting the effects of policy interventions in an application. However, we think there is methodological merit in developing "bottom up" approaches to causality that seek the broadest families of full causal models consistent with a particular policy application, to compliment "top down" approaches that start from full causal models embodying all prior information, and we then map out the policy applications for which they are valid. We recognize that the invariance test we actually conduct, for invariance of selected Markov transition probability parameters, falls far short of the battery of tests necessary to exhaust the empirical implications of a full causal model, or the relevant invariances for many policy applications, and note further that there are classes of causal models in which stationarity is not required.

Second, we claim in our paper that if our invariance and no direct causality (hereafter, NDC) tests are accepted, this is indeed evidence against the existence of a direct causal path. There are obvious limits to our claim in finite samples, particularly given the dimensions of invariance that remain untested. In light of the comments and the last paragraph, a more precise, and limited, statement is that acceptance of these tests is evidence against the existence of a direct causal path that is active (or, in genetic terms, expressed) within the class of invariances under consideration. In addition, there are an abundance of possible sources of model misspecifi- 

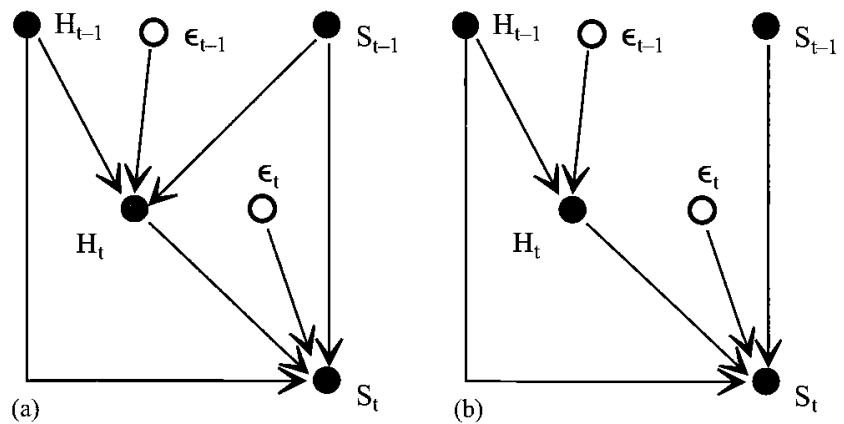

Fig. 11.9 Direct acyclic graph

cation that may confound our analysis and limit its power, particularly its linear single-index structure, untested treatment of "instantaneous causality," and first-order Markov dynamics. The power of the tests against plausible alternatives appears to be low; the observation that simulation using the models "as is" generates strong wealth-health links despite the acceptance of our tests for most conditions suggests this to be the case.

Several discussants, and also David Bloom in a personal communication, claim that our setup is statistically inconsistent so that there are circumstances where NDC will be accepted even when a direct causal link is present in a valid fully specified causal model. Kevin Hoover states that "A finding of invariance in the conditional model does not indicate a true causal relationship unless there is simultaneously a failure of invariance in the marginal model for the conditioning variable" $(2003,124)$. This is a succinct way of stating that our tests have power only against active direct causal links. In particular, we agree that one can devise examples where a direct causal effect is exactly offset by an unobserved common factor, or an ignored common factor exhibits no variation across populations that allow its effect to be identified, and our tests will have zero power against these alternatives, but we believe it improbable that these will occur and go undetected when the class of invariance tests is sufficiently broad. Speaking loosely, in the space of full causal models we expect manifolds on which effects are unvarying or exactly offsetting and thus not separately identifiable to have a priori probability zero, and if alternatively the effects can be identified under some circumstance, say by comparing populations with different initial conditions, then there will be a corresponding invariance test that should be rejected.

Finally, consider the broad question of whether our testing setup is a useful way station or a distraction. There are some legitimate concerns. Our testing procedure is generally insufficient for a full $\mathrm{S}$ or $\mathrm{P}$ causal analysis. Our treatment can be criticized as limited in applicability, because it is silent in the likely circumstance that direct causal effects are present but are 
confounded by unobserved common factors, and we offer no way of describing and identifying direct causal effects when they are in fact present. We agree with the discussants' suggestion that drawing conclusions on causality within an incomplete framework for causal modeling invites mischief. We have ourselves used our model in a simulation mode with hypothetical policy alternatives, with an untested assumption that "instantaneous causality" has a specific causal chain structure, and it is somewhat disingenious for us to argue that the results can be used only for model evaluation, not for policy analysis. On the positive side, we believe that for policy applications, framing causality analysis in terms of the minimal conditions needed to support evaluation of specific policy alternatives is a useful counterpoint to a full $\mathrm{S}$ or $\mathrm{P}$ analysis, and for this reason it is scientifically useful to provide "pullouts" on the road to causal modeling.

We conclude with a few specific responses to points raised by individual discussants. First, Jerry Hausman notes that if the first-order Markov assumption for our specified state vector is not satisfied, then our estimation procedure is not statistically consistent. We agree; a test for this assumption will be practical when the panel is a little longer, and is important to do. He observes correctly that our invariance tests will have low power if there is limited variability in explanatory variables. For this reason, the transferability invariance tested by Adda, Chandola, and Marmot is particularly helpful.

Several discussants, including John Geweke, Jean-Pierre Florens, and James Heckman, observe that our treatment of "instantaneous causality" is untested and possibly disputable. The order we have selected for health conditions is based, roughly, on the etiology of the various diseases, but we agree that this is a potential source of serious model misspecification. If our hypothesized causal chain is not valid, then instantaneous causality induces a simultaneous equations problem that causes our model estimates to be statistically inconsistent. We have emphasized time aggregation between panel waves as a source of simultaneous causality, but agree that across some health conditions there could be true mutual instantaneous causality, perhaps in the form of the multivariate jump processes discussed by Florens. If our hypothesized causal chain is incorrect, then this should be detectable via a relatively straightforward invariance test using a joint probit structure for the various health conditions. It is possible to conduct such a test in a LM form that does not require estimation of the joint probit model.

John Geweke comments that portfolio management under life-cycle consumer theory may produce discontinuous shifts in portfolio mix, as well as discrete changes in measured wealth due to transfers and taxmotivated reorganizations. In our models for wealth component changes, this would produce outliers that are linked across asset categories. This may explain some of the noise we observe in wealth components. A good 
solution will have to await further research. We note, however, that outliers in total wealth are sufficiently large and frequent to suggest that much of the noise we see is measurement error rather than true variation in the underlying economic variables.

The AHEAD study has notified users that incidence of new heart conditions in wave 3 was not collected and coded properly for subjects who had no previous history of a heart condition. In our working sample, the recorded 310 wave 3 incidences are then an undercount, and we estimate that approximately 122 additional incidences were not recorded. Because the intercepts for wave 2 to wave 3 incidence of heart conditions were allowed to vary freely in our models, this data problem will not affect our substantive conclusions if the undercount occurs at random, but will have a direct impact on our models for incidence of heart conditions between waves 2 and 3 , and on the invariance tests based on comparing these transitions to the extent that the undercount does not occur at random. Because remaining models for health condition incidence and wealth change are conditioned on heart condition incidence, any direct impact of this data problem will have some effect on all the models in our paper.

In response to reviewer comments, we suggest that it would be possible to conduct a LM test for correlation of disturbances in our chain of incidence models. We have now calculated these tests and accept the hypothesis of no correlation of these disturbances in the equations for various health conditions. We note, however, that these tests are likely to have low power. 